\title{
Correcciones
}

pag. 43, línea 1: pone $P(\mathbf{X}=\mathbf{x}>\mathbf{0})$ y debe poner $P(\mathbf{X}=\mathbf{x})>\mathbf{0}$

pag. 44, línea 1: pone $\mathrm{c}$ y debe poner $c$

pag. 51, línea 12, pag. 52, líneas 2,12,15,28: pone anneling y debe poner annealing

pag. 51, línea 22: pone $x+\Delta x$ y debe poner $x_{k}+\Delta x$

pag. 54, expresión 3.27: pone $p\left(x_{i j}, \mathbf{X}_{S \backslash i j}\right)$ y debe poner $p\left(x_{i j}=l, \mathbf{X}_{S \backslash i j}\right)$

pag. 55, expresiones 3.28 a 3.30: pone $p\left(x_{i j} \mid \mathbf{X}_{S \backslash i j}\right)$ y debe poner $p\left(x_{i j}=l \mid \mathbf{X}_{S \backslash i j}\right)$

pag. 67, línea 12: pone ...temperatura es $T=1$. y debe poner ...temperatura es $T=1$. Se consideran sólo potenciales de cliques formados por dos pixels.

pag. 77, línea 12: pone ...así pues la función umbral: y debe poner ...así pues la función umbral se puede definir también como:

pag. 80, expresión 4.8: pone $\mathcal{R}^{2}\left(\mathcal{T}\right.$.. y debe poner en $\mathcal{R}^{2} \quad(\mathcal{T} \ldots$

pag. 94 , figura 4.14 b: pone $\delta^{1}\left(f_{M}, f\right)$ y debe poner $\delta^{\infty}\left(f_{M}, f\right)$

pag. 101, línea 27: pone ...menor de las mismas. y debe poner ...menor de las mismas (ver figura 4.20).

pag. 129, línea 10: pone ...donde se plantea un modelo Auto-model (ver sección 3.3) en el que los coeficientes $\beta_{i j m n}$ no dependen de... y debe poner ...donde se plantea un modelo en el que los potenciales de cliques de dos pixels no dependen de...

pag. 135, línea 4: pone ...de entrada, evitando... y debe poner ...de entrada, procurando...

pag. 151, línea penúltima: pone ...respecto a estos valores. Son... y debe poner ...respecto a estos valores; se ha tomado como operador morfológico el residuo del fondofibra con reconstrucción. Son...

pag. 152, tabla 6.1: pone $\beta_{b c} \alpha_{b e} \alpha_{c e}$ y debe poner $\beta_{b c} \beta_{b e} \beta_{c e}$

pag. 163, línea 3: pone ...como resultado el finalizar... y debe poner ...como resultado al finalizar...

pag. 235, línea 1: pone anneling y debe poner annealing 


\title{
Universidad Politécnica de Valencia Escuela Técnica Superior de Ingenieros de Telecomunicación
}

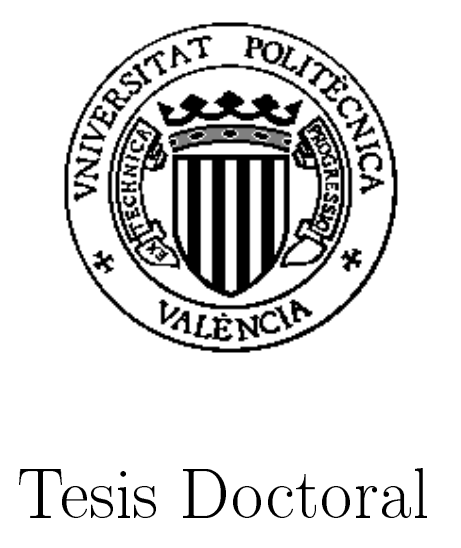

\section{Contribución a la detección y análisis de microcalcificaciones en mamografías mediante tratamiento digital de imagen}

\author{
Presentada por: \\ José Manuel Mossi García \\ Dirigida por: \\ Dr. Antonio Albiol Colomer
}

Valencia, 1998. 
A Maria Dolors i Claudia 
“... l'esperanca és mentida

si no hi ha cada dia un esforc pel nou demà"

Lluís Llach 


\section{Agradecimientos}

Quiero mostrar mi agradecimiento a mi director, por toda la confianza que ha depositado en mi y por toda la ayuda que me ha prestado. Gracias, Antonio.

A Maria Dolors, mi mujer, por su apoyo durante todo este tiempo.

A Pepa, mi hermana, por su fe en mi y su disposición a ayudarme.

Quiero mostrar mi agradecimiento también, a todas aquellas personas del Departamento de Comunicaciones con las que he compartido estos años de trabajo y que de manera directa o indirecta me han prestado su ayuda, entre ellos, Juan Morales, Ramón Miralles, Esther Hidalgo, Inma Mora, Alberto, Pablo, Joaquín y especialmente mi compañera de asignatura, Valery.

A Ferrán Marqués y Luis Torres por su cordial visita a Valencia y la invitación al curso que impartían, que nos abrió las puertas a la Morfología Matemática.

Finalmente a Luís Vergara, Director del Departamento de Comunicaciones, y al Doctor José María Pérez Clavijo, jefe del Servicio de Radiología del Hospital de Sagunto, quienes hicieron posible que comenzara a trabajar en mamografía. 


\section{Índice}

1 Introducción $\quad 5$

2 Revisión de la literatura $\quad 15$

$2.1 \quad$ Etapa previa al FIWDM . . . . . . . . . . . . . . . . . 16

2.1.1 Detección de microcalcificaciones . . . . . . . . . . 16

2.1.2 Detección de masas . . . . . . . . . . . . . . . . 18

2.1 .3 Otros . . . . . . . . . . . . . . . . 18

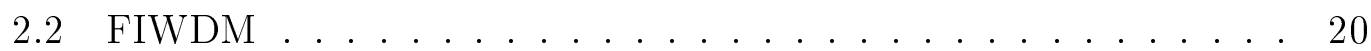

2.2.1 Detección de microcalcificaciones . . . . . . . . . . 20

2.2 .2 Detección de masas . . . . . . . . . . . . . . . . . 22

2.2 .3 Otros . . . . . . . . . . . . . . . 23

2.2.4 Conclusión . . . . . . . . . . . . . . . . . . . 23

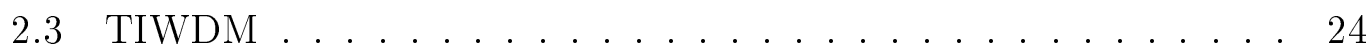

2.4 Período posterior al TIWDM . . . . . . . . . . 35

3 Campos Aleatorios de Markov $\quad 39$

3.1 Introducción . . . . . . . . . . . . . . . . . . . . . . 39

3.2 Teoría de los Campos Aleatorios de Markov . . . . . . . . . . . . 40

3.2.1 Definición de un campo aleatorio de Markov . . . . . . . . 41

3.2.2 Definición de un campo aleatorio de Gibbs . . . . . . . . . 43

3.2.3 Equivalencia entre campo aleatorio de Markov y de Gibbs 45

3.3 Ejemplos de campos aleatorios de Markov . . . . . . . . . . . . . 45

3.3.1 Auto-Modelos . . . . . . . . . . . . . . . 46

3.3.2 Modelo Multilevel Logistic . . . . . . . . . . . . . . . . . . 48

3.4 Campos Aleatorios de Markov Compuestos . . . . . . . . . . . . . 49

3.5 Algoritmos de segmentación . . . . . . . . . . . . . . . 50

3.5.1 Introducción . . . . . . . . . . . . . . . . . . 50

3.5.2 Iterated Conditional Modes . . . . . . . . . . . 52

3.5.3 Highest Confidence First . . . . . . . . . . . . . . . . . 57

3.5.4 Block Highest Confidence First . . . . . . . . . . . . . . 60 
3.5.5 Estudio Comparativo . . . . . . . . . . . . . . . 62

4 Morfología Matemática $\quad 75$

4.1 Introducción . . . . . . . . . . . . . . . . 75

4.1 .1 Celosía y Vecindario . . . . . . . . . . . . . . 77

4.2 Transformaciones morfológicas básicas . . . . . . . . . . . . 80

4.2.1 Erosión y Dilatación . . . . . . . . . . . . . . 83

4.2 .2 Apertura y Cierre . . . . . . . . . . . . . 85

4.2 .3 Filtros morfológicos . . . . . . . . . . . . . 87

4.2 .4 Residuos . . . . . . . . . . . . . . 90

4.3 Transformaciones geodésicas y reconstrucción . . . . . . . . . . 91

4.3.1 Dilatación y erosión geodésicas . . . . . . . . . . . 91

4.3.2 La reconstrucción . . . . . . . . . . . . . . . . . . . 92

4.4 Filtros Conexos . . . . . . . . . . . . . . . . . . . . . . 94

4.4.1 Extremos de una imagen . . . . . . . . . . . . . 95

4.4.2 Operadores morfológicos conexos . . . . . . . . . . . 99

4.4 .3 Apertura Superficial . . . . . . . . . . . . . . . . . 102

5 Algoritmo $\quad 121$

5.1 Introducción . . . . . . . . . . . . . . . . . . . . . 121

5.2 Elección del campo aleatorio de Markov . . . . . . . . . . . . . 128

5.3 Entrada al campo aleatorio de Markov . . . . . . . . . . . . . 131

5.4 Operaciones morfológicas . . . . . . . . . . . . . . . . 135

5.4 .1 Top-Hat . . . . . . . . . . . . . . . 135

5.4 .2 Residuo del fondofibra . . . . . . . . . . . . . . 140

5.4.3 Residuo del fondofibra con reconstrucción . . . . . . . . 143

6 Resultados 147

6.1 Tamaño del Elemento Estructurante . . . . . . . . . . . . . . 149

6.2 Parámetros del campo aleatorio de Markov . . . . . . . . . . . . 151

6.2.1 Influencia de los parámetros alfa . . . . . . . . . . . . . 152

6.2.2 Influencia de los parámetros beta . . . . . . . . . . 156

6.2.3 Influencia de los parámetros del vecindario ampliado . . . 164 
6.2.4 Influencia del número de iteraciones . . . . . . . . . . . . 167

6.3 Top-Hat . . . . . . . . . . . . . . . . . . . 171

6.4 Residuo Fondofibra . . . . . . . . . . . . . . . . . 175

6.5 Residuo Fondofibra con reconstrucción . . . . . . . . . . . . . 183

6.6 Residuo Fondofibra con apertura superficial . . . . . . . . . . . 196

7 Conclusiones y futuras líneas $\quad 203$

7.1 Conclusiones . . . . . . . . . . . . . . . . . . . . 203

7.2 Líneas futuras . . . . . . . . . . . . . . . . . . . 205

$\begin{array}{ll}\text { A Base de datos de mamografías } & 207\end{array}$

A.1 Especificaciones . . . . . . . . . . . . . . . . . . . . 207

A.2 Área significativa de las mamografías . . . . . . . . . . . . . 208

A.3 Ecualización del ruido . . . . . . . . . . . . . . . . . . . . . . . . 209

A.3.1 Estimación del ruido de la imagen . . . . . . . . . . . . . 211

A.3.2 Cálculo de la Transformación . . . . . . . . . . . . . . . . 212

A.4 Diagnóstico médico de cada mamografía . . . . . . . . . . . . . . 212

$\begin{array}{ll}\text { B Ejemplos de Mamografías } & 215\end{array}$ 


\section{Capítulo 1}

\section{Introducción}

En Enero de este año se ha publicado en la revista Radiology de la Radiological Society of North America, una de las más importantes a nivel internacional, el artículo Breast Cancer Screening: First Round in the Population-based Program in Valencia, Spain [128] en el que se detallan los resultados del primer Programa de Prevención de Cáncer de Mama de la Comunidad Valenciana y además se dan las siguientes cifras: el cáncer de mama provoca en esta comunidad el $3.7 \%$ de todas las muertes en mujeres y es la primera causa de muerte en mujeres con edades comprendidas entre 35 y 54 años. Además la tendencia es creciente porque en 1987 el ratio de muertes por este motivo fue de 23.76 por cada 100000 y en 1994 fue de 30.57 por cada 100000 .

Afortunadamente si la detección es precoz la probabilidad de curación es muy alta. En muchas ocasiones la fase temprana de la enfermedad no tiene síntomas perceptibles por la propia mujer y la radiografía de la mama, llamada abreviadamente Rx-mamografía o mamografía, es el método que hoy por hoy se muestra más eficaz en la detección precoz. De ahí que las autoridades sanitarias hayan puesto en marcha programas de screening consistentes en la realización de mamografías a todas las mujeres comprendidas en un cierto margen de edad. En países que han comenzado con anterioridad experiencias en programas de screening [68] se ha llegado a la conclusión de que los programas de screening redundan en una reducción de la mortandad por cáncer de mama de al menos un 30\%. La American Cancer Society ha recomendado que las mujeres con edades comprendidas entre 40 y 49 años se hagan una exploración mamográfica cada dos años y las que tienen más de 50 años lo hagan anualmente. Esta misma organización advierte de la importancia que el cáncer de mama tiene en las sociedades occidentales basándose en los informes de la misma en la que se establece que en Estados Unidos una de cada nueve mujeres padecerá cáncer de mama en algún momento de su vida. 
En el programa de la Comunidad Valenciana cada exploración consta de dos mamografías por mama, una con proyección craneo-caudal (proyección vertical) y la otra con proyección medio lateral oblicua. Cada mamografía es interpretada por dos miembros del grupo de colaboradores en el programa, en total 8 imágenes analizadas por mujer. En la primera fase fueron invitadas 112139 mujeres de las que participaron 78224 (70\%). En total la población de mujeres entre 45 y 65 años asciende a 450000 lo que supone en régimen permanente con una exploración cada año o cada dos años entre 1800000 y 3600000 mamografías analizadas, a las que habría que sumar las de las mujeres mayores de 65 años a medida que se amplíe el programa.

El diagnóstico se estableció en cinco posibilidades, mama normal, lesión benigna, lesión probablemente benigna, lesión probablemente maligna y lesión maligna, siendo considerados casos negativos los normales y benignos, y considerados positivos o anormales los diagnósticos probablemente benigno, probablemente maligno y maligno. De las 78224 mujeres que participaron en esta primera ronda 12151 fueron físicamente examinadas bien porque tenían síntomas o por hallazgos en la mamografía, lo cual supone que 66073 mujeres tuvieron un diagnóstico negativo $(84.47 \%)$.

La mamografía es una radiografía de difícil lectura debido a que la estructura interna de la mama es compleja (ver figura 1.1 y Anexo B) y los diversos tejidos que la forman tienen una absorción a los rayos $\mathrm{x}$ parecida. Por ejemplo en el caso de diagnóstico de fracturas de hueso la tarea en la mayor parte de los casos es más fácil porque la absorción a los rayos x del tejido óseo es mucho mayor que la del resto de tejidos circundantes. En una situación general en la que se ilumina un objeto y se capta la radiación reflejada o que atraviesa dicho objeto el contraste depende de la cantidad de radiación incidente de manera que si se precisa mayor contraste se puede obtener con una mayor cantidad de radiación. En mamografía ocurre lo mismo pero es importante mantener las dosis de radiación en niveles bajos porque la misma radiación puede provocar cáncer tal como lo demuestran los estudios sobre incidencia de cáncer de mama en las mujeres de Hiroshima/Nagasaki y en otras que han seguido tratamientos terapéuticos a base de radiaciones en el tórax. En estos casos las radiaciones eran al menos de un orden de magnitud mayor que las necesarias en mamografía [68],pero mejor es prevenir manteniendo dosis bajas.

En el Anexo B se puede observar el aspecto de una mamografía. La mamografía real es una placa translúcida que necesita de una fuente de luz apropiada para ser observada. Para facilitar la observación del lector se han reproducido sobre papel que no necesita de fuentes de luz específicas, a costa de una menor calidad de imagen. No obstante las reproducciones permiten apreciar que la imagen mamográfica es muy texturada, que los patrones geométricos de las regiones de la imagen son muy diversos y sobre todo que el contraste es muy bajo. 


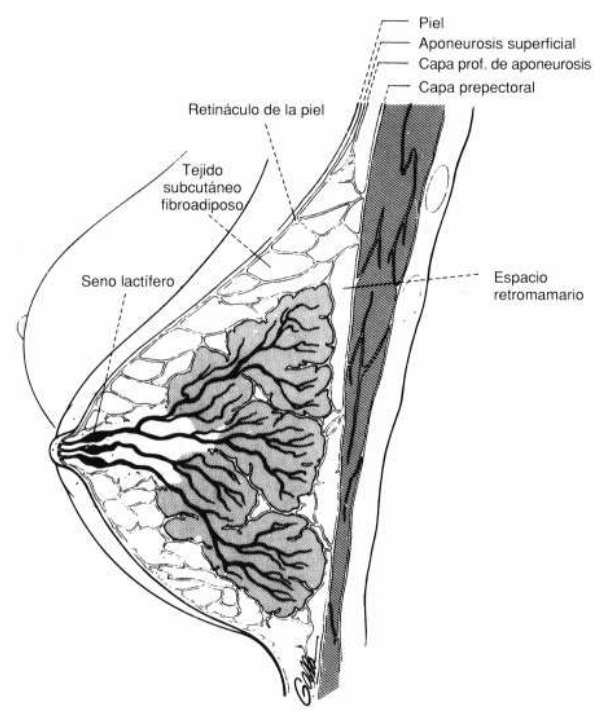

Figura 1.1: Representación esquemática de la anatomía básica de la mama. Se aprecia el patrón ramificado de las glándulas a partir del pezón. Entremezclado con él están el resto de tejidos. Adaptado de [68]

Los diferentes hallazgos que se pueden encontrar en la mamografía [68] son:

- las calcificaciones y microcalcificaciones

- las masas circunscritas de bordes bien definidos

- las masas mal definidas

- las masas lobuladas

- lesiones espiculares

- densidad asimétrica

- tejido mamario asimétrico

- distorsión arquitectural

- densidades múltiples

- lesiones radiolucentes

- engrosamiento de la trabeculación y de la piel

Las microcalcificaciones son uno de los más importantes en la detección precoz porque casi la mitad (43\% - 49\%) [72] de los cánceres clínicamente ocultos son detectados gracias a la presencia de microcalcificaciones, de las cuales el $21 \%$ tienen 
un tamaño menor de $0.25 \mathrm{~mm}$. Las microcalcificaciones son pequeños acúmulos de calcio en el tejido mamario cuyo origen puede ser diverso, procesos inflamatorios, degenerativos, metabolismo tóxico, reacciones a intervenciones quirúrgicas, etc. Las sustancias que las forman presentan una absorción a los rayos x mayor que otros tejidos, por lo que en la mamografía aparecen como regiones más claras que sus proximidades. Las calcificaciones que tienen significación clínica son las microcalcificaciones que están agrupadas, es lo que normalmente se llaman clusters. El criterio que determina cuantas microcalcificaciones deben haber como mínimo y en qué espacio para que se consideren un cluster difiere según los autores, pero en término medio se puede considerar que el mínimo está entre 2 y 5 , y el espacio mínimo entre 0.5 y $1 \mathrm{~cm}$.

El objetivo de la presente tesis es implementar un detector de clusters de microcalcificaciones mediante técnicas de tratamiento digital de imagen.

No todas las calcificaciones van asociadas a procesos malignos. Algunos ejemplos que no sugieren malignidad son las calcificaciones secretorias cuyo aspecto radiológico es que aparecen aisladas y con un tamaño de varios milímetros o mayor, forma esférica con bordes bien definidos y centro radiolucente (color más oscuro en el centro), cuando la secreción se produce en conductos toman formas cilíndricas macizas (ver figura 1.2). Las calcificaciones cutáneas también con centro lucente son redondas o poligonales y se encuentran cerca de la periferia de la mama. Para determinar la ubicación a veces es necesario recurrir a dos proyecciones ortogonales de la mama. Las calcificaciones vasculares provienen de la calcificación de las paredes de las arterias, aparecen como tractos paralelos y suele verse el vaso asociado. No suelen confundirse con otras de mayor significación aunque en estadios precoces cuando todavía sólo se ha calcificado un lado de la pared del vaso sí que pueden confundir el diagnóstico. Existen varios ejemplos más de benignidad.

Básicamente el cáncer aparece en el tejido glandular [21] por lo que la ubicación de las microcalcificaciones más importantes en el diagnóstico del cáncer puede ser en los lóbulos o en los conductos (normalmente llamados ductos). Cuando se presentan en los lóbulos tienen aspecto de acúmulo circular originado por la forma del tejido que las acoge. En la figura 1.3 son de naturaleza maligna mientras que en la figura 1.4 se presenta el aspecto cuando son benignas. Cuando el cáncer es ductal y tiene microcalcificaciones asociadas éstas tienen formas lineales con bordes irregulares y algunas están ramificadas en forma de y griega. La figura 1.5 muestra un diagrama de la situación. Las diferencias en muchos casos son muy sutiles, por ejemplo se pueden confundir este tipo de microcalcificaciones que se acaban de mencionar con microcalcificaciones vasculares en estadios tempranos; en otros casos las microcalcificaciones ductales todavía son tan pequeñas que no han tomado la forma lineal. 


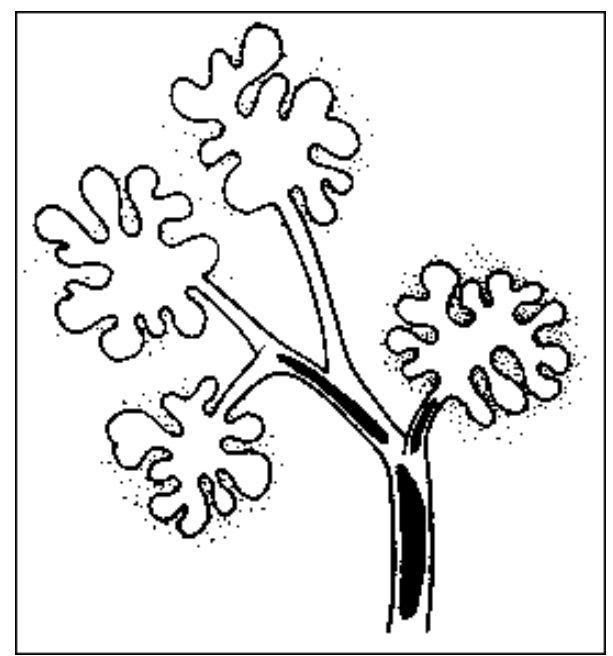

a) estructura

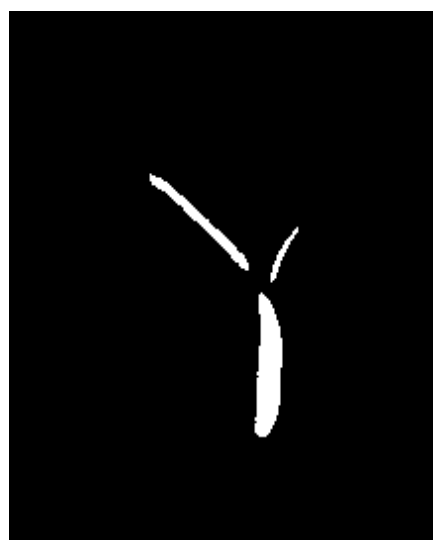

b) microcalcificaciones

Figura 1.2: Microcalcificaciones secretorias ductales. Su aspecto es cilíndrico macizo. Benignas. Adaptado de [68]

Para valorar la capacidad de diagnóstico de existencia de cáncer de una determinada técnica, como por ejemplo la mamografía, se utiliza el valor de predicción positiva. Es el cociente entre cánceres realmente existentes dividido por número de pacientes en los que se ha diagnosticado que la mamografía tiene algún signo indicativo de cáncer. En [128] el valor de predicción positiva obtenido a partir de la lectura de la mamografía por dos radiólogos es del $8.57 \%$, cifra que refleja la dificultad de precisar sobre la benignidad o malignidad en el diagnóstico. En otros trabajos [72] la cifra es similar.

Si recordamos que cada mujer implica 8 mamografías inspeccionadas se justifica la conveniencia de estudiar la viabilidad de desarrollar un sistema computerizado que analice automáticamente las mamografías. El caso ideal es que el sistema de directamente el diagnóstico, pero mientras eso llega, un objetivo más cercano es intentar reducir la cantidad de mamografías que el radiólogo debe inspeccionar realizando un sistema que descarte aquellas que no tienen ningún indicio de anomalía. La casuística que se puede presentar en mamografía es amplia y puede ser complicado diagnosticar con exactitud la benignidad o malignidad de ciertos hallazgos, pero sí que es un objetivo abordable la detección automática de anormalidades con niveles de detección altos. Esta preselección automática de mamografías anormales, o más exactamente, potencialmente anormales es importante porque una proporción mayoritaria de mamografías normales (proporción constatada por las cifras de la Comunidad Valenciana) tiende a provocar que pasen más desapercibidos para el radiólogo los casos anormales. Dada la diversidad de anomalías, las publicaciones que se producen sobre detección en mamografía son específicas para cada tipo y el objetivo más frecuente es obtener 


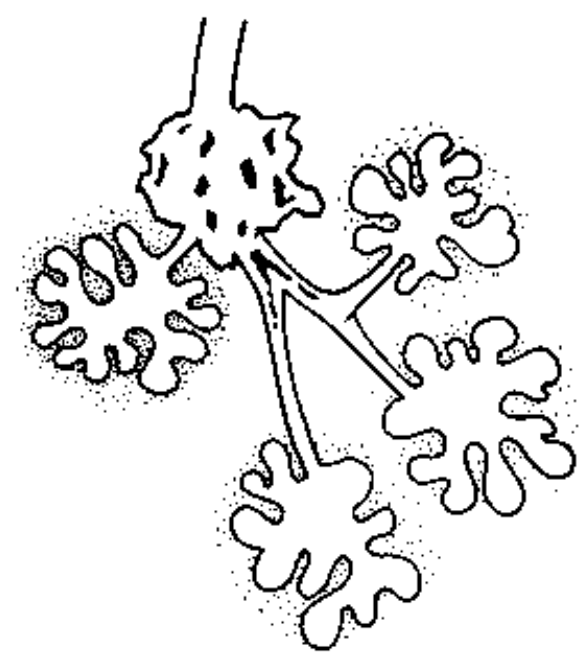

a) estructura

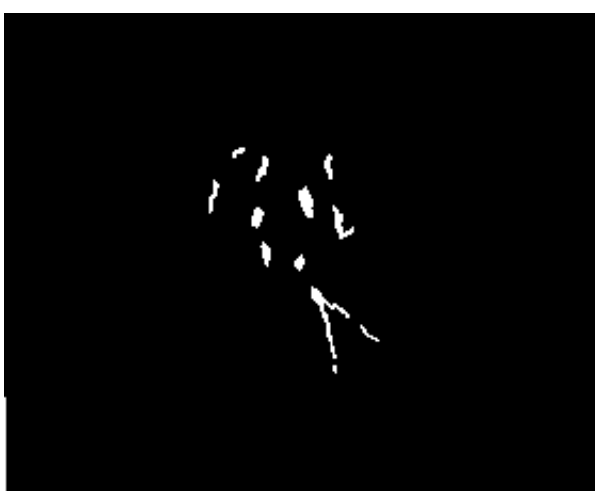

b) microcalcificaciones

Figura 1.3: Microcalcificaciones lobulares malignas. Son irregulares en forma y tamaño. Adaptado de [68]

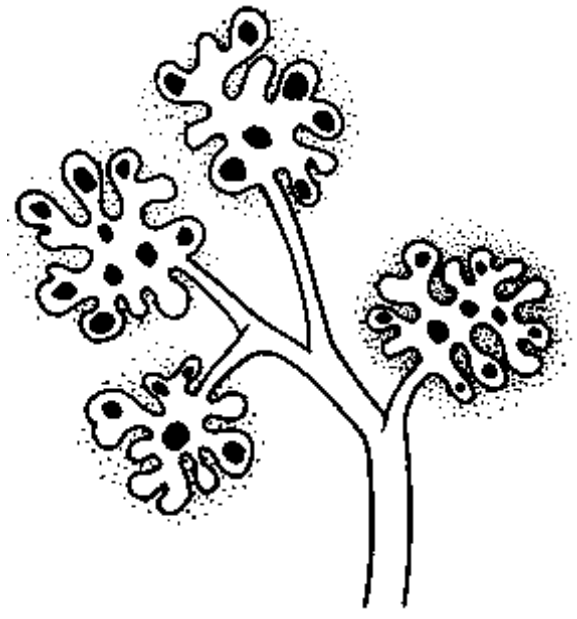

a) estructura

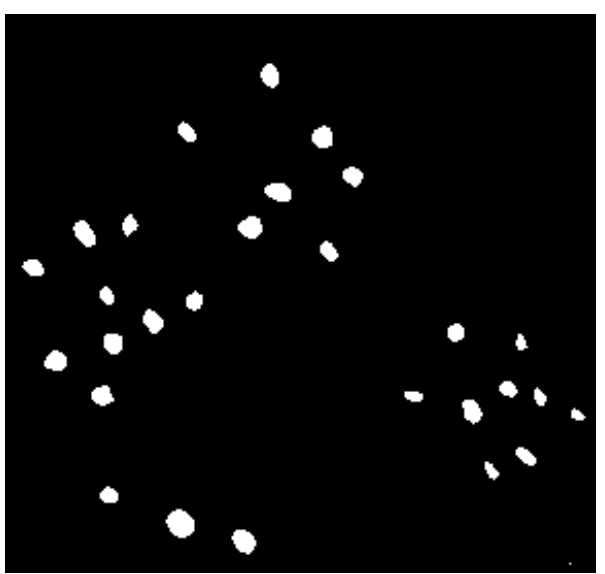

b) microcalcificaciones

Figura 1.4: Microcalcificaciones lobulares benignas. Su aspecto es redondeado y su ubicación dispersa, en ocasiones aparecen varios grupos próximos entre sí. Adaptado de [68] 


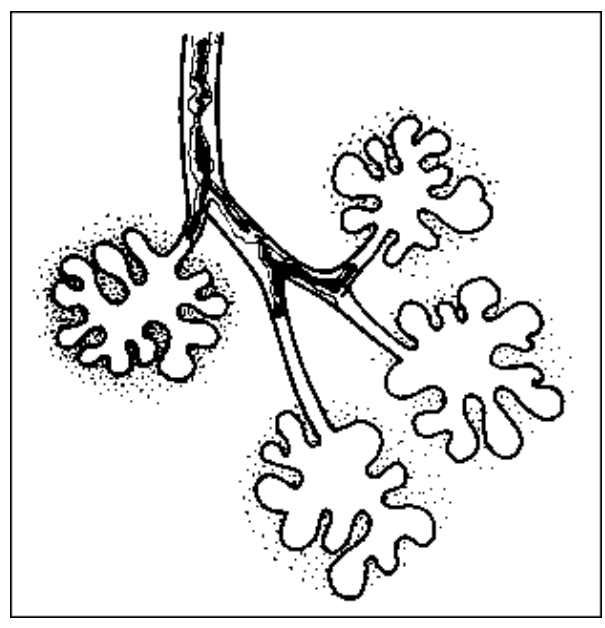

a) estructura

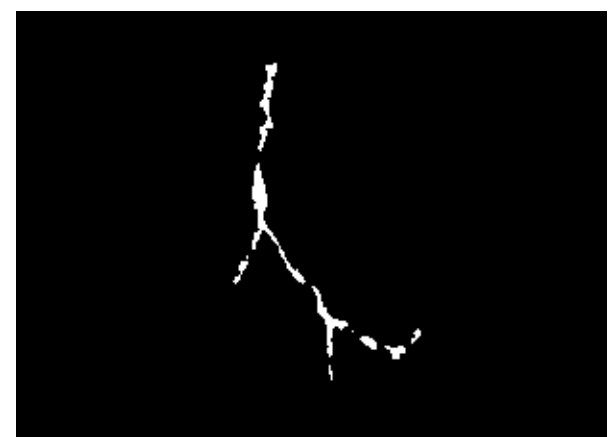

b) microcalcificaciones

Figura 1.5: Microcalcificaciones ductales malignas. $\mathrm{Su}$ aspecto es lineal con bordes irregulares y algunas presentan ramificaciones. Adaptado de [68]

como resultado la determinación de las zonas de la mamografía donde puede estar la anomalía para que el radiólogo centre su atención en dichas zonas y no tenga que invertir tiempo y capacidad de concentración en la totalidad de la mamografía. Si la precisión del sistema lo permite éste mismo proceso serviría para descartar automáticamente aquellas mamografías en las que no se ha detectado ninguna zona que deba ser analizada por el radiólogo.

Como se ha dicho anteriormente en los programas de screening se recomienda doble lectura, es decir, que la mamografía sea analizada por dos radiólogos o bien que el mismo radiólogo la analice dos veces en dos momentos distintos dado que muchos estudios reflejan inconsistencias en el diagnóstico dada la dificultad del mismo [135]. Otro planteamiento de aplicación del sistema computerizado sería que tanto el radiólogo como el sistema analizaran todas las mamografías sirviendo este último como segunda lectura.

Adquisición de la imagen. La adquisición de la imagen, es decir, la obtención de la matriz rectangular de números que será tratada por el sistema computerizado, puede ser de dos formas, digitalizando una placa de radiografía convencional o bien con un sistema de mamografía digital directa en el que la radiación que atraviesa la mama incide sobre un sensor que directamente permite dar la información de la imagen en forma numérica sin revelado fotográfico intermedio.

Ambos casos comparten el modo de realización de la exposición de la mama a los rayos $\mathrm{x}$. Desde una distancia de varias decenas de centímetros se emite la 
radiación con un foco que idealmente debe ser puntual y que en la práctica tiene un tamaño inferior al milímetro. La mama se comprime con fuerza para evitar una sobreexposición de los tejidos anteriores de menor espesor y una infraexposición de la base. Los tejidos no deben ser dañados y se debe tener en cuenta el dolor provocado a la paciente pero cuanto mayor es la compresión, mejor es la mamografía. Con la compresión también se asegura la ausencia de movimiento durante la exposición a la radiación reduciendo el efecto de emborronamiento por movimiento, y además también se reduce la radiación dispersa. En la figura 1.6 se muestra la disposición del equipo mamográfico.

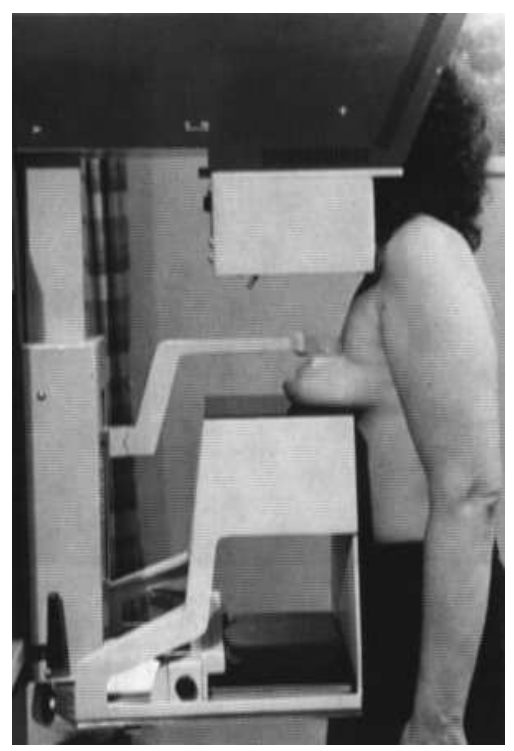

Figura 1.6: Realización de una mamografía. Proyección craneo-caudal. Adaptado de [68]

Respecto a la digitalización de mamografía convencional, hay que realizar el proceso mediante un escáner. Las tecnologías utilizadas son básicamente dos, láser y CCD. Ambas miden la densidad óptica de cada punto o pixel de la imagen. Es frecuente asumir que el pixel es una región cuadrada. El tamaño del pixel viene determinado por el tamaño del láser o por el tamaño de las células del CCD. La resolución de la imagen está determinada por dicho tamaño de pixel y normalmente se da en número de puntos por unidad de longitud o bien directamente la longitud del lado del pixel. El resultado de la medida de la densidad del pixel es un número unidimensional o nivel de gris cuyo número de bits depende de las capacidades del sistema.

La figura 1.7 a muestra la disposición de los elementos es una adquisición con láser. Se ilumina un sólo punto con una cantidad de luz conocida y la radiación que consigue atravesar la placa radiográfica incide sobre un sensor. A continuación se desplaza el haz láser para que incida en el siguiente punto a adquirir y de 
modo secuencial se adquiere toda la imagen, generalmente con un movimiento similar al de lectura de un texto escrito a base de líneas horizontales de izquierda a derecha y de arriba a abajo. La técnica basada en CCD (ver figura 1.7b) generalmente utiliza un sensor lineal compuesto de un número de sensores individuales alrededor de uno o varios millares, de manera que se adquiere una línea de pixels simultáneamente. Para adquirir la imagen completa es suficiente con desplazar el sensor en la dirección perpendicular al mismo.

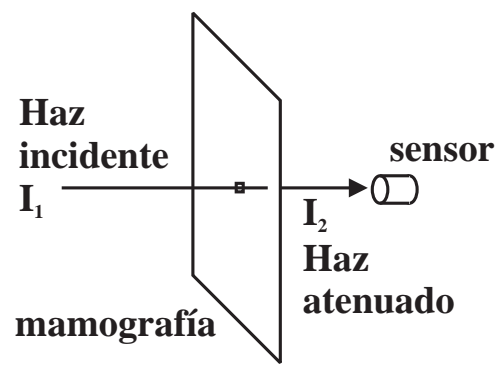

a) escáner láser

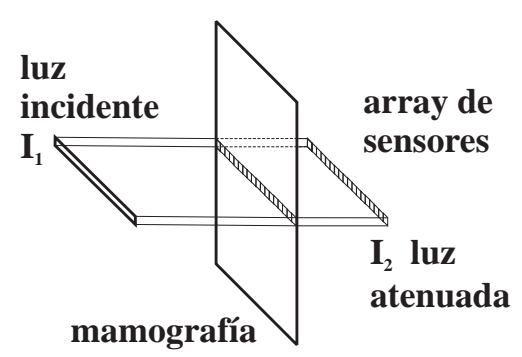

b) escáner CCD

Figura 1.7: Diagrama de digitalización de la imagen mamográfica. a) dispositivo basado en láser. La resolución está determinada por el tamaño del haz láser; b) dispositivo basado en CCD lineal. La resolución está determinada por el tamaño de los sensores individuales dentro del array lineal.

En ambos casos la luz al atravesar un determinado punto de la mamografía sufre una atenuación que es medida a través de la transmitancia $T$ :

$$
T=\frac{I_{2}}{I_{1}}
$$

donde $I_{1}$ es la luz incidente, que debe ser conocida, e $I_{2}$ es la luz que atraviesa la mamografía y es medida por el sensor. Como el margen dinámico es muy grande se utiliza la densidad óptica $D$ definida como:

$$
D=-\log T
$$

El número o nivel de gris que finalmente se adjudica a cada pixel es proporcional a la densidad óptica, y el valor concreto depende del margen de densidades ópticas que el dispositivo sea capaz de manejar.

Cabe citar aquí que existen otros métodos para el diagnóstico de cáncer como los basados en ultrasonidos, tomografía, etc. que complementan el diagnóstico del cáncer de mama, pero la mamografía es hoy por hoy el método que ha demostrado ser mejor en la detección precoz mediante procesos de screening.

Estructura de la tesis. La tesis presenta dos áreas del tratamiento digital de imágenes, los campos aleatorios de Markov y la Morfología Matemática. Con 
ellas se desarrollan varios procedimientos y se evalúan sus prestaciones en la tarea de detección de las microcalcificaciones. La combinación de ambas permite mejorar los resultados que se hubieran alcanzado con una sola de ellas. Dentro de los campos aleatorios se estudian los algoritmos de detección existentes y se proponen alternativas para disminuir los aspectos en que disminuyen sus prestaciones. En el área de Morfología Matemática se proponen operadores específicos puesto que las microcalcificaciones en mamografía no se corresponden con los problemas de segmentación genérica de imágenes.

El texto está estructurado en capítulos. En el siguiente se hace una revisión de la literatura publicada respecto al tratamiento de mamografía y en particular sobre la detección de microcalcificaciones. En el capítulo 3 se presentan los campos aleatorios de Markov y se implementan varios algoritmos de segmentación, mostrándose con ejemplos sus capacidades y limitaciones en la tarea de segmentación general de imágenes. En el capítulo 4 se revisan los fundamentos de las herramientas de Morfología Matemática que se utilizan en la presente tesis. El capítulo 5 presenta diferentes algoritmos para la detección de las microcalcificaciones basados en las técnicas expuestas en los capítulos precedentes y en el capítulo de resultados que le sigue se evalúan todos ellos con una base de imágenes mamográfica (ver Anexo A) utilizada internacionalmente para poder comparar las capacidades de nuestra propuesta con otras ya publicadas. Las conclusiones finales y futuras líneas de trabajo se exponen en el capítulo 7 . 


\section{Capítulo 2}

\section{Revisión de la literatura}

El trabajo que está realizando la comunidad científica internacional alrededor del tratamiento computerizado de mamografía digital está dirigido fundamentalmente hacia la ayuda en los programas de screening masivo. Como se ha dicho en la introducción estos programas representan un método eficaz en la detección precoz y consecuentemente un aumento muy importante de las probabilidades de curación. Las consecuencias del resultado que el sistema computerizado dictamine tras el análisis de una mamografía son tan importantes para la vida de cada mujer, que el tratamiento de todas las mamografías del programa masivo de screening no se puede dejar exclusivamente en manos de la máquina a menos que esté exhaustivamente comprobado que el número de fallos es muy bajo, y en estos momentos eso todavía no es una realidad. Así las cosas el objetivo realista que en la literatura se establece es que la máquina realice en vez del screening un prescreening conducente a reducir el número de mamografías que los radiólogos tienen que estudiar.

La literatura acerca de tratamiento computerizado de mamografía se puede clasificar atendiendo al tipo de patología o anormalidad que pretende detectar o analizar. Según este criterio, los dos grupos más numerosos de artículos tratan acerca de las microcalcificaciones y de las masas. El resto, menos numeroso, versan acerca de asimetrías, clasificación de estructuras del parénquima mamario, detección de estructuras fibrosas, localización del pezón [21], etc.

Si la clasificación se hace atendiendo a un criterio cronológico la estructuración podría hacerse de diversas formas, una posible consiste en establecer una primera etapa previa a la celebración del First International Workshop on Digital Mammography, FIWDM y las siguientes etapas coincidentes con cada edición. En el primer congreso, celebrado en San José, California, en 1993, se sientan las bases para la celebración periódica del mismo en el futuro. Fruto de esta idea fue el segundo congreso, celebrado en York, Reino Unido, en 1994, y el tercero, ce- 
lebrado en Chicago, Illinois, USA, en 1996. El próximo congreso se celebrará en 1998 en Nijmegen, Holanda. Los resultados del presente trabajo se presentarán en esta edición [91]. Junto a este congreso también hay muchas aportaciones en los congresos de tratamiento de imagen organizados por instituciones como el IEEE, IEE, IASTED, SPIE, etc., pero la mayor concentración se produce en el mencionado anteriormente. Dado que el tratamiento computerizado de mamografía es la confluencia de dos ciencias fundamentales, a saber, el tratamiento de señal y la medicina, también desde las organizaciones médicas se celebran reuniones y congresos sobre este tema.

Aunque para establecer un marco de referencia dentro del área de la mamografía [135] mencionaremos algunas publicaciones no específicas de microcalcificaciones, la revisión que haremos se centrará fundamentalmente en éstas.

\subsection{Etapa previa al FIWDM}

\subsubsection{Detección de microcalcificaciones}

De los trabajos previos al FIWDM, muchos de ellos tratan de microcalcificaciones o detección precoz de cáncer [20][129][45] [116][19][43] [94][29][60] [7][79]. Los de detección precoz de cáncer lo hacen a través de la detección de microcalcificaciones, así que implícitamente también son de microcalcificaciones. Los tres trabajos mejor conocidos y más referenciados son los publicados por Chan y Doi [20], Davies y Dance [29] y Karssemeijer [60]. Chan y Doi utilizando extracción de características y umbrales consiguen unos resultados de $82 \%$ en ratio de clusters verdaderos positivos (RVP) detectados con 1 cluster falso positivo por imagen en promedio. Las imágenes utilizadas son 20 mamografías todas ellas conteniendo clusters de microcalcificaciones. Mayor es el ratio de verdaderos positivos presentado por Davies y Dance que alcanza un $96 \%$ con un promedio de falsos positivos de 0.18 por imagen. Son resultados muy superiores no solo por ser $96 \%$ frente a $82 \%$ sino porque además reduce a más de la quinta parte los falsos positivos detectados. El conjunto de mamografías utilizado consiste en 50 imágenes de las cuales la mitad tienen clusters y la otra mitad no. Se utilizan 25 para entrenar el algoritmo. También el tipo de procedimiento utilizado consiste en detectar regiones, básicamente a través de filtrado paso alto, calcular características de estas regiones y aplicar umbrales. A diferencia Karssemeijer utiliza un modelo estocástico para la mamografía y aplica clasificación bayesiana. Nuestro trabajo deriva de éste. En la figura 2.1 se presenta un esquema de la versión ampliada [61] en el que se refleja que el proceso se divide en dos partes, una primera en la que a partir de la imagen de niveles gris se obtienen tres imágenes también de niveles de gris, que son el contraste local, el contraste 
local filtrado paso bajo, y la salida de un detector de líneas/bordes basado en la orientación local del gradiente. La segunda parte toma como entradas estas tres imágenes y da como resultado la segmentación con las microcalcificaciones detectadas. El contraste local lo calcula como la diferencia entre el nivel de gris del pixel y el promedio en una ventana cuadrada centrada en el mismo. Los

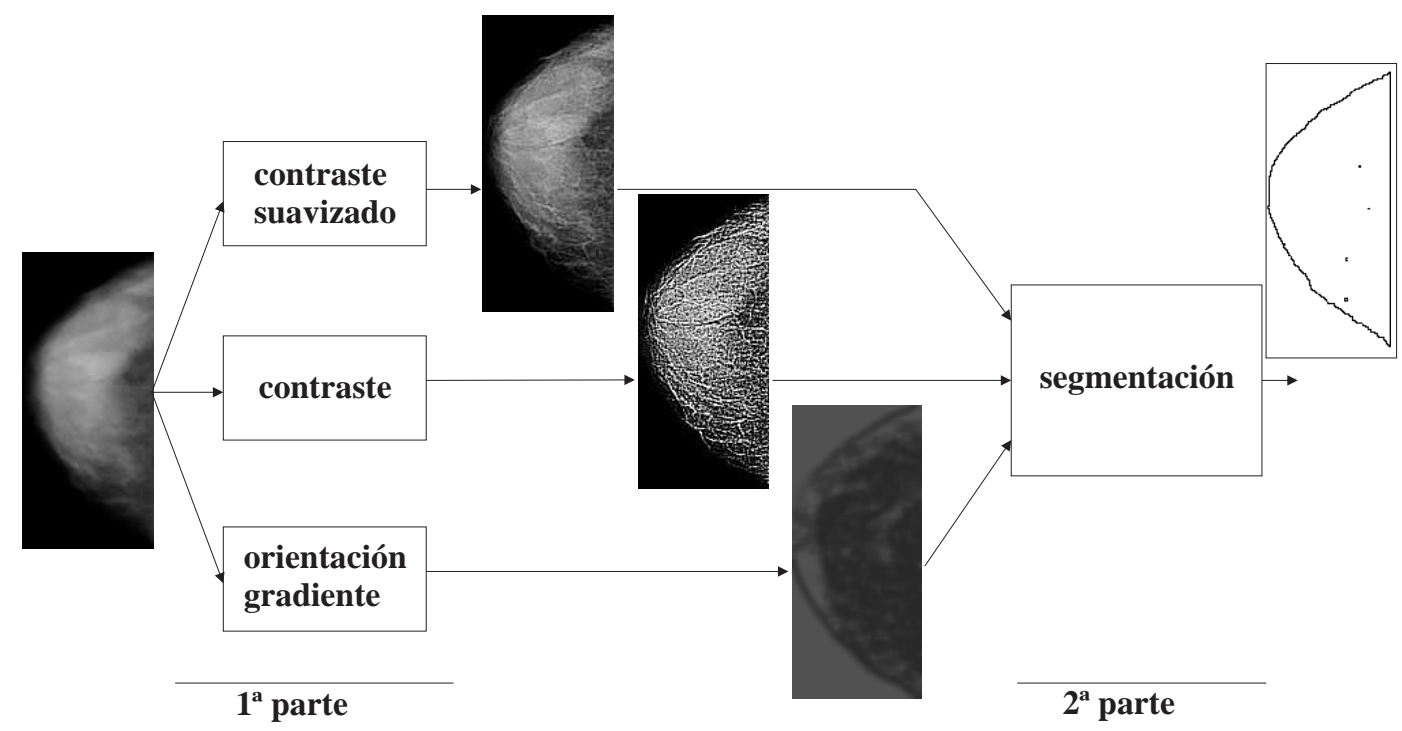

Figura 2.1: Diagrama del detector [61]. Sigue un planteamiento frecuente en la literatura referente a la detección de las microcalcificaciones al dividir el proceso en dos partes. En particular, en [61] la primera parte genera tres imágenes y a partir de ellas la etapa de segmentación genera el resultado.

resultados que obtiene son muy similares a los de Chan y Doi ( $82 \%$ con 1 falso positivo por imagen) pero el algoritmo permite ajustar la sensibilidad y por tanto obtener diferentes niveles de detección con las correspondientes falsas alarmas, dando un $100 \%$ de verdaderos positivos detectados con 2 falsos positivos por imagen. Utiliza 25 mamografías para entrenar y otras 40, distintas a las 25 de entrenamiento para la evaluación del proceso. La novedad importante es que las 40 mamografías de test las ha puesto a disposición pública para que puedan contrastarse los resultados con otras investigaciones. Del resto de trabajos referenciados al principio del párrafo la técnica más empleada son umbrales sobre características de regiones potencialmente calcificaciones [20, 19, 43, 29, 7]. Otro tipo de técnicas empleadas están dentro del campo de la clasificación como son los k-vecinos más próximos [45] y los árboles de decisión binarios [116].

Aunque Davies y Dance obtienen resultados bastante buenos, para que el procedimiento tenga una implantación en la rutina clínica es necesario verificar que el tipo de imágenes utilizado contempla tanto imágenes con clusters fáciles de detectar como difíciles. Las 40 imágenes de Karssemeijer aparte de haberlas hecho públicas, lo cual le da una mayor importancia a su trabajo por la po- 
sibilidad de poder verificar la validez de los resultados obtenidos en el mismo, contienen entre ellas imágenes realmente complicadas en la labor de detección. Ya otros investigadores han puesto de manifiesto que los resultados alcanzados por Karssemeijer sobre esas imágenes no son nada sencillos de obtener [135, 119].

\subsubsection{Detección de masas}

Respecto a los trabajos previos al FIWDM dirigidos hacia la detección y análisis de masas o tumores [2, 108, 69, 13, 73, 137, 62], el promedio alcanzado en la detección es del 90\%, pero al igual que en microcalcificaciones todavía es necesario reducir el número de falsos positivos y contrastar los resultados con bases de datos mucho más extensas de las utilizadas en las publicaciones. En las masas presentes en mamografía la taxonomía que se puede realizar consiste en dos clases, las bien definidas [13, 69] y las mal definidas [62]. El adjetivo definida se refiere a la frontera entre la masa y el tejido mamario en el que está inmersa. Por bien definida se entiende una masa con una frontera estrecha que delimita un cambio brusco de densidad dentro de la masa respecto de la densidad en el tejido circundante a la masa y que la forma de dicha frontera sea básicamente circular sin cambios bruscos en la curvatura. Por mal definida se entiende cualquier posibilidad no incluida en bien definida, por ejemplo una frontera ancha, en el sentido de que la densidad de la masa va decreciendo de forma progresiva y no brusca hacia la densidad del tejido circundante. Un caso de especial interés son las estrelladas [62 $]^{1}$ dado que implican una alta probabilidad de ramificación del tumor y propagación al resto de tejidos (metástasis).

En cuanto a la posibilidad de establecer comparaciones de resultados con otros procedimientos utilizados por el resto de investigadores no hay posibilidad pues las bases de datos son diferentes e incluso la forma de evaluar los resultados son distintas, por ejemplo en cuanto a criterios de cuando una masa ha sido detectada o no. En algunos casos se considera detectada cuando el centro del área detectada por el algoritmo está dentro de la zona marcada por el radiólogo, otros cuando el área detectada superpone en un cierto porcentaje la zona marcada por el radiólogo, etc.

\subsubsection{Otros}

En esta sección se citan otros frentes importantes en los que se trabaja actualmente y de los que ya se publicaron artículos en esta etapa como por ejemplo la relación del patrón del parénquima mamario con el riesgo de cáncer, las distor-

\footnotetext{
${ }^{1}$ del inglés stellate
} 
siones en la arquitectura de la mama, o el realzado de imagen para mejorar la inspección por parte del radiólogo.

Algunos investigadores han estudiado que los parénquimas mamarios de las mujeres son distintos y han intentado realizar una clasificación en base a diferentes características, entre ellas la arquitectura y la densidad. Quizás el más famoso sea la clasificación de Wolfe [131] en la que agrupa un conjunto de casos clínicos en cuatro patrones [68] y establece que unos tienen mayor riesgo de cáncer que otros; también en $[105,112,75,16]$ se realizan trabajos en esta línea, pero el debate no se ha cerrado todavía con una opinión unánime de la comunidad científica sobre si existe una relación directa o no.

Respecto al realzado Dhawan [39, 37], Gordon [48], Woods [133] y Tahoces [121] basan sus aportaciones en filtrado y umbrales adaptativos sobre el vecindario de cada pixel, Morrow [89] en cambio utiliza crecimiento de regiones y aporta en su trabajo la definición de una medida cuantitativa de la mejora del contraste conseguida por el proceso que propone (basada en el histograma). 


\section{$2.2 \quad$ FIWDM}

Dado que éste ha sido el primer congreso exclusivamente dedicado a la mamografía digital es interesante hacer un sumario [135] para establecer el estado de los trabajos en este punto de partida.

\subsubsection{Detección de microcalcificaciones}

\begin{tabular}{|c|c|c|c|c|}
\hline Autores & Contenido & $\begin{array}{ll}\text { Número } & \text { de } \\
\text { imágenes } & \end{array}$ & Resultados & Comentario \\
\hline $\begin{array}{lr}\text { Barman } & \mathrm{y} \\
\text { Grandlun } & {[8]}\end{array}$ & $\begin{array}{l}\text { detección de } \\
\text { calcificacio- } \\
\text { nes }\end{array}$ & $\begin{array}{l}2 \text { imágenes, } 1 \\
\text { en alta resolu- } \\
\text { ción }\end{array}$ & ninguno & $\begin{array}{l}\text { trabajo } \\
\text { preliminar } \\
\text { utilizando } \\
\text { wavelets }\end{array}$ \\
\hline $\begin{array}{ll}\text { Qian } & \text { et } \\
\text { al [98] } & \end{array}$ & $\begin{array}{l}\text { clusters de } \\
\text { calcificacio- } \\
\text { nes }\end{array}$ & 15 imágenes & $\begin{array}{l}100 \% \text { RVP, } \\
0.2 \mathrm{FP} / \mathrm{img}\end{array}$ & $\begin{array}{l}\text { wavelets, re- } \\
\text { sultados eva- } \\
\text { luados subje- } \\
\text { tivamente }\end{array}$ \\
\hline Zhao [139] & $\begin{array}{l}\text { características } \\
\text { de calcifica- } \\
\text { ciones }\end{array}$ & 3 imágenes & ninguno & $\begin{array}{l}\text { No detalla el } \\
\text { proceso }\end{array}$ \\
\hline $\begin{array}{ll}\text { woods } & \text { et } \\
\text { al }[134] & \end{array}$ & $\begin{array}{l}\text { detección de } \\
\text { calcificacio- } \\
\text { nes }\end{array}$ & $\begin{array}{l}9 \text { imágenes } \\
\text { de entrena- } \\
\text { miento y } 15 \\
\text { de test todas } \\
\text { con calcs. }\end{array}$ & $\begin{array}{l}85 \% \text { RVP con } \\
20 \% \text { RVP so- } \\
\text { bre calcs indi- } \\
\text { viduales }\end{array}$ & $\begin{array}{l}\text { extracción } \\
\text { de regiones } \\
\text { potenciales y } \\
\text { clasificación } \\
\text { de esas regio- } \\
\text { nes. Curvas } \\
\text { ROC }\end{array}$ \\
\hline
\end{tabular}




\begin{tabular}{|c|c|c|c|c|}
\hline Autores & Contenido & $\begin{array}{ll}\text { Número } & \text { de } \\
\text { imágenes } & \end{array}$ & Resultados & Comentario \\
\hline $\begin{array}{l}\text { Bankman et } \\
\text { al [6] }\end{array}$ & $\begin{array}{ll}\text { clusters } & \text { de } \\
\text { calcs. } & \end{array}$ & $\begin{array}{l}3 \text { imágenes } \\
\text { de entrena- } \\
\text { miento y } 9 \text { de } \\
\text { test }\end{array}$ & $\begin{array}{lr}100 \% & \text { RVP } \\
\text { con } & 0.22 \\
\text { FP/img } & \end{array}$ & $\begin{array}{lr}\text { No se } & \text { tienen } \\
\text { detalles } & \text { del } \\
\text { proceso } & \end{array}$ \\
\hline $\begin{array}{l}\text { Karssemeijer } \\
{[61]}\end{array}$ & $\begin{array}{l}\text { cluster de } \\
\text { calcs. }\end{array}$ & $\begin{array}{l}40 \text { imágenes } \\
\text { todas con } \\
\text { clusters }\end{array}$ & $\begin{array}{l}100 \% \\
\text { con } 2 \mathrm{FP} / \mathrm{img}\end{array}$ & $\begin{array}{l}\text { modelo es- } \\
\text { tocástico. } \\
\text { Curvas ROC }\end{array}$ \\
\hline $\begin{array}{l}\text { Shenet et } \\
\text { al }[114]\end{array}$ & $\begin{array}{l}\text { detección de } \\
\text { calcs. y cla- } \\
\text { sificación be- } \\
\text { nigna/ malig- } \\
\text { na }\end{array}$ & 4 imágenes & $\begin{array}{l}87 \% \text { RVP con } \\
0 \text { FP benigna. } \\
89 \% \text { RVP con } \\
29 \text { FP malig- } \\
\text { na. }\end{array}$ & $\begin{array}{l}\text { Clasificación } \\
\text { benig/malig } \\
\text { correcta: } 94 \% \\
\text { benig. } \\
\text { malig. }\end{array}$ \\
\hline $\begin{array}{ll}\text { Dhawan } & \text { et } \\
\text { al [38] } & \end{array}$ & $\begin{array}{l}\text { clasificación } \\
\text { de clusters } \\
\text { benigno/ } \\
\text { maligno }\end{array}$ & 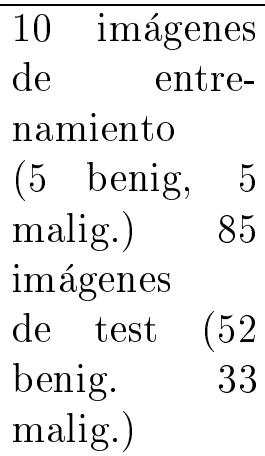 & $\begin{array}{l}74 \% \text { clasifica- } \\
\text { ción correcta } \\
\text { a nivel de } \\
\text { calcs indivi- } \\
\text { duales. } 66 \% \\
\text { a nivel de } \\
\text { grupo }\end{array}$ & $\begin{array}{l}\text { segmentación } \\
\text { manual de las } \\
\text { calcs. Clasi- } \\
\text { ficación con } \\
\text { red neuronal }\end{array}$ \\
\hline $\begin{array}{ll}\text { Parker } & \text { et } \\
\text { al }[96] & \end{array}$ & $\begin{array}{l}\text { clasificación } \\
\text { de clusters } \\
\text { benigno/ } \\
\text { maligno }\end{array}$ & $\begin{array}{l}4 \text { imágenes de } \\
\text { entrenamien- } \\
\text { to }(2 \text { benig., } \\
2 \text { malig. })\end{array}$ & $\begin{array}{l}100 \% \text { cla- } \\
\text { sificación } \\
\text { correcta en } \\
\text { los casos } \\
\text { "típicos", } \\
\text { algunos } \\
\text { atípicos mal } \\
\text { clasificados }\end{array}$ & $\begin{array}{l}\text { segmentación } \\
\text { manual de } \\
\text { las calcs } \\
\text { individuales }\end{array}$ \\
\hline
\end{tabular}




\subsubsection{Detección de masas}

\begin{tabular}{|c|c|c|c|c|}
\hline Autores & Contenido & $\begin{array}{ll}\text { Número } & \text { de } \\
\text { imágenes } & \end{array}$ & Resultados & Comentario \\
\hline $\begin{array}{l}\text { Nishikawa et } \\
\text { al [93] }\end{array}$ & $\begin{array}{l}\text { calcificaciones } \\
\text { y masas }\end{array}$ & $\begin{array}{lr}154 \text { pares } & \text { de } \\
\text { imágenes, } & 90 \\
\text { de ellos con } \\
\text { masas y } & 78 \\
\text { img con } & 36 \\
\text { grupos } & \text { de } \\
\text { calc. } & \end{array}$ & $\begin{array}{l}85 \% \text { RVP } \\
\text { ambos casos, } \\
3.0 \text { FP/img } \\
\text { en masas, } 1.5 \\
\text { FP/img en } \\
\text { calc. }\end{array}$ & \begin{tabular}{l}
\multicolumn{2}{l}{ clasificador } \\
ANN para \\
reducir FP. \\
leave-one-out \\
entrena/test
\end{tabular} \\
\hline $\begin{array}{l}\text { Brzakovic et } \\
\text { al }[12]\end{array}$ & $\begin{array}{l}\text { calcificaciones } \\
\text { y masas }\end{array}$ & $\begin{array}{l}17 \text { imágenes } \\
\text { con calcs. y } \\
12 \text { con masas }\end{array}$ & $\begin{array}{l}76 \% \text { RVP, } 0 \\
\text { FP/img en } \\
\text { calcs, } 67 \% \\
\text { RVP en ma- } \\
\text { sas, no da } \\
\text { datos de FP }\end{array}$ & $\begin{array}{l}\text { proceso mul- } \\
\text { tiresolución, } \\
\text { algunos tests } \\
\text { son sobre } \\
\text { simulaciones }\end{array}$ \\
\hline $\begin{array}{ll}\text { Mazur } & \text { et } \\
\text { al }[82] & \end{array}$ & $\begin{array}{l}\text { detección } \\
\text { de masas } \\
\text { incipientes }\end{array}$ & $\begin{array}{l}1 \text { imagen CT } \\
\text { con masas si- } \\
\text { muladas }\end{array}$ & $\begin{array}{l}\text { centros de las } \\
\text { masas }\end{array}$ & $\begin{array}{l}\text { Da un } \\
\text { método de } \\
\text { evaluar masas } \\
\text { crecientes }\end{array}$ \\
\hline $\begin{array}{ll}\text { Burdett } & \text { et } \\
\text { al }[15] & \end{array}$ & $\begin{array}{l}\text { clasificación } \\
\text { de lesio- } \\
\text { nes benig- } \\
\text { na/maligna }\end{array}$ & $\begin{array}{l}8 \text { imágenes } \\
\text { con } 4 \text { lesiones } \\
\text { malignas y } 6 \\
\text { benignas }\end{array}$ & ninguno & $\begin{array}{l}\text { segmentación } \\
\text { manual }\end{array}$ \\
\hline
\end{tabular}




\subsubsection{Otros}

\begin{tabular}{|c|c|c|c|c|}
\hline Autores & Contenido & $\begin{array}{ll}\text { Número } & \text { de } \\
\text { imágenes } & \end{array}$ & Resultados & Comentario \\
\hline $\begin{array}{l}\text { Miller y } \text { As- } \\
\text { tley [87] }\end{array}$ & $\begin{array}{l}\text { Asimetría de } \\
\text { las mamas }\end{array}$ & $\begin{array}{l}30 \text { pares de } \\
\text { imágenes } \\
\text { con } 12 \text { pares } \\
\text { anómalos }\end{array}$ & $\begin{array}{l}91.7 \% \text { RVP } \\
\text { con } 16.7 \% \text { de } \\
\text { RFP }\end{array}$ & $\begin{array}{l}\text { clasificador } \\
\text { con } 6 \text { carac- } \\
\text { terísticas. } \\
\text { Mismas } \\
\text { imágenes } \\
\text { para entre. y } \\
\text { para test }\end{array}$ \\
\hline $\begin{array}{ll}\text { Hajnal } & \text { et } \\
\text { al }[51] & \end{array}$ & $\begin{array}{l}\text { clasificación } \\
\text { de mamo- } \\
\text { grafías por } \\
\text { densidad }\end{array}$ & $\begin{array}{l}20 \text { pares de } \\
\text { imágenes } \\
\text { para entrena- } \\
\text { miento } 103 \\
\text { pares para } \\
\text { test }\end{array}$ & $\begin{array}{l}72 \% \text { RVP con } \\
21 \% \text { RFP }\end{array}$ & $\begin{array}{l}\text { curvas ROC. } \\
8 \text { imágenes no } \\
\text { clasificadas }\end{array}$ \\
\hline $\begin{array}{l}\text { Richardson } \\
{[99]}\end{array}$ & compresión & 1 imagen & ninguno & wavelets \\
\hline $\begin{array}{ll}\text { Astley } & \text { et } \\
\text { al [4] } & \end{array}$ & $\begin{array}{lr}\text { marcado } & \text { de } \\
\text { zonas } & \text { para } \\
\text { mejorar } & \text { la } \\
\text { precisión } & \end{array}$ & $\begin{array}{l}30 \text { imágenes } \\
\text { con } 15 \text { zonas }\end{array}$ & $\begin{array}{l}\text { la precisión } \\
\text { del radiólogo } \\
\text { mejora }\end{array}$ & $\begin{array}{l}\text { sumario de } \\
\text { como percibe } \\
\text { el radiólogo } \\
\text { las anomalías }\end{array}$ \\
\hline
\end{tabular}

\subsubsection{Conclusión}

Como conclusión común, independientemente de las diferentes técnicas de tratamiento de imagen empleadas, se observa la dificultad de comparar las prestaciones entre las diferentes alternativas debido a que todos los trabajos están evaluados con sus propias imágenes. Además no hay ninguna indicación sobre la complejidad de las imágenes utilizadas, por lo que los trabajos que aportan ratios de detección elevados con pocos falsos positivos [98,6] deben ser contrastados. Otra conclusión es que en algunos trabajos el número de imágenes es únicamente de varias unidades $[82,8,99,139,6,114,96,15]$ lo cual no permite elevar las conclusiones a definitivas. 


\subsection{TIWDM}

La última edición celebrada del International Workshop on Digital Mammography ha sido la tercera. En ésta el número de contribuciones ha sido mucho mayor que la primera y mencionar todos los trabajos sería demasiado extenso por lo que vamos a centrar la revisión en los referentes a microcalcificaciones.

Carman y Eliot [17] basa su trabajo de detección en procesado lineal. Dice que las calcificaciones se pueden modelar como grupos pequeños y localizados de pixels más brillantes que su vecindario por lo que utiliza la aproximación discreta de la Laplaciana de una Gaussiana (LG) [44] ya que la versión continua de Marr [78] muestra ser subóptima [44]. Carman, además aproxima el operador (LG) por el filtro Diferencia de Gaussianas (DG) tal como propone Dengler et al. [32]. La novedad de Carman respecto al trabajo de Dengler et al. [32] es que como los filtros necesitan uno o más parámetros que dependen del tamaño de los objetos a detectar (conocidos como escala) se propone un método adaptativo. Sobre el resultado se aplica un umbral obteniéndose una imagen binaria a la que se aplica el algoritmo de identificar componentes conexas y obtener las regiones resultantes que son las posibles microcalcificaciones. Sobre las regiones calcula cuatro características que son el área, contraste, circularidad y valor medio del gradiente en el borde y con ellas las clasifica como pertenecientes a microcalcificación o no. Este enfoque del problema en el que hay un proceso de filtrado, una binarización y una clasificación sobre las características de las regiones resultantes es bastante frecuente [135, 32]. Prueba dos clasificadores, el primero paralelepípedo, es decir, umbralizar en cada característica, y el segundo vecino más próximo. Obtiene mejores resultados con el primero, y son una detección del $70 \%$ de clusters malignos con aproximadamente 2 falsos positivos por imagen. Es una lástima que de los resultados de esta manera porque la mayoría de los trabajos dan sus cifras de detección sobre clusters totales y como no especifica los cluster benignos que tiene su base de mamografías no se pueden comparar los resultados directamente con otros.

Una afirmación suya que contrasta con las realizadas por otros [135] es que el método de segmentación no influye sobre los resultados del clasificador.

Hara et al [52] también utiliza como primer paso filtrado lineal. Su modelo de microcalcificación es aproximadamente cónico y el aspecto que fundamentalmente utiliza del cono es que la proyección del gradiente sobre un plano son círculos concéntricos el los que la dirección del gradiente es excéntrica. Los círculos concéntricos que utiliza tienen diámetro 3,5 y 7 pixels, de ahí que le llame al filtrado Triple-Ring Filter. El módulo y la dirección del gradiente lo calcula con las máscaras de Sobel. En cierto sentido aplica una técnica jerárquica porque con el resultado anterior determina qué pixels son candidatos a pertenecer a microcalcificaciones y sobre ellos repite el proceso anterior pero esta vez variando 
el diámetro de círculo basado en el resultado del crecimiento de regiones aplicado a partir del punto con mayor valor en el módulo del gradiente. Sobre este segundo filtrado se umbraliza y a continuación calcula el área y la circularidad. Sobre estas características se umbraliza de nuevo y el resultado es la detección final. Como se puede observar la parte final del proceso es similar a la empleada en [17] cuando utiliza la clasificación en paralelepípedo. Finalmente agrupa las microcalcificaciones en clusters y los clasifica entre benignos, indefinido y maligno en base al tamaño y forma de las microcalcificaciones individuales, y la distancia media entre ellas. Nosotros, y de acuerdo con [72], pensamos que no son características suficientes para hacer un diagnóstico preciso puesto que no se tienen en cuenta aspectos muy determinantes sobre la benignidad/malignidad tales como la forma del cluster y el tipo de tejido sobre el que se encuentra.

Netsch [92] enlaza el uso de filtrado lineal con análisis multiescala. En algunos aspectos este trabajo y el de Carman [17] comparten las mismas ideas, ya que ambos utilizan la Laplaciana de una Gaussiana (LG) como filtro detector de puntos y además tienen en cuenta diferentes escalas debido a que el tamaño de las microcalcificaciones va desde varios pixels a decenas de pixels. Un máximo local en el resultado de la LG corresponde a una estructura brillante más o menos circular en una escala apropiada. Como la LG se puede interpretar como un filtro pasobanda hay muchas estructuras en la mamografía que dan una salida elevada y por tanto se necesita una mayor selectividad. Introduce entonces como modelo para la microcalcificación un cilindro y determina la forma de la respuesta en una representación escala-espacio. Según el tamaño y el contraste del cilindro los parámetros de la representación escala-espacio tendrán un cierto valor. Para la detección de las microcalcificaciones a partir de la representación escala-espacio se estima el contraste de la misma y si éste supera un cierto umbral lo considera microcalcificación, sino no. La variación del umbral le permite ajustar la sensibilidad del proceso de detección. Sobre el resultado agrupa las microcalcificaciones en clusters y evalúa el ratio de verdaderos positivos y el número de falsos positivos por imagen resultándole un valor elevado debido sobre todo a las microcalcificaciones de tamaño pequeño, por lo que realiza un pre-clustering en la escala de tamaño pequeño exigiendo un número mínimo de 4 para ser considerada como grupo frente a las dos exigidas en el resto.

Consideramos los resultados de este trabajo especialmente interesantes porque se evalúa el algoritmo sobre la misma base de mamografías que nosotros utilizamos y porque se dan en forma de curva ROC (Receiver Operating Characteristic) $[18,84,120,136]$ que es la forma más valorada por la comunidad científica llegando a unos resultados similares a los nuestros. Indica que los tiempos de cálculo de la representación escala-espacio son altos pero no da cifras concretas.

Yoshida et al [138], como otros que se citan más adelante, tiene como tema principal de su trabajo para la detección de las microcalcificaciones las wave- 
lets. Su aportación consiste en seleccionar el subconjunto de wavelets de entre un conjunto más amplio tal que reconstruya mejor la mamografía. La diferencia entre la mamografía y la reconstrucción la llama imagen residual. A su vez repite el proceso sobre la imagen residual lo que conduce a un proceso iterativo que hace terminar cuando la energía de la imagen residual desciende por debajo de un valor predeterminado o el número de iteraciones alcanza un predeterminado valor. A continuación pondera el conjunto de wavelets con un conjunto de coeficientes con la intención de que el conjunto ponderado de wavelets reconstruya exclusivamente las microcalcificaciones y no el resto de estructuras de la mamografía. Para buscar el conjunto de coeficientes que logren el objetivo citado define la función de error cuadrático medio sobre las diferencia entre las imágenes reconstruidas a partir de las wavelets ponderadas y las imágenes maestro. Las imágenes maestro son imágenes binarias indicando los pixels que son microcalcificación según el criterio de un radiólogo experto. Una vez concluido el proceso de minimización del error se obtienen los coeficientes ponderadores. Cuando una mamografía es procesada con las wavelets ponderadas se llega a una imagen de niveles de gris que se binariza con un cierto umbral. El valor del umbral permite ajustar la sensibilidad que lleva aparejada un cierto ratio de falsos positivos. La evaluación del algoritmo se hace sobre regiones de interés (ROIs) de 128x128 pixels (tamaño de pixel $0.1 \mathrm{~mm}$ ), 41 conteniendo microcalcificaciones y $41 \mathrm{sin}$ ellas. Los resultados se dan en forma de curva ROC y área bajo ROC. Dado que de una ROI sólo considera si ha detectado o no un cluster, el número de clusters posibles es el mismo que de ROIs y por tanto puede calcular el Ratio de Falsos Positivos como el cociente del número de falsos positivos dividido por el número de ROIs empleadas para el test, quedando este ratio acotado entre cero y uno por la propia definición. Como a su vez el Ratio de Verdaderos Positivos también está acotado la representación del RVP en función del RFP (curva ROC) se realiza sobre una gráfica de área unidad. Se define entonces el área bajo $R O C A_{z}$ como la superficie delimitada por la curva ROC, el eje de abcisas, la recta que une el origen $(0,0)$ y el punto de la curva ROC correspondiente a la abcisa 0 y por último la recta que une el último punto del eje de abcisas, es decir $(0,1)$, con el punto de la curva ROC correspondiente a la abcisa 1. La figura 2.2 ilustra este concepto. Con esta definición se intenta sintetizar en una sola cifra numérica las prestaciones del detector. En el caso de un detector ideal $A_{z}=1$. En este trabajo el resultado es $A_{z}=0.93$.

En otros muchos trabajos $[61,17,92,90,91]$ etc., en los que se procesa la mamografía completa el número de falsos positivos se da por imagen por lo que esta cifra no está acotada, y no se puede estandarizar tan fácilmente un parámetro similar que sintetice en una sola cifra la información contenida en la curva ROC, puesto que en algunos trabajos el eje de abcisas contempla de cero a tres falsos positivos, en otros de cero a diez, en incluso hay diferencias en si la escala de abcisas es lineal o logarítmica. 


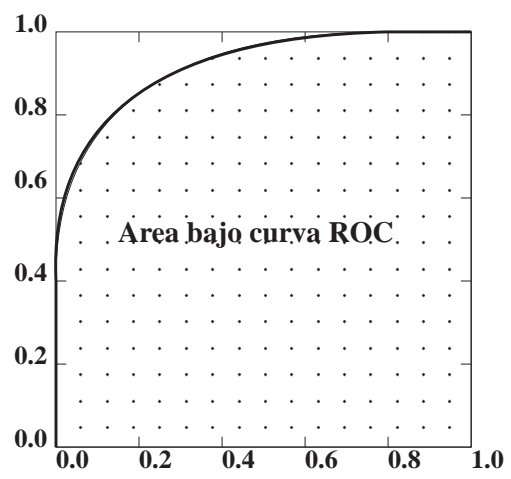

Figura 2.2: Área bajo ROC.

Nosotros como intento de traducir de forma aproximada resultados basados en ROIs a resultados basados en mamografía completa proponemos lo siguiente. El ratio de verdaderos positivos es el mismo. Respecto de los falsos positivos y suponiendo que las ROIs que no contienen verdaderos positivos incluidas en el conjunto de test son representativas de la mamografía en general es necesario traducir el ratio de falsos positivos a falsos positivos por imagen. Esto se puede hacer tomando dicho ratio y multiplicarlo por la cantidad de ROIs que puede haber en una mamografía. Así por ejemplo y suponiendo un tamaño de pixel en la digitalización de $0.1 \mathrm{~mm}$, una mamografía puede tener 2048x2048 pixels lo que supone $(2048 / 128) \times(2048 / 128)=256$ ROIs de $128 \times 128$ pixels. Si el trabajo con ROIs no incluye entre sus muestras ejemplares del fondo de la mamografía que no pertenece a la mama, entonces habría que compararlo con los trabajos que se realizan sobre mamografía completa y la procesan previamente para descartar la zona que no pertenece a la mama lo cual supone en término medio procesar sólo un tercio de la superficie y consecuentemente de las 256 posibles ROIs realmente hay que considerar la tercera parte resultando como factor multiplicativo para la comparación 85.

McLeod et al [83] también utilizan wavelets. Lo hace básicamente como filtro pasobanda reemplazando el filtro adaptado que utilizaban en sus trabajos anteriores. Utiliza las wavelets de Daubechies y sobre la señal de salida del filtro aplica un umbral que calcula a partir de la estadística de la imagen pero no especifica como. Sobre la imagen binaria resultante utiliza morfología para eliminar los pixels aislados. Este proceso también se encuentra en otros autores [28]. Aunque en varios trabajos se eliminan los pixels aislados, a efectos comparativos en importante tener en cuenta el tamaño de pixel en la digitalización o la adquisición. Este artículo trabaja sobre radiografía computerizada digitalizada directamente y no como digitalización de la película fotográfica expuesta a la radiación y posteriormente revelada. Desafortunadamente el autor da como información de la adquisición el número de pixels de las imágenes (2370x1770) pero no a qué superficie corresponde. Los resultados que reporta son $84 \%$ de 
verdaderos positivos con 1.9 falsos positivos por imagen.

Aghdasi [3] también hace referencia a Daubechies para las wavelets pero plantea que en el caso de las microcalcificaciones éstas pueden ser más visibles en transformaciones wavelets con escalas que no sean las tradicionales octavas tal y como aparece en [119]. Aghdasi propone que la escala, así como el desplazamiento, sea determinada mediante una red neuronal para optimizar la detección de las microcalcificaciones. Como resultado da un 3\% de mal clasificados. En la misma línea está el trabajo de Chitre y Dhawan [23] en el que también se utilizan wavelets y se optimizan para la detección de las microcalcificaciones pero en este caso la metodología de optimización no está basada en redes neuronales sino en el algoritmo genético GENESIS desarrollado por J. Grefenstette. La detección se realiza sobre regiones de interés extraídas manualmente de la mamografía. No da resultados en términos de ratio de verdaderos positivos detectados acompañados del ratio de falsos positivos correspondiente.

Otro grupo de autores $[28,102,106,117,130]$ tienen como herramienta central de sus propuestas las redes neuronales. Meersman [28] plantea la utilización de dichas redes para detectar las microcalcificaciones mediante la clasificación a nivel de pixel. En este sentido es similar al trabajo de la presente tesis. En otros trabajos el planteamiento es distinto porque se clasifica a nivel de regiones. Las redes que utiliza son de tres capas feedforward con distintos tamaños y el entrenamiento se hace con el algoritmo de backpropagation. Para el entrenamiento define el error como uno o menos uno si se ha clasificado incorrectamente y cero en caso de clasificación correcta y sobre él calcula el error cuadrático medio que se va minimizando a medida que avanza el entrenamiento. Las entradas de las redes son directamente el nivel de gris del pixel que se pretende clasificar y los de su vecindario. Considera dos tipos de vecindario 9x9 y 15x15. La evaluación la realiza con un conjunto de 150 regiones de interés de 128x128 pixels, la mitad con microcalcificaciones la otra mitad sin ellas elegido al azar. Da los resultados con curvas ROC. Como muestra decir que para ratio de verdaderos positivos del $83 \%$ tiene un ratio de falsos positivos del $2 \%$. Según lo que hemos escrito más arriba sobre la comparación de resultados de ratio de falsos positivos cuando se trabaja sobre ROIs a falsos positivos por imagen cuando se trabaja sobre mamografía completa esto supone aproximadamente $0.02 \cdot 85=1.7$ falsos positivos por imagen. Hemos utilizado 85 y no 256 como factor de conversión porque dice que los ejemplares sin microcalcificaciones los toma de tejido sano lo que nos hace pensar que no incluye fondo que no corresponda a la mama.

Rosen et al [102] también trabaja directamente con clasificación a nivel de pixel tomando como información de entrada a la red neuronal el nivel de gris del pixels a clasificar y los niveles de gris de sus vecinos en una ventana de $7 \times 7$. Las diferencias de su aportación residen en que elige una nueva función de ajuste y algoritmo de aprendizaje especialmente indicados para problemas de clasifica- 
ción binaria [104]. La red neuronal que utiliza tiene las $7 \times 7$ entradas, una capa oculta de 9 elementos y la salida de un elemento. El entrenamiento lo realiza seleccionando 1000 regiones que incluyen microcalcificaciones y aproximadamente 10000 regiones que no incluyen microcalcificaciones, seleccionadas al azar del resto de las mamografías. Una peculiaridad es que el entrenamiento lo realiza en dos fases, primero entrena una subred formada por los $7 \times 7$ elementos de entrada y un elemento de salida y luego construye la red incluyendo en la subred la capa oculta de 9 elementos, tomando como coeficientes iniciales de la capa de entrada para la nueva fase de entrenamiento los obtenidos anteriormente. Para el entrenamiento utiliza el $80 \%$ de las imágenes de la base de mamografías de Nijmegen y para el test el $20 \%$ restante. Los resultados que reporta son en forma de gráfica ROC y como ejemplo para el valor de 1 falso positivo por imagen tiene un ratio de verdaderos positivos de $94 \%$, lo cual es un buen resultado. El $20 \%$ de imágenes de la base de Nijmegen suponen 8 imágenes y nosotros pensamos que para que estos resultados puedan elevarse a definitivos deberían procesarse con una mayor cantidad de imágenes, y dado que en el conjunto de imágenes hay algunas con bastante más dificultad que otras en la tarea de detección no estaría de más especificar las 8 imágenes utilizadas para el test.

Sajda et al [106] exploran las ventajas de la multiresolución para la detección utilizando una HPNN (hierarchical pyramid neural network). Entrena primero las redes a baja resolución para detectar las microcalcificaciones, aunque, debido al diezmado de la imagen éstas no están presentes por lo que la red aprende es información de contexto donde es probable que las microcalcificaciones estén así como las estructuras de la imagen que no suelen tenerlas. Las redes que trabajan a mayor resolución tienen como entrada la imagen a mayor resolución y en las capas ocultas incorporan además entradas que reciben los resultados generados por las redes de baja resolución. Para entrenar utiliza ROIs. Para cada ROI se genera un resultado entre 0 y 1 que indica la probabilidad de que esa ROI tenga un cluster de microcalcificaciones. Posteriormente con un umbral binariza la decisión de si la ROI es positiva o negativa, de forma que con el valor del umbral puede establecer diferentes sensibilidades. Da resultados para diferentes situaciones según qué criterio se considere para la definición de cluster (número de microcalcificaciones, distancia entre ellas, etc.) y como ejemplo reproducimos aquí que considerando clusters como 2 microcalcificaciones o más alcanza un $100 \%$ de ratio de verdaderos positivos con un ratio de falsos positivos de $24 \%$. Un $24 \%$ puede parecer alto si se le aplica el factor de traducción multiplicativo de 85 pero esto es en el supuesto de que las ROIs verdaderas negativas se hayan elegido al azar y en el artículo da a entender que son ROIs negativas pero fácilmente interpretables como positivas lo cual nos lleva a pensar que no representan la normalidad del tejido mamario sino que son un conjunto escogido de regiones para representar situaciones más complicadas. 
Otro enfoque multiresolución con redes neuronales es el presentado por Strauss et al [117] pero en este caso el propósito no es la detección propia de clusters de microcalcificaciones sino hacer una preselección y evitar que la detección con otro algoritmo [122] (mucho más costoso en tiempo) resulte demasiado larga. Es interesante la estructura que plantea en tres redes neuronales en cascada basándose primero en seleccionar aquellas regiones de interés que tengan niveles de gris heterogéneos, de éstas seleccionar aquellas que tengan puntos blancos y finalmente de éstas seleccionas aquellas que sean candidatas a tener clusters de microcalcificaciones. De esta manera la cantidad de regiones que llegan a la tercera etapa son muchas menos que a la entrada. El resultado es que de una mamografía de entrada con 4000x4000 pixels, el proceso da como término medio 40 regiones de interés de 128x128 que son candidatas a tener clusters, entre las cuales están todos los verdaderos positivos.

Wei et al [130] presenta también un trabajo basado en redes neuronales en el que, al igual que Sajda et al [106], un umbral a la salida permite ajustar la sensibilidad del detector. Estudia la relación existente entre las prestaciones de la clasificación con la red neuronal respecto a la relación entre los niveles de gris de la entrada y la parte lineal de la sigmoide. Plantea que la clasificación de problemas binarios con la sigmoide funciona bien pero cuando la señal de entrada es de niveles de gris es importante remapear para conseguir una detección alta.

Hojjatoleslami y Kittler [54] plantean el problema desde el punto de vista de clasificación de regiones. Determinan regiones potenciales, extraen características y con ellas clasifican mediante $\mathrm{K}$ vecinos más próximos (K-NN) o con clasificador Gaussiano. La determinación de las regiones potenciales se realiza con un Top-Hat y se binarizan con umbral adaptativo basado en la mediana del vecindario próximo y por último realiza crecimiento de regiones teniendo en cuenta el contraste y el gradiente, determinando no sólo la región en sí misma, llamémosle núcleo, sino además una segunda región constituida por los pixels que rodean a la primera, que podemos llamar periferia. Las características de cada región tienen en cuenta el núcleo y la periferia, así como la forma del contorno de ambas partes. Se calculan en total treinta y cinco características diferentes. Sobre el clasificador K-NN hace un estudio comparativo sobre la utilización para el cálculo de la distancia entre la muestra y los elementos de entrenamiento de la distancia Euclídea o la métrica propuesta por Short y Fukunaga [115] y modificada por la propuesta de Devijver [36]. Dicha métrica minimiza localmente el error cuadrático medio de la probabilidad de clasificación errónea entre clasificación entrenada con gran número de muestras y clasificación con pocas muestras. Para el entrenamiento y test utiliza la base de mamografías pública MIAS que tiene el doble de resolución espacial que la mayoría de las imágenes de resto de trabajos. Toma 300 microcalcificaciones de 3 imágenes para la clase microcalcificación y selecciona al azar 900 regiones de tejido normal para la clase normal. 
Los resultados finales que reporta son una detección del $100 \%$ y $83 \%$ para los clusters malignos y benignos respectivamente con una quinta parte de imágenes con falsos positivos.

Neto et al [31] implementan su trabajo con Morfología Matemática, concretamente con la herramienta línea divisoria de aguas ${ }^{2}$. Justifica su elección en que es una herramienta potente de segmentación que no necesita de ajustes o parámetros heurísticos. No obstante debido al ruido de la imagen la línea divisoria de aguas tiende a segmentar la imagen en más regiones de las que realmente hay. Para evitarlo se modifica el algoritmo y se introducen los marcadores [127] de manera que por cada marcador se crea una región y el algoritmo determina qué pixels pertenecen a cada una de ellas. Neto hace uso de esto para introduciendo manualmente un marcador por cada microcalcificación determinar la región que abarca cada una de ellas y posteriormente calcular su forma. Con dos parámetros clásicos de forma, la compacticidad ${ }^{3}$ y los momentos invariantes de primer orden como entradas a un clasificador de vecino más próximo clasifica las microcalcificaciones entre benignas y malignas. Los resultados que obtiene son una clasificación correcta del $90.48 \%$ en las benignas y un $98.11 \%$ en las malignas representando un total de clasificaciones correctas del $95.95 \%$. El trabajo lo realiza sobre 74 microcalcificaciones de la Radiology Teaching Library of Foothills Hospital, Calgary, Canadá, de las cuales 21 son benignas y 53 malignas procedentes de dos secciones comprobadas con biopsia. Nuestra opinión es que estos resultados hay que tomarlos de forma relativa ya que 74 microcalcificaciones son pocas para que los resultados se puedan elevar a concluyentes, teniendo además en cuenta que las 21 microcalcificaciones benignas proceden de dos tumores y las 53 malignas proceden del mismo tumor y por tanto no contempla la extensa casuística que puede presentarse en la realidad. Asimismo el título no expresa demasiado bien el contenido del artículo porque es "Detección de calcificaciones en mamografía mediante Morfología Matemática" y la detección de si hay o no microcalcificación la realiza manualmente. El objetivo de este artículo es el mismo que el de Dengler et al [32] en el sentido de que a partir de la forma de la microcalcificación se quiere clasificar entre benigna y maligna. Una de las conclusiones de Dengler et al es que dado que se clasifica a partir de la forma, o lo que es lo mismo, a partir del contorno, las prestaciones del clasificador están condicionadas a la precisión con que son extraídos los contornos. Dengler et al utilizan crecimiento de regiones a partir de semillas también manuales que crecen la región hasta límites determinados heurísticamente. Nuestra opinión es coincidente con la de Neto et al en que la utilización de la línea divisoria de aguas es un algoritmo apropiado para la determinación del contorno de las microcalcificaciones. Nosotros añadimos que probablemente mejore la precisión de los contornos extraídos por Dengler et al y sería interesante aplicar ambos

\footnotetext{
${ }^{2}$ traducción de ligne de partage des eaux o watershed

${ }^{3}$ traducción de compactness
} 
procedimientos sobre una misma base de datos extensa para llegar a conclusiones definitivas. No obstante hay que tener presente que pensamos, al igual que Lanyi [72], que exclusivamente el contorno de las microcalcificaciones individualmente no es un criterio suficiente en el diagnóstico de la benignidad/malignidad sino que es necesario tener en cuenta características referentes al cluster e incluso a la ubicación del mismo dentro de la mama.

A continuación se presenta un cuadro que tabula algunos aspectos interesantes de los trabajos citados en esta sección. Se facilita de esta manera comparar aspectos como el criterio de cluster, qué imágenes se utilizan y en qué cantidad, resolución de las mismas, etc. 


\begin{tabular}{|c|c|c|c|c|c|}
\hline Autores & Contenido & $\begin{array}{ll}\text { Criterio de } \\
\text { Cluster }\end{array}$ & Imágenes & $\begin{array}{l}\text { Imagen com- } \\
\text { pleta / ROIs }\end{array}$ & Resultados \\
\hline $\begin{array}{l}\text { Carman y } \\
\text { Eliot [17] }\end{array}$ & $\begin{array}{l}\text { Filtros linea- } \\
\text { les, clasifica- } \\
\text { ción de regio- } \\
\text { nes }\end{array}$ & $\begin{array}{l}\text { más de } \\
\text { mcalcs } \\
\text { un cn } \\
\text { de } 15 \text { mm } \\
\text { diámetro }\end{array}$ & $\begin{array}{lr}\text { Base } & \text { pro- } \\
\text { pia, } & 397 \\
\text { imágenes, } & 0.1 \\
\text { mm, } & 12 \text { bits }\end{array}$ & $\begin{array}{l}\text { Imagen com- } \\
\text { pleta }\end{array}$ & $\begin{array}{l}70 \% \text { RVP, } \\
2 \mathrm{FP} / \mathrm{img}\end{array}$ \\
\hline $\begin{array}{ll}\text { Hara } & \text { et } \\
\text { al }[52] & \end{array}$ & $\begin{array}{l}\text { Gradiente de } \\
\text { Sobel, mode- } \\
\text { lo geométrico } \\
\text { de las mcals } \\
\text { cónico, cla- } \\
\text { sificación de } \\
\text { regiones }\end{array}$ & $\begin{array}{l}\text { más de tres } \\
\text { en } 50 \mathrm{~mm}^{2}\end{array}$ & $\begin{array}{l}\text { Base propia, } \\
131 \text { normales } \\
\text { y } 62 \text { con clus- } \\
\text { ters, } 0.1 \mathrm{~mm} \text {, } \\
12 \text { bits }\end{array}$ & $\begin{array}{l}\text { Imagen com- } \\
\text { pleta }\end{array}$ & $\begin{array}{l}86 \% \text { RVP, } \\
0.55 \mathrm{FP} / \mathrm{img}\end{array}$ \\
\hline Netsch [92] & $\begin{array}{l}\text { Análisis } \\
\text { multiescala } \\
\text { basado en } \\
\text { Laplaciana } \\
\text { de Gaussiana }\end{array}$ & $\begin{array}{l}4 \quad \text { o más } \\
\text { para } \\
\text { pequeñas } \\
\begin{array}{l}\text { o más en } \\
\text { e el } \\
\text { resto }\end{array}\end{array}$ & $\begin{array}{lr}\text { Base } & \text { de } \\
\text { Nijmegen } & 40 \\
\text { imágenes } & 0.1 \\
\text { mm } 12 \text { bits }\end{array}$ & $\begin{array}{l}\text { Imagen com- } \\
\text { pleta }\end{array}$ & $\begin{array}{l}\text { Curvas } \\
\text { ROC, } \\
90 \% \text { RVP, } \\
1 \mathrm{FP} / \mathrm{img}\end{array}$ \\
\hline $\begin{array}{l}\text { Yoshida } \\
\text { et al [138] }\end{array}$ & Wavelets & $\begin{array}{ll}\text { más } & \text { de } \\
\text { en la } & \text { misma } \\
\text { ROI } & \end{array}$ & 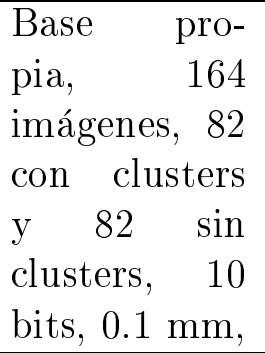 & $\begin{array}{ll}\text { ROIs } & \text { de } \\
128 \times 128 & \end{array}$ & $\begin{array}{l}\text { Curvas } \\
\text { ROC, } \\
83 \% \text { RVP, } \\
\text { RFP } 20 \%\end{array}$ \\
\hline $\begin{array}{l}\text { McLeod } \\
\text { et al [83] }\end{array}$ & $\begin{array}{l}\text { Wavelets, } \\
\text { umbral, eli- } \\
\text { mina pixels } \\
\text { aislados }\end{array}$ & $\begin{array}{l}\text { umbral ajus- } \\
\text { table sobre } \\
\text { desviación } \\
\text { standard en } \\
\text { ventana de } \\
30 \times 30 \text { pixels }\end{array}$ & $\begin{array}{l}\text { Base propia, } \\
\text { adquisición } \\
\text { digital di- } \\
\text { recta, } \\
\text { imágenes } \\
\begin{array}{ll}2370 x 1770 \\
\text { pixels, } \\
\text { bits }\end{array}\end{array}$ & $\begin{array}{l}\text { Imagen com- } \\
\text { pleta }\end{array}$ & $\begin{array}{l}84 \% \text { RVP, } \\
1.9 \mathrm{FP} / \mathrm{img}\end{array}$ \\
\hline Aghdasi [3] & $\begin{array}{l}\text { Wavelets } \\
\text { y redes } \\
\text { neuronales }\end{array}$ & no especifica & $\begin{array}{l}\text { Base propia } \\
68 \text { imágenes, } \\
0.1 \mathrm{~mm}\end{array}$ & no especifica & $\begin{array}{l}3 \% \text { de mal } \\
\text { clasificadas }\end{array}$ \\
\hline $\begin{array}{l}\text { Chitre y } \\
\text { Dhawan } \\
{[23]}\end{array}$ & $\begin{array}{ll}\text { Wavelets } & y \\
\text { algoritmo } & \\
\text { genético } & \end{array}$ & no especifica & $\begin{array}{lr}\text { Base pro- } & \text { pia } 191 \\
\text { pia } & 19 \text { genes, } \\
0.16 \mathrm{~mm}\end{array}$ & ROIs & $\begin{array}{l}\text { No especifi- } \\
\text { ca nivel de } \\
\text { detección }\end{array}$ \\
\hline
\end{tabular}




\begin{tabular}{|c|c|c|c|c|c|}
\hline Autores & Contenido & $\begin{array}{l}\text { Criterio de } \\
\text { Cluster }\end{array}$ & Imágenes & $\begin{array}{l}\text { Imagen com- } \\
\text { pleta/ROIs }\end{array}$ & Resultados \\
\hline $\begin{array}{l}\text { Meersman } \\
{[28]}\end{array}$ & $\begin{array}{l}\text { Redes neuro- } \\
\text { nales aplica- } \\
\text { das a nivel de } \\
\text { pixel, elimi- } \\
\text { na pixels ais- } \\
\text { lados }\end{array}$ & 2 o más & $\begin{array}{l}150 \quad \text { ROIs } \\
\text { seleccionadas } \\
\text { de la base de } \\
\text { Nijmegen, } 75 \\
\text { con clusters } \\
\text { y } 75 \quad \text { sin } \\
\text { clusters }\end{array}$ & $\begin{array}{lr}\text { ROIs } & \text { de } \\
128 x 128 & \\
\text { pixels, } & 0.1 \\
\text { mm, } 12 \text { bits }\end{array}$ & $\begin{array}{ll}\text { Curva } & \text { ROC, } \\
80 \% \text { RVP, } & \\
2 \% \text { RFP }\end{array}$ \\
\hline $\begin{array}{l}\text { Rosen et } \\
\text { al [102] }\end{array}$ & $\begin{array}{l}\text { Redes neuro- } \\
\text { nales aplica- } \\
\text { das a nivel de } \\
\text { pixel }\end{array}$ & $\begin{array}{l}2 \text { o más por } \\
\mathrm{cm}^{2}\end{array}$ & $\begin{array}{l}\text { Base de Nij- } \\
\text { megen, } 32 \\
\text { imágenes pa- } \\
\text { ra entrenar } 8 \\
\text { para test }\end{array}$ & $\begin{array}{l}\text { Imagen com- } \\
\text { pleta }\end{array}$ & $\begin{array}{l}\text { Curvas ROC, } \\
91 \% \text { RVP, } \\
0.13 \mathrm{FP} / \mathrm{img}\end{array}$ \\
\hline $\begin{array}{l}\text { Sajda et } \\
\text { al [106] }\end{array}$ & $\begin{array}{l}\text { Redes neuro- } \\
\text { nales y multi- } \\
\text { resolución }\end{array}$ & $\begin{array}{l}\text { varios crite- } \\
\text { rios }\end{array}$ & $\begin{array}{l}137 \text { ROIs } 50 \\
\text { con clusters y } \\
87 \text { sin clus- } \\
\text { ters, } 10 \text { bits, } \\
0.1 \mathrm{~mm}\end{array}$ & $\begin{array}{l}\text { ROIs } \quad \text { de } \\
99 x 99 \text { pixels }\end{array}$ & $\begin{array}{lr}\begin{array}{l}\text { Área } \\
\text { jo }\end{array} & \text { ba- } \\
100 \% & \text { RVP, } \\
\text { FPF } 21 \%\end{array}$ \\
\hline $\begin{array}{l}\text { Strauss et } \\
\text { al [117] }\end{array}$ & $\begin{array}{l}\text { Redes neu- } \\
\text { ronales para } \\
\text { seleccio- } \\
\text { nar ROIs } \\
\text { sospechosas }\end{array}$ & $\begin{array}{l}\text { no especifi- } \\
\text { ca }\end{array}$ & $\begin{array}{l}50 \text { Imágenes, } \\
0.05 \mathrm{~mm}, 12 \\
\text { bits }\end{array}$ & $\begin{array}{l}\text { Imagen com- } \\
\text { pleta }\end{array}$ & $\begin{array}{l}\text { Reduce los } \\
\text { datos a ana- } \\
\text { lizar al } 4 \% \\
\text { del inicial }\end{array}$ \\
\hline $\begin{array}{l}\text { Wei et } \\
\text { al [130] }\end{array}$ & $\begin{array}{l}\text { Redes neuro- } \\
\text { nales y pos- } \\
\text { terior análisis } \\
\text { de textura }\end{array}$ & $\begin{array}{l}2 \text { o más } \\
\text { mcalcs en } \\
\text { una ROI }\end{array}$ & $\begin{array}{l}39 \text { Imágenes } \\
\text { de } 49 \times 49 \text { y } 50 \\
\text { de } 145 \times 145 \\
\text { pixels, } 10 \\
\text { bits, } 0.1 \mathrm{~mm}\end{array}$ & ROIs & $\begin{array}{l}\text { sensibilidad } \\
100 \% \text {, es- } \\
\text { pecificidad } \\
79 \%\end{array}$ \\
\hline $\begin{array}{l}\text { Hojjatol. } \\
\text { y Kit- } \\
\text { tler }[54]\end{array}$ & $\begin{array}{l}\text { Top-Hat, } \\
\text { crecimiento } \\
\text { de regiones y } \\
\text { clasificación } \\
\text { K-NN y } \\
\text { Gaussiana }\end{array}$ & $\begin{array}{l}\text { más de } 4 \text { en } \\
1 \mathrm{~cm}^{2}\end{array}$ & $\begin{array}{l}\text { Base MIAS, } \\
8 \text { bits, } 0.05 \\
\mathrm{~mm}\end{array}$ & $\begin{array}{l}\text { Imagen com- } \\
\text { pleta }\end{array}$ & $\begin{array}{l}100 \% \text { RVP, } \\
0.2 \mathrm{FP} / \mathrm{img}\end{array}$ \\
\hline $\begin{array}{ll}\text { Neto } & \text { et } \\
\text { al }[31] & \end{array}$ & $\begin{array}{l}\text { Clasificación } \\
\text { benigna/ } \\
\text { maligna, } \\
\text { Morfología } \\
\text { Matemática, } \\
\text { marcadores } \\
\text { manuales, } \\
\text { clasificador } \\
\text { K-NN }\end{array}$ & no procede & $\begin{array}{lr}\text { Base propia, } \\
3 \quad \text { imágenes } \\
\text { con } \quad 74 \\
\text { mcalcs. }\end{array}$ & $\begin{array}{l}\text { mcalcs indi- } \\
\text { viduales }\end{array}$ & $\begin{array}{l}95 \% \text { de cla- } \\
\text { sificación co- } \\
\text { rrecta }\end{array}$ \\
\hline
\end{tabular}




\subsection{Período posterior al TIWDM}

Dhawan et al presentan en [40] un trabajo que tiene en común algunos aspectos contemplados en el artículo que junto con Chitre [23] presentaron en el TIWDM. En [23] hace uso de wavelets y algoritmo genético para minimizar el error y seleccionar la wavelet óptima mientras que en [40] el planteamiento es el siguiente: clasificar el cluster como benigno/maligno con varios clasificadores, la selección de las características se realiza con algoritmo genético y las características de las regiones de interés que se calculan son de dos tipos, el primero son características de textura global obtenidas a partir de estadísticos del histograma de segundo orden (entropía, momentos, media, correlación, etc.), el segundo tipo son características de textura local extraídas a partir de la transformada wavelet. Junto con esto se utilizan también características de las microcalcificaciones que forman el cluster, para ello segmenta las microcalcificaciones que hay en la región de interés con el siguiente procedimiento: calcula el contraste local en cada pixel de la imagen y utiliza la desviación local de los niveles de gris como umbral para decidir si un pixel pertenece o no a la clase microcalcificación [107]. El contraste local se calcula restando el nivel de gris del pixel y la media de los niveles de gris de los pixels en una ventana de 15x15. A la imagen binaria resultante le aplica un cierre morfológico y tras calcular las componentes conexas que resultan descarta todas aquellas que tienen un área menor que cinco pixels. Las características de cluster que considera son:

número de microcalcificaciones, media y desviación del área de las microcalcificaciones, media y desviación de los niveles de gris de las microcalcificaciones, media y desviación de la distancia que las separa, media y desviación de la distancia entre el centro de masa y cada una de ellas, y finalmente, energía potencial del sistema utilizando el producto de la media del nivel de gris y el área como indicador de la masa. Los resultados de la clasificación son evaluados mediante curvas ROC y de ellas se da el área bajo curva $R O C$, con unos valores que van de 0.6 a 0.81 .

En nuestra opinión es interesante notar que el algoritmo de segmentación de las microcalcificaciones es bastante simple y presumiblemente sea un factor que incide negativamente en los resultados finales de clasificación. Además se descartan todas aquellas microcalcificaciones con menos de cinco pixels, que con la resolución de $0.16 \mathrm{~mm}$ empleada corresponde aproximadamente a microcalcificaciones de 9 pixels en imágenes digitalizadas con $0.1 \mathrm{~mm}$. Si este procedimiento fuera empleado en la base de mamografías que nosotros utilizamos serían descartadas muchas microcalcificaciones importantes. A título ilustrativo en algunas de las imágenes que se emplean en los próximos capítulos, por ejemplo en la imagen 12c, más de la mitad de su centenar de microcalcificaciones son menores que 9 pixels. Respecto a la lista de características de cluster contempladas consideramos que sería interesante añadir algunas que tengan en cuenta la forma de 
las microcalcificaciones individualmente [32] así como del cluster [72].

En el trabajo de Zheng et al [140], a diferencia del trabajo al que alude el párrafo anterior, el objetivo fundamental es la detección. Las claves del contenido son el uso de redes neuronales, el entrenamiento basado en propagación hacia atrás con filtro de Kalman y el umbral final a la salida de la red neuronal se determina dinámicamente en función de la entropía espectral. Realiza una comparación entre las prestaciones de detección alcanzadas cuando la entrada al proceso son los niveles de gris de la mamografía directamente y cuando la entrada es la mamografía preprocesada con el algoritmo basado en wavelets presentado en [57]. Como características de clasificación toma de dos tipos: en el dominio espacial y en el dominio espectral. Del primer tipo son la varianza de los niveles de gris y la varianza de la energía (definida como el nivel de gris al cuadrado); del segundo tipo son la energía de la componente alterna y la entropía espectral, ambas calculadas a través de la transformada discreta del coseno por motivos de eficiencia en el tiempo de cálculo. El cálculo de las características se realiza sobre un bloque centrado en el pixel en cuestión y los valores resultantes de las características son las entradas a la red neuronal. Para detectar las microcalcificaciones se repite este proceso para todos los pixels de la imagen y finalmente si hay tres o más microcalcificaciones por $\mathrm{cm}^{2}$ se considera que se ha detectado un cluster.

La base de imágenes mamográficas que utiliza consiste en 30 casos, 20 con clusters de microcalcificaciones (21 clusters en total) y 10 correspondientes a casos normales. La digitalización de la película radiográfica se ha hecho con un tamaño de pixel de $0.11 \mathrm{~mm}$ y con una profundidad en la escala de niveles de gris de 12 bits. Aporta resultados para diferentes cantidades de neuronas en la capa oculta y en el mejor de los casos el ratio de verdaderos positivos es del $91 \%$ con 0.71 clusters falsos positivos por imagen.

Gurcan et al [50] proponen para la detección de las microcalcificaciones utilizar estadísticos de orden superior. Filtra la imagen en pasobajo, pasobanda y pasoalto y asume que la distribución de los niveles de gris en rectángulos correspondientes a regiones de fondo en la imagen pasobanda tienen una distribución gaussiana mientras que en regiones que contienen microcalcificaciones la distribución difiere porque la cola positiva contiene mayor energía que la negativa al ser éstas regiones contrastadas brillantes. Para distinguir estas dos situaciones calcula el grado de simetría de la función de densidad de probabilidad y el grado de planicidad de la función respecto a la distribución gaussiana, parámetros conocidos normalmente por skewness y kurtosis respectivamente. La clasificación la realiza con umbrales fijos para cada una de las características calculadas sobre regiones rectangulares de 30x30 solapadas 15 pixels. Evalúa el procedimiento sobre la base de Nijmegen y obtiene para detección 100\% 3.3 falsos positivos por imagen. 
Heine et al [53] tiene en algunos aspectos un enfoque similar a [50] porque también se descompone la imagen en bandas (en [53] se hace con wavelets) y se intenta modelar cada tipo de tejido con funciones de distribución de probabilidad sobre las cuales se calcula algún parámetro, concretamente los modelos utilizados son la distribución de Laplace y la exponencial. En particular en este trabajo las microcalcificaciones son un objetivo indirecto en el sentido de que se pretenden detectar las regiones correspondientes a tejido normal cuyos parámetros estadísticos estimados aproximan a los obtenidos en la fase previa de modelización. Todas aquellas regiones que diverjan del modelo normal se resaltan para que sean estudiadas por el radiólogo. Los resultados alcanzados son que reconoce correctamente el $46 \%$ de las imágenes normales.

En [90] y [91] se presentan de forma abreviada los resultados de la presente tesis. En el primero se exponen los resultados preliminares alcanzados con los contenido presentados incluyendo la sección 6.4 y en el segundo los resultados finales.

En [64] la detección se basa en la estadística de la textura de la región circundante. Alrededor de cada pixel define 3 ventanas de tamaños 3, 5 y 7 sobre la que calcula 4 parámetros de textura basados en los histogramas de segundo orden en cuya definición interviene un umbral que permite ajustar la sensibilidad y consecuentemente la influencia del ruido y por tanto el número de falsos positivos. Con las cuatro características realiza una clasificación en dos clases (hay microcalcificaciones o no) con una red neuronal de tres capas. Trabaja con Regiones de Interés de $128 \times 128$ pixels con 12 bits/pixel y $0.1 \mathrm{~mm}$ de tamaño de pixel. En total utiliza 172 imágenes del tamaño mencionado extraídas de una base de mamografías propia de las cuales 72 tienen clusters y 100 corresponden a tejido normal. Los resultados los da en forma de curva ROC y obtiene un área bajo ROC de 0.92 ; como ejemplo para $89 \%$ de ratio de verdaderos positivos tiene un $20 \%$ de ratio de falsos positivos.

A fecha de hoy el número de publicaciones acerca de tratamiento digital de mamografía es elevado. Aún así el objetivo de tener un sistema fiable y eficaz de prescreening al alcance de todas las unidades de detección precoz de cáncer de mama está todavía en fase de desarrollo. 


\section{Capítulo 3}

\section{Campos Aleatorios de Markov}

\subsection{Introducción}

De entre los diferentes enfoques para modelar imágenes, en la presente tesis se ha elegido un modelo estocástico; por modelo entendemos un proceso matemático que construye o describe una imagen. Un modelo debe cumplir dos propiedades. Primero caracterizar las propiedades de interés de la imagen de modo adecuado y segundo que el tratamiento matemático necesario sea abordable. Los modelos se han utilizado en síntesis de imágenes, realzado, restauración, segmentación, codificación y compresión, análisis de texturas, análisis de forma, representación y reconocimiento [5] [103]. Nosotros estamos interesados en imágenes digitales bidimensionales (2-D). Una imagen digital 2-D se puede representar como una matriz de dimensión $\mathrm{MxN}$ (M, N finitos) o una celosía (lattice) donde sus elementos (llamados pixels) pueden tomar valores enteros entre 0 y $G-1$ representando la escala de brillos, niveles de gris posibles, o el conjunto de colores [103].

Concretamente si denotamos una imagen por x y la celosía por $\mathcal{S}$, entonces

$$
\mathbf{x}=\{x(i, j),(i, j) \in \mathcal{S}\}, \quad \mathcal{S}=\{i, j, 0 \leq i<M, \quad 0 \leq j<N\}
$$

Una propiedad que debe caracterizar el modelo matemático es que el nivel de gris de un pixel depende en gran medida del nivel de gris de los pixels vecinos y es prácticamente independiente de los pixels lejanos.

Entre los modelos estocásticos más importantes están el modelo gaussiano independiente y el campo aleatorio de Markov $^{1}$. El modelo estocástico para imagen

\footnotetext{
${ }^{1}$ en las referencias inglesas Markov Random Field
} 
es un campo aleatorio. El campo aleatorio es una familia de variables aleatorias definida sobre la celosía $\mathcal{S}$. En esta tesis usaremos letras mayúsculas para campos aleatorios y variables aleatorias, y letras minúsculas para las realizaciones de los campos y las variables. Dado que las imágenes están definidas sobre una celosía discreta y finita $\mathcal{S}$ (eq 3.1) y que la variable aleatoria asociada a cada punto de la celosía sólo puede tomar valores discretos en el margen (0, G-1), los campos tratados son sólo los campos aleatorios de índice discreto sobre celosías discretas y finitas.

El campo aleatorio más simple en términos de la estructura de su función de densidad de probabilidad (fdp), es el campo aleatorio independiente, cuyas variables aleatorias son independientes y la fdp conjunta es el producto de las fdp's de todos los pixels individuales. Al ser independientes las fdp's este modelo implica que no hay interacción espacial entre pixels.

Si la fdp de cada pixel es una Gaussiana, entonces tenemos un campo aleatorio Gaussiano $^{2}$ [95]. El campo aleatorio queda definido por la media y la varianza de la variable aleatoria asociada a cada pixel $\mu(m, n),{ }^{2}(m, n)$

$$
p(X(m, n)=x(m, n))=\frac{1}{\sqrt{2}(m, n)} \exp \left[-\frac{(x(m, n)-\mu(m, n))^{2}}{2^{2}(m, n)}\right]
$$

Si suponemos, como normalmente se hace, $\mu(m, n)$ y ${ }^{2}(m, n)$ constantes para una determinada región de la imagen ya no dependen del pixel pasando a ser $\mu$ y ${ }^{2}$, y la fdp del campo aleatorio en dicha región es:

$$
p(\mathbf{X}=\mathbf{x})=\prod_{m, n} \frac{1}{\sqrt{2}} \exp \left[-\frac{(x(m, n)-\mu)^{2}}{2^{2}}\right]
$$

La mayor limitación del modelo Gaussiano independiente es la suposición misma de independencia porque en imágenes del mundo real es frecuente que el valor de un pixel dependa de otros, sobre todo de los vecinos más próximos. Si queremos considerar un modelo que tenga en cuenta esta dependencia hay que recurrir a modelos Markovianos.

\subsection{Teoría de los Campos Aleatorios de Markov}

Los campos aleatorios de Markov se están utilizando ampliamente para modelar imágenes en distintas aplicaciones [9][27][47][25][10][22][63][74]

En este apartado se presentan las definiciones y la teoría que sirve de base para los algoritmos que se utilizarán posteriormente.

\footnotetext{
${ }^{2}$ en las referencias inglesas Gauss Random Field, GRF)
} 


\subsubsection{Definición de un campo aleatorio de Markov}

El concepto de Markovianidad en una dimensión es intuitivamente sencillo: la probabilidad de que ocurra algo en un instante, dado todo lo que ha ocurrido en el pasado, depende sólo de lo que ha ocurrido recientemente. Este concepto ha encontrado aplicación en muchas áreas, tanto en su versión unidimensional (cadenas de Markov) como en su versión bidimensional (campos aleatorios de Markov [35] o también aplicado a grafos [88]. Respecto a los campos aleatorios de Markov ha habido un incremento importante del interés sobre ellos desde el artículo de Besag "On spatial Interaction and the statistical analysis of lattice systems" [9].

Un proceso de Markov se puede clasificar como discreto, si está definido sobre un conjunto contable (por ejemplo un conjunto de números enteros), o continuo si está definido sobre un conjunto incontable (por ejemplo un intervalo de los números reales). En lo que respecta a imágenes interesa modelarlas con un proceso discreto de Markov.

En el caso unidimensional: Sea $\mathbf{x}=\left\{x_{0}, x_{1}, \ldots, x_{N}\right\}$ una secuencia de Markov entonces,

$$
p\left(x_{k} \mid x_{k-1}, \ldots, x_{0}\right)=p\left(x_{k} \mid x_{k-1}, \ldots, x_{k-M}\right)
$$

siendo $\mathrm{M}$ el orden del proceso de Markov.

La dependencia exclusivamente de la vencindad modela bastante bien lo que ocurre en muchos procesos reales tal como las imágenes, esto hace del proceso de Markov un marco teórico muy útil para modelarlos. Otra ventaja importante es que la fdp conjunta se puede poner como producto de las fdp condicionales (por sencillez se toma $M=1$ )

$$
p(\mathbf{x})=p\left(x_{N} \mid x_{N-1}\right) p\left(x_{N-1} \mid x_{N-2}\right) \cdots p\left(x_{1} \mid x_{0}\right) p\left(x_{0}\right)
$$

Mientras que en el caso unidimensional, el concepto de pasado reciente está claro, en un celosía bidimensional no cabe hablar de pasado reciente sino de vecinos próximos. A continuación se presentan las definiciones necesarias para establecer un campo aleatorio de Markov discreto sobre una celosía bidimensional, discreta y finita $\mathcal{S}$

Definición 1 (Distancia entre dos pixels) La distancia $D$ entre dos pixels $(i, j)$ y $(m, n)$ en una celosía rectangular es la distancia euclídea:

$$
D=\sqrt{(i-m)^{2}+(j-n)^{2}}
$$


Dado que la celosía es rectangular las distancias entre pixels sólo pueden tomar un conjunto de valores discretos $\{1, \sqrt{2}, 2, \sqrt{5}, \sqrt{8}, 3, \ldots\}$.

Definición 2 (Vecindario de un pixel) El vecindario $\eta(i, j)$ de un pixel $(i, j)$ está formado por un conjunto de pixels $\eta(i, j)=\{(m, n)\}$ que cumplen las siguientes condiciones:

- a) $(i, j) \notin \eta(i, j)$

- b) si $(m, n) \in \eta(i, j)$, entonces $(i, j) \in \eta(m, n)$

- c) la distancia que separa los pixels $(i, j)$ y $(m, n)$ es menor o igual que un valor dado

Se pueden considerar distintos tipos de vecindarios según se considere o no causalidad. La causalidad es algo natural en secuencias unidimensionales, pero no en imágenes, aunque algunos autores han utilizado modelos causales [55, 35] para imágenes. La definición dada anteriormente implica no causalidad. Para que la definición de vecindario incluya causalidad hay que incluir además las siguientes condiciones $m>i$ y $n>j$.

Definición 3 (Sistema de vecindario) Un sistema de vecindario en una celosía $\mathcal{S}$ se define como:

$$
\eta=\{\eta(i, j), \quad(i, j) \in \mathcal{S}, \quad \eta(i, j) \quad \mathcal{S}\}
$$

El sistema de vecindario será de orden $1, \eta^{1}$, si la distancia máxima entre un pixel y sus vecinos es 1 , de orden $2, \eta^{2}$, si la distancia máxima es $\sqrt{2}$, y así sucesivamente. Dado que el sistema de vecindario de orden 2 incluye al de orden 1, el de orden 3 incluye al de orden 2 y 1, y así sucesivamente estamos ante una situación jerárquica. La figura 3.1 muestra los vecindarios de orden 1, 2, 3, 4 y 5 , con el pixel central marcado en negro.

Definición 4 (Campo aleatorio de Markov) Sea $\eta$ un sistema de vecindario sobre una celosía bidimensional $\mathcal{S}$. Un campo aleatorio

$$
\mathbf{X}=\{X(i, j),(i, j) \in \mathcal{S}\}
$$

es un campo aleatorio de Markov respecto a $\eta$ si y sólo si se cumplen estas dos condiciones 


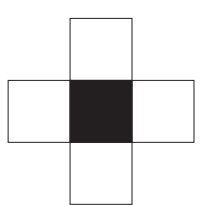

a) orden 1

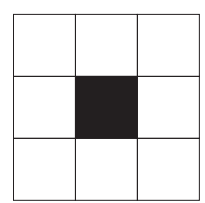

b) orden 2

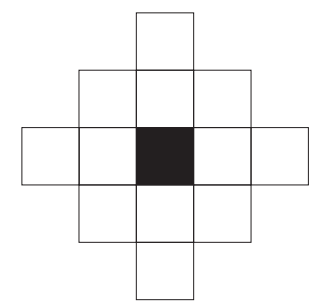

c) orden 3

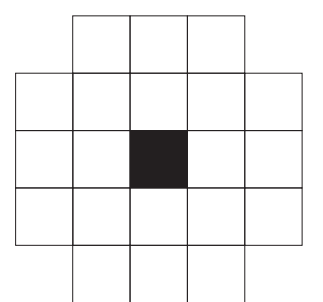

d) orden 4

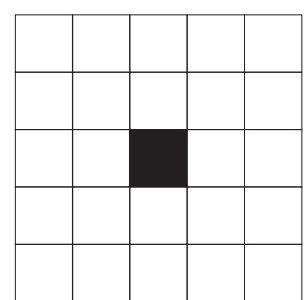

e) orden 5

Figura 3.1: Vecindarios de un pixel según el orden.

- a) positividad $P(\mathbf{X}=\mathbf{x})>0$, para todo $\mathbf{x}$

- b) markovianidad

$$
\begin{gathered}
P(X(i, j)=x(i, j) \mid X(m, n)=x(m, n),(m, n) \in \mathcal{S},(m, n) \neq(i, j))= \\
=P(X(i, j)=x(i, j) \mid X(m, n)=x(m, n), \quad(m, n) \in \eta(i, j))
\end{gathered}
$$

donde $P(\cdot)$ y $P(\cdot \mid \cdot)$ son las distribuciones de probabilidad conjunta y condicional, respectivamente, del campo aleatorio.

La positividad implica que todas las realizaciones del campo deben ser posibles y la markovianidad limita la dependencia de un pixel a sus vecinos y no a todos los pixels de la imagen.

La dependencia únicamente del vecindario, hace que un campo aleatorio de Markov describa al campo a través de sus características locales, es decir a través de la probabilidad condicionada de un pixel a sus vecinos. Las características globales de la imagen, es decir la descripción de la imagen a través de la probabilidad conjunta de todas los pixels de la imagen, se modelan mejor a través de los campos aleatorios de Gibbs $^{3}[41]$.

\subsubsection{Definición de un campo aleatorio de Gibbs}

Para poder definir un campo aleatorio de Gibbs hay que definir primero lo que se ha llamado en inglés un "clique", palabra que utilizaremos sin traducir en esta tesis.

Definición 5 (Clique) Dado el par $(\mathcal{S}, \eta)$ formado por la celosía $\mathcal{S}$ y el sistema de vecindario $\eta$, un clique c sobre la celosía $\mathcal{S}$ es un subconjunto de $\mathcal{S}$, tal que:

\footnotetext{
${ }^{3}$ en las referencias inglesas Gibbs Random Field
} 
- a) $c$ contiene al menos un punto de $\mathcal{S}$

- b) si $(m, n) \in c,(i, j) \in c \mathrm{y}(i, j) \neq(m, n)$, entonces $(i, j) \in \eta(m, n)$

el conjunto de todos los cliques del par $(\mathcal{S}, \eta)$ se denota por $C(\mathcal{S}, \eta)$, abreviadamente $C$.

Intuitivamente un clique es un grupo de pixels que son vecinos. La figura 3.2 muestra los diferentes tipos de cliques que se dan en el vecindario de orden $1 \mathrm{y}$ 2. En el vecindario de orden 2 son posibles los del vecindario de orden 1 más los que aparecen debajo del vecindario de orden 2.

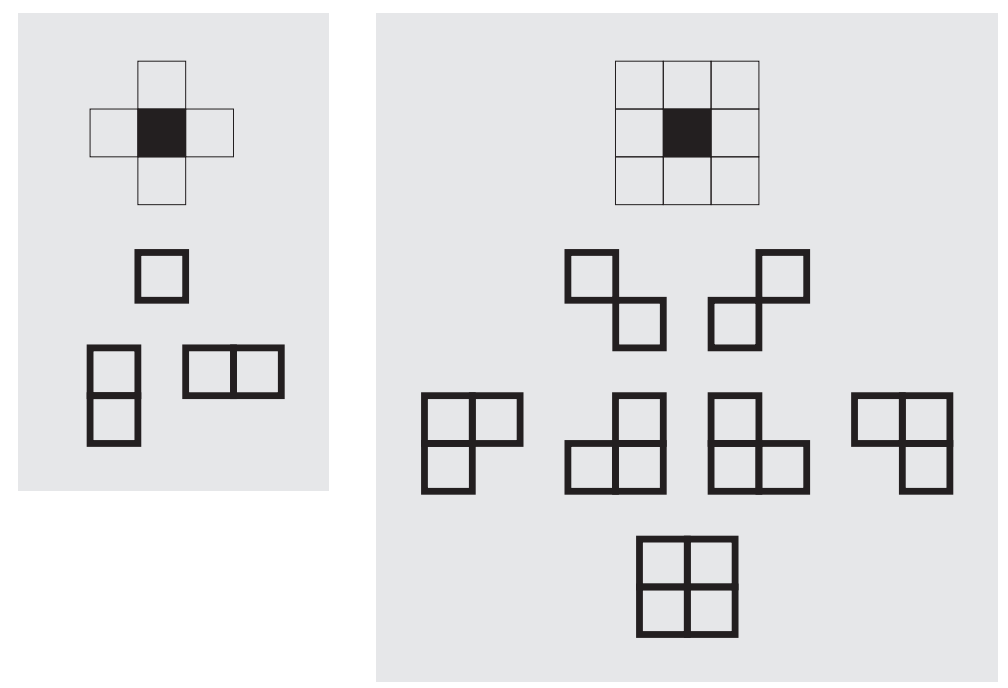

Figura 3.2: Cliques posibles en los vecindarios de orden 1 y orden 2.

Ahora podemos definir un campo aleatorio de Gibbs como

Definición 6 (Campo aleatorio de Gibbs) Un campo aleatorio

$$
\mathbf{X}=\{X(i, j),(i, j) \in \mathcal{S}\}
$$

es un campo de Gibbs respecto a un sistema de vecindario $\eta$ dado, si y sólo si su función de distribución de probabilidad conjunta tiene la siguiente forma:

$$
P(\mathbf{X}=\mathbf{x})=\frac{e^{-U(\mathbf{x})}}{Z}
$$

donde

$$
U(\mathbf{x})=\sum_{c \in C} V_{c}(\mathbf{x})
$$

$y$

$$
Z=\sum_{\forall \mathbf{x}} e^{-U(\mathbf{x})}
$$


$U(\mathbf{x})$ se llama función de energía; $V_{c}(\mathbf{x})$ se llama función de clique o potencial y depende sólo de los puntos que forman el clique $c ; Z$ se llama la función de partición y es una constante de normalización para que $P$ sea una distribución de probabilidad válida. También se expresa de la siguiente forma

$$
P(\mathbf{X}=\mathbf{x})=\frac{e^{-\frac{1}{T} U(\mathbf{x})}}{Z}
$$

donde $T$ es una constante y se llama temperatura. Esta terminología se debe a que la primera vez que se utilizaron estas distribuciones fue para modelar el comportamiento magnético de materiales ferromagnéticos (trabajo desarrollado por Ising, discípulo de Lenz [66]) donde la temperatura del material es un factor importante y se expresa explícitamente en la función de energía. Mientras que el campo aleatorio de Gibbs está definido en términos de su distribución de probabilidad conjunta y caracteriza completamente en términos estadísticos el campo aleatorio, el campo aleatorio de Markov da poca información acerca de la distribución de probabilidad conjunta.

\subsubsection{Equivalencia entre campo aleatorio de Markov y de Gibbs}

Para que la descripción del campo aleatorio en base a las probabilidades condicionales (markovianidad) sean válidas, éstas deben ser consistentes con funciones de distribución conjuntas que existan. El teorema de Hammersly-Clifford [9] establece la correspondencia entre un campo aleatorio de Markov y un campo aleatorio de Gibbs, cuyo enunciado se reproduce a continuación.

Teorema 1 Un campo aleatorio

$$
\mathbf{X}=\{X(i, j),(i, j) \in \mathcal{S}\}
$$

definido sobre una celosía $\mathcal{S}$ es un campo aleatorio de Markov respecto a un sistema de vecindario $\eta$ si y sólo si es un campo de Gibbs respecto al mismo $\eta$

Demostración: ver [9]

\subsection{Ejemplos de campos aleatorios de Markov}

Desde que Ising [66] utilizó los campos aleatorios de Markov ya en la década de los 20, se han utilizado diferentes tipos de dichos campos. Una publicación 
interesante que recoge muchos de ellos es [35]. En los modelos utilizados normalmente para imágenes se considera como únicos cliques, los formados por un pixel único y por pares de pixels.

\subsubsection{Auto-Modelos}

Fue propuesto por Besag [9] [35]. La función de energía tiene la siguiente forma:

$$
U(\mathbf{x})=\sum_{i, j} x_{i j} G_{i j}\left(x_{i j}\right)+\sum_{i, j} \sum_{m, n} \beta_{i j m n} x_{i j} x_{m n}
$$

donde

- $(i, j)$ y $(m, n)$ son elementos de la celosía $\mathcal{S}$,

- $\left\{G_{i j}(\cdot)\right\}$ es un conjunto de funciones arbitrarias que determinan la influencia individual de cada pixel, y

- $\left\{\beta_{i j m n}\right\}$ es un conjunto de constantes que modelan la interacción entre los elementos $(i, j)$ y $(m, n)$ con la restricción de que $\beta_{i j m n}=0$ excepto si $(i, j)$ $\mathrm{y}(m, n)$ son vecinos.

A la vista de la ecuación 3.13 se deduce que la energía está determinada por dos sumandos, uno que depende de los pixels individualmente y otro que depende de pares de pixels por lo que los cliques distintos de cero son aquellos formados por un elemento único o un par de elementos, independientemente del orden del vecindario.

Poniendo restricciones a esta forma general de los automodelos se llega a tres tipos importantes de modelos que se han utilizado en procesado de imágenes y que son:

- modelo auto-logístico

- modelo auto-binomial, y

- modelo autonormal

\section{Modelo autologístico}

En este modelo [9] [26] las variables aleatorias que forman el campo descrito por la expresión 3.13 pueden tomar sólo dos valores (por ejemplo $+1,-1$ o bien 0,1 ). La función de energía toma entonces la forma 


$$
U(\mathbf{x})=\sum_{i, j} \alpha_{i j} x_{i j}+\sum_{i, j} \sum_{m, n} \beta_{i j m n} x_{i j} x_{m n}
$$

Este modelo restringido a un vecindario de orden 1 corresponde con el modelo utilizado por Ising [66] para describir el comportamiento de los materiales ferromagnéticos.

\section{Modelo autobinomial}

El modelo se especifica a través de sus características locales más que a través de los potenciales de clique y asume [9] que las variables aleatorias tienen una probabilidad condicional binomial con parámetro $\theta$ y número de intentos o repeticiones $G-1$, cada variable aleatoria del campo puede tomar valores en el conjunto $(0,1,2, \ldots, G-1)$, donde $\mathrm{G}$ es el número de niveles de gris.

$$
P\left(X_{i j}=l \mid X_{\eta_{i j}}\right)=\left(\begin{array}{c}
G-1 \\
l
\end{array}\right) \theta^{l}(1-\theta)^{G-1-l}
$$

donde

$$
\theta=\frac{e^{T}}{1+e^{T}}
$$

con $T$ una función del vecindario $x_{\eta_{i j}}$ y de un conjunto de parámetros cuyo número depende del orden sistema de vecindario.

Para orden $1 \mathrm{~T}=\mathrm{T} 1$, con

$$
T_{1}=\alpha+\beta_{1}\left(x_{i, j-1}+x_{i, j+1}\right)+\beta_{2}\left(x_{i-1, j}+x_{i+1, j}\right)
$$

y para orden $2 \mathrm{~T}=\mathrm{T} 2$

$$
T_{2}=T_{1}+\beta_{3}\left(x_{i-1, j-1}+x_{i+1, j+1}\right)+\beta_{4}\left(x_{i-1, j+1}+x_{i+1, j-1}\right)
$$

para órdenes mayores $T$ se define de forma similar.

El modelo autobinomial ha sido utilizado por Cross and Jain [27] para modelar texturas y posteriormente por Chen y Huang [22] para clasificación de las mismas.

\section{Modelo auto-normal}

También llamado campo aleatorio de Markov Gaussiano (Gaussian Markov Random Field GMRF) [41]. 
En muchas aplicaciones prácticas es razonable asumir que la función de distribución conjunta es una distribución normal multidimensional. Si la correlación es distinta de cero, el campo además de ser gaussiano es markoviano porque la probabilidad de unos pixels depende de los otros. Si la dependencia está limitada a los pixels del vecindario en la matriz de correlación sólo hay términos no nulos en los elementos correspondientes a los vecinos. En concreto la expresión que da la probabilidad condicional [9] es:

$$
P\left(X_{i j}=x_{i j} \mid X_{\eta_{i j}}\right)=\frac{1}{\sqrt{2^{2}}} \exp \left[-\frac{\left\{x_{i j}-\mu_{i j}-\sum_{m, n} \beta_{i j m n}\left(x_{m n}-\mu_{m n}\right)\right\}^{2}}{2^{2}}\right]
$$

donde $\mu_{i j}$ es la media en cada elemento de la celosía $\mathcal{S}$ y $(m, n) \in \eta_{i j}$

Este modelo ha sido utilizado por varios autores con nombres ligeramente distintos [132] [9] [113] al utilizado por [35].

\subsubsection{Modelo Multilevel Logistic}

Este modelo es una generalización del modelo utilizado por Ising al caso multinivel. Ising definió los potenciales en función de si los elementos del clique eran iguales o no. En este caso multinivel los potenciales se definen de igual forma sin tener en cuenta cuan diferentes sean entre ellos. Supongamos que hay dos parámetros $\beta_{a}$ y $\beta_{a}^{\prime}$ asociados a cada tipo de clique de más de un elemento $c_{a}$, entonces el potencial de clique para todos los cliques de tipo $a$ se define como

$$
V_{c}(x)= \begin{cases}\beta_{a} & \text { si todos } x_{i j} \text { de } c \text { son iguales } \\ -\beta_{a}^{\prime} & \text { en caso contrario }\end{cases}
$$

Los potenciales de clique, para los cliques de elemento único se definen así:

$$
V_{c}(x)=\alpha_{l} \text { si } x_{i j}=l \text { para } c=(i, j)
$$

A diferencia del modelo de Ising que estaba definido para un sistema vecindario de orden 1, este puede definirse para cualquier orden. Este modelo también recibe el nombre de proceso de Strauss [101] [118]. 


\subsection{Campos Aleatorios de Markov Compuestos}

Los campos aleatorios presentados permiten modelar una región en la que tenga validez un tipo de campo con unos parámetros concretos. Pero las imágenes que normalmente se procesan no están formadas por una única región, por ejemplo uno de los casos más simples donde la imagen contiene un objeto sobre un fondo ya tiene dos regiones. Salvo en el caso ideal el objeto no tiene todos sus pixels al mismo nivel de gris y lo mismo ocurre con el fondo. Así pues se necesitará un campo aleatorio para modelar el objeto y otro campo aleatorio, del mismo tipo o no, para modelar el fondo. En el caso más general, la imagen estará compuesta por un número de clases y/o regiones y cada clase y/o región tendrá un campo aleatorio que se ajuste a ella (pueden ser campos de diferentes tipos o del mismo tipo con diferentes parámetros). Una de las aplicaciones de esto es la segmentación de la imagen. En ella se pretende dividir la imagen en las diferentes regiones en las que está formada.

Para abordar este problema se utiliza el planteamiento de campo aleatorio compuesto, dividiendo el problema en dos niveles jerárquicos [47] [56] [77]. Un campo aleatorio de bajo nivel que modela la distribución de las diferentes regiones en la imagen y, en el nivel superior, un conjunto de campos aleatorios independientes donde cada uno de ellos corresponde a cada clase de región.

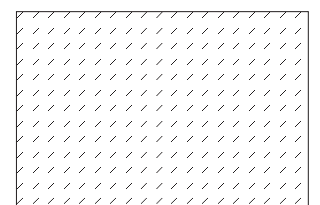

campo tipo 1

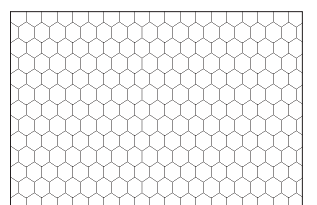

campo tipo 2

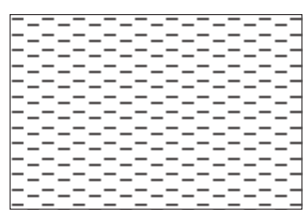

campo tipo 3

varios campos de nivel superior

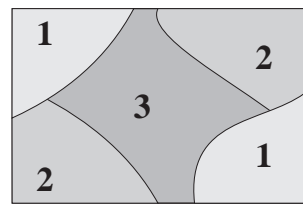

campo de nivel inferior

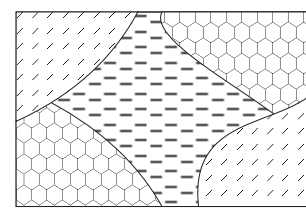

campo aleatorio compuesto

Figura 3.3: Ejemplo de campo aleatorio compuesto 
Algunos autores [33] [41] utilizan los términos bajo y alto nivel intercambiados.

Definición 7 (Campo aleatorio compuesto) Un campo aleatorio compuesto

$$
(\mathbf{X}, \mathbf{Y})=\left\{X_{i j}, Y_{i j}\right\}
$$

definido sobre una celosía $\mathcal{S}$ está formado por un nivel inferior $\mathbf{X}$ y un nivel superior $\mathbf{Y} . \mathbf{X}$ es un campo aleatorio discreto donde cada elemento del campo $X_{i j}$ puede tomar una etiqueta del conjunto $\{1, \ldots, K\}$. $\mathbf{Y}$ es un campo aleatorio donde cada $Y_{i j}$ puede tomar valores de un conjunto de $K$ campos aleatorios independientes $\left\{\mathbf{Y}^{l}\right\}$ con $l \in\{1, \ldots, K\}$ siendo

$$
Y_{i j}(\cdot)=Y_{i j}^{l}(\cdot) \text { si } X_{i j}(\cdot)=l, \text { con } l=1, \ldots, K
$$

\subsection{Algoritmos de segmentación de imágenes modeladas con campos aleatorios de Mar- kov}

\subsubsection{Introducción}

Una vez tenemos modelada la imagen con un campo aleatorio compuesto hay que segmentar la imagen. En la literatura sobre campos aleatorios de Markov se han presentado varios algoritmos de segmentación. El primero basado en programación dinámica [34, 42] (dynamic programming algorithm) y los siguientes basados en procedimientos iterativos de relajación y que se pueden clasificar en dos tipos:

- relajación estocástica

- relajación determinista.

La segmentación se lleva a cabo usualmente mediante la estimación máxima a posteriori (MAP). Se supone que la imagen es una realización del campo de nivel alto $(\mathbf{Y}=\mathbf{y})$, llamada observación, y se pretende determinar el campo de nivel bajo $(\mathbf{X}=\mathbf{x})$ que ha dado lugar a $\mathbf{y}$, utilizando la regla de Bayes

$$
P(\mathbf{X}=\mathbf{x} \mid \mathbf{Y}=\mathbf{y})=\frac{P(\mathbf{Y}=\mathbf{y} \mid \mathbf{X}=\mathbf{x}) P(\mathbf{X}=\mathbf{x})}{P(\mathbf{Y}=\mathbf{y})}
$$


dado que la imagen $\mathbf{y}$ es la misma durante el proceso de búsqueda de $\mathbf{X}, P(\mathbf{Y}=\mathbf{y})$ no afecta durante la maximización.

El algoritmo de [34, 42] segmenta la imagen en dos regiones, buscando una solución subóptima, porque la óptima tiene una carga computacional muy alta, mediante un procesado por bandas de pixels estrechas. El resultado es bueno cuando se trata de dos tipos o clases de región, pero la carga computacional crece si se pretende segmentar la imagen en más de dos regiones, en cuyo caso habría que aplicar K-1 veces el algoritmo para dos clases, siendo K el número de clases. De los mismos autores se pueden encontrar más aplicaciones del algoritmo en $[33]$.

La relajación estocástica se presenta en el trabajo [47]. El algoritmo recuerda al proceso de enfriamiento de materiales, de ahí que se llame "simulated annealing" [1]. El trabajo [47] trata de la restauración de imágenes, modelando la imagen restaurada como una segmentación de la imagen deteriorada. Para la segmentación maximiza la expresión 3.19 mediante el siguiente procedimiento de optimización, iterativo y estocástico que permite encontrar el mínimo de una función y que se puede resumir en los siguientes pasos:

Sea $F(x)$ la función a minimizar y $x$ el conjunto de variables, entonces

1. Inicialización. Seleccionar una "temperatura" inicial $T_{o}, y$ aleatoriamente elegir un valor inicial $x_{o}$ para $x$.

2. Comienzan las iteraciones.

En el paso $k$, perturbar $x_{k}$ con $\hat{x}_{k+1}=x_{k}+\Delta x$ y calcular

$$
\Delta F=F\left(\hat{x}_{k+1}\right)-F\left(x_{k}\right)
$$

3. - Si $\Delta F<0$, aceptar el cambio, es decir $x_{k+1}=x_{k}+\Delta x$

- Si $\Delta F>0$, aceptar el cambio con probabilidad

$$
p=e^{-\frac{\Delta F}{T_{k}}}
$$

4. Si ha habido un decremento suficiente de la función o se han llevado a cabo suficientes iteraciones, bajar la temperatura: $T_{k+1}<T_{k}$

5. Si el valor de F se estabiliza y la temperatura es suficientemente baja se ha llegado al final, en caso contrario volver al punto 2.

En el caso de la segmentación $F(x)$ sería la función de energía y $x$ el conjunto de pixels que componen la imagen. 
La forma en la que hay que bajar la temperatura es un parámetro importante de control en simulated annealing, y se llama plan de enfriamiento. Parar un buen resultado, la temperatura debe bajarse lentamente y el óptimo que garantiza la convergencia [47] es:

$$
T_{k}=\frac{C}{\log (1+k)}
$$

donde $T_{k}$ es la temperatura en el paso $k$, y $C$ es una constante positiva.

No obstante, esta expresión produce un enfriamiento demasiado lento para que sea aplicable en tratamiento de imagen [47]. Un plan de enfriamiento alternativo se presenta en [46] y que da resultados bastante buenos:

$$
T_{k}=\alpha^{k} T_{o}, \quad 0<\alpha<1
$$

El trabajo de Geman and Geman no sólo presenta el algoritmo simalated annealing sino que junto a [9] establece las bases teóricas de muchos trabajos en la materia de campos aleatorios, así como un algoritmo para generar realizaciones de un campo aleatorio de Markov, llamado Gibbs Sampler. El inconveniente del simulated annealing es su tiempo /carga computacional. En [47] se establece como número aproximado de iteraciones unas 300, que pueden llegar incluso a 1000 para que la segmentación sea de calidad suficiente. Si el plan de enfriamiento es más rápido (menor número de iteraciones) la solución final depende más de la segmentación inicial.

El elevado número de iteraciones necesario es la razón por la que varios trabajos [10, 24, 77], entre los que se encuentra el presente, se hayan realizado con técnicas que no garantizan alcanzar el mínimo global, pero el número de iteraciones necesario es mucho menor.

\subsubsection{Iterated Conditional Modes}

El algoritmo "Iterated Conditional Modes", abreviado ICM, fue presentado por Besag [10]. Es un algoritmo de relajación determinista, que converge a un máximo local de la distribución de probabilidad a posteriori a partir de una estimación inicial. El ICM tiene la ventaja de precisar un número de iteraciones mucho menor para llegar a la convergencia que el simulated annealing pero por contra no garantiza que la convergencia esté situada en el máximo (o mínimo) global sino que puede quedar atrapado en un máximo local. Este máximo local depende de la estimación inicial que se le ha proporcionado para comenzar las iteraciones. 
El ICM consiste en: dada la imagen observada $\mathbf{Y}$, supongamos una estimación inicial $\hat{\mathbf{X}}$ de la segmentación verdadera $\mathbf{X}^{*}$ que ha dado lugar a $\mathbf{Y}$, y que deseamos actualizar la etiqueta actual $\hat{x}_{i j}$ del pixel $(i, j)$ de forma óptima utilizando toda la información disponible en el instante actual. Besag propone elegir la etiqueta que maximice la probabilidad condicional, dada la imagen observada $\mathbf{Y}$ y la segmentación (o etiquetado) actual de toda la imagen, excepto el pixel i,j $\mathbf{X}_{S \backslash i j}$

$$
x_{i j}^{\prime}=\max _{l}\left[p\left(x_{i j}=l \mid \mathbf{Y}, \mathbf{X}_{S \backslash i j}\right)\right]
$$

Si se va aplicando la expresión 3.20 consecutivamente a cada pixel de la segmentación para actualizarla queda definido un proceso iterativo para la estimación de $\mathbf{X}^{*}$

Se busca la etiqueta que maximiza 3.20, que se puede escribir como

$$
\begin{gathered}
p\left(x_{i j}=l \mid \mathbf{Y}, \mathbf{X}_{S \backslash i j}\right)= \\
=\frac{p\left(x_{i j}=l, \mathbf{Y}, \mathbf{X}_{S \backslash i j}\right)}{p\left(\mathbf{Y}, \mathbf{X}_{S \backslash i j}\right)}= \\
=\frac{p\left(\mathbf{Y} \mid x_{i j}=l, \mathbf{X}_{S \backslash i j}\right) p\left(x_{i j}=l, \mathbf{X}_{S \backslash i j}\right)}{p\left(\mathbf{Y}, \mathbf{X}_{S \backslash i j}\right)}= \\
=\frac{p\left(\mathbf{Y} \mid x_{i j}=l, \mathbf{X}_{S \backslash i j}\right) p\left(x_{i j}=l \mid \mathbf{X}_{S \backslash i j}\right)}{p\left(\mathbf{Y} \mid \mathbf{X}_{S \backslash i j}\right)}= \\
=\frac{p(\mathbf{Y} \mid \mathbf{X}) p\left(x_{i j}=l \mid \mathbf{X}_{S \backslash i j}\right)}{p\left(\mathbf{Y} \mid \mathbf{X}_{S \backslash i j}\right)}=
\end{gathered}
$$

Como se supone un campo markoviano, entonces

$$
=\frac{p(\mathbf{Y} \mid \mathbf{X}) p\left(x_{i j}=l \mid x_{\eta_{i j}}\right)}{p\left(\mathbf{Y} \mid \mathbf{X}_{S \backslash i j}\right)}
$$

siendo $x_{\eta_{i j}}$ el etiquetado del vecindario del pixel $(i, j)$. 
Si suponemos que en el valor de cada pixel de la imagen observada $y_{i j}$ sólo depende de la etiqueta $x_{i j}$ :

$$
p\left(y_{i j} \mid \mathbf{X}\right)=p\left(y_{i j} \mid x_{i j}\right)
$$

y que además son independientes entre sí, entonces 3.21 se puede poner como

$$
p\left(x_{i j}=l \mid \mathbf{Y}, \mathbf{X}_{S \backslash i j}\right)=\frac{\prod_{\forall m, n} p\left(y_{m n} \mid x_{m n}\right) p\left(x_{i j}=l \mid x_{\eta_{i j}}\right)}{p\left(\mathbf{Y} \mid \mathbf{X}_{S \backslash i j}\right)}
$$

que se puede dividir en un producto de dos partes, donde la primera depende del valor de $l$ que asignemos a $x_{i j}$ y la segunda permanece constante para cualquier valor $l$ asignado a $x_{i j}$

$$
p\left(x_{i j}=l \mid \mathbf{Y}, \mathbf{X}_{S \backslash i j}\right)=p\left(y_{i j} \mid x_{i j}\right) p\left(x_{i j}=l \mid x_{\eta_{i j}}\right) \frac{\prod_{\forall m, n \in S \backslash i j} p\left(y_{m n} \mid x_{m n}\right)}{p\left(\mathbf{Y} \mid \mathbf{X}_{S \backslash i j}\right)}
$$

por tanto se puede poner que:

$$
p\left(x_{i j}=l \mid \mathbf{Y}, \mathbf{X}_{S \backslash i j}\right) \propto p\left(y_{i j} \mid x_{i j}\right) p\left(x_{i j}=l \mid x_{\eta_{i j}}\right)
$$

Si queremos poner la expresión 3.25 en función de la energía $U$ o de los potenciales $V_{c}$, tenemos lo siguiente:

Por la regla de Bayes podemos poner

$$
p\left(x_{i j}=l \mid \mathbf{X}_{S \backslash i j}\right)=\frac{p\left(x_{i j}=l, \mathbf{X}_{S \backslash i j}\right)}{\sum_{m=1}^{K} p\left(x_{i j}=m, \mathbf{X}_{S \backslash i j}\right)}
$$

donde el índice $m$ recorre todo el conjunto de las $K$ etiquetas posibles. Según 3.9, 3.10 y 3.11 , y separando en 3.10 el conjunto $C$ en dos partes, la primera formada por los cliques que contienen al pixel $(i, j)$ y la segunda el resto

$$
C=\left\{C_{i j}, C_{S \backslash i j}\right\}
$$

entonces el numerador de 3.26 queda

$$
p\left(x_{i j}=l, \mathbf{X}_{S \backslash i j}\right)=\frac{1}{Z} \exp \left[-\frac{1}{T}\left(\sum_{c \in C_{S \backslash i j}} V_{c}+\sum_{c \in C_{i j}} V_{c}\left(x_{i j}=l\right)\right)\right]
$$


donde se pone de forma explícita que la etiqueta del pixel $(i, j)$ es $l$. De forma similar se puede proceder con el denominador, cancelándose en la expresión 3.26 la constante Z, que aparecería si sustituyéramos en ella la expresión 3.27:

$$
p\left(x_{i j}=l \mid \mathbf{X}_{S \backslash i j}\right)=\frac{\exp \left[-\frac{1}{T}\left(\sum_{c \in C_{S \backslash i j}} V_{c}+\sum_{c \in C_{i j}} V_{c}\left(x_{i j}=l\right)\right)\right]}{\sum_{m=1}^{K} \exp \left[-\frac{1}{T}\left(\sum_{c \in C_{S \backslash i j}} V_{c}+\sum_{c \in C_{i j}} V_{c}\left(x_{i j}=m\right)\right)\right]}
$$

donde el primer sumatorio del exponente del denominador no depende del índice $m$ y por tanto se puede sacar de dicho sumatorio, y se cancela con el mismo término que hay en el numerador

$$
p\left(x_{i j}=l \mid \mathbf{X}_{S \backslash i j}\right)=\frac{\exp \left[-\frac{1}{T} \sum_{c \in C_{i j}} V_{c}\left(x_{i j}=l\right)\right]}{\sum_{m=1}^{K} \exp \left[-\frac{1}{T} \sum_{c \in C_{i j}} V_{c}\left(x_{i j}=m\right)\right]}
$$

Puesto que el denominador siempre abarca todo el conjunto de etiquetas, es independiente del valor de $l$ y se puede poner

$$
p\left(x_{i j}=l \mid \mathbf{X}_{S \backslash i j}\right) \propto \exp \left[-\frac{1}{T} \sum_{c \in C_{i j}} V_{c}\left(x_{i j}=l\right)\right]
$$

se observa que 3.30 depende sólo del vecindario del pixel $(i, j)$, por tanto

$$
p\left(x_{i j}=l \mid \mathbf{X}_{S \backslash i j}\right)=p\left(x_{i j}=l \mid \eta_{i j}\right) \propto \exp \left[-\frac{1}{T} \sum_{c \in C_{i j}} V_{c}\left(x_{i j}=l\right)\right]
$$

Llevando 3.31 a la expresión 3.25

$$
p\left(x_{i j}=l \mid \mathbf{Y}, \mathbf{X}_{S \backslash i j}\right) \propto p\left(y_{i j} \mid x_{i j}=l\right) \exp \left[-\frac{1}{T} \sum_{c \in C_{i j}} V_{c}\left(x_{i j}=l\right)\right]
$$

o bien,

$$
p\left(x_{i j}=l \mid \mathbf{Y}, \mathbf{X}_{S \backslash i j}\right) \propto \exp \left[-\frac{1}{T}\left\{\sum_{c \in C_{i j}} V_{c}\left(x_{i j}=l\right)-T \ln p\left(y_{i j} \mid x_{i j}=l\right)\right\}\right]
$$


El objetivo de maximizar 3.25 es equivalente pues, a minimizar la expresión entre llaves del exponente de la expresión 3.33 que según la nomenclatura utilizada en 3.10 es una energía, en este caso a posteriori, porque incluye la observación $y_{i j}$ y las etiquetas que tenga el vecindario $\eta_{i j}$ del pixel $(i, j)$, y se expresa:

$$
E_{i j}(l)=\sum_{c \in C_{i j}} V_{c}\left(x_{i j}=l\right)-T \ln p\left(y_{i j} \mid x_{i j}=l\right)
$$

La convergencia a un máximo local está garantizada porque la probabilidad $p(\mathbf{X} \mid \mathbf{Y})$ crece monótonamente con cada paso de la iteración, y queda demostrado con

$$
\begin{gathered}
p(\mathbf{X} \mid \mathbf{Y})=p\left(x_{i j}=l, \mathbf{X}_{S \backslash i j} \mid \mathbf{Y}\right)= \\
p\left(x_{i j}=l \mid \mathbf{Y}, \mathbf{X}_{S \backslash i j}\right) p\left(\mathbf{X}_{S \backslash i j} \mid \mathbf{Y}\right)
\end{gathered}
$$

dado que $p\left(x_{i j}=l \mid \mathbf{Y}, \mathbf{X}_{S \backslash i j}\right)$ crece cada vez que se asigna un nueva etiqueta a $x_{i j}$, mientras que $p\left(\mathbf{X}_{S \backslash i j} \mid \mathbf{Y}\right)$ permanece inalterado.

\section{Orden de procesamiento}

Besag [10] propone dos alternativas al orden en el que los pixels se van procesando en función del tipo de máquina o lenguaje en el que se va a implementar el algoritmo ICM, a las que podemos llamar recursiva (secuencial) y no recursiva (paralela).

La no recursiva consiste en procesar todos los pixels a la vez, y es adecuada para máquinas multiprocesador, o lenguajes matriciales. En este caso la velocidad de procesado es mayor, pero no está garantizada la convergencia [10] y pueden ocurrir pequeñas oscilaciones. Es adecuado en este caso fijar un número máximo de iteraciones para asegurar que el proceso termina. En máquinas secuenciales el resultado de cada pixel no se tiene en cuenta para los cálculos de lo siguientes pixels hasta que no se ha finalizado cada iteración completa de la imagen.

La alternativa recursiva o secuencial, procesa un pixel tras otro en un determinado orden. La convergencia sí está asegurada porque para cada pixel actual se toma en cuenta el resultado del procesado de los pixels vecinos que le preceden en el orden de procesamiento. No obstante, esta manera de proceder tiene el inconveniente de que el máximo alcanzado depende del orden de procesamiento. Es conveniente pues, variar este orden en cada iteración para minimizar esta dependencia $[10,77]$. 
Como punto de compromiso se puede utilizar como orden de procesamiento los "coding sets", orden propuesto por el mismo Besag [9]. Uno de los órdenes de procesamiento normalmente utilizado es el de televisión: exploración a base de líneas horizontales de izquierda a derecha, y de arriba a abajo. Otros autores han profundizado sobre el orden de procesamiento. Por ejemplo [24] propone no tomar un orden preestablecido sino que el orden sea determinado en función del contenido de la imagen, procesando primero los pixels cuyo etiquetado ofrezca una mayor seguridad de ser cierto, dejando los pixels más dudosos para el final. Este modo de proceder lo llamaron Highest Confidence First y se trata en la sección siguiente.

\subsubsection{Highest Confidence First}

Este algoritmo [24], abreviado HCF, está basado en el mismo proceso de maximización que el ICM, pero establece un determinado orden de procesamiento de los pixels según el contenido de la imagen, procesando primero los pixels que más clara tienen la pertenencia a una etiqueta (o región) y por último los más dudosos. Con esto se evita que el etiquetado previo de un pixel dudoso influya sobre el etiquetado posterior de sus vecinos, tal como puede ocurrir en el ICM, que precisa de un etiquetado inicial de todos los pixels para comenzar las iteraciones. Así pues la primera diferencia entre el HCF y el ICM es que el HCF no utiliza un etiquetado inicial en el mismo sentido que el ICM, sino que amplia el conjunto de etiquetas posibles

$$
L=\left\{l_{1}, \ldots, l_{K}\right\}
$$

con una más, llamada sin-asignar o también etiqueta nula. El etiquetado de partida consiste en todos los pixels con la etiqueta: sin-asignar. Siguiendo [24] definimos:

Sea $\bar{L}=L \cup\left\{l_{0}\right\}$, el conjunto de etiquetas ampliado, donde $l_{0}$ es una etiqueta nula correspondiente al estado de "sin asignación de etiqueta".

Sea:

$$
\Omega=\left\{\mathbf{x}=\left(x_{11}, \ldots, x_{M N}\right) \mid x_{i j} \in L, \quad(i, j) \in \mathcal{S}\right\}
$$

el espacio de configuraciones de etiquetas posibles para el conjunto de la imagen, $y$

$$
\bar{\Omega}=\left\{\mathbf{x}=\left(x_{11}, \ldots, x_{M N}\right) \mid x_{i j} \in \bar{L}, \quad(i, j) \in \mathcal{S}\right\}
$$

el espacio de configuraciones similar al anterior pero aumentado a la posibilidad de que los pixels puedan tener asignada la etiqueta $l_{0}$.

La idea básica del HCF es partir de la configuración inicial

$$
\mathbf{x}^{0}=\left(l_{0}, \ldots, l_{0}\right)
$$


donde todos los pixels tienen la etiqueta nula, y construir una secuencia de configuraciones $\mathbf{x}^{\mathbf{1}}, \mathbf{x}^{\mathbf{2}}, \ldots, \mathbf{x}^{\mathbf{f}}$ de $\bar{\Omega}$, donde $\mathbf{x}^{\mathbf{f}}$ corresponde a un mínimo de $U(\mathbf{x})$ respecto a $\Omega$. Al decir respecto a $\Omega$ y no respecto a $\bar{\Omega}$, significa que ningún pixel puede tener en la configuración final la etiqueta nula $l_{0} . U(\mathbf{x})$ corresponde a la expresión 3.10 .

Durante la construcción de la secuencia de configuraciones se impone la regla de que una vez se ha asignado a un pixel una etiqueta no nula, a éste no se le puede asignar la etiqueta nula, pero puede cambiar su etiqueta a cualquiera del conjunto $L$. La razón de esto es que la etiqueta nula es una etiqueta de "espera", Pero una vez han sido etiquetados con alguna etiqueta del conjunto $L$ ya no pueden quedar de nuevo a la "espera".

En HCF también se utiliza la expresión 3.34 pero ampliada aquí a una configuración $\mathbf{x}^{\prime} \in \bar{\Omega}$, es decir donde algunos pixels pueden tener la etiqueta nula, quedando

$$
E_{i j}(l)=\sum_{c \in C_{i j}} V_{c}^{\prime}\left(x_{i j}^{\prime}=l\right)-T \ln p\left(y_{i j} \mid x_{i j}\right)
$$

donde $\mathbf{x}^{\prime}$ es una configuración que coincide con $\mathbf{x}$ en todos los pixels excepto en $x_{i j}^{\prime}=l$ y $V_{c}^{\prime}$ es 0 si algún pixel del clique tiene la etiqueta nula, en caso contrario $V_{c}^{\prime}=V_{c}$. Es decir, si un pixel está en espera éste no contribuye en el etiquetado de sus vecinos. $E_{i j}(l)$ cuantifica la bondad de la etiqueta $l$ respecto de la configuración actual, lógicamente, como se trata de un campo aleatorio de Markov sólo participan los pixels de la configuración $\mathbf{x}^{\prime}$ que son vecinos del $(i, j)$.

Para establecer el orden de asignación de etiquetas, que es la clave del HCF, hay que evaluar y ordenar los pixels de manera que los primeros sean los que más clara tengan su pertenencia a una etiqueta en el estado actual, utilizando la nomenclatura del HCF, primero los más fiables. Se busca que la etiqueta que se va a asignar minimice la energía. Habrá una etiqueta $k$ que corresponda al mínimo, y una etiqueta $q$ que sea la que corresponde a una energía mayor que $k$ pero menor que el resto. Si la diferencia entre $E_{i j}(k)$ y $E_{i j}(q)$ es grande la asignación de la etiqueta $k$ es fiable, es decir tiene clara su etiquetado con $k$, pero si la diferencia es pequeña la fiabilidad es menor, es decir su etiquetado con $k$ es más dudoso y es mejor dejar estos pixels para el final.

Se define entonces la estabilidad $G_{i j}(\mathbf{x})$ del pixel $(i, j)$ respecto de una configuración $\mathbf{x}$, como:

$$
G_{i j}(x)=\min _{k \in L, k \neq x_{i j}} \Delta E_{i j}\left(k, x_{i j}\right) \text { si } x_{i j} \in L
$$




$$
G_{i j}(x)=-\min _{k \in L, k \neq q} \Delta E_{i j}(k, q) \text { si } x_{i j}=l_{0}
$$

donde $q$ en 3.38 cumple $: q \in L$ tal que $E_{i j}(q) \min _{k \in L} E_{i j}(k)$ y $\Delta E_{i j}(q, k)=$ $E_{i j}(q)-E_{i j}(k)$ respecto a $\mathbf{x}$

En cada paso de la construcción se asigna etiqueta sólo al pixel menos estable. Un valor negativo de $G$ significa que hay una etiqueta que disminuye el valor de la energía con la etiqueta actual y por tanto es conveniente cambiar. Por tanto la estabilidad, o configuración final, se alcanza cuando todos los valores de $G_{i j}$ sean no negativos. La expresión 3.38 garantiza que todos los pixels con etiqueta nula tienen estabilidad negativa y que por tanto se les asignará una etiqueta del conjunto $L$ en algún momento. Cuando se asigna una etiqueta, la energía de los vecinos puede cambiar y por tanto su estabilidad, sin embargo mientras un pixel tenga la etiqueta nula no afecta en la energía de sus vecinos.

La implementación en una máquina secuencial se puede realizar a través de una cola ordenada, de menor estabilidad (primero) a mayor estabilidad (último de los pixels). En cada paso se cambia la etiqueta del pixel menos estable. Como este cambio afecta a la energía del pixel y a la de sus vecinos se recalcula la estabilidad de ellos y se recolocan en la cola. El pixel que menos estabilidad tenga tras la recolocación es el próximo en cambiar su etiqueta; el algoritmo finaliza cuando el primer pixel de la cola tiene estabilidad positiva, indicando que ya no hay ninguna etiqueta que disminuya la energía de la actual. Este procedimiento se puede sintetizar con el siguiente pseudo-código

$$
x=x_{0} ; \quad x_{0}=\left(l_{0}, \ldots, l_{0}\right)
$$

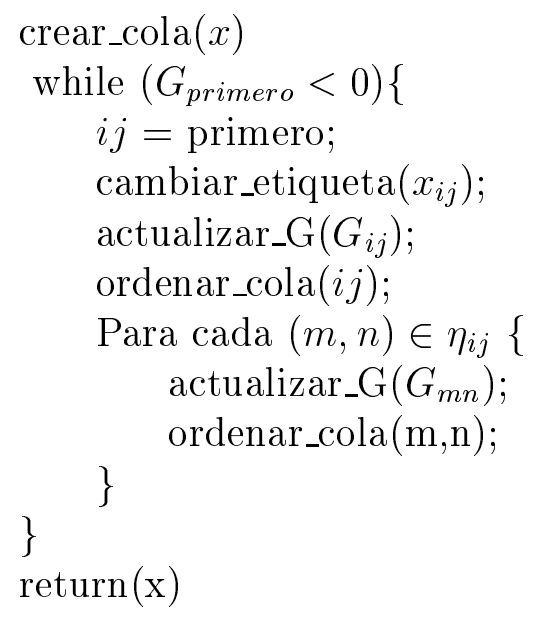

El significado de las funciones es el siguiente: Cambiar_etiqueta $\left(x_{i j}\right)$ cambia la etiqueta actual $x_{i j}$ del pixel $(i, j)$ por la etiqueta $l \in L$ que minimiza la energía. Como se ha dicho antes, este cambio repercute en un cambio de la estabilidad del 
pixel y de sus vecinos, lo que hace necesario recalcular la estabilidad y reordenar, proceso que realizan respectivamente actualizar_ $G\left(G_{i j}\right)$ y ordenar_cola $(i, j)$ para el pixel $(i, j)$ y sus vecinos. Afortunadamente para el mantenimiento de la cola sólo hay que reordenar un número de pixels mucho menor ( 9 en el caso de un vecindario de orden 2) que para construir la cola durante la inicialización (por ejemplo 65536 en una imagen de 256x256): Este hecho junto con que aproximadamente el $99 \%$ de los pixels sólo se asigna etiqueta la primera vez y ya no vuelven a cambiar de etiqueta hace que el algoritmo tenga unos tiempos de cálculo aceptables. Algunos autores descartan este algoritmo argumentando que la necesidad de actualizar la cola en cada iteración tiene un coste computacional altísimo, pero hay que tener en cuenta que sólo hay que recolocar 9 pixels y el resto mantienen su ordenación. Con una estrategia adecuada la recolocación tiene un coste computacional muchísimo menor que construir la cola por entero en cada paso. Además hay que tener en cuenta que el ICM visita todos los pixels unas 8 a 10 veces en total (ya que se suele alcanzar la convergencia con este número de iteraciones), mientras que el HCF en promedio está un poco por encima de una vez. Desde nuestro punto de vista el mayor inconveniente del HCF no es su tiempo de cálculo, que para imágenes grandes sólo la construcción inicial de la cola sin incluir el mantenimiento es muy grande, sino la sensibilidad del resultado de la segmentación respecto a los parámetros del modelo de campo aleatorio de Markov y la tendencia a etiquetar toda la imagen con la misma etiqueta. Resultado que resulta paradójico, pero la misma idea que hace atractivo el HCF y que a priori induce a pensar que mejorará el resultado de la segmentación (el más fiable primero) puede hacer que el resultado no sea el esperado, porque (según los parámetros del campo aleatorio de Markov) cuando un pixel muy fiable se etiqueta tiende a aumentar la confianza de los vecinos y estos a su vez la confianza de los suyos en detrimento de los pixels alejados y que todavía están sin asignar, de manera que el algoritmo tiende a ir creciendo demasiado las regiones de los pixels dominantes. Esto no ocurre en ICM puesto que se parte de una inicialización donde todos los pixels tienen una etiqueta. La propuesta que realizamos en la sección siguiente reduce la tendencia del HCF al excesivo crecimiento de las regiones.

\subsubsection{Block Highest Confidence First}

La propuesta que nosotros hacemos para evitar el problema mencionado anteriormente provocado por la excesiva influencia de un pixel fiable sobre sus vecinos no etiquetados es cambiar la estrategia de etiquetado de uno en uno que tiene el $\mathrm{HCF}$ por un etiquetado por bloques, siendo un bloque el conjunto de $B$ pixels sucesivos en la tabla ordenada de estabilidades. De manera que el etiquetado de un pixel no influye inmediatamente en el cálculo de cual es el próximo pixel a etiquetar, pero sí en el cálculo de cuál es la etiqueta a asignar al próximo pi- 
xel a etiquetar, puesto que esto es necesario para garantizar la convergencia del algoritmo [10].

Expresando lo mismo en otras palabras, en el HCF la etiqueta asignada al pixel en curso puede hacer cambiar dos valores:

- las energías de los pixels vecinos, y

- la estabilidad de los pixels vecinos.

En el ICM de Besag las estabilidades no se tienen en cuenta, en HCF se recalculan cada vez que se etiqueta un pixel, en el BHCF se recalculan sólo cada $B$ pixels etiquetados. En el ICM, en el HCF y en el BHCF las energías se recalculan cada vez que un pixel es etiquetado (sólo es necesario recalcular las energías de los vecinos del pixel que se va a etiquetar).

Puesto que en BHCF el procedimiento para el cálculo de la etiqueta a asignar a un pixel, es el mismo que en HCF y en ICM la convergencia a un mínimo local de la energía está garantizada [10], sólo que el mínimo local no tiene porque ser el mismo en los tres ya que el orden de etiquetado es diferente.

También se podía haber pensado en modificar el HCF a través de variar los parámetros del modelo del campo aleatorio de Markov (por ejemplo a través de la temperatura) de manera que la influencia de los pixels etiquetados del vecindario tuvieran una menor influencia al principio e irla aumentando en cada iteración, pero esto tendría una repercusión muy grande en el tiempo de cálculo puesto que en HCF hay que reordenar las estabilidades en cada iteración. Si los parámetros no cambian esta ordenación no es muy costosa porque consta de recolocar en la tabla ordenada sólo los pixels vecinos del pixel que acaba de ser etiquetado y no de todos los pixels de la imagen. Si cambia algún parámetro del modelo, entonces habría que volver a calcular la estabilidad de todos los pixels de la imagen y ordenarlos todos, lo cual sí es muy costoso porque hay que hacerlo en cada iteración. 


\subsubsection{Estudio Comparativo}

Para ilustrar las prestaciones de los diferentes algoritmos expuestos se han realizado segmentaciones con supervisión sobre dos tipos de imágenes sintéticas. La primera es una imagen binaria formada por cuadriláteros y círculos y la llamaremos cuacir. La segunda es una imagen multinivel con regiones de formas arbitrarias y la llamaremos formas. Ambos tipos de imágenes están formadas por regiones de un determinado nivel de gris constante más ruido gaussiano independiente. A la imagen formada exclusivamente por las regiones de nivel constante sin ruido gaussiano las llamaremos imágenes sin ruido. Dado que el margen dinámico de una gaussiana es desde $-\infty$ a $+\infty$, los niveles por encima de un valor máximo y por debajo de un valor mínimo se han saturado a un valor máximo y a un valor mínimo respectivamente. Como las imágenes de entrada al algoritmo de segmentación que se van a utilizar son de 8 bits por pixel (monocromas) el valor mínimo utilizado ha sido el 0 y el máximo el 255 , aunque en la notación utilizaremos también el margen $(0,1)$ con escalones de $1 / 255$ para referirnos a las mismas imágenes.

El primer tipo de imagen consta de una imagen sin ruido formada por regiones con un nivel de gris constante de entre dos posibles, más el ruido gaussiano. Los dos valores posibles pertenecen al margen $(0,1)$. La imagen sin ruido con niveles 0.4 y 0.6 se presenta en la figura $3.4 a$.

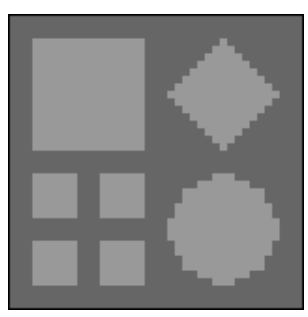

a) cuacir

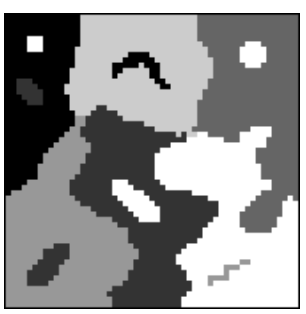

b) formas

Figura 3.4: a) Imagen cuacir con valores de objeto y fondo 0.4 y 0.6 respectivamente; b) imagen formas.

El segundo tipo de imagen consta de una imagen sin ruido formada por regiones con un nivel de gris constante de entre seis posibles, más el ruido gaussiano. Los valores posibles pertenecen al margen $(0,1)$. La imagen sin ruido con niveles de gris $0,0.2,0.4,0.6,0.8$ y 1 se muestra en la figura 3.4b. Se han escogido imágenes sintéticas frente a naturales porque se conoce cual es la segmentación verdadera y se puede controlar el nivel de ruido introducido. Se han escogido dos tipos de imágenes para ilustrar los dos casos más generales en tratamiento de imagen que son el caso binario (dos etiquetas) y el multietiqueta (más de dos etiquetas). El término multietiqueta se utiliza para no utilizar el término 
multinivel que podría confundirse con el número de niveles de gris de la entrada, que en ambos tipos de imagen es de 256 niveles.

Respecto al caso multietiqueta se han escogido seis niveles porque aunque puede parecer un número bajo, permite diferenciar visualmente las diferentes regiones. Si se toma un valor alto, visualmente es difícil apreciar en caso de regiones con valores próximos, si son regiones con el mismo valor o diferentes. Para ver la robustez de la segmentación ante el ruido se realizan ejecuciones de los algoritmos sobre imágenes con diferente nivel de dificultad. Este nivel de dificultad se puede variar mediante dos procedimientos:

- actuando sobre la varianza de la gaussiana, y

- aproximando o alejando los niveles de gris de las regiones sin ruido, que llamaremos medias, y mantener la varianza del ruido añadido constante.

Ambos procedimientos permiten modificar el número de pixels que serían correctamente etiquetados si se utiliza el procedimiento de estimación de máxima verosimilitud (MLE, Maximum Likelihood Estimate) consistente en asignar la etiqueta que maximice la probabilidad, calculada según la distribución gaussiana de media cada una de las medias posibles y la varianza correspondiente, sin tener en cuenta el etiquetado de los pixels vecinos. El procedimiento MLE es el más utilizado para las inicializaciones en las publicaciones sobre MRF [10] [47]. Se ha elegido el procedimiento segundo (aproximar las medias) porque aumentar la varianza supone un mayor número de pixels que exceden el margen dinámico previsto $((0,255)$ con escalones unidad, o el equivalente normalizado a $1(0,1)$ con escalones $1 / 255)$ y por tanto el número de pixels saturados es mayor, lo que se traduce en una cantidad de pixels con valor 0 o 1 que no se adecua al modelo gaussiano.

En la primera columna de la figura $3.5 a$ y $b$ se presentan diferentes versiones de la imagen cuacir (bietiqueta). Cada versión está constituida de un fondo y objetos cuyos niveles de gris están cada vez más próximos. El primer caso (subíndice 0) tiene un nivel de gris del fondo de 0.4 y un nivel de gris de los objetos de 0.6. No se han considerado medias más alejadas porque la segmentación es ya casi perfecta. El segundo caso de $a$ tiene un nivel de gris del fondo de $0.41 \mathrm{y}$ un nivel de gris de los objetos de 0.59. El tercer caso de $a$ tiene niveles de 0.42 y 0.58; y así sucesivamente hasta el último caso de $b$ con niveles de 0.47 y 0.53. En la figura 3.6 están representadas las funciones gaussianas utilizadas.

La segunda columna presenta para cada caso la imagen ruidosa consistente en sumar a la imagen sin ruido de cada caso una imagen de ruido gaussiano independiente de media 0 y desviación estándar 0.05, asignando el valor 0 a todos aquellos pixels que después de la suma queden por debajo de cero y el 


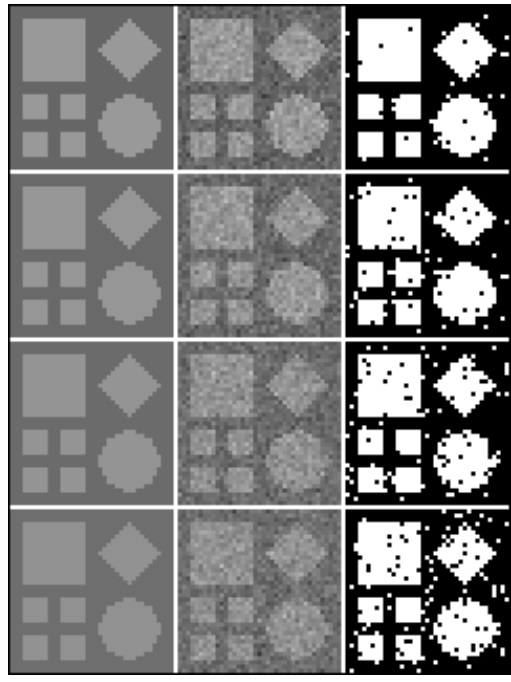

a) $0,1,2,3$

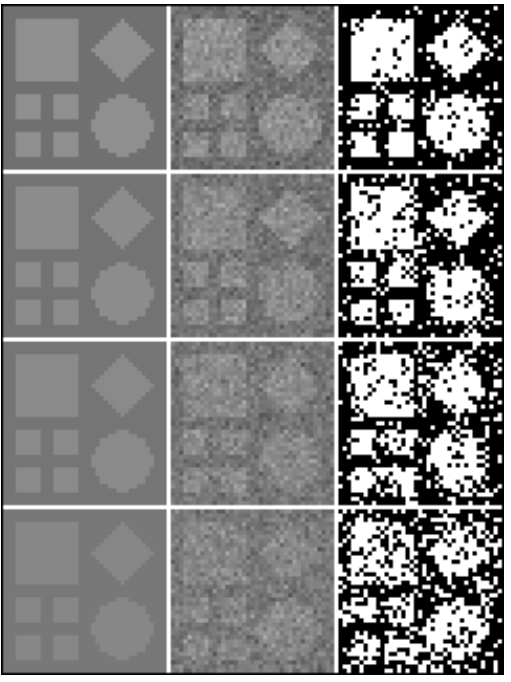

b) $4,5,6,7$

Figura 3.5: Imagen cuacir con diferentes niveles para el fondo y el objeto; la primera columna de $a$ y $b$ corresponde a las imágenes sin ruido, las segundas columnas a las imágenes con ruido y las terceras al etiquetado según la estimación de máxima verosimilitud (MLE).

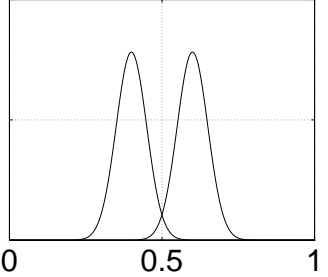

a) $(0.40,0.60)$

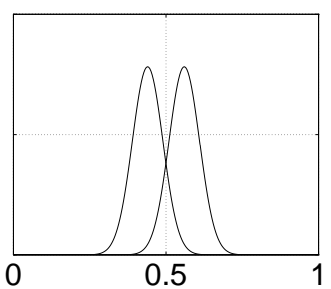

e) $(0.44,0.56)$

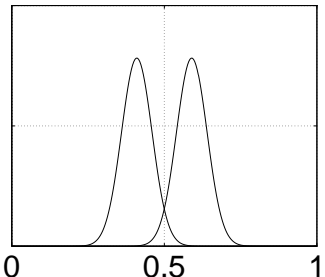

b) $(0.41,0.59)$

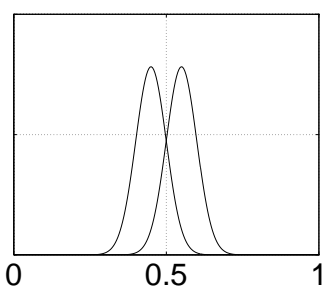

f) $(0.45,0.55)$

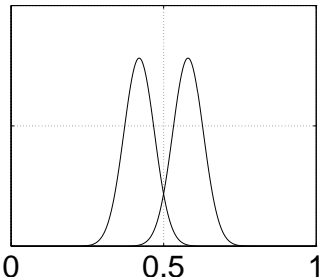

c) $(0.42,0.58)$

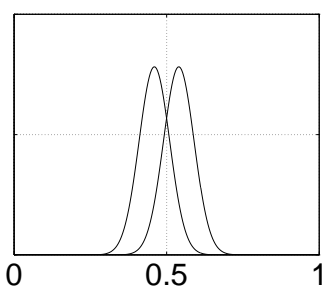

g) $(0.46,0.54)$

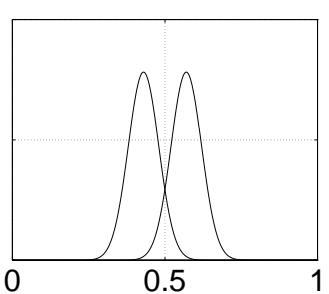

d) $(0.43,0.57)$

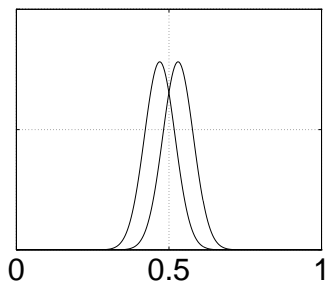

h) $(0.47,0.53)$

Figura 3.6: Representación de las funciones gaussianas utilizadas para la imagen cuacir. Debajo de cada gráfica figuran los valores para las dos medias utilizadas en cada caso. Se puede observar el solapamiento creciente entre ambas funciones. 
valor 1 a todos aquellos pixels que después de la suma queden por encima de 1. La tercera columna presenta para cada caso el etiquetado de los pixels según la estimación de máxima verosimilitud (MLE), que es la óptima si no se incluye información sobre el vecindario.

Se puede apreciar que a medida que aumenta el ruido el número de pixels mal etiquetados en el MLE aumenta. En la tabla 3.1 se da el porcentaje de pixels etiquetados incorrectamente con el procedimiento de máxima verosimilitud de los 8 casos de la figura 3.5.

\begin{tabular}{|c|c|c|c|c|c|c|c|c|}
\hline caso & 0 & 1 & 2 & 3 & 4 & 5 & 6 & 7 \\
\hline \hline \%ei & 2.30 & 4.67 & 5.79 & 7.10 & 11.24 & 16.50 & 20.38 & 27.55 \\
\hline
\end{tabular}

Tabla 3.1: Porcentaje de pixels etiquetados incorrectamente (ei) con el procedimiento de máxima verosimilitud sobre la imagen cuacir.

Se ha procedido de forma similar con la imagen formas. Se generan 8 casos con medias cada vez más próximas. Los seis niveles de gris de la imagen sin ruido de cada caso se dan en la tabla 3.2 .

\begin{tabular}{|c|c|c|c|c|c|c|c|c|}
\hline \multirow{2}{*}{ región } & \multicolumn{9}{|c|}{ caso } \\
\cline { 2 - 9 } & 0 & 1 & 2 & 3 & 4 & 5 & 6 & 7 \\
\hline \hline 0 & 0 & 0.05 & 0.1 & 0.15 & 0.2 & 0.25 & 0.3 & 0.35 \\
\hline 1 & 0.2 & 0.23 & 0.26 & 0.29 & 0.32 & 0.35 & 0.38 & 0.41 \\
\hline 2 & 0.4 & 0.41 & 0.42 & 0.43 & 0.44 & 0.45 & 0.46 & 0.47 \\
\hline 3 & 0.6 & 0.59 & 0.58 & 0.57 & 0.56 & 0.55 & 0.54 & 0.53 \\
\hline 4 & 0.8 & 0.77 & 0.74 & 0.71 & 0.68 & 0.65 & 0.62 & 0.59 \\
\hline 5 & 1 & 0.95 & 0.9 & 0.85 & 0.8 & 0.75 & 0.7 & 0.65 \\
\hline $\begin{array}{l}\text { distancia } \\
\text { entre ni- } \\
\text { veles }\end{array}$ & 0.2 & 0.18 & 0.16 & 0.14 & 0.12 & 0.1 & 0.08 & 0.06 \\
\hline
\end{tabular}

Tabla 3.2: Niveles de gris de cada región de la imagen formas para cada uno de los ocho casos.

Al igual que con la imagen cuacir se presenta en la figura 3.7 la imagen donde en la primera columna de $a$ y de $b$ aparece para cada caso la imagen sin ruido, en la segunda columna la imagen con ruido (también de desviación estándar 0.05 para todos los casos) y la tercera columna el etiquetado con el MLE.

Así mismo en la tabla 3.3 se dan los porcentajes de pixels etiquetados incorrectamente cuando se utiliza el procedimiento MLE.

Una vez presentados los diferentes casos de los dos tipos de imágenes de partida utilizados para la ilustración de los algoritmos se presentan los resultados 


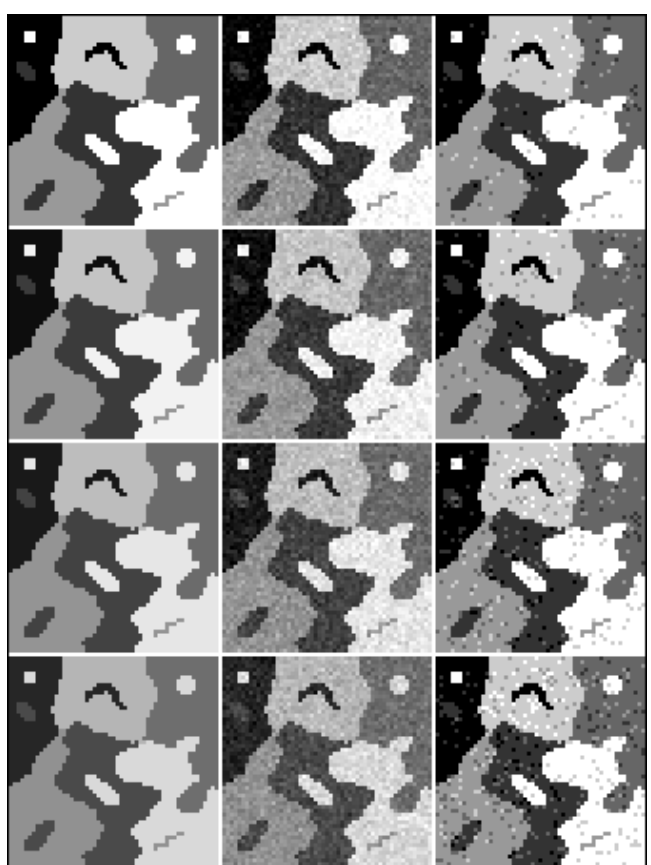

a) $0,1,2,3$

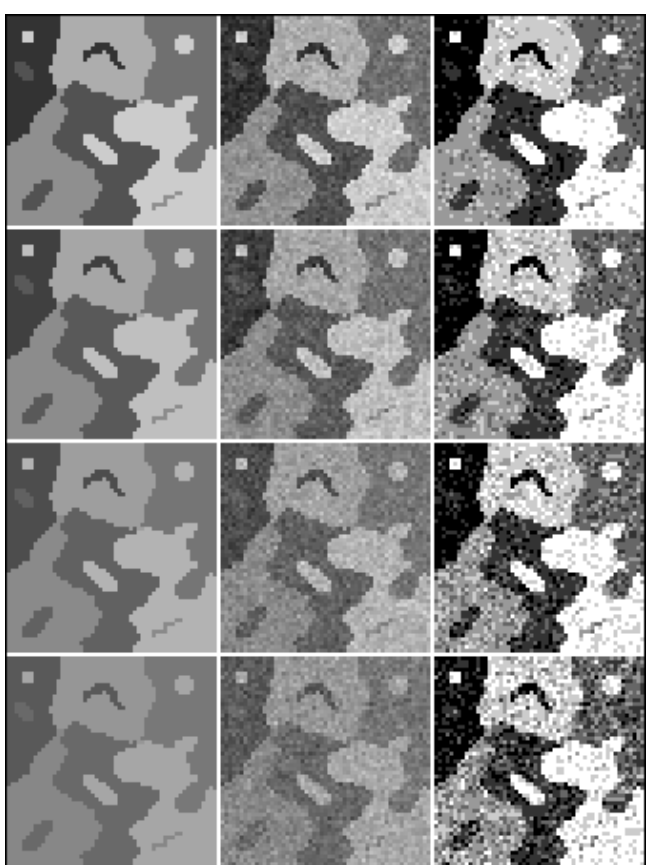

b) $4,5,6,7$

Figura 3.7: Imagen formas con diferentes niveles para cada uno de los seis tipos de regiones; la primera columna de $a$ y $b$ corresponde a las imágenes sin ruido, las segundas columnas a las imágenes con ruido y las terceras al etiquetado según la estimación de máxima verosimilitud (MLE).

\begin{tabular}{|c|c|c|c|c|c|c|c|c|}
\hline caso & 0 & 1 & 2 & 3 & 4 & 5 & 6 & 7 \\
\hline \hline \%ei & 4.17 & 5.32 & 9.72 & 12.79 & 19.27 & 28.0 & 34.44 & 44.92 \\
\hline
\end{tabular}

Tabla 3.3: Porcentaje de pixels etiquetados incorrectamente (ei) con la estimación de máxima verosimilitud sobre la imagen formas. 
primero para todos los casos y algoritmos sobre la imagen cuacir (bietiqueta) y luego todos los casos y algoritmos sobre la imagen formas (multietiqueta). Dado que estas imágenes tienen una componente aleatoria en el ruido, se han procesado varias realizaciones dando resultados similares y las realizaciones que se han escogido son las más representativas del comportamiento del conjunto.

\section{Imagen cuacir}

Para cada algoritmo se presentan los 8 casos de la figura 3.5 junto a las imágenes correspondientes al resultado de cada algoritmo, tomando como modelo de campo aleatorio de Markov para la imagen, el modelo multilevel logistic, con un potencial de clique igual para todos ellos y de valor $\beta_{a}=0$ para el caso que todos $\operatorname{los} x_{i j}$ de $c$ sean iguales y valor $\beta_{a}^{\prime}=\beta$ en caso contrario, valor de los coeficientes $\alpha$ igual a cero. El valor de la temperatura utilizado es $T=1$. Se consideran sólo potenciales de cliques formados por dos pixels.

La expresión 3.29 queda entonces

$$
p\left(x_{i j} \mid \mathbf{X}_{S \backslash i j}\right) \propto \frac{\exp \left[-\beta u_{i j}(l)\right]}{\sum_{k=1}^{K} \exp \left[-\beta u_{i j}(k)\right]}
$$

donde $u_{i j}(l)$ es el número de pixels en el vecindario de orden 2 del pixel $i j$ no etiquetados con la etiqueta $l$. El valor de $\beta$ utilizado es 1.5 [10] [100].

Las figuras $3.8 b$ y $3.9 b$ muestran el resultado que se alcanza al etiquetar los pixels de la imagen cuacir con los algoritmos ICM, HCF y BHCF. Dado que se conoce la segmentación perfecta, se compara ésta con los resultados de la segmentación alcanzada por los diferentes algoritmos y el número de pixels etiquetados incorrectamente en cada uno de los 8 casos se presenta en la tabla junto con el número de pixels etiquetados incorrectamente de la imagen de etiquetas alcanzada con la estimación de máxima verosimilitud.

\begin{tabular}{|c|c|c|c|c|c|c|c|c|}
\hline caso & 0 & 1 & 2 & 3 & 4 & 5 & 6 & 7 \\
\hline \hline MLE & 2.30 & 4.67 & 5.78 & 7.10 & 11.24 & 16.50 & 20.38 & 27.55 \\
\hline ICM & 0.53 & 0.66 & 0.92 & 1.05 & 3.02 & 4.14 & 5.92 & 9.07 \\
\hline HCF & 0.53 & 0.66 & 1.05 & 0.66 & 3.22 & 5.85 & 20.77 & 42.27 \\
\hline BHCF & 0.53 & 0.66 & 1.05 & 0.79 & 3.68 & 5.12 & 11.5 & 20.64 \\
\hline
\end{tabular}

Tabla 3.4: Porcentaje de pixels etiquetados incorrectamente (ei) con los diferentes algoritmos sobre la imagen cuacir.

Algoritmo ICM. Se puede observar como el algoritmo alcanza una segmentación que reduce significativamente el número de pixels etiquetados incorrecta- 


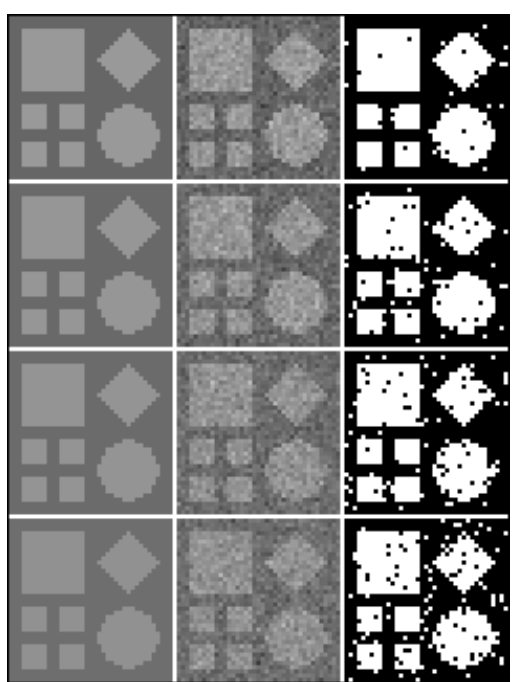

a) sin ruido, con ruido, MLE

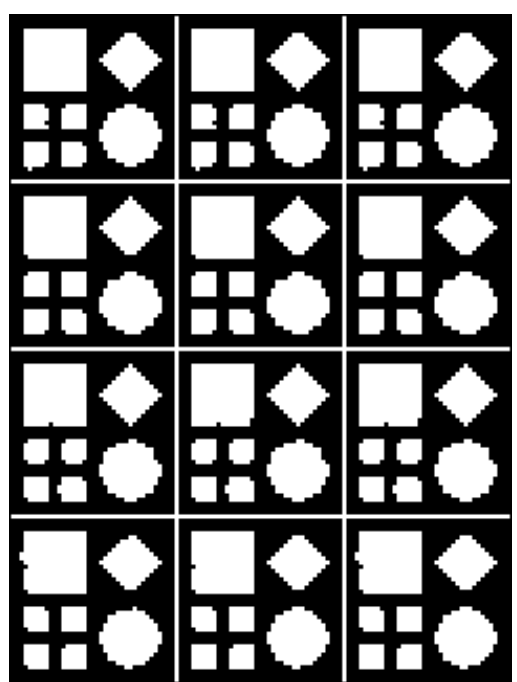

b) ICM, HCF, BHCF

Figura 3.8: Resultados de los cuatro primeros casos de la imagen cuacir; a) la primera columna de $a$ corresponde a las imágenes sin ruido, la segunda columna a las imágenes con ruido y la tercera al etiquetado según la estimación de máxima verosimilitud (MLE); b) primera columna resultado del etiquetado alcanzado con ICM, segunda columna con HCF y tercera columna con BHCF.

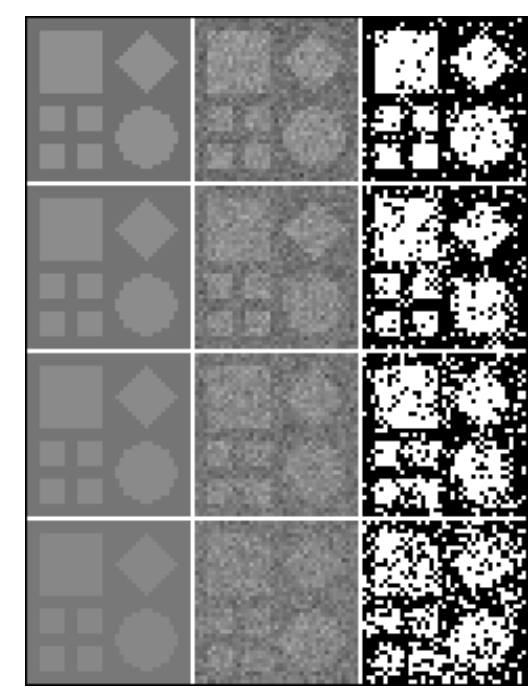

a) sin ruido, con ruido, MLE

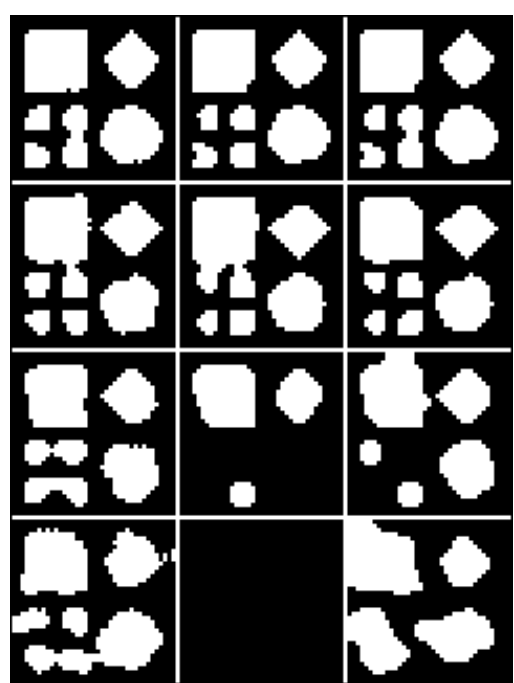

b) ICM, HCF, BHCF

Figura 3.9: Resultados de los cuatro segundos casos de la imagen cuacir; a) la primera columna de $a$ corresponde a las imágenes sin ruido, la segunda columna a las imágenes con ruido y la tercera al etiquetado según la estimación de máxima verosimilitud (MLE); b) primera columna resultado del etiquetado alcanzado con ICM, segunda columna con HCF y tercera columna con BHCF. 


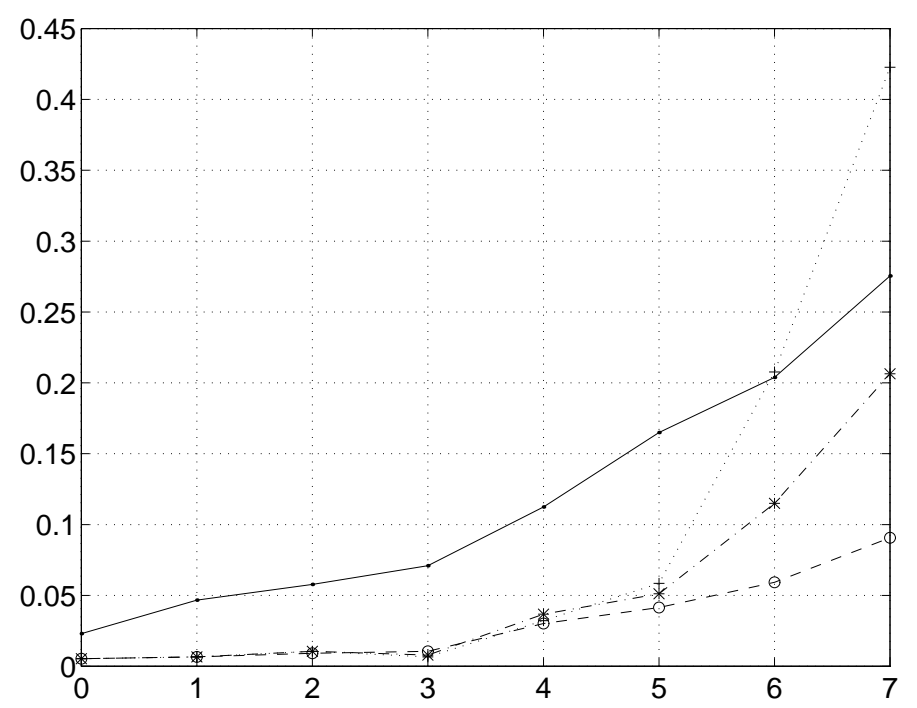

Figura 3.10: Gráfica con los ratios de pixels etiquetados incorrectamente de los casos presentados en la tabla 3.4. La curva de trazo continuo corresponde al MLE, en trazo discontinuo y con 'o' el ICM, en trazo de puntos y con '+' el $\mathrm{HCF}$; y en trazo de puntos y rayas y con ' ${ }^{*}$ ' el BHCF.

mente respecto a la segmentación inicial. Hay que hacer notar que la segmentación inicial es la óptima con la información a priori, puesto que es el MLE y es mejorada al introducir el modelo de MRF.

Nótese que a medida que aumenta el ruido aumenta el número de pixels etiquetados incorrectamente de la segmentación que proporciona el algoritmo ICM, aunque éste mantiene su capacidad de mejorar la segmentación respecto a la inicial incluso cuando aumenta el ruido.

Algoritmo HCF. En este caso no se toma ninguna imagen como inicialización puesto que el HCF no la precisa ya que se inicializan todos los pixels de la imagen con la etiqueta 'en espera'. Se pueden realizar varias observaciones:

1. al igual que en el ICM a medida que aumenta el ruido aumenta (o la señal disminuye) el número de pixels etiquetados incorrectamente,

2. a diferencia del ICM cuando el ruido aumenta hasta el nivel del caso 7, el HCF no mantiene su capacidad de mejorar el etiquetado respecto al MLE,

3. cuando el ruido es importante (caso 7) se produce una tendencia a que en la segmentación final desaparezcan regiones pequeñas. Esto es así porque la diferencia de probabilidad debida al nivel de gris de la imagen de entrada disminuye si las medias se aproximan, y por tanto su influencia en 
la decisión de qué etiqueta asignar también, adquiriendo mayor influencia en la energía la parte debida al modelo de campo aleatorio de Markov. Como este modelo tiende a priorizar similitud entre vecinos el resultado es generar regiones grandes a costa de desaparecer otras cuyo extremo es la segmentación de la imagen en una sola región. Aunque en ICM el modelo de campo aleatorio de Markov es el mismo, esto no ocurre porque en el procedimiento de segmentación se parte de una inicialización donde todos los pixels tienen una etiqueta y en promedio hay las mismas erróneas en un sentido como en otro.

Como conclusión sobre la imagen cuacir, el HCF y el ICM alcanzan segmentaciones similares si la relación señal ruido es alta pero en HCF la segmentación empeora si la relación señal ruido disminuye.

Algoritmo BHCF. En este caso al igual que en HCF no se toma inicialización alguna puesto que no la precisa. El tamaño de bloque elegido, en número de pixels, es del 5\% del número total de pixels de la imagen. Comparando estos resultados con los del HCF se aprecia que mejoran substancialmente y mantienen la capacidad de mejorar la segmentación incluso en el caso 7, haciendo menos probable que la imagen sea etiquetada toda con la misma etiqueta, debido a la modificación propuesta de procesar por bloques. No obstante, los resultados del ICM son mejores que los del BHCF.

\section{Imagen formas}

Para el caso multietiqueta sobre la imagen formas, se ha procedido de igual manera que con la imagen cuacir. En las figuras 3.11 y 3.12 se presentan las imágenes resultantes para los ocho casos y en la tabla 3.5 aparecen los porcentajes de pixels etiquetados incorrectamente.

\begin{tabular}{|c|c|c|c|c|c|c|c|c|}
\hline caso & 0 & 1 & 2 & 3 & 4 & 5 & 6 & 7 \\
\hline \hline MLE & 4.17 & 5.32 & 9.72 & 12.79 & 19.27 & 28.0 & 34.44 & 44.92 \\
\hline ICM & 0.0 & 0.13 & 0.03 & 0.17 & 0.33 & 0.60 & 1.59 & 6.61 \\
\hline HCF & 0.0 & 0.13 & 0.03 & 0.23 & 0.63 & 0.63 & 18.24 & 28.40 \\
\hline BHCF & 0.0 & 0.13 & 0.03 & 0.33 & 0.63 & 0.63 & 4.83 & 18.21 \\
\hline
\end{tabular}

Tabla 3.5: Porcentaje de pixels etiquetados incorrectamente (ei) con los diferentes algoritmos sobre la imagen formas.

Algoritmo ICM. De nuevo el algoritmo alcanza una segmentación que reduce significativamente el número de pixels etiquetados incorrectamente respecto a la 


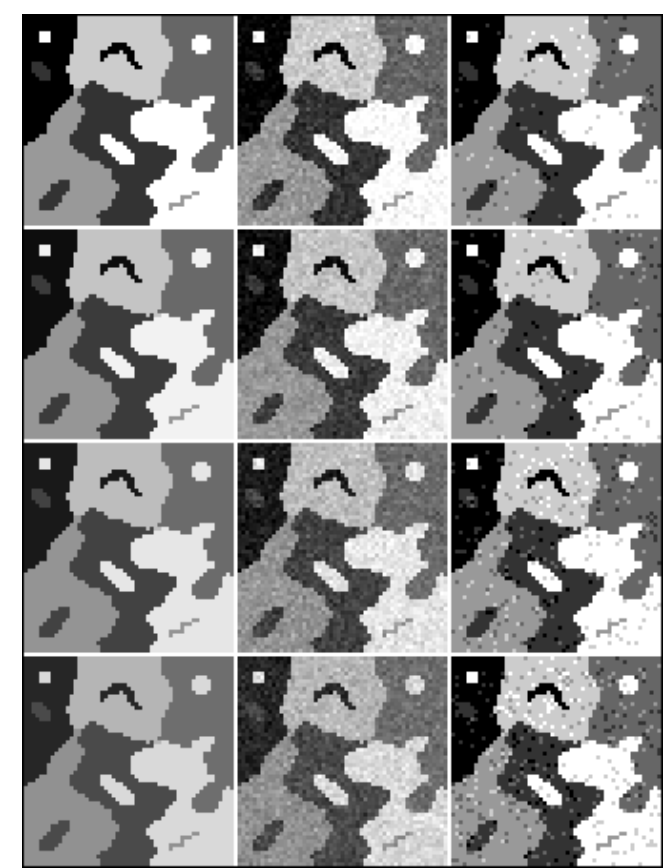

a) sin ruido, con ruido, MLE

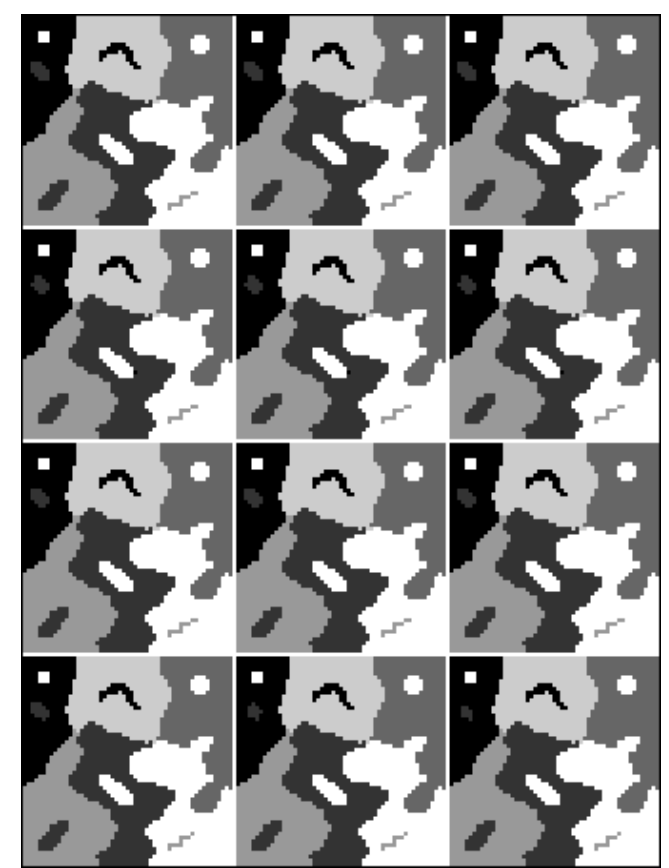

b) ICM, HCF, BHCF

Figura 3.11: Resultados de los cuatro primeros casos de la imagen formas; a) la primera columna de $a$ corresponde a las imágenes sin ruido, la segunda columna a las imágenes con ruido y la tercera al etiquetado según la estimación de máxima verosimilitud (MLE); b) primera columna resultado del etiquetado alcanzado con ICM, segunda columna con HCF y tercera columna con BHCF. 


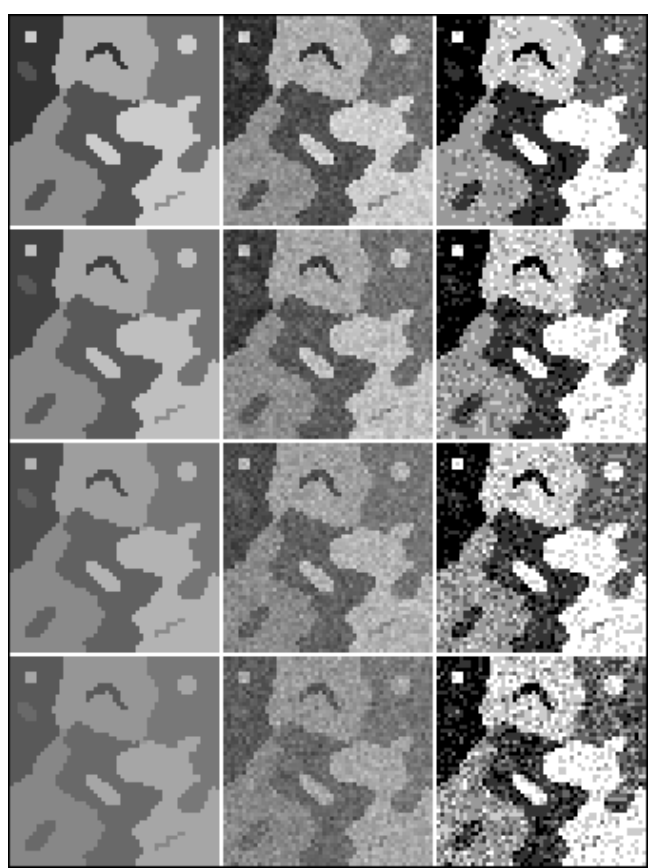

a) sin ruido, con ruido, MLE

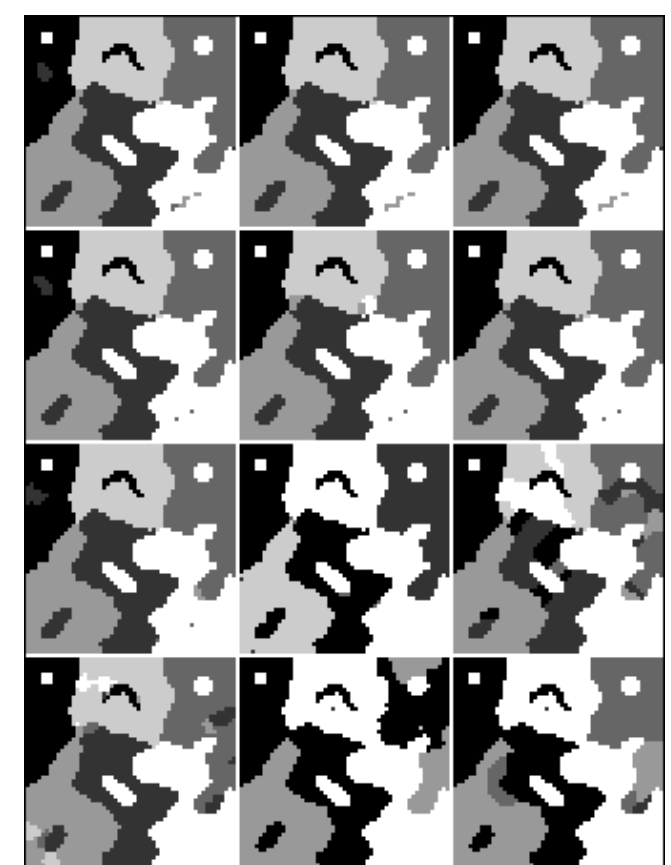

b) ICM, HCF, BHCF

Figura 3.12: Resultados de los cuatro segundos casos de la imagen formas; a) la primera columna de $a$ corresponde a las imágenes sin ruido, la segunda columna a las imágenes con ruido y la tercera al etiquetado según la estimación de máxima verosimilitud (MLE); b) primera columna resultado del etiquetado alcanzado con ICM, segunda columna con HCF y tercera columna con BHCF. 


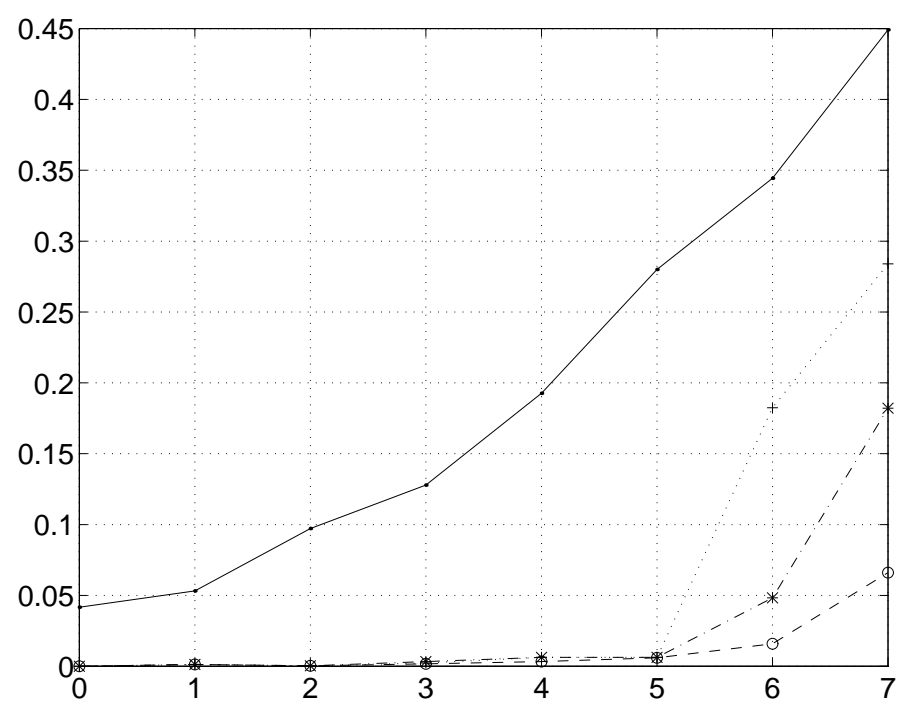

Figura 3.13: Gráfica con los ratios de pixels etiquetados incorrectamente de los casos presentados en la tabla 3.5. La curva de trazo continuo corresponde al MLE, en trazo discontinuo y con 'o' el ICM, en trazo de puntos y con '+' el $\mathrm{HCF}$; y en trazo de puntos y rayas y con ' ${ }^{*}$ ' el BHCF.

segmentación inicial, que es la óptima con la información a priori, puesto que es el MLE. En general los porcentajes de pixels etiquetados incorrectamente son menores en la imagen formas que en la imagen cuacir dado que aún siendo la diferencia de medias entre dos regiones consecutivas la misma que la diferencia entre las medias de la imagen cuacir como en la imagen formas las regiones no todas tienen medias consecutivas la diferencia entre dos regiones vecinas puede ser mayor que la diferencia existente entre los dos tipos de región de la imagen cuacir y por tanto es lógico que el etiquetado sea mejor.

Algoritmo HCF. Comparando los resultados con el algoritmo ICM, el HCF alcanza segmentaciones iguales o peores en todos los casos. Las diferencias más significativas se alcanzan cuando el nivel de ruido aumenta, llegando incluso a etiquetar todos los pixels de varias regiones incorrectamente. En este caso de la imagen formas no se llega a asignar a toda la imagen la misma etiqueta. La razón es la misma que se ha comentado más arriba y que justifica unos porcentajes de pixels etiquetados incorrectamente menores en general en la imagen formas respecto a la imagen cuacir.

Algoritmo BHCF. A la vista de las imágenes y de los resultados de la tabla 3.5 se puede ver que los resultados mejoran respecto al HCF cuando los niveles de ruido son significativos. La diferencia más apreciable está en la región 
grande superior derecha donde el HCF etiqueta incorrectamente gran parte de ella mientras que el $\mathrm{BHCF}$ lo hace correctamente, por tanto nuestra propuesta de modificación de HCF es efectiva respecto a éste, aunque como conclusión final el algoritmo que mejores resultados obtiene es el ICM.

En el caso multinivel ocurre algo que es previsible. Los pixels de las zonas fronterizas entre regiones de nivel de gris más parecido quedan peor etiquetadas que las zonas fronterizas entre regiones de nivel de gris menos parecido, y si una de las regiones es pequeña el efecto se acentúa porque incluso puede llegar a desaparecer. Un ejemplo de ello son las dos regiones pequeñas que están dentro de la región negra de la esquina superior derecha. En la última fila de la figura 3.12 se puede apreciar que la región pequeña blanca sobrevive mientras que la gris, cuya diferencia con el negro es menor, desaparece. 


\section{Capítulo 4}

\section{Morfología Matemática}

\subsection{Introducción}

En el capítulo dedicado a la segmentación de imágenes haciendo uso de los campos aleatorios se ha llamado a la imagen de partida observación. Dicha observación puede corresponder a la digitalización directa de la escena a segmentar o puede ser una transformación de la misma. En nuestro trabajo utilizaremos la segunda opción. El motivo es que no se pretende segmentar la imagen mamográfica como tal, sino segmentar para detectar zonas muy específicas, las microcalcificaciones, y para ello es más útil partir de una transformación que resalte éstas frente a todo aquello que no tiene interés en el problema y que podría ser una fuente de falsas alarmas. Dado que las zonas a detectar, como se expondrá con más detalle en posteriores capítulos, tienen como primera característica que son pequeñas, las transformaciones que se busca aplicar a la mamografía deberán ser del tipo paso alto. Para implementar la transformación, en principio, se puede hacer uso de cualquier técnica. Como se ha visto en la revisión bibliográfica, en la literatura hay ejemplos de muchos tipos. En el presente trabajo dicha transformación se va a implementar con técnicas no lineales basadas en morfología matemática.

La morfología matemática es desarrollada a partir de los años 60 por los trabajos de G. Matheron y J. Serra, siendo una técnica aplicable a muchos problemas de tratamiento de señales y entre éstas las imágenes.

En este capítulo se realiza una presentación de las herramientas de morfología matemática utilizadas para nuestra aplicación. Para el lector que quiera profundizar sobre morfología matemática encontrará un análisis exhaustivo en las obras de J. Serra [109][110] y de Matheron [80] [81]. Los operadores están en su fundamentación teórica íntimamente ligados a los conjuntos y funciones. 
Nuestras necesidades se limitan a su aplicación a imágenes, en concreto bidimensionales. Las imágenes están definidas sobre el espacio euclidiano discreto $\mathcal{Z}^{2}$ y pueden ser binarias o de niveles de gris, según las siguientes definiciones:

Definición 8 (Imagen binaria) Una imagen binaria $I$ es una aplicación de un subconjunto $\mathcal{D}_{I}$ de $\mathcal{Z}^{2}$, llamado dominio de definición de I, en el par $\{0,1\}$ :

$$
\begin{aligned}
& I: \mathcal{D}_{I} \quad \mathcal{Z}^{2} \rightarrow\{0,1\} \\
& p \rightarrow I(p)
\end{aligned}
$$

Cada elemento $p$, del subconjunto $\mathcal{D}_{I}$ donde está definida la imagen se llama pixel. Cuando se trata de imágenes binarias, generalmente van asociadas a escenas donde hay un fondo y uno o varios objetos del mismo tipo, es decir dos clases. Consecuentemente a cada pixel de la imagen se le asigna uno de los dos valores posibles, $\{0,1\}$, según pertenezca a una clase u otra. El enfoque de la teoría de conjuntos de la morfología matemática se aplica directamente a las imágenes binarias sin más que considerar la imagen binaria $I$ como el conjunto de pixels con valor 1 , es decir $\left\{p \in \mathcal{D}_{I}, I(p)=1\right\}$, que a su vez es un subconjunto del espacio $\mathcal{D}_{I}$ en el que está definida. La relación de orden es la inclusión.

Definición 9 (Imagen de niveles de gris) Una imagen de niveles de gris I es una aplicación de un subconjunto $\mathcal{D}_{I}$ de $\mathcal{Z}^{2}$, llamado dominio de definición de $I$, en $\mathcal{Z}$ :

$$
\begin{array}{cl}
I: \mathcal{D}_{I} & \mathcal{Z}^{2} \rightarrow \mathcal{Z} \\
p \rightarrow & I(p)
\end{array}
$$

Así como a las imágenes binarias se les puede aplicar la teoría de conjuntos, a las imágenes de niveles de gris se aplica la teoría de funciones. Las dos definiciones anteriores se pueden hacer en el espacio de los números reales $I: \mathcal{D}_{I} \quad \mathcal{R}^{2} \rightarrow \mathcal{R}$ pero las imágenes que se usan en la práctica están definidas sobre un dominio finito discreto y generalmente son rectangulares. Tanto pedagógicamente como matemáticamente, es útil interpretar las dos dimensiones del dominio de definición de la imagen junto con la dimensión del nivel de gris que puede tomar cada pixel para formar un relieve tridimensional donde la altura de cada punto es proporcional a su nivel de gris. En ocasiones este relieve tridimensional conviene descomponerlo en un conjunto de cortes de nivel con planos horizontales para formar imágenes binarias con fondo y objeto (ver figura 4.1). Esta descomposición en imágenes binarias sirve como nexo para poder utilizar también la teoría de conjuntos sobre las imágenes de niveles de gris. En la descomposición cada imagen binaria corresponde al resultado de la función umbral a un determinado nivel de gris $t$, definida como:

$$
U_{t}(f)= \begin{cases}1 & \text { si } f(x) \geq t \\ 0 & \text { si } f(x)<t\end{cases}
$$


donde $f(\cdot)$ es la imagen, $x$ representa los elementos que pertenecen al dominio donde está definida la imagen y $t$ representa un nivel de gris. Alternativamente la imagen binaria se puede definir únicamente como el conjunto de pixels de valor 1, así pues la función umbral se puede definir también como:

$$
U_{t}(f)=\{x \mid f(x) \geq t\}
$$

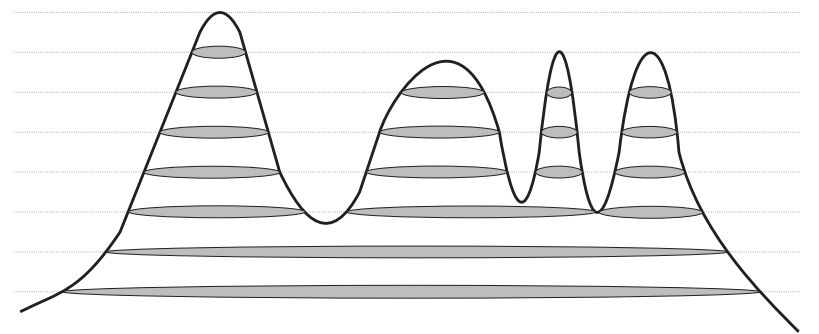

Figura 4.1: Relieve tridimensional y cortes con planos horizontales para formar imágenes binarias en cada nivel de gris.

De este espacio tridimensional se define subgrafo SG (ver figura 4.2) de una imagen de niveles de gris como la parte del espacio tridimensional que está debajo de la superficie que define la función. Si llamamos $t$ a la variable que representa la altura, $x$ a un elemento de $D_{I}$, y $f$ a la función o imagen de niveles de gris, entonces:

$$
S G(f)=\left\{(x, t) \in \mathcal{Z}^{2} \times \mathcal{Z}, t \leq f(x)\right\}
$$

Para las funciones el orden se establece así:

Sean $f$ y $g$ dos funciones o imágenes de niveles de gris

$$
\forall(f, g) \in \mathcal{F}\left(\mathcal{R}^{2}, \mathcal{R}\right)^{2}, \quad f \leq g \Longleftrightarrow \forall x \in \mathcal{R}^{2}, f(x) \leq g(x)
$$

\subsubsection{Celosía y Vecindario}

Las imágenes que se acaban de definir están compuestas por elementos o pixels dispuestos de forma no arbitraria. La disposición de los mismos obedece normalmente a cierto patrón regular a lo largo del dominio bidimensional. Además, esta disposición geométrica de los pixels junto con la relación que les une forman la celosía $\mathcal{S}$. Alternativamente a esta palabra en otros textos se utiliza trama, retícula o malla. La utilización de la palabra celosía se corresponde con el significado que se le da a la palabra lattice en las referencias sobre campos aleatorios de Markov citadas en el capítulo $3^{1}$.

\footnotetext{
${ }^{1}$ Otras definiciones diferentes de lattice, basadas en conceptos de álgebra se pueden encontrar en $[109,110,11]$
} 


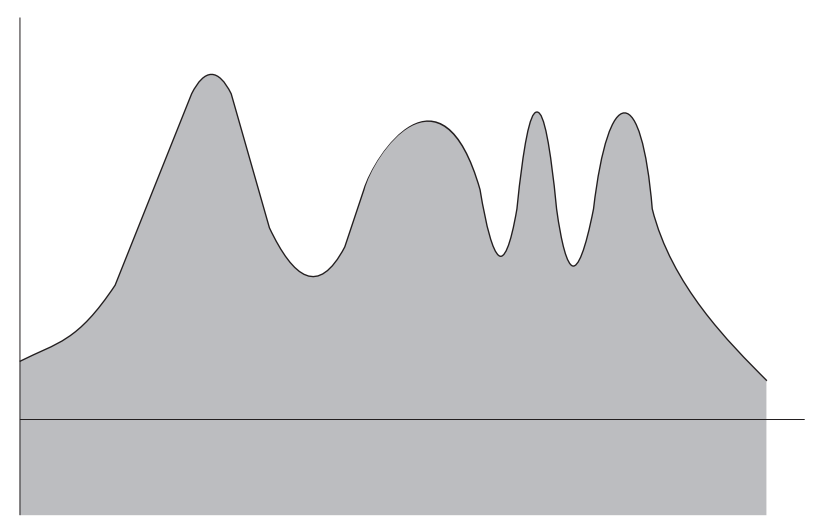

Figura 4.2: Subgrafo de un función.

En nuestro caso una forma posible de construir la celosía es situar cada uno de los elementos de cada dimensión separados una distancia constante en dos ejes perpendiculares y los pixels son todas las combinaciones posibles de pares de elementos, uno de cada dimensión. La celosía que formaría el dominio de la imagen sería el conjunto de puntos de la figura $4.3 a$. Se puede observar que el patrón geométrico de distribución es rectangular.

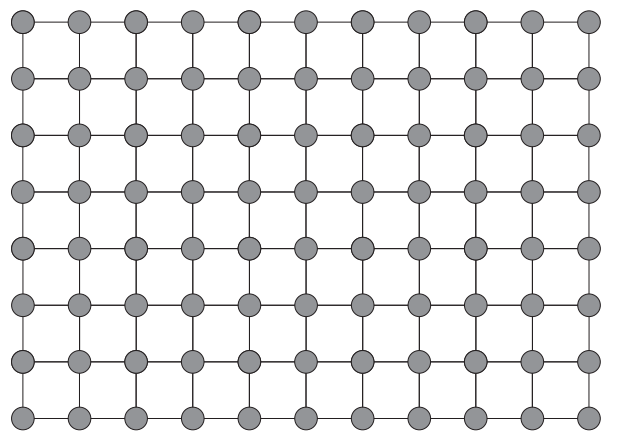

a) conectividad a 4

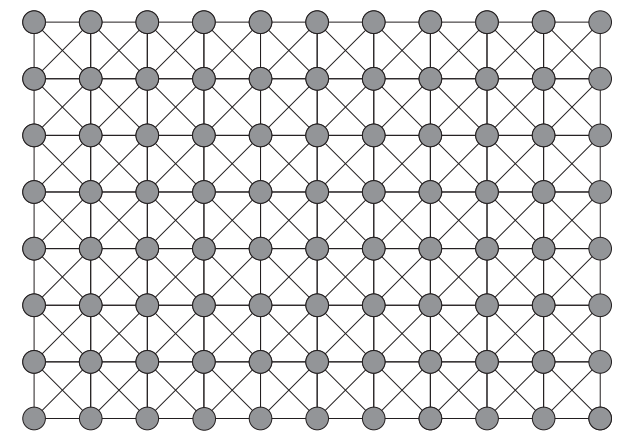

b) conectividad a 8

Figura 4.3: Ejemplos de celosía rectangular. a) Conectividad a 4. b) Conectividad a 8

Asimismo, en la figura 4.3 se puede observar que si nos fijamos en un pixel, del resto de pixels de la imagen hay unos que están más próximos que otros. De la misma manera que en el capítulo sobre campos aleatorios de Markov se define el concepto de vecindario, en las imágenes utilizadas en Morfología Matemática también es aplicable dicha definición, en cuanto que en primer lugar los vecinos de un pixel son un subconjunto de pixels, en segundo lugar un pixel no es vecino de sí mismo y en tercer lugar si un pixel $p$ es vecino de un pixel $q$ entonces $q$ es vecino de $p$. Utilizando la misma notación que en el capítulo anterior diremos que $\eta_{p}$ es el conjunto de pixels que son vecinos del pixel $p$. 
Para la celosía rectangular se suele utilizar alternativamente dos tipo de vecindario. Uno consiste en considerar como vecinos los pixels de arriba, abajo, derecha e izquierda, con lo que cada pixel tiene cuatro vecinos. El otro tipo de vecindario considera además de estos cuatro, el superior derecho, el superior izquierdo, inferior derecho e inferior izquierdo, lo que supone un total de ocho. La figura $4.3 a$ y $b$ muestran respectivamente las celosías resultantes. Los círculos representan los elementos de la misma y los segmentos rectilíneos entre dos círculos significa que entre ellos existe una relación de ser vecinos mutuamente. Estos dos casos es lo que en el capítulo sobre los campos aleatorios se ha llamado vecindario de orden 1 y orden 2 respectivamente.

En Morfología Matemática se utiliza ampliamente otro tipo de celosía, la hexagonal, mostrada en la figura 4.4, donde cada pixel tiene seis vecinos. Tiene la ventaja de que es más isótropa porque la distancia de cualquier pixel a sus seis vecinos es más similar que en la trama rectangular con conectividad a 8 . Además de otros aspectos que más adelante se tratan. El inconveniente es que a la hora de almacenar y procesar una imagen en un sistema basado en microprocesador la estructura de acceso a las memorias está más adaptada para la celosía rectangular que para la hexagonal, de hecho cuando se necesita procesar sobre celosía hexagonal se implementa con celosía cuadrada donde en la mitad de las filas alternadamente hay n elementos y en la otra mitad $n+1$, con las relaciones de vecindad adecuadas para equivaler a celosía hexagonal.

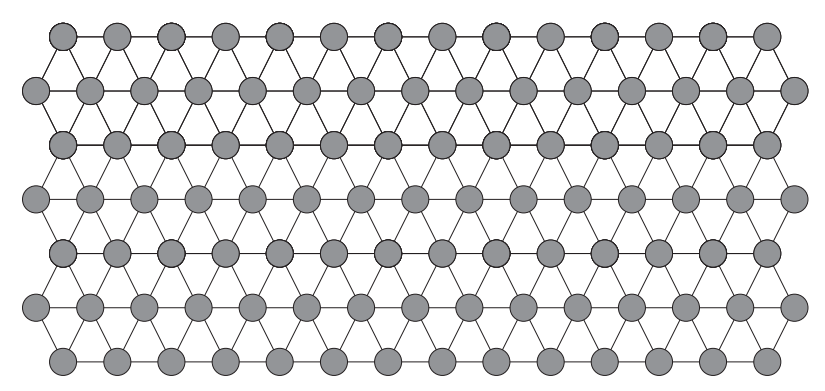

Figura 4.4: Celosía hexagonal.

En muchas ocasiones una imagen representa la proyección bidimensional de una escena tridimensional donde hay uno o varios objetos sobre un fondo. Por simplicidad tomemos el ejemplo de un sólo objeto sobre un fondo. Esta situación queda reflejada en la imagen como que un conjunto de pixels "pertenecen" al objeto y el resto pertenecen al fondo. La expresión coloquial de "pertenecer al objeto", es un concepto muy importante y formalmente corresponde a la definición de componente conexa que pasamos a definir. Para ello es conveniente definir primero lo que es un camino.

Definición 10 (Camino) Un camino $C$, de longitud $l(C)=n$, entre dos pixels 
p y q en la celosía $S$ es una $(n+1)$ tupla $\left(p_{0}, p_{1}, \ldots, p_{n}\right)$ de pixels tal que:

$$
\begin{gathered}
p_{0}=p \text { y } p_{n}=q \\
\forall i \in[1, n], \quad p_{i} \in \eta_{p_{i-1}}
\end{gathered}
$$

Definición 11 (Componente conexa) Sea $A$ un conjunto de pixels incluido en el dominio $\mathcal{D}_{I}$ donde está definida la imagen binaria $I$ y $x$ un pixel de $A$. La componente conexa de $A$ que contiene a $x, C_{x}(A)$ es la unión de los caminos con origen $x$ incluidos en $A$.

Se dirá también que dos pixels $p$ y $q$ son conexos en $A$ si existe un camino con extremos en $p$ y $q$ que esté incluido en $A$.

Intuitivamente una componente conexa es un conjunto de pixels donde todos ellos mantienen una relación de vecindad con al menos uno de los restantes pixels de conjunto. La figura 4.5 a muestra una imagen, suponiendo conectividad a 4 , con tres objetos formando tres componentes conexas. Sería de esperar que el resto de los pixels de la imagen, que corresponden al fondo, formaran una única componente conexa, pero queda dividido en tres. Este problema tiene solución si se permite conectividad a 8 en el fondo (figura 4.5b). Alternativamente si se asume conectividad a 8 en la imagen los tres objetos forman una misma componente conexa, es decir un único objeto y el fondo también forma una única componente conexa, cuando sería de esperar que un objeto como el de la figura dividiera el fondo en tres componentes conexas, ver figura $4.5 c$. El efecto esperado para este caso se consigue tomando conectividad a 8 para los objetos y conectividad a 4 para el fondo, tal como ilustra la figura $4.5 d$. La celosía hexagonal no adolece de este problema como se puede ver en la figura 4.5e, donde para el objeto y para el fondo la conectividad es la misma y no existe ningún tipo de paradoja.

\subsection{Transformaciones morfológicas básicas}

Antes de pasar a las transformaciones morfológicas, aplicadas sobre $\mathcal{P}\left(\mathcal{R}^{2}\right)$, y definidas como,

$$
\text { en } \mathcal{R}^{2} \quad\left(\mathcal{T}: \mathcal{P}\left(\mathcal{R}^{2}\right) \longrightarrow \mathcal{P}\left(\mathcal{R}^{2}\right)\right)
$$

es útil definir algunas propiedades que suelen cumplir y que son extensividad, creciente, idempotencia y dualidad. 


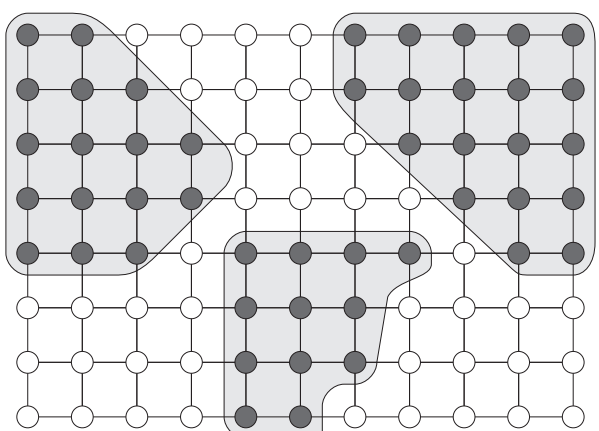

a)

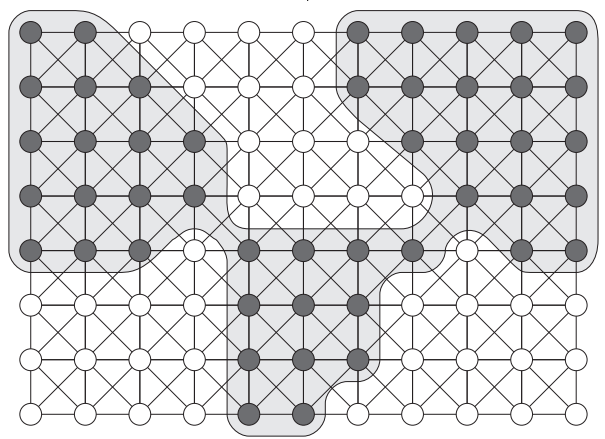

c)

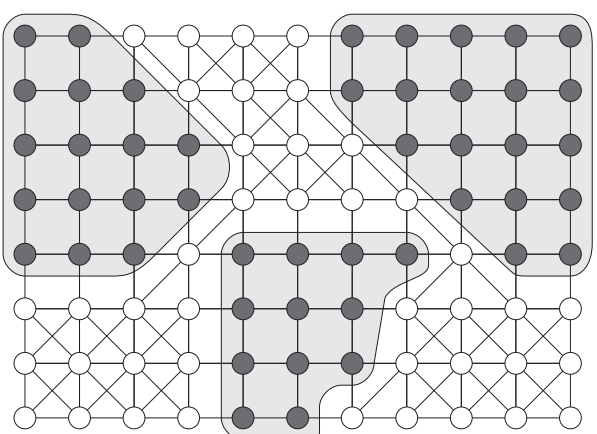

b)

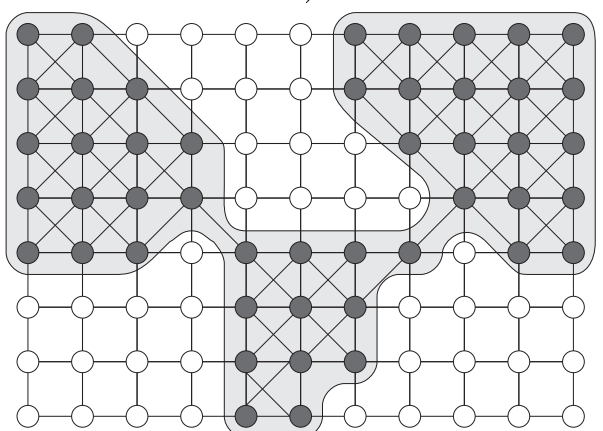

d)

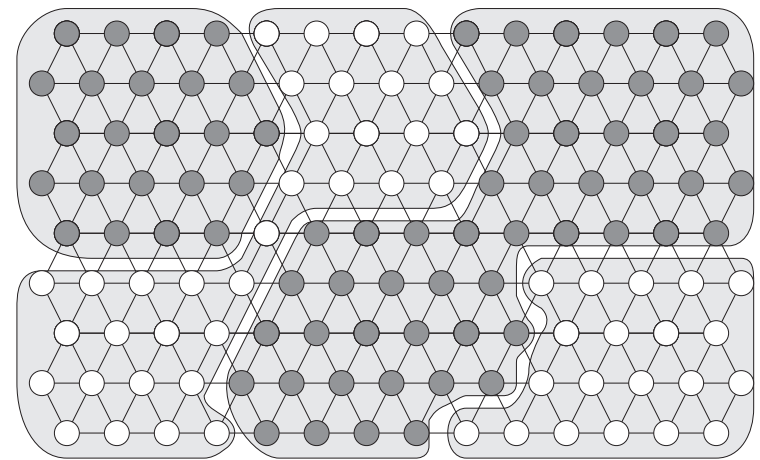

e)

Figura 4.5: Componentes conexas. a) Celosía rectangular con conectividad a 4 . Los pixels objeto forman tres componentes conexas distintas y también el fondo queda dividido en tres componentes conexas. b) Considerando conectividad a 8 para el fondo, éste forma una única componente conexa. c) Con conectividad a 8 hay una única componente para el objeto y otra para el fondo superponiéndose en algunas zonas. d) No hay superposición si se considera conectividad a 4 para el fondo, quedando dividido en tres componentes conexas. e) Celosía hexagonal. En este caso existe coherencia para objeto y fondo manteniendo para ambos la misma conectividad a 6 . 
Una transformación es extensiva si y sólo si su salida es siempre mayor que su entrada. Para el caso binario,

$$
\forall X \in \mathcal{P}\left(\mathcal{R}^{2}\right), \quad X \subseteq \mathcal{T}(X)
$$

y para el caso de niveles de gris,

$$
\forall f \in \mathcal{F}, \quad f \leq \mathcal{T}(f)
$$

de la misma forma es anti-extensiva si y sólo si su salida es siempre menor que su entrada

$$
\forall X \in \mathcal{P}\left(\mathcal{R}^{2}\right), \quad X \supseteq \mathcal{T}(X)
$$

$\mathrm{O}$

$$
\forall f \in \mathcal{F}, \quad f \geq \mathcal{T}(f)
$$

La transformación $\mathcal{T}$ será creciente si para dos entradas ordenadas sus salidas siguen estando ordenadas, es decir:

$$
\forall X, Y \in \mathcal{P}\left(\mathcal{R}^{2}\right), \quad X \subseteq Y \Rightarrow \mathcal{T}(X) \subseteq \mathcal{T}(Y)
$$

$\mathrm{O}$

$$
\forall f, g \in \mathcal{F}, \quad f \leq g \Rightarrow \mathcal{T}(f) \leq \mathcal{T}(g)
$$

de la misma manera es decreciente en caso contrario:

$$
\forall X, Y \in \mathcal{P}\left(\mathcal{R}^{2}\right), \quad X \supseteq Y \Rightarrow \mathcal{T}(X) \subseteq \mathcal{T}(Y)
$$

$\mathrm{O}$

$$
\forall f, g \in \mathcal{F}, \quad f \geq g \Rightarrow \mathcal{T}(f) \leq \mathcal{T}(g)
$$

Respecto a la siguiente propiedad, una transformación $\mathcal{T}$ será idempotente si el resultado de aplicarla concatenadamente varias veces es el mismo que al aplicarla una sola vez,

$$
\forall X \in \mathcal{P}\left(\mathcal{R}^{2}\right), \quad \mathcal{T}(\mathcal{T}(X))=\mathcal{T}(X)
$$

O

$$
\forall f \in \mathcal{F}, \quad \mathcal{T}(\mathcal{T}(f))=\mathcal{T}(f)
$$

En imágenes binarias se define el complementario.

Definición 12 (Complementario) Sea $X$ el conjunto de pixels de la imagen que tienen valor $1, D_{I}$ el dominio donde está definida la imagen y $E$ el conjunto que abarca la totalidad de elementos del dominio de la imagen, el complementario de $X$ denotado como $X^{c}$ es tal que:

$$
X \cap X^{c}=\emptyset \quad y \quad X \cup X^{c}=E
$$


En el caso de funciones el complementario de $f(x)$ se corresponde con la inversión: $-f(x)$; si se está utilizando un conjunto de valores positivos, por ejemplo entre 0 y $G$ la inversión se define como $G-f(x)$.

Finalmente, dos transformaciones $\mathcal{T}_{1}, \mathcal{T}_{2}$, serán duales si y sólo si el complementario del resultado de $\mathcal{T}_{1}$ sobre la entrada es el mismo que el resultado de aplicar $\mathcal{T}_{2}$ sobre el complementario de la entrada:

$$
\forall X \in \mathcal{P}\left(\mathcal{R}^{2}\right), \quad \mathcal{T}_{1}(X)^{c}=\mathcal{T}_{2}\left(X^{c}\right)
$$

$\mathrm{O}$

$$
\forall f \in \mathcal{F}, \quad-\mathcal{T}_{1}(f)=\mathcal{T}_{2}(-f)
$$

\subsubsection{Erosión y Dilatación}

Las dos transformaciones más comunes de la morfología matemática, y que son la base de muchas otras transformaciones morfológicas son la erosión y la dilatación [109]. A continuación se presentan las definiciones con la notación que se utilizará durante el resto del texto. Consideremos en $\mathcal{R}^{2}$ un punto arbitrario $O$ y llamémosle origen, y sea $B \in \mathcal{P}\left(\mathcal{R}^{2}\right)$ un conjunto, denotaremos como el conjunto simétrico traspuesto $\breve{B}$ respecto al origen $O$, como:

$$
\breve{B}=\{-x, x \in B\}
$$

y $B_{a}$ a la traslación de $B$ por el vector $a$, con $a \in \mathcal{R}^{2}$ :

$$
B_{a}=\{x+a, x \in B\}
$$

consideremos también un conjunto $X \in \mathcal{R}^{2}$.

Definición 13 (Dilatación) La dilatación de $X$ por $B$ es el conjunto de los $x$ de $\mathcal{R}^{2}$ tal que la intersección de $X$ y $B_{x}$ no es el conjunto vacío. Denotaremos esta operación con $\delta_{B}(X)$ :

$$
\delta_{B}(X)=\left\{x \in \mathcal{R}^{2}, B_{x} \cap X \neq \emptyset\right\}
$$

a B se le llama elemento estructurante.

Definición 14 (Erosión) De la misma manera la erosión de $X$ por $B$ es el conjunto de los $x$ de $\mathcal{R}^{2}$ tal que $B_{x}$ está totalmente incluido en $X$ :

$$
\epsilon_{B}(X)=\left\{x \in \mathcal{R}^{2}, B_{x} \quad X\right\}
$$




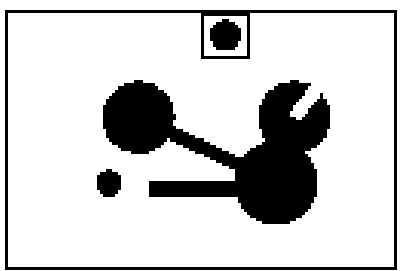

a) Original

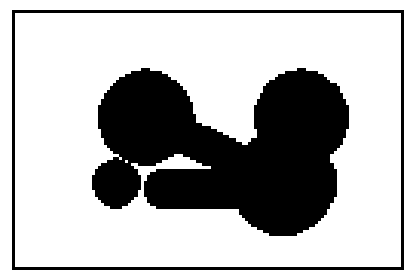

b) Dilatación

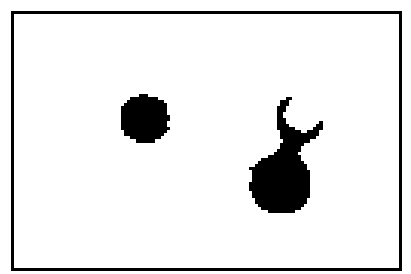

b) Erosión

Figura 4.6: Dilatación y erosión de una imagen binaria. El elemento estructurante utilizado está recuadrado en la imagen original.

en muchos textos se utiliza respectivamente para estas dos operaciones la notación introducida por Minkowski, $\oplus, \ominus$, puesto que la dilatación (respectivamente la erosión) es equivalente a la adición (respectivamente la sustracción) de Minkowski de $X$ y $\breve{B}$.

El efecto que la dilatación produce es un agrandamiento de los objetos de la imagen, mientras que la erosión los reduce, llegando a eliminarlos si el elemento estructurante no cabe en ellos.

En el caso de funciones o imágenes de niveles de gris, si $B$ es un elemento estructurante plano, la dilatación de la función $f$ en el punto $x$ es el valor máximo de la función $f$ dentro de la ventana de observación definida por $B$ desplazado de manera que el origen de $B$ esté centrado en $x$ :

$$
\delta_{B}(f)(x)=\max \left\{x_{k}, k \in B\right\}
$$

donde $x_{k}$ es el valor que toma la imagen en el punto $x+k$, es decir $f(x+k)$ Igualmente, la erosión se define como:

$$
\epsilon_{B}(f)(x)=\min \left\{x_{k}, k \in B\right\}
$$

En la utilización que nosotros hacemos de la erosión y la dilatación siempre hacemos uso de elementos estructurantes planos, no obstante si $B$ es no plano la definición de dilatación (resp. erosión) se corresponde con la adición (resp. sustracción) de Minkowski.

Las propiedades más importantes de la dilatación y la erosión son que ambas transformaciones son crecientes, y que si el origen del elemento estructurante está contenido en él mismo, entonces, son extensivas y anti-extensivas respectivamente. Ambas funciones son además duales, de manera que:

$$
\delta_{B}(X)^{c}=\epsilon_{B}\left(X^{c}\right)
$$

Tanto la erosión como la dilatación no son idempotentes. Aplicar sucesivas veces la erosión por ejemplo a imágenes binarias va reduciendo iterativamente la 


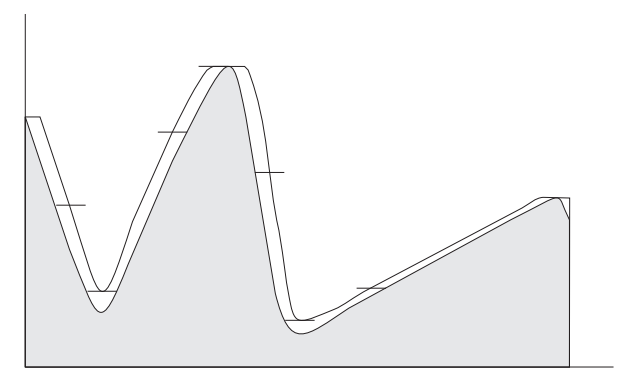

a) Dilatación

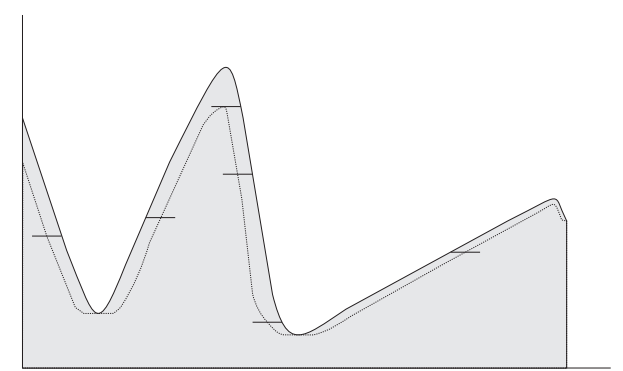

b) Erosión

Figura 4.7: Dilatación y erosión de una función por un elemento estructurante plano.

cantidad de pixels pertenecientes a los objetos de la imagen.

$$
\delta_{B}(X) \neq \delta_{B}\left(\delta_{B}(X)\right), \quad \epsilon_{B}(X) \neq \epsilon_{B}\left(\epsilon_{B}(X)\right)
$$

\subsubsection{Apertura y Cierre}

La combinación mediante la aplicación concatenada de dos erosiones sucesivas o dos dilataciones sucesivas no aporta ningún operador conceptualmente nuevo, pero sí se obtienen operadores interesantes si se combinan mediante la aplicación concatenada erosión con dilatación o viceversa, llamadas respectivamente apertura y cierre $^{2}$.

Definición 15 (Apertura) La apertura de un conjunto $X$ por un elemento estructurante $B$, denotada por $\gamma_{B}(X)$, se define como:

$$
\gamma_{B}(X)=\delta_{B}\left(\epsilon_{\breve{B}}(X)\right)
$$

lo que significa que primero se realiza una erosión y al resultado de la misma se realiza la dilatación. Si el elemento estructurante es simétrico, entonces la transposición del elemento estructurante no produce ningún cambio y se puede poner que $\gamma_{B}(X)=\delta_{B}\left(\epsilon_{B}(X)\right)$.

La apertura cumple, entre otras, las siguientes dos propiedades [109]:

$$
\begin{aligned}
\text { creciente }: & X \leq Y \Longleftrightarrow \gamma(X) \leq \gamma(Y) \\
\text { anti-extensiva }: & \gamma(X) \leq X
\end{aligned}
$$

\footnotetext{
${ }^{2}$ En ocasiones también se utilizan directamente los nombres originales en francés ouverture, fermeture. En inglés open, close o también opening, closing.
} 
Definición 16 (Cierre) De igual manera, el cierre de un conjunto $X$ por un elemento estructurante $B$, denotado por $\varphi_{B}(X)$, se define como:

$$
\varphi_{B}(X)=\epsilon_{B}\left(\delta_{\breve{B}}(X)\right)
$$

lo que significa que primero se realiza una dilatación y sobre el resultado de la misma se realiza la erosión. Si el elemento estructurante es simétrico, entonces la transposición del mismo no produce ningún cambio y se puede poner que $\varphi_{B}(X)=\epsilon_{B}\left(\delta_{B}(X)\right)$.

El cierre cumple, entre otras, las siguientes dos propiedades [109]:

$$
\begin{aligned}
\text { creciente }: & X \leq Y \Longleftrightarrow \varphi(X) \leq \varphi(Y) \\
\text { extensiva }: & \varphi(X) \geq X
\end{aligned}
$$

Las expresiones 4.32 y 4.35 establecen el siguiente ordenamiento parcial:

$$
\gamma(X) \leq X \leq \varphi(X)
$$

Ambas definiciones se extienden a las funciones. Por brevedad, en ocasiones se simplificará la notación de la concatenación de funciones, de manera que una sucesión de transformaciones tal como $\mathcal{T}_{B}^{1}\left(\mathcal{T}_{B}^{2}\left(\ldots \mathcal{T}_{B}^{n}(X)\right)\right)$ se escribirá como $\mathcal{T}_{B}^{1} \mathcal{T}_{B}^{2} \ldots \mathcal{T}_{B}^{2}(X)$, e incluso se eliminará de la notación el elemento estructurante y/o la entrada $X$.

De la misma manera que la pareja erosión-dilatación son duales también lo son la pareja apertura-cierre, de forma que:

$$
\gamma_{B}(X)^{c}=\varphi_{B}\left(X^{c}\right)
$$

y a diferencia de la erosión y la dilatación, la apertura y el cierre son idempotentes.

Demostración:

llamemos $X_{1}$ a la apertura de $X, X_{1}=\delta \epsilon(X)$, como la apertura es antiextensiva (4.32) $X_{1} \leq X$; si aplicamos la erosión a ambos miembros de la inecuación, como esta operación es creciente se mantiene el orden y queda

$$
\epsilon \delta \epsilon(X) \leq \epsilon(X)
$$

por otra parte, llamemos $X_{2}$ a la erosión de $X, X_{2}=\epsilon(X)$, como el cierre es extensivo (4.35) tenemos $\epsilon \delta\left(X_{2}\right) \geq X_{2}$ y sustituyendo $X_{2}$ por la erosión de $X$ queda

$$
\epsilon \delta \epsilon(X) \geq \epsilon(X)
$$


que es la inecuación inversa de la anterior y por tanto:

$$
\epsilon \delta \epsilon=\epsilon
$$

si se aplica una dilatación a ambas partes de 4.40 y por ser creciente la dilatación, se cumple que $\delta \epsilon \delta \epsilon=\delta \epsilon$, quedando demostrada la idempotencia de la apertura, y por el procedimiento similar la idempotencia del cierre:

$$
\gamma \gamma=\gamma \quad \varphi \varphi=\varphi
$$

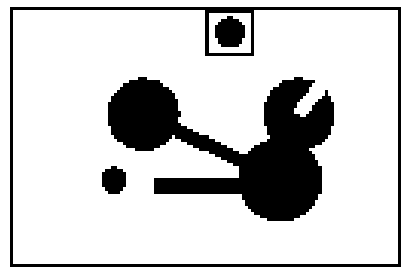

a) Original

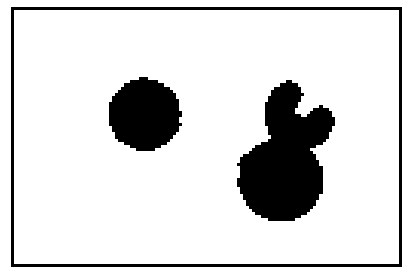

b) Apertura

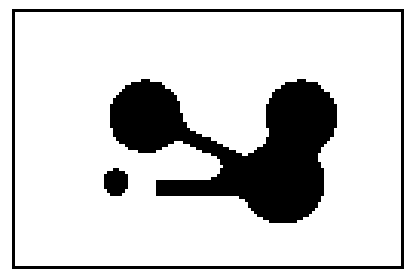

b) Cierre

Figura 4.8: Apertura y cierre de una imagen binaria. El elemento estructurante utilizado está recuadrado en la imagen original.

En el caso binario (ver figura 4.8), las dos operaciones tienden a suavizar los contornos de los objetos. La apertura elimina las convexidades, mientras que el cierre elimina las concavidades. Asimismo si un objeto tiene dos partes unidas por un istmo de tamaño menor que el elemento estructurante, la apertura separará dicho objeto en dos desconectándolos, mientras que si dos objetos están separados por un espacio de fondo menor que el elemento estructurante, el cierre une ambos objetos para formar uno único conectándolos. En el caso de las funciones o imágenes de niveles de gris, y a través del subgrafo, como la apertura elimina las convexidades, se traduce en la eliminación de los picos (positivos), y como el cierre elimina las concavidades, se traduce en la eliminación de los valles. En la figura 4.9 se muestra este proceder sobre una función unidimensional.

\subsubsection{Filtros morfológicos}

El concepto de filtro está muy extendido en tratamiento de señal clásico y básicamente se refiere a cualquier proceso que un sistema realiza sobre una o varias entradas para generar una o varias salidas. En los sistemas lineales el filtrado va asociado a la convolución de la entrada con una determinada función (continua o discreta) que caracteriza al sistema. En morfología matemática el término filtro tiene un significado muy preciso [109], sujeto a la siguiente definición: 


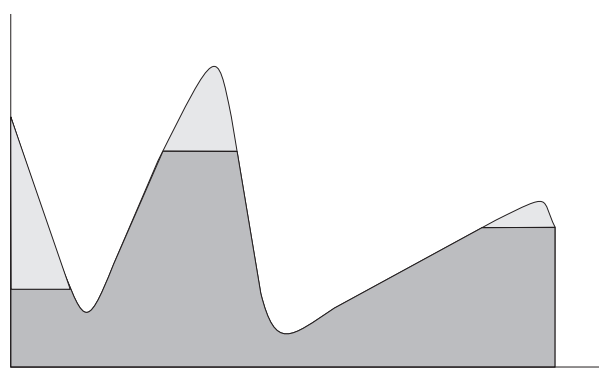

a) Apertura

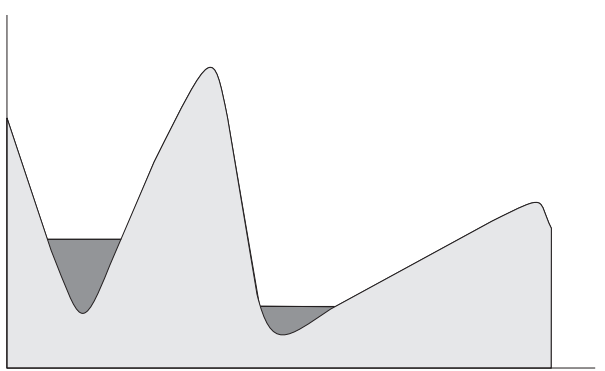

b) Cierre

Figura 4.9: Apertura y cierre de una función. En a) está en gris claro la parte de la función que elimina la apertura y en b) está en gris oscuro la parte que aparece debida al cierre.

Definición 17 (Filtro) Un filtro morfológico es una transformación $\mathcal{T}$ creciente e idempotente.

$$
\begin{gathered}
\forall f, g \in \mathcal{F}, \quad f<g \Rightarrow \mathcal{T}(f)<\mathcal{T}(g) \\
\forall f \in \mathcal{F}, \quad \mathcal{T}(\mathcal{T}(f))=\mathcal{T}(f)
\end{gathered}
$$

La propiedad creciente es la más importante porque permite mantener la ordenación de los conjuntos o funciones tras la operación de filtrado.

Las operaciones básicas de dilatación y erosión no son filtros morfológicos porque no son idempotentes, salvo en el caso particular de que el elemento estructurante sea un único punto o elemento, situación en que las transformaciones se reducen a la identidad. Sin embargo la combinación de ambas, la apertura y el cierre definidos antes, sí son filtros morfológicos porque cumplen ser crecientes e idempotentes. En general las combinaciones de aperturas y cierres dan lugar a filtros morfológicos, y da lugar a una familia de transformaciones interesantes según la combinación se realice concatenando las transformaciones (por ejemplo filtros alternados secuenciales) o realizando todas las transformaciones en paralelo sobre una misma función de entrada y combinando las salidas mediante el supremo o el ínfimo (por ejemplo el contraste morfológico, o el centro morfológico). En la figuras 4.10 se muestra el diagrama de bloques de una estructura paralelo y en la figura 4.11 se muestra un ejemplo en el que se pretenden extraer los elementos de la imagen con orientaciones horizontales y verticales. Las transformaciones son aperturas con elementos estructurantes en dichas orientaciones y el criterio para generar la salida es el supremo. En nuestro trabajo hacemos uso de una estructura paralela en relación con los tejidos fibrosos de la mamografía.

Concretamente para nuestro objetivo de la detección de microcalcificaciones es interesante obtener un filtro que detecte las estructuras lineales claras de la imagen para que no generen falsas alarmas. Se puede obtener particularizando 


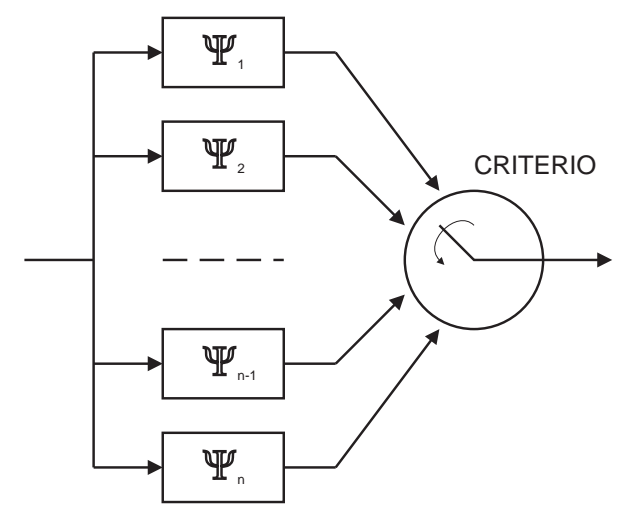

Figura 4.10: Filtros morfológicos por combinación de transformaciones en paralelo.

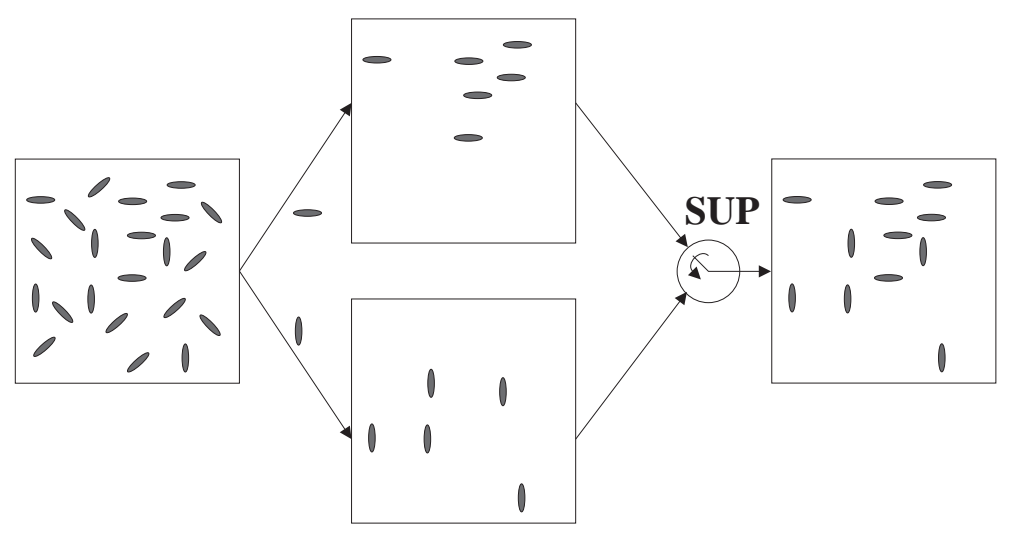

Figura 4.11: Ejemplo de aplicación de filtros morfológicos por combinación de transformaciones en paralelo. La transformación en su conjunto extrae de la imagen de entrada sólo las componentes con orientaciones horizontales y verticales, utilizando aperturas con elementos estructurantes en dichas orientaciones y combinando los resultados mediante el supremo. 
la estructura de transformaciones en paralelo a aperturas con elemento estructurante lineal cada una de ellas con una orientación distinta. El criterio de combinación es el supremo. En cada orientación particular la apertura genera a su salida una imagen con todo aquello donde ha cabido el elemento estructurante, por tanto aparecerán las estructuras grandes de la imagen junto con las estrechas lineales coincidentes con la orientación del elemento estructurante. Al combinar los distintos resultados de las transformaciones con el criterio de supremo la salida final de la transformación incluirá las estructuras lineales de la imagen en cualquier dirección.

\subsubsection{Residuos}

La teoría de filtros morfológicos resalta las propiedades de creciente y de idempotencia, pero para nuestro trabajo hay otra familia de transformaciones que estudia la diferencia entre dos o más transformaciones básicas. El concepto común en esta familia de transformaciones es el aspecto de diferencia también llamado residuo. El diagrama de bloques de esta familia se representa en la figura 4.12

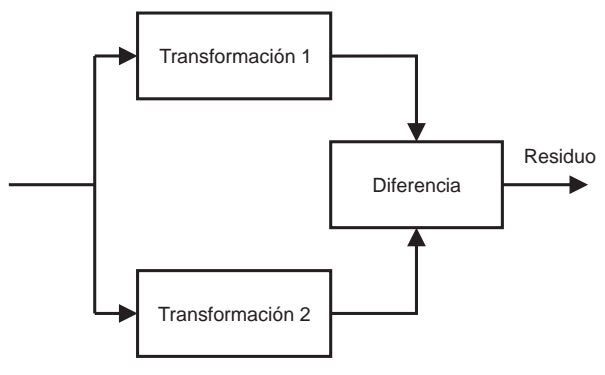

Figura 4.12: Familia de transformaciones basada en la diferencia entre transformaciones.

Entre ellas destacan las transformaciones Top-Hat ${ }^{3}$ que en su versión blanca o positiva se define particularizando la transformación $\mathcal{T}_{1}$ a la identidad y la transformación $\mathcal{T}_{2}$ a la apertura con un determinado elemento estructurante $B$ :

$$
T H_{B}^{+}(f)=f-\gamma_{B}(f)
$$

como la apertura es anti-extensiva el Top-Hat positivo es siempre igual o mayor que cero, quedando extraídos los detalles positivos de la función $f$ que han desaparecido al realizar la apertura. Si se quieren extraer los detalles negativos se puede utilizar la versión negra o negativa del Top-Hat definida como:

$$
T H_{B}^{-}(f)=\varphi_{B}(f)-f
$$

\footnotetext{
${ }^{3}$ en francés chapeaux haut de forme
} 
En el presente trabajo estamos interesados en las microcalcificaciones que son detalles blancos o positivos de la imagen mamográfica y por defecto cuando nos refiramos al Top-Hat será a su versión positiva.

\subsection{Transformaciones geodésicas y reconstruc- ción}

En las aplicaciones de tratamiento de imagen asumiendo un espacio euclideo la distancia entre dos puntos es la longitud del camino rectilíneo que los une. Hay aplicaciones donde el espacio que separa los dos puntos contiene partes que por algún motivo no pueden ser atravesadas por el camino que une ambos puntos y consecuentemente la distancia ya no es la distancia euclídea. Este concepto lleva a definir una nueva distancia llamada distancia geodésica. Cuando tratamos con geodesia tenemos dos conjuntos, uno es el que contiene los dos puntos de los que queremos calcular la distancia geodésica y el otro es el que nos marca qué partes del espacio pueden ser atravesadas por el camino que unirá los dos puntos. El primero se llama marcador y el segundo se llama máscara geodésica. La geodesia y la reconstrucción geodésica, que será introducida posteriormente, fueron propuestas en la tesis de J.C. Klein [67] en 1976.

Definición 18 (Distancia geodésica) En el caso de los conjuntos (morfología binaria) la distancia geodésica $d_{M}(x, y)$ entre dos puntos $x, y \in M$ donde $M$ (conjunto de $\mathcal{R}^{2}$ ) es la máscara geodésica, es la menor longitud de los caminos posibles que unen los puntos $x$ e $y$ dentro de $M$.

Si $M$ está compuesto por dos o más zonas separadas entre sí (componentes no conexas) y los puntos $x$ e $y$ no pertenecen a la misma componente, no habrá camino posible dentro de $M$ que los una. En este caso, por convención, la distancia geodésica será infinita $d_{M}(x, y)=+\infty$.

\subsubsection{Dilatación y erosión geodésicas}

En base a esto se puede definir la dilatación geodésica:

Definición 19 (Dilatación geodésica binaria) La dilatación geodésica binaria de tamaño $n$, denotada $\delta^{n}(M, X)$, de un conjunto $X$ incluido en la máscara 
$M$ se define como:

$\delta^{1}(M, X)=\delta_{B 1}(X) \cap M ; \quad \delta^{n}(M, X)=\underbrace{\left.\delta_{B 1}\left(\delta_{B 1}\left(\ldots \delta_{B 1}(X) \cap M\right) \ldots \cap M\right) \cap M\right)}_{n \text { veces }}$

donde $\delta_{B 1}(X)$ es la dilatación morfológica con un elemento estructurante formado por un disco de radio 1 según el tipo de conectividad.

Nótese que la dilatación geodésica de tamaño $n$ no es la intersección de la dilatación morfológica de tamaño $n$ con $M$.

$$
\delta^{n}(M, X) \neq \delta^{n}(X) \cap M
$$

La erosión geodésica es la transformación dual:

$$
\epsilon^{n}(M, X)=M-\delta^{n}(M, M-X)
$$

donde para conjuntos $M-X=M \cap X^{c}$.

Para las funciones o imágenes de niveles de gris la dilatación geodésica se define de una manera similar, donde ahora la entrada a dilatar es una función y la máscara geodésica (también llamada referencia) es una función mayor.

Definición 20 (Dilatación geodésica de funciones) La dilatación geodésica de funciones o imágenes de niveles de gris, denotada $\delta^{n}\left(f_{M}, f\right)$, de una función $f$ bajo la función máscara $f_{M},\left(f \leq f_{M}\right)$ se define como:

$$
\delta^{1}\left(f_{M}, f\right)=\inf \left(\delta_{B 1}(f), f_{M}\right) ; \quad \delta^{n}\left(f_{M}, f\right)=\underbrace{\delta^{1}\left(f_{M}, \delta^{1}\left(f_{M}, \ldots \delta^{1}\left(f_{M}, f\right) \ldots\right)\right)}_{n \text { veces }}
$$

La erosión geodésica de funciones se obtiene por dualidad como:

$$
\epsilon^{n}\left(f_{M}, f\right)=-\delta^{n}\left(-f_{M},-f\right)
$$

\subsubsection{La reconstrucción}

Una aplicación importante de la dilatación geodésica es implementar la operación llamada reconstrucción. En muchas ocasiones a la función a dilatar se le llama marcador. Si la función marcador es menor que la máscara, por definición el resultado de la dilatación geodésica siempre está dentro de alguna componente conexa de la máscara. Si la entrada a dilatar geodésicamente (conjunto o función) 
es distinto de cero en alguna o algunas componentes conexas de la máscara o referencia, la dilatación geodésica infinita dará lugar a la reconstrucción exacta de dicha o dichas componentes:

$$
\forall X, Y \in \mathcal{P}\left(\mathcal{R}^{2}\right), X \quad Y \Rightarrow \delta^{\infty}(Y, X)=Y
$$

La figura 4.13 muestra la dilatación infinita sobre una imagen binaria. En la práctica en vez de infinitas iteraciones se dilata tantas veces como sea necesario hasta llegar a la idempotencia. En $4.13 a$ aparece en gris la función máscara y en negro la función marcador. En $4.13 b$ se aprecia un paso intermedio en la reconstrucción y en $4.13 c$ se ha alcanzado la situación final, donde se aprecia en negro toda la componente conexa de la máscara donde estaba incluida la función marcador.

En el caso de funciones, la reconstrucción permite igualmente recuperar aquellas regiones de la función referencia marcadas por la imagen marcador. De nuevo la dilatación geodésica infinita en la práctica se reduce al número de iteraciones suficiente hasta llegar a la idempotencia. Las regiones son reconstruidas de manera que quedan incluidos en cada una de las regiones marcadas todos aquellos pixels que tienen un nivel inferior al máximo de la imagen marcador en cada región marcada. Si la imagen marcador contiene todos los máximos de la imagen de referencia la reconstrucción dará como resultado la misma imagen referencia. La figura 4.14 muestra un ejemplo de reconstrucción de funciones.

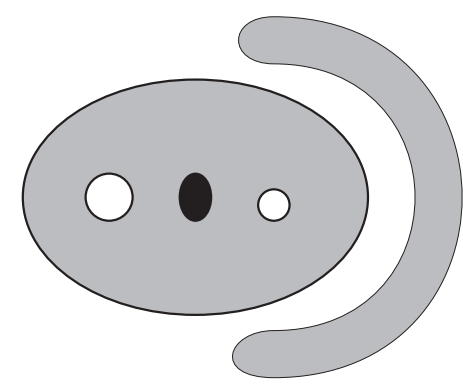

a)

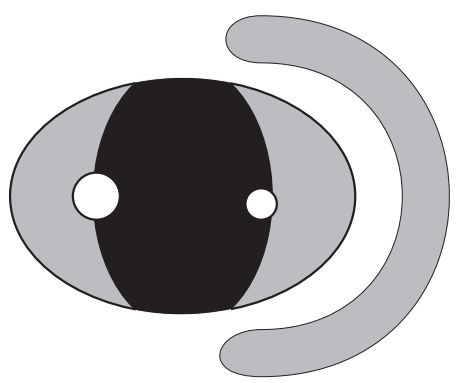

b)

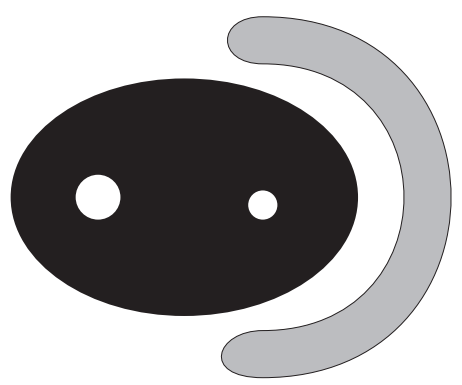

c)

Figura 4.13: Reconstrucción geodésica binaria. La dilatación geodésica hasta la idempotencia permite recuperar exactamente las componentes de la máscara geodésica marcadas por la imagen marcador.

Para nosotros la reconstrucción es particularmente interesante porque en el propósito de detectar las microcalcificaciones es necesario distinguirlas de las estructuras de la mamografía que no lo son; principalmente dos tipos de regiones. Por un lado las regiones grandes más o menos uniformes y por otro las regiones lineales correspondientes a las fibras. Como se ha dicho en la sección anterior para detectar este tipo de regiones se puede construir una estructura de filtrado 
de transformaciones en paralelo combinadas a su salida con la operación supremo. Aunque esta aproximación al problema es correcta el resultado se puede mejorar introduciendo la reconstrucción para corregir el inconveniente de que el elemento estructurante sea en algunos casos demasiado largo. Sobre estos aspectos se profundiza en los capítulos siguientes.

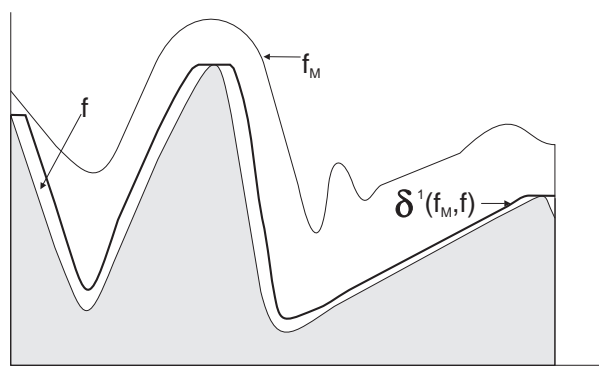

a)

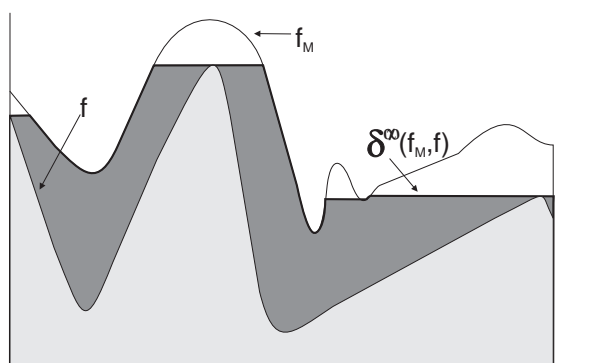

b)

Figura 4.14: Reconstrucción geodésica de una función. a) Dilatación geodésica de tamaño 1 de $f$ con referencia $f_{M}$. b) Reconstrucción geodésica de $f_{M}$ con $f$ como marcador.

A partir de la reconstrucción se puede construir una familia de transformaciones morfológicas llamadas transformaciones por reconstrucción definidas como la composición de una transformación morfológica elemental y de la reconstrucción geodésica, por dilatación si la transformación es anti-extensiva, o por erosión si es extensiva.

Definición 21 (Transformaciones con reconstrucción) Sea $\mathcal{T}$ una transformación morfológica. Se define la correspondiente transformación con reconstrucción asociada a $\mathcal{T}, \mathcal{T}^{\text {rec }}$, de la siguiente manera:

$$
\begin{aligned}
& \mathcal{T}^{\text {rec }}(f)=\delta^{\infty}(f, \mathcal{T}(f)) \text { si } \mathcal{T} \text { es anti-extensiva } \\
& \mathcal{T}^{\text {rec }}(f)=\epsilon^{\infty}(f, \mathcal{T}(f)) \text { si } \mathcal{T} \text { es extensiva }
\end{aligned}
$$

Este tipo de transformaciones permite filtrar las imágenes, por ejemplo eliminando objetos menores que un cierto tamaño al tiempo que, gracias a la reconstrucción, no se modifican los contornos de los objetos que permanecen tal y como muestra el ejemplo de la figura 4.15.

\subsection{Filtros Conexos}

Para detectar las microcalcificaciones en la mamografía minimizando el número de falsas alarmas es conveniente filtrar la imagen para en la medida de lo posible 


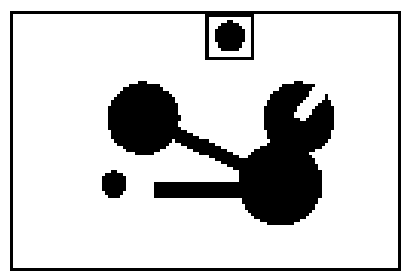

a) Original

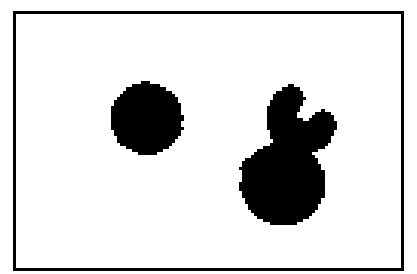

b) Apertura

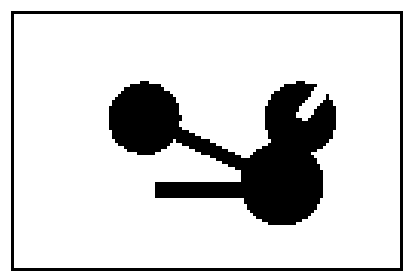

c) Apertura con reconstrucción

Figura 4.15: Transformaciones con reconstrucción. a) Original; b) apertura con el elemento estructurante recuadrado en el original; c) Apertura con reconstrucción tomando como imagen máscara la original y marcador la apertura. Nótese como en la apertura con reconstrucción la componente que permanece a la salida no ha perdido la forma a pesar de que hay zonas en las que no cabe el elemento estructurante y como consecuencia de ello en una apertura como la de la figura $b$ la forma queda modificada. Si hay componentes conexas en las que no cabe el elemento estructurante éstas desaparecen completamente tanto en una apertura como en una apertura con reconstrucción, tal como sucede con el círculo pequeño.

eliminar aquellas estructuras de la imagen que en el proceso de segmentación puedan dar lugar a los mencionados falsos positivos. A su vez es interesante también que durante el proceso de filtrado permanezcan lo más intactas posibles aquellas estructuras de interés, tales como las microcalcificaciones. En las secciones anteriores se ha introducido como primeros ejemplos de filtros morfológicos la apertura y el cierre. En el caso de la apertura con un determinado elemento estructurante por ejemplo, se ha dicho que en el caso de las imágenes binarias produce dos efectos, el primero, elimina aquellos objetos en los que no cabe el elemento estructurante y el segundo, elimina de los objetos en los que sí ha cabido aquellas convexidades en las que no ha cabido, modificando, por tanto la forma de los objetos. En ocasiones este segundo efecto es indeseable, siendo interesante que la operación de filtrado sea en un cierto sentido todo/nada de manera que cada componente conexa pueda permanecer toda o desaparecer toda, pero no ser modificada. Un ejemplo de este concepto sería la reconstrucción. La generalización de dicho concepto nos lleva a introducir los operadores morfológicos conexos $[111,123]$. Previamente introduciremos el concepto de extremo de una imagen.

\subsubsection{Extremos de una imagen}

En el análisis de imágenes en ocasiones son especialmente importantes la extracción de características de las estructuras o regiones que componen la imagen, bien sea porque se desean obtener datos cuantitativos, bien porque se desea filtrar la 
imagen para generar otra atendiendo a criterios sobre estas características, o bien porque se desea segmentar desde un punto de vista concreto o genérico la imagen. En el caso binario el problema es sencillo porque a través de la conectividad se pueden agrupar todos los pixels pertenecientes a la clase objeto que sean conexos entre sí para formar las distintas regiones. Pero en el caso de imágenes de niveles de gris está menos claro. En algunos casos las estructuras de la imagen están determinadas por los máximos o los mínimos de cada posible región, que llamaremos también extremos. El concepto de máximo y mínimo de una función en matemáticas, llamémosle máximo clásico es bien conocido; pero en tratamiento de imagen es interesante introducir el concepto de máximo regional (respectivamente mínimo regional), ya que tal como se define en matemáticas genéricas el máximo clásico de una función, a saber, aquel punto donde la primera derivada es cero y la segunda menor que cero trasladado esto a imágenes discretas, para que exista un máximo se precisaría que todos sus vecinos tuvieran un nivel de gris inferior al original. En las imágenes de niveles de gris puede ocurrir que haya un grupo de pixels vecinos entre sí con el mismo nivel de gris y por tanto ninguno de ellos podría ser un máximo. Retomemos el concepto de asociar a una función o imagen de niveles de gris un relieve topográfico. El mencionado grupo de pixels con el mismo nivel de gris formaría una planicie ${ }^{4}$. Si coincide que este grupo de pixels no tiene vecinos con mayor nivel de gris nos encontraríamos que esta planicie formaría una meseta, y desde algún punto de vista una meseta se puede entender como un máximo o extremo. Mientras que un pico de montaña tiene su correspondencia con un máximo clásico, es interesante que una meseta también tenga su correspondiente, y de ahí que se introduzca el máximo regional como el correspondiente a lo que topográficamente es una meseta. Si al grupo de pixels que forman el máximo regional no se le ponen criterios de mínima cantidad de pixels, de manera que puede estar formado por un único pixel entonces el concepto de máximo regional incluye el concepto de máximo clásico. Lo expuesto para las mesetas tiene su respectivo en las zonas oscuras de la imagen que se corresponderían con los valles. La figura 4.16 ilustra todo ello.

Estos conceptos intuitivos, se pueden exponer de forma más rigurosa a través de estas dos definiciones [70, 71, 76, 111]:

Definición 22 (Planicie) La planicie de una función $f: E \quad \mathcal{Z}^{2} \rightarrow \mathcal{Z}$ en el punto $x$, llamada $P \ln x(f)$, es la componente conexa más grande de $f$ que contiene a $x$ y de altitud constante e igual a $f(x)$ :

$$
P \ln x(f)=C_{x}(\{y \in E \mid f(y)=f(x)\})
$$

donde $C_{x}$ designa la apertura conexa puntual que extrae de todo el dominio donde esta definida la imagen la componente conexa que contiene a $x$.

\footnotetext{
${ }^{4}$ en francés plateau
} 


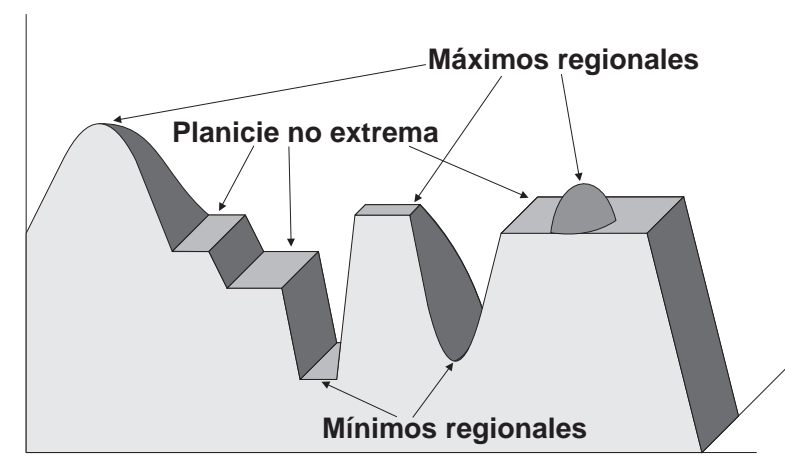

Figura 4.16: Extremos de una imagen de niveles de gris. Se pueden distinguir planicies que forman mesetas, valles o ninguna de las dos cosas. Las mesetas y los picos forman los máximos regionales. Los valles formados por un único pixel o por varios forman los mínimos regionales. Los máximos regionales y los mínimos regionales forman los extremos de la imagen.

Atendiendo a la definición siguiente las planicies pueden ser de tres tipos: las mesetas o máximos regionales, los valles o mínimos regionales y el tercer tipo son las que no son mesetas ni valles, que llamaremos planicies no extremas. Nótese que una planicie puede estar formada por un único pixel.

Definición 23 (Máximo regional) Llamaremos máximo regional $M$, de una imagen de niveles de gris $f$, a toda planicie sin vecinos de mayor nivel de gris, y mínimo regional a toda planicie sin vecinos de menor nivel de gris.

También se puede dar una definición alternativa [125] haciendo uso de la operación umbral definida como $U_{l}(f)=\{x \mid f(x) \geq l\}$, (ver ecuación 4.4):

Definición 24 (Máximo regional) Un máximo regional $M$ de altura $l$ de una imagen de niveles de gris $f$ es una componente conexa $C$ de $U_{l}(f)$ tal que $C \cap$ $U_{l+1}(f)=\emptyset$

Para determinar los máximos regionales se han propuesto varios algoritmos [125] y entre ellos uno de los más eficientes es el que hace uso de la reconstrucción en base a que los máximos regionales de nivel $l$ de la función $f$ son las componentes conexas de $U_{l}(f)$ no reconstruidas por $U_{l+1}(f)$, o lo que es lo mismo, las componentes de $U_{l}(f)$ no reconstruidas por $U_{l}(f-1)$ (ver figura 4.17). Si designamos por $\mathcal{M a x}(f)$ al conjunto de máximos regionales de $f$, la imagen binaria $\mathcal{M} a x(f)$ se puede obtener como

$$
\operatorname{Max}(f)=U_{1}\left(f-\delta^{\infty}(f, f-1)\right)
$$




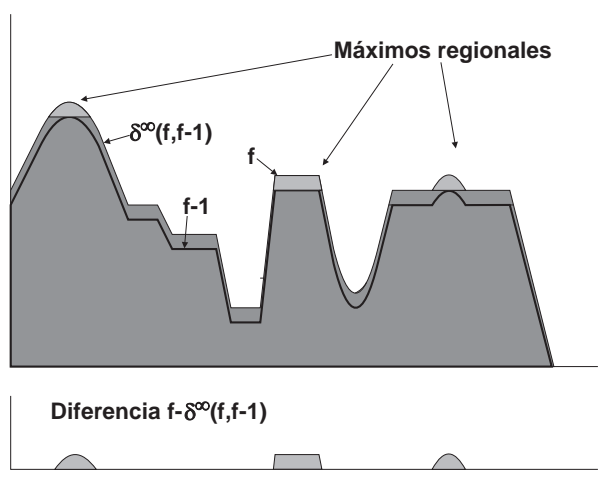

Figura 4.17: Extracción de los máximos regionales de una imagen $f$ por reconstrucción de $f$ a partir de $(f-1)$.

Aunque determinar los máximos y mínimos regionales puede ser un buen método para determinar las regiones de la imagen en un problema de segmentación genérica, la realidad es que adolece de varios problemas, que son [123]:

- Planicies no extremas. En una imagen puede haber regiones grandes con un nivel constante de gris vecinas de una región con mayor nivel y por tanto no ser máximos regionales. Este problema se puede solucionar a través de la función distancia al borde. Si a la imagen $f$ se le suma el resultado de la función distancia al borde de la planicie calculada para cada pixel de cada planicie, se crean artificialmente máximos regionales, con lo que las planicies no extremas pasan a tener un máximo regional y por tanto serán detectadas.

- Ruido. Normalmente las imágenes reales tienen ruido, y éste crea muchos máximos regionales en cada región por lo que si a cada máximo le asociamos una región la imagen queda rápidamente sobresegmentada. Una posible solución es eliminar el ruido con cualquier filtrado adecuado que no elimine las regiones de interés. En muchas ocasiones este filtrado es una parte importante de la tarea de segmentación.

- Aproximación jerárquica. En ocasiones es interesante realizar una segmentación a diferentes niveles de detalle en alguna magnitud, como por ejemplo el área. Si la segmentación se hace a través de los máximos regionales sin tener en cuenta nada más, puede haber varios máximos regionales asociados a regiones de detalles pequeños sobre una región más grande y que es la que se desea segmentar quedando sobresegmentada por contener varios máximos. No hay por tanto en ocasiones una relación directa entre los extremos y la información contenida en la imagen.

Una de las causas más importantes de los problemas que se generan cuando 
se utilizan los extremos de una imagen son debidos a que un máximo (resp. mínimo) regional lo es aún cuando la diferencia entre él y sus vecinos es un solo nivel de gris, por lo que pequeñas fluctuaciones generan extremos. Esto se puede evitar si se exigiera a una región para ser seleccionada un número $h$ arbitrario de niveles de gris de diferencia. Esto lleva al concepto de h-extremos que reduce significativamente el número de planicies que cumplen el criterio y por tanto la sobresegmentación. Si el lector quiere profundizar sobre estos conceptos se le remite a $[49,125,127]$.

\subsubsection{Operadores morfológicos conexos}

La idea de los operadores conexos es mantener indivisibles las componentes conexas durante la transformación. Este concepto ha sido formalizado por J. Serra y P. Salembier [111] y es la base de transformaciones morfológicas tan importantes como la reconstrucción en imágenes de niveles de gris [67], la dinámica [49] y la apertura surperficial [126]. Este último operador es de especial interés para nosotros porque basándonos en él construimos una transformación para mejorar el proceso de detección de las microcalcificaciones.

Antes de pasar a las definiciones es necesario que quede establecido lo que se entiende por diferencia simétrica $A \Delta B$ entre $A$ y $B$ :

$$
A \Delta B=\left(A \cap B^{c}\right) \cup\left(A^{c} \cap B\right)
$$

Recordemos también que $\mathcal{C}(A)$ designa el conjunto de las componentes conexas de $A$. La figura 4.18 muestra un ejemplo.

Definición 25 (Operador morfológico conexo binario) Un operador morfológico binario T será conexo [111] si para todo conjunto A de E, la diferencia simétrica entre $A$ y $\mathcal{T}(A)$ está constituida exclusivamente de componentes conexas de $A$ o de su complementario $A^{c}$ :

$$
\mathcal{T} \text { esconexo } \Leftrightarrow \mathcal{C}(A \Delta \mathcal{T}(A)) \quad\left(\mathcal{C}(A) \cup \mathcal{C}\left(A^{c}\right)\right)
$$

Con esta definición se asegura que los operadores preservan las relaciones de conectividad, es decir, si dos pixels $p, q \in \mathcal{D}_{I}$ son conexos en $A$ o en $A^{c}$, entonces en el resultado de la transformación o en el complementario los pixels $p$ y $q$ son conexos. La consecuencia es que el proceso que los operadores conexos binarios realizan sobre la entrada es únicamente conservar o suprimir las componentes conexas pero no modificarlas (ver figura 4.19). Es decir, los pixels correspondientes a una misma componente conexa tienen todos el mismo valor en la salida. 


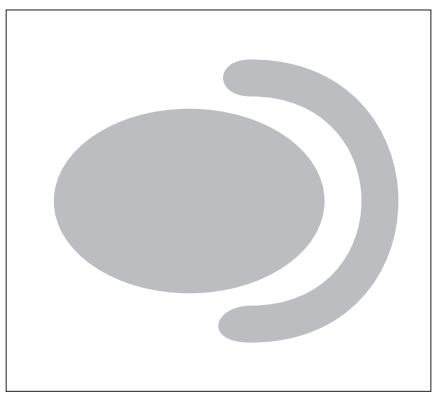

a) Imagen a

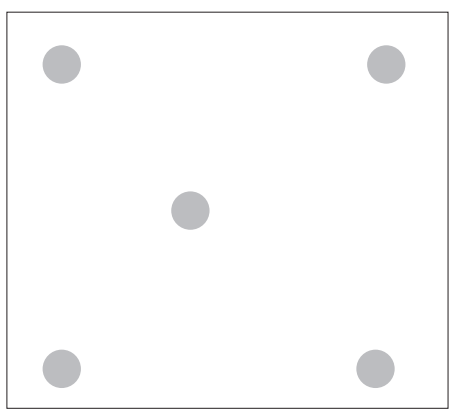

b) Imagen b

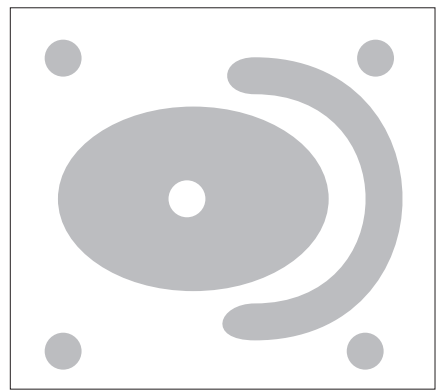

c) Diferencia simétrica $a \Delta b$

Figura 4.18: Diferencia simétrica entre dos imágenes binarias

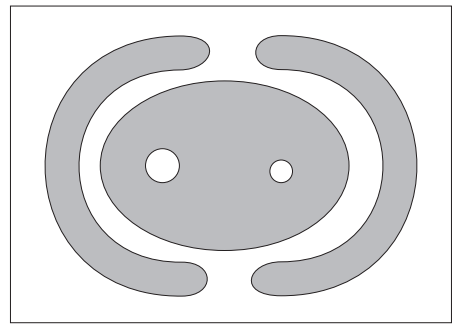

a) Original

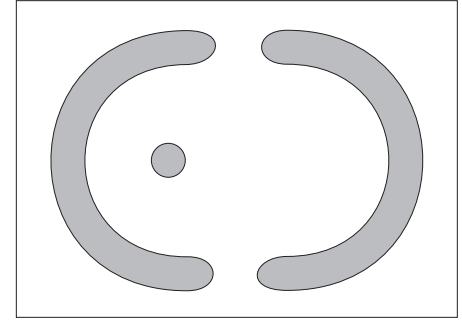

b) Operador conexo

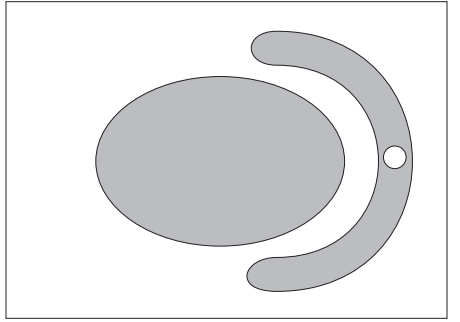

c) Operador no conexo

Figura 4.19: Operador conexo binario 
La extensión de operador conexo a las imágenes de niveles de gris precisa extender el concepto de componente conexa binaria. En binario los pixels que forman una componente conexa tienen dos características, por un lado tienen el mismo valor, y por otro mantienen una relación de vecindad entre ellos. Trasladar la característica de vecindad es inmediato porque la relación de vecindad se establece sobre la celosía, y ésta es válida tanto para imágenes binarias como de niveles de gris. Respecto al valor de los pixels posibles es la característica que diferencia ambos tipos de imágenes y por tanto es donde hay que realizar la extensión. La extensión realizada en [111] consiste en trasladar la propiedad de conservación de las componentes conexas a conservar las planicies de las imágenes de niveles de gris. Realizando la siguiente definición [111]:

Definición 26 (Operador conexo para imágenes de niveles de gris) Una transformación morfológica $\mathcal{T}$ u operador para imágenes de niveles de gris es conexo si y sólo si no reduce las planicies de la imagen de entrada. Si p es un pixel de la imagen de niveles de gris o función $f$ :

$$
\mathcal{T} \text { es conexo } \Leftrightarrow \forall p \in \mathcal{D}_{I}, P \ln _{p}(f) \subseteq P \ln _{p}(\mathcal{T}(f))
$$

Esta definición implica que un operador conexo ante una planicie en la imagen de entrada (todos los valores son iguales) debe generar a la salida otra planicie formada por los mismos pixels. En lo que no pone ninguna restricción la definición es en el nivel de gris asignado a la nueva planicie, es decir, el operador está obligado a transformar los niveles de gris de las planicies, vistas éstas como unidades indivisibles. De algún modo lo que un operador genérico transforma niveles de gris de pixels, los operadores conexos transforman los niveles de gris de las planicies. En los operadores genéricos la unidad indivisible son los pixels de la imagen de entrada y en los operadores conexos la unidad indivisible son las planicies. A su vez como sí puede unir pero no dividir las planicies, la imagen resultante suele tener un número menor de las mismas (ver figura 4.20).

Como se ha visto en la sección anterior, al aplicar la reconstrucción por dilatación o por erosión geodésica respectivamente tras, por ejemplo, una apertura o cierre permite recuperar las componentes conexas de la imagen que no han desaparecido totalmente. Es por ello que una transformación seguida de la reconstrucción geodésica correspondiente según sea, anti-extensiva $\mathcal{T}^{\text {rec }}(f)=$ $\delta^{\infty}(f, \mathcal{T}(f))$, o extensiva $\mathcal{T}^{r e c}(f)=\epsilon^{\infty}(f, \mathcal{T}(f))$, resulta ser un operador conexo. Una transformación morfológica genérica, por ejemplo la apertura o el cierre, salvo casos particulares según el dominio y el elemento estructurante, no son operadores conexos. De hecho al introducir la apertura se ha dicho que eliminan los salientes de las componentes en las que no cabe el elemento estructurante, por lo que al no conservar la componente conexa en su integridad no cumple la condición de operador conexo. 


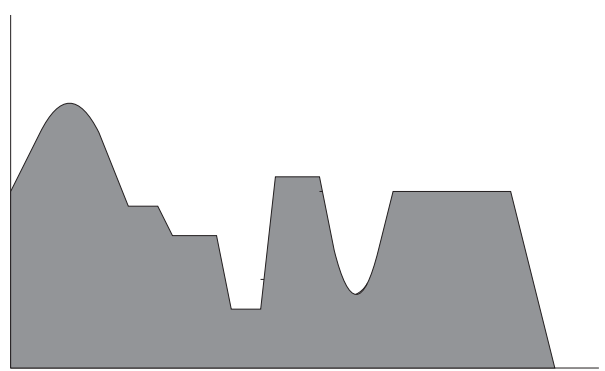

a) Original

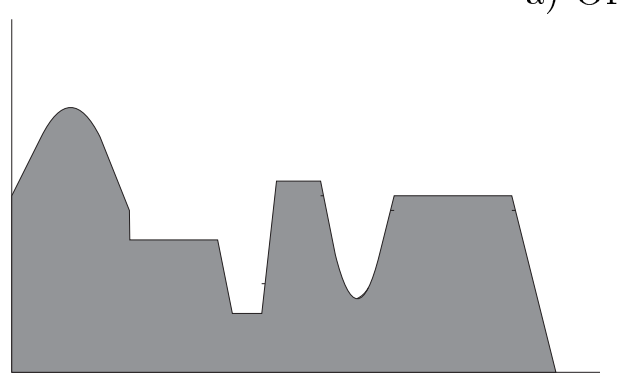

b) Operador conexo

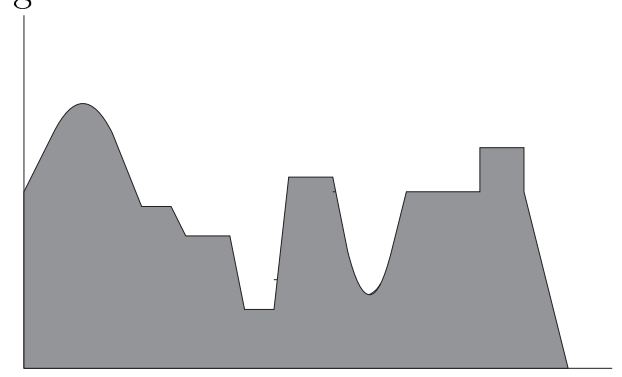

c) Operador no conexo

Figura 4.20: Operador conexo de niveles de gris. a) Operador conexo, todas las planicies se mantienen como tales a la salida. La transformación ha fusionado las dos planicies no extremas de la entrada; b) Operador no conexo. La planicie mayor de la entrada ha generado dos planicies a la salida

\subsubsection{Apertura Superficial}

Un operador conexo interesante para nuestro trabajo es la apertura superficial. La apertura morfológica con un determinado elemento estructurante elimina de la imagen determinadas estructuras brillantes en función de la forma del elemento estructurante. En ocasiones las estructuras que se quieren tratar no responden a un criterio de forma específico sino a otros criterios, entre ellos, uno posible es la superficie. En el caso de imágenes binarias el concepto es fácilmente entendible y la transformación consiste en extraer las componentes conexas cuya superficie es superior a un valor dado. Cuando se habla de superficie generalmente en la práctica se traduce a número de pixels. La apertura superficial para imágenes de niveles de gris ha sido introducida recientemente por Vincent [126] como la generalización de la apertura superficial binaria, definiéndola de la siguiente forma:

Definición 27 (Apertura superficial) La apertura superficial de tamaño $\lambda$ de una imagen de niveles de gris $f$, denotada por $\gamma_{\lambda}^{a}(f)$, se define como

$$
\gamma_{\lambda}^{a}(f)(x)=\sup \left\{h \leq f(x) \mid \operatorname{Sur} f\left(C_{x}\left(U_{h}(f)\right)\right) \geq \lambda\right\}
$$


donde $\operatorname{Surf}(\cdot)$ es el operador que calcula el área del operando binario sobre el que actúa, que generalmente consiste en contar el número de pixels, y $U_{h}(\cdot)$ es la transformación umbral mayor o igual que $\mathrm{h}$.

Intuitivamente la apertura superficial elimina los picos brillantes que tienen una superficie menor que $\lambda$. Eliminar los picos significa reducir su nivel de gris al nivel en el que la planicie que resulta ya tiene un tamaño mayor o igual que $\lambda$. El cierre superficial es la transformación dual.

Esta transformación como se describirá en los siguientes capítulos nos será útil en la construcción de un operador destinado a reducir el número de falsos positivos detectados originados por estructuras de la imagen difícilmente eliminables.

\section{CÁLCULO EFICAZ}

La aplicación directa de la definición para calcular la imagen resultante de la apertura superficial requiere un tiempo de cálculo muy grande porque se busca el supremo del conjunto de las componentes conexas del resultado del umbral para todos los valores del margen de niveles de gris posibles, lo que implica para cada pixel y en cada imagen binaria resultante de cada operación umbral calcular la componente conexa que lo contiene y computar su superficie, para así poder determinar en qué nivel de gris dicha superficie es mayor o igual a $\lambda$, siendo este nivel de gris el valor que se le debe asignar al pixel en la imagen de salida.

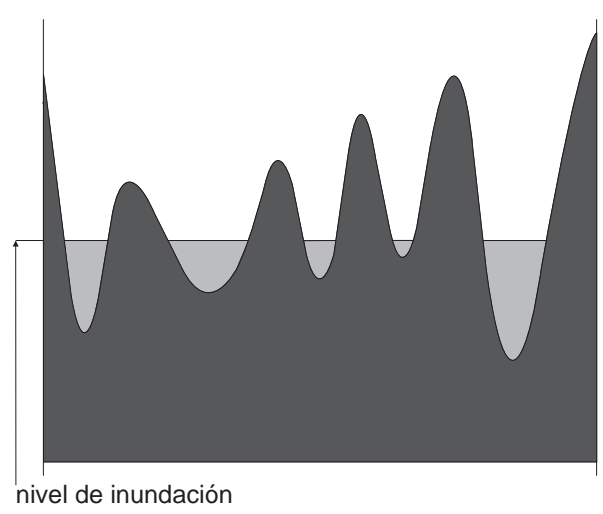

a)

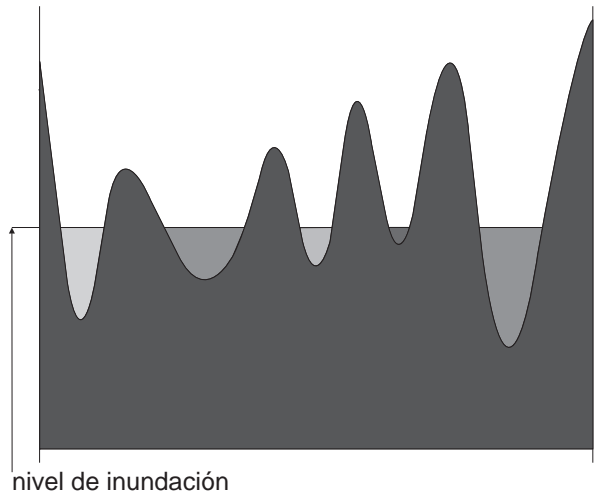

b)

Figura 4.21: Proceso de inundación de un relieve topográfico. a) El agua penetra por los mínimos y alcanza el mismo nivel en todos los valles. b) Si se introduce por cada mínimo agua coloreada de forma diferente, en cada mínimo se pueden mantener identificados los pixels que pertenecen a la cuenca asociada a cada mínimo. 
Como se ha dicho anteriormente la apertura superficial es un operador conexo y como tal se construye sobre la base de transformar las planicies de la imagen. Al estar implicadas las planicies, durante los cálculos una parte importante del tiempo se debe dedicar a reconocer dichas planicies, es decir, a tener registrados de algún modo el conjunto de pixels que forman cada una de las planicies. Otra parte del proceso, dado que los operadores conexos actúan fusionando planicies vecinas, se debe dedicar a tener registradas las relaciones de vecindad entre las planicies. Este concepto de fusionar planicies vecinas se puede entender como que la transformación consiste en propagar el valor asignado a los pixels de la primera planicie hacia los pixels de la segunda. A su vez esta idea de la propagación lleva a pensar en la idea de la inundación utilizada para calcular de forma eficiente transformaciones como la línea divisoria de aguas ${ }^{5}$. Estas formas eficientes de cálculo fueron propuestas por L. Vincent [124, 125] y por F. Meyer [85]. El núcleo de estos algoritmos basados en propagación radica generalmente en colas $^{6}$ para construir la secuencia de pixels a propagar.

Desde un punto de vista ilustrativo es más fácil entender el procedimiento de inundación en el que se basa el cálculo eficaz de la apertura superficial si se ilustra sobre el cierre superficial, de manera que en vez de reducir el nivel de los picos se aumenta el nivel de los valles. Si tenemos una imagen y la interpretamos como un relieve topográfico e imaginamos que todos los valles del relieve tienen un orificio en su parte inferior por donde puede penetrar el agua, inundar a un determinado nivel implica que todos aquellos puntos del relieve que estén en ese nivel o por debajo estarán inmersos en agua, tal como ilustra la figura 4.21a. Si además imaginamos que el agua que penetra por cada mínimo del relieve está pigmentada con un color distinto podemos tener identificados los pixels que pertenecen a la cuenca de cada mínimo (figura 4.21b).

Si el nivel de inundación se va incrementando, en algunos puntos se encontraran las aguas de dos cuencas vecinas, tal como ilustra la figura 4.22. El conjunto de puntos donde esto ocurre forman la línea divisoria de aguas.

Si entendemos las figuras $4.21 b$ y 4.22 como una secuencia, queda ilustrado que el proceso comienza inundando por el nivel más bajo posible para luego ir incrementando el nivel del agua. En lo que sigue se va a hacer una descripción del proceso para calcular el cierre superficial a través de la inundación. La relación entre la inundación y el cálculo del cierre superficial reside en que el objetivo del cálculo es determinar los niveles de inundación $\left\{g_{c}\right\}_{\lambda}$, en el que cada cuenca tiene una superficie igual o mayor que $\lambda$. Una vez determinados estos niveles, el nivel de gris de cada pixel de la imagen de salida es el mayor valor entre el nivel de gris del pixel en la imagen de entrada y el valor $g_{c}$ determinado para la

\footnotetext{
${ }^{5}$ en francés ligne de partage des eaux o whatershed en inglés

${ }^{6}$ en francés files d'attente hiérarchiques
} 


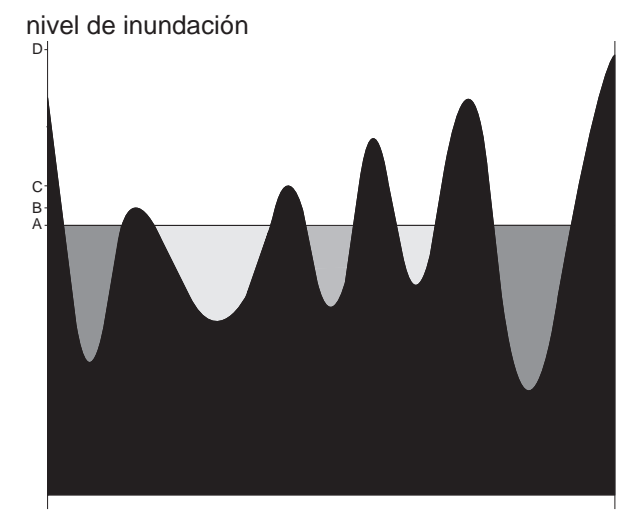

a)

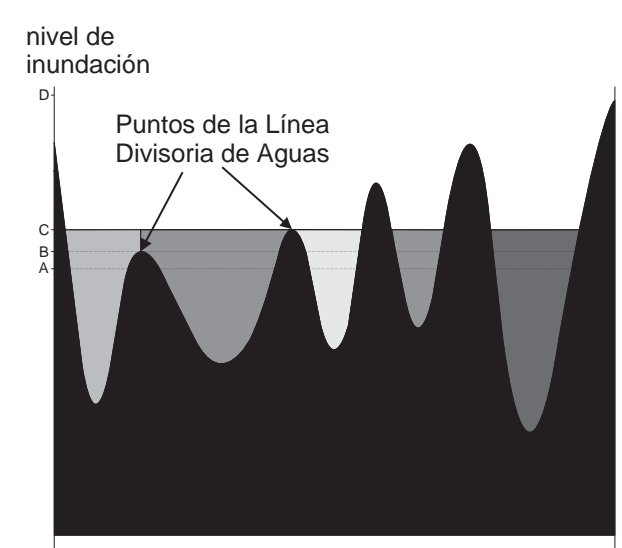

c)

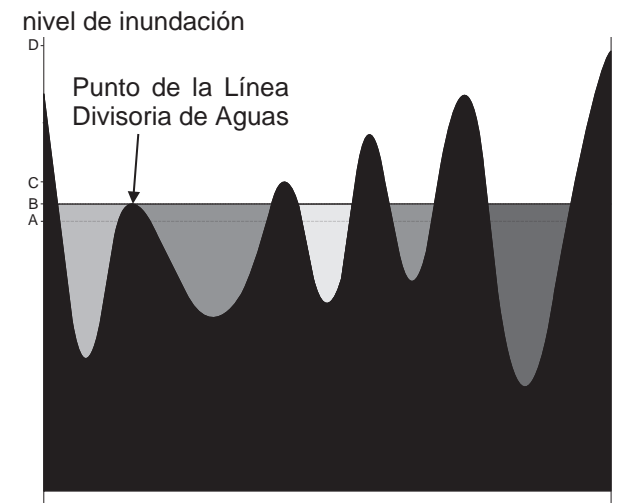

b)

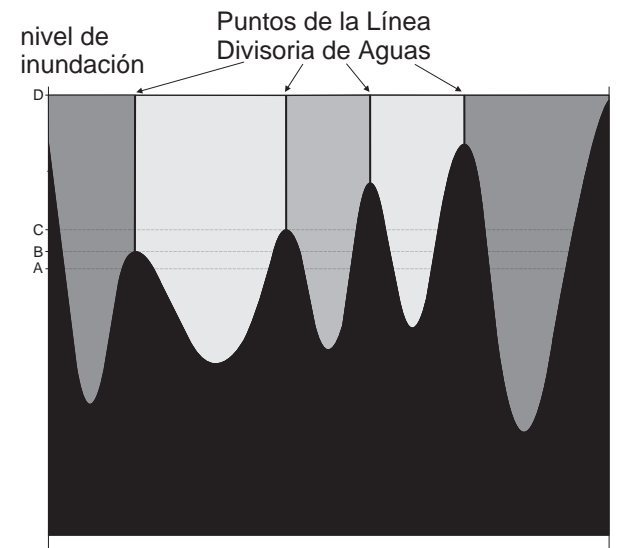

d)

Figura 4.22: Proceso de inundación y determinación de la línea divisoria de aguas 
cuenca a la que pertenece (ver figura 4.23). Obsérvese que cuando la superficie de una cuenca no alcanza el valor $\lambda$ antes de llegar a la línea divisoria de aguas es necesario considerar la superficie de las cuencas vecinas, tal como se ve en los dos valles estrechos de la figura 4.23.

Como en las imágenes los niveles de gris posibles son un conjunto de niveles discretos de 0 a $G-1$, habrá que comenzar por el nivel cero e ir subiendo. Para conocer qué pixels quedan inundados cuando el nivel de inundación es cero simplemente hay que determinar qué pixels tienen valor cero en la imagen. Si hay alguno, éstos son los mínimos de menor nivel que existen, si son varios y no son vecinos entre sí, cada uno corresponde al mínimo de una cuenca distinta. Para poder calcular durante el proceso de inundación cuando la superficie de la cuenca alcanza o supera el valor $\lambda$ hay que ir identificando para cada nivel de inundación los pixels que pertenecen a cada cuenca. Este proceso requiere de una imagen intermedia donde almacenar esta información y que llamamos imagen de etiquetas. Cada etiqueta es el identificativo de una cuenca. Durante el proceso de inundación el primer pixel que se etiqueta en una cuenca es su mínimo, asignándole una etiqueta nueva que se propaga (ver figura 4.24) por el resto de pixels de la cuenca (es decir, se va asignando de un pixel que ya la tiene a un pixel vecino y a su vez a un vecino de este último).

Como se puede inferir a partir del gráfico unidimensional de la figura 4.24, en una imagen y para un nivel de inundación, puede haber varios pixels con ese valor y que pertenezcan a cuencas distintas por lo que se deberá propagar a cada uno la etiqueta de su vecino que haya sido previamente etiquetado en un nivel de inundación anterior.

Al comienzo del proceso los pixels de la imagen de etiquetas deben estar todos inicializados a un valor que represente un estado en-espera. Durante el proceso de inundación y a medida que se incrementa el nivel, cada pixel que es alcanzado por ésta verá sustituida su etiqueta en-espera por la etiqueta que le corresponda. Si un pixel no es un mínimo, la etiqueta que le corresponde es alguna de las de los pixels vecinos que han sido etiquetados previamente, ya que si no es un mínimo, necesariamente tiene algún vecino con nivel de gris menor y por tanto habrá sido procesado antes. Si el pixel es un mínimo esta condición queda evidenciada porque ninguno de sus vecinos habrá sido etiquetado en un nivel de inundación anterior. De lo expuesto hasta aquí se concluye que es necesario un orden en el proceso de etiquetado y éste orden es creciente en la escala de niveles de gris de la imagen, comenzando por el nivel más bajo. Por tanto puede establecerse que el proceso queda dividido en tantas etapas como niveles de gris tenga la imagen pudiéndose determinar a priori la cantidad de pixels que hay que procesar en cada una de estas etapas calculando el histograma.

Dentro de cada etapa, puesto que el número de pixels con el mismo nivel 


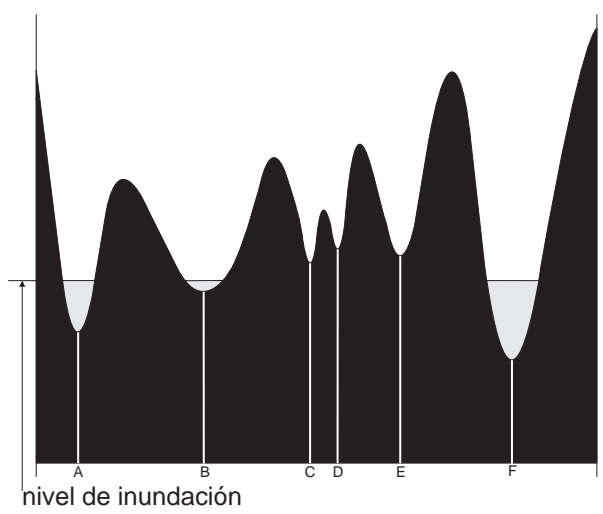

a)

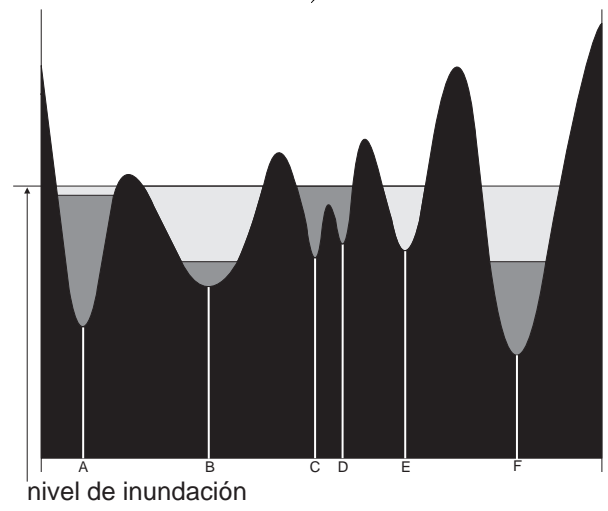

c)

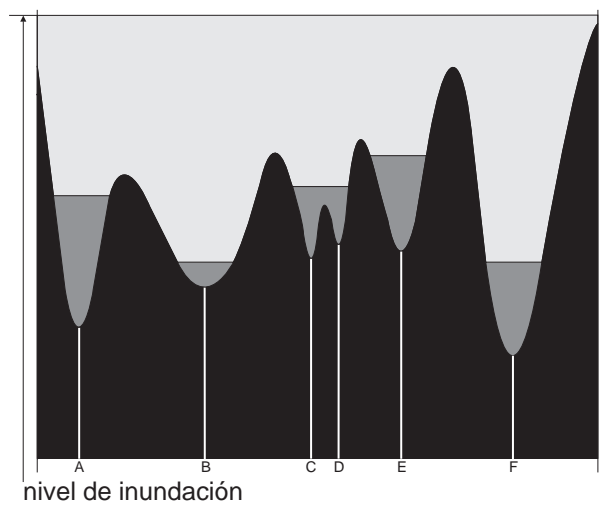

e)

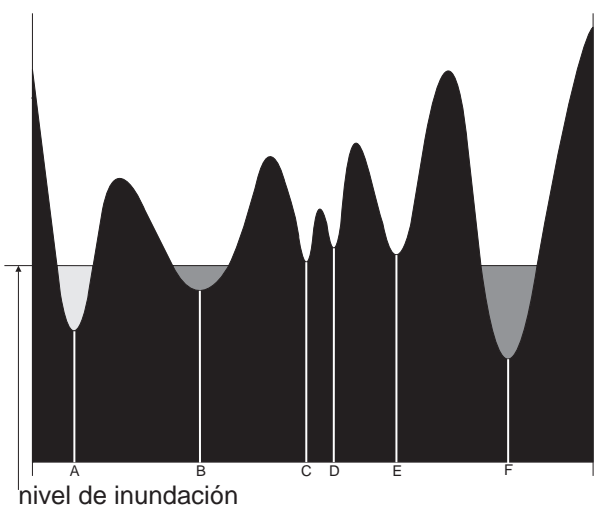

b)

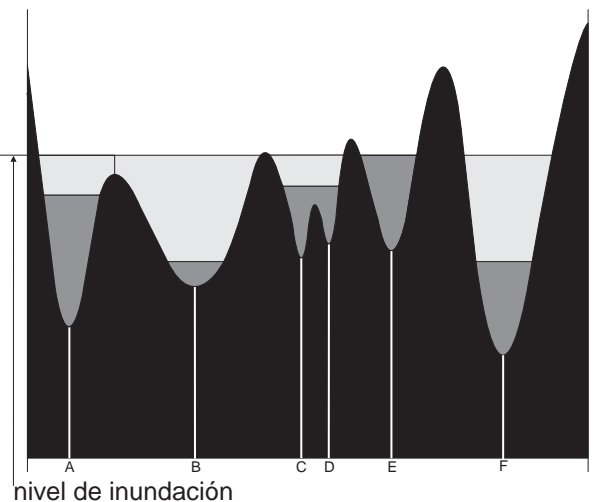

d)

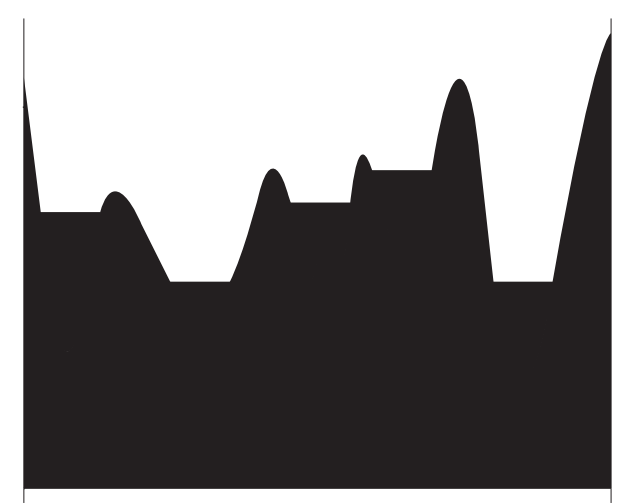

f)

Figura 4.23: Proceso de inundación y relación con el cálculo del cierre superficial. El nivel de gris mínimo de los pixels de una cuenca en la función de salida corresponde con el nivel de inundación en el que la cuenca alcanza una determinada superficie. Figuras a) a e): distintos instantes en el proceso de inundación; f) función de salida. 


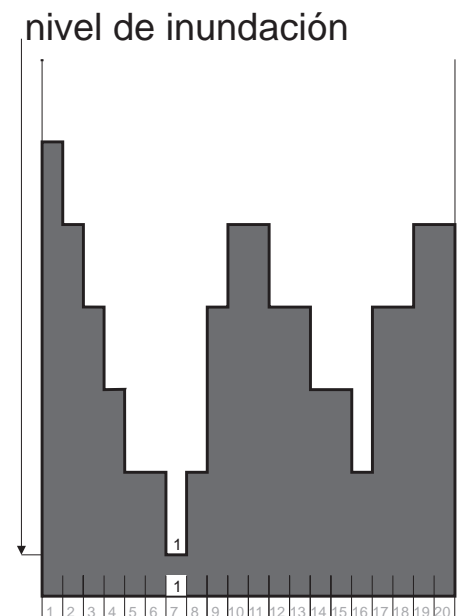

a)

nivel de inundación

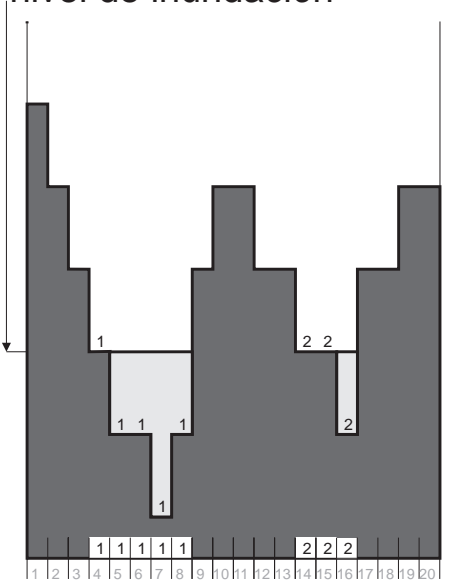

c)

nivel de inundación

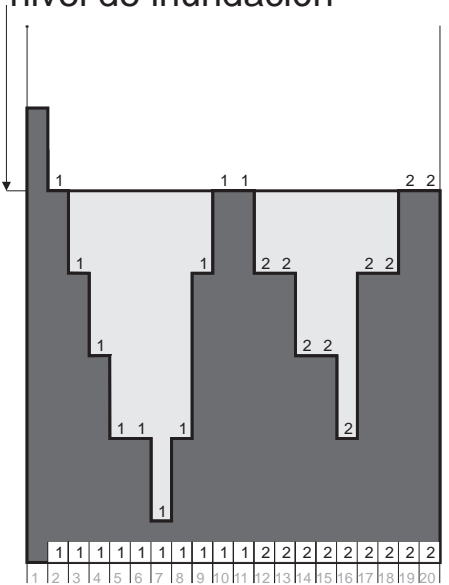

e) nivel de inundación

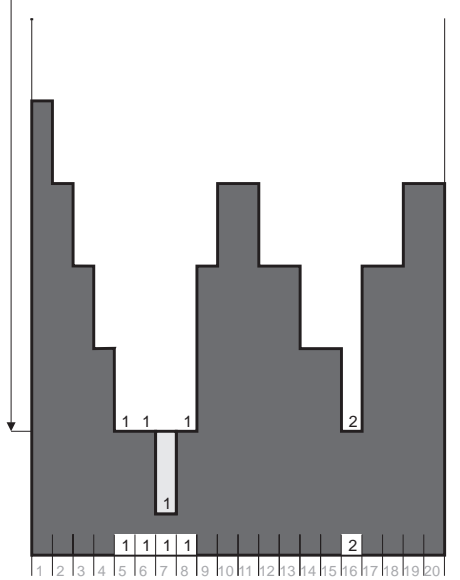

b)

nivel de inundación

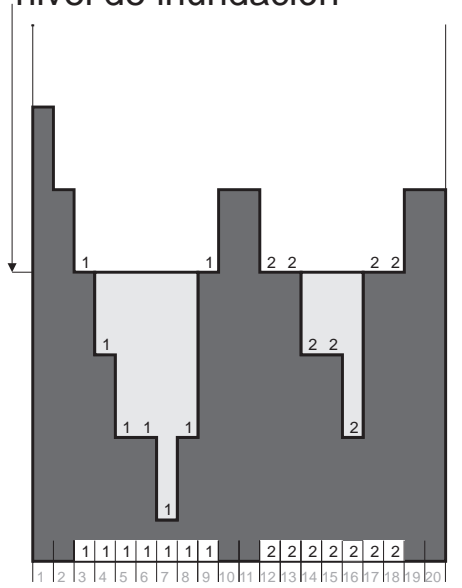

d)

nivel de inundación

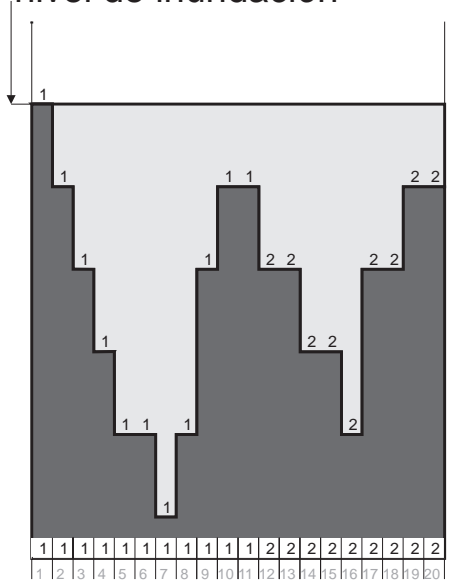

f)

Figura 4.24: Proceso de inundación y propagación de las etiquetas desde los mínimos hacia sus vecinos. Figuras a) a f) corresponden con niveles de inundación crecientes. La etiqueta que recibe cada pixel aparece sobre la parte inferior del gráfico y también a la altura de su nivel de gris. 
de gris es generalmente mayor que uno, hay que establecer una estrategia para etiquetarlos. Hay varias alternativas posibles. La más evidente a priori, aunque poco eficiente, consiste en confeccionar una lista de los pixels que forman la etapa actual, es decir, los que tienen el actual nivel de inundación. A continuación ir recorriendo la lista hasta encontrar un pixel que pueda ser etiquetado. Los pixels que pueden ser etiquetados son aquellos que tienen al menos un vecino ya etiquetado o aquellos que no teniendo ninguno son todos de mayor nivel de gris (correspondiente al caso de un mínimo de una nueva cuenca). Cuando un pixel se etiqueta se elimina de la lista. Probablemente tras el primer recorrido de la lista quedarán pixels que no habrán podido ser etiquetados y será necesario recorrer de nuevo los pixels que han quedado pendientes. Si en este segundo recorrido de la lista no quedan todos etiquetados, se procede a un tercero y así sucesivamente hasta poder etiquetar a todos los de la etapa actual. Los sucesivos recorridos por la lista son necesarios porque las etiquetas se han de "propagar" y el orden en que se propagan depende de la imagen en concreto, por tanto ese orden se busca a través de los diferentes recorridos de la lista. El proceso que hay que realizar para cada pixel es relativamente costoso porque hay que examinar las etiquetas de los vecinos así como sus niveles de gris, y si por ejemplo, un pixel queda etiquetado en el cuarto recorrido que se hace, la tarea necesaria se ha repetido cuatro veces.

Todo este proceso se puede optimizar, evitando estas repeticiones, si uno se cerciora de que cuando un pixel es etiquetado los siguientes pixels a los que se puede propagar su etiqueta es a sus vecinos. Así pues, si en algún sitio se anota esto ya no será necesario buscar el orden de procesado sino que este se puede ir construyendo de forma natural al mismo tiempo que se va etiquetando. Ese sitio es una cola. Hay que tener en cuenta que hay dos niveles de ordenación, uno es debido a la inundación progresiva y el otro a la ordenación dentro del conjunto de pixels de un mismo nivel de gris. Como la ordenación en la forma de procesado optimizado se construye poniendo en la cola los pixels vecinos al etiquetado actualmente y estos pueden tener cualquier nivel de gris pero deben ser procesados cada uno en la etapa en la que el nivel de inundación alcanza su nivel de gris es necesario poner los pixels en cola de forma selectiva según su nivel de gris. En otras palabras, dentro del orden que se va estableciendo en la cola hay que procesar primero todos los pixels de la imagen que tengan un mismo nivel de gris antes de pasar a pixels de la cola que tengan nivel de gris superior. Por lo que aparece la necesidad de una nueva tarea de búsqueda en la cola (o en la imagen si no han sido puestos en la cola por no tener ningún vecino que haya sido etiquetado) según el nivel de gris. Esta tarea de búsqueda se puede evitar de nuevo si en vez de tener una cola única se tienen tantas colas como niveles de gris de manera que cuando se deban poner en cola los vecinos de un pixel que está siendo actualmente etiquetado se pongan cada uno en la cola correspondiente a su nivel de gris. Se establece así una jerarquía porque las colas 
de nivel de gris inferior tienen prioridad. El tipo de colas necesarias son colas donde el primer pixel que se pone en la cola es el primero que debe ser sacado para ser etiquetado.

La figura 4.25 ilustra en qué consisten y cómo se utilizan las colas jerárquicas. Antes de explicar lo referente a las colas en la figura 4.25, es necesario justificar la necesidad de unas estructuras de datos más, que llamaremos listas. Dado que los pixels se van a procesar en un orden que depende del propio contenido de la imagen, es posible que en varios momentos del proceso sea necesario conocer si ya están procesados todos los pixels de un determinado nivel o no. Para saberlo se puede recorrer, cada vez que se necesite, todos los pixels de la imagen, averiguar su nivel de gris para compararlo con el nivel de inundación actual y además averiguar si ya está procesado o no. Una alternativa más eficiente consiste en antes de comenzar cualquier proceso se construye una serie de listas, una por cada nivel de gris, conteniendo las coordenadas de los pixels que tienen cada nivel de gris, de manera que cuando queramos conocer algo referente a los pixels de un determinado nivel de gris no haya que recorrer toda la imagen sino la lista correspondiente. En la figura 4.25 se han considerado sólo seis niveles de gris para no complicar la exposición. Así pues la lista general consta de seis listas, una para cada uno de los niveles de gris (A, B, C, D, E y F). Como la figura contiene una función unidimensional las coordenadas de cada pixel de la lista son un único número. Para ayudar a seguir el proceso se ha sombreado en la lista los pixels que van siendo procesados.

En las seis partes de la figura 4.25 se han representado seis instantes iniciales del proceso, suficientes para ilustrar el funcionamiento de las colas. En $4.25 a$ se encuentra el pixel con menor nivel de la imagen, se asigna la primera etiqueta y sus vecinos son puestos ambos (6 y 8) en la cola de nivel B. Acto seguido se consulta la cola de nivel A y a continuación la lista del nivel A resultando que no queda ningún pixel de dicho nivel por procesar por lo que se pasa a la cola de nivel B (figura 4.25b). Se saca de la cola el pixel 6 se etiqueta y se ponen en la cola sus vecinos. Como el pixel el pixel 7 ya esta etiquetado sólo se pone en la cola el 5, estando en ese instante en la cola de nivel B el 8 y el 5. A continuación se extrae el siguiente pixel de la cola B, resultando ser el 8 (figura $4.25 c$ ) , se etiqueta y se pone en la cola D el pixel 9. En la siguiente extracción de la cola B resulta etiquetado el 5 y puesto en cola el 4 . Tras realizar esto la cola $\mathrm{B}$ queda vacía (figura $4.25 \mathrm{~d}$ ), pero no todos los pixels de nivel $\mathrm{B}$ de la imagen han sido procesados. Este hecho se comprueba consultando la lista de nivel B y observando que queda por procesar el pixel 16, por lo que se pasa a etiquetarlo. $\mathrm{Al}$ comprobar que ninguno de sus vecinos tiene etiqueta nos encontramos ante un nuevo mínimo y por tanto la aparición de una nueva cuenca asignándole entonces una nueva etiqueta (figura 4.25e), como en todos los pixels etiquetados, sus vecinos son puestos en cola resultando incluidos el pixel 15 en la cola C y el 17 


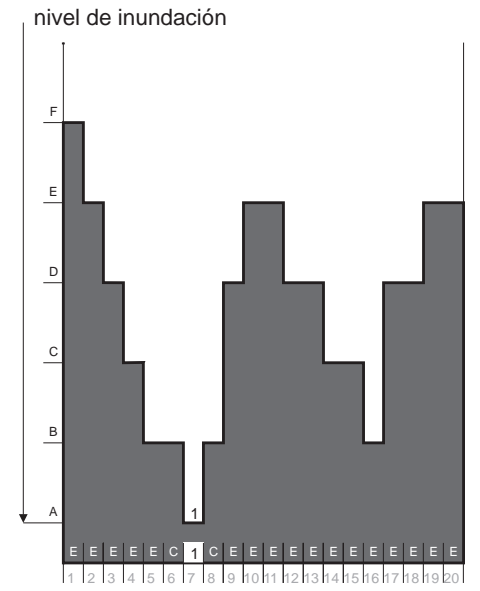

a)

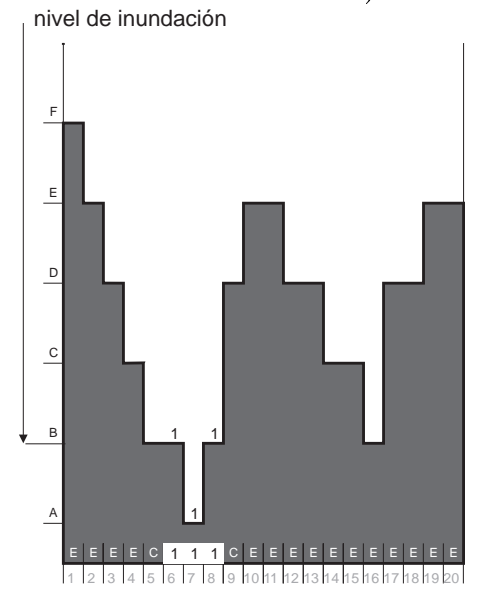

c)

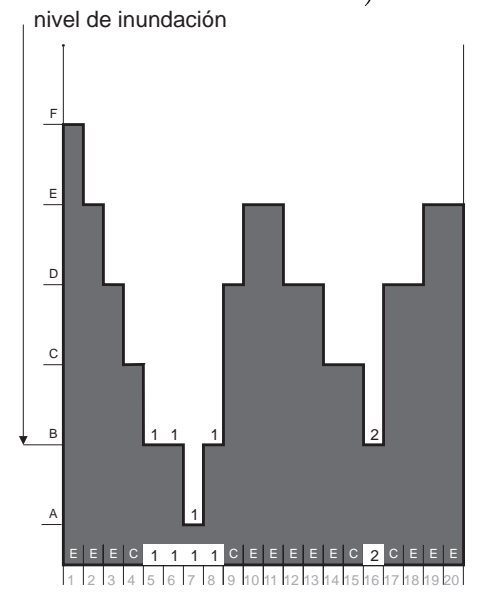

e)
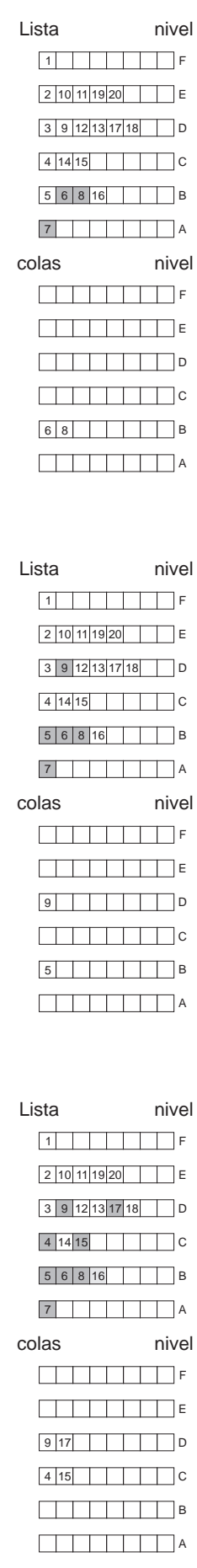

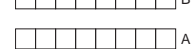
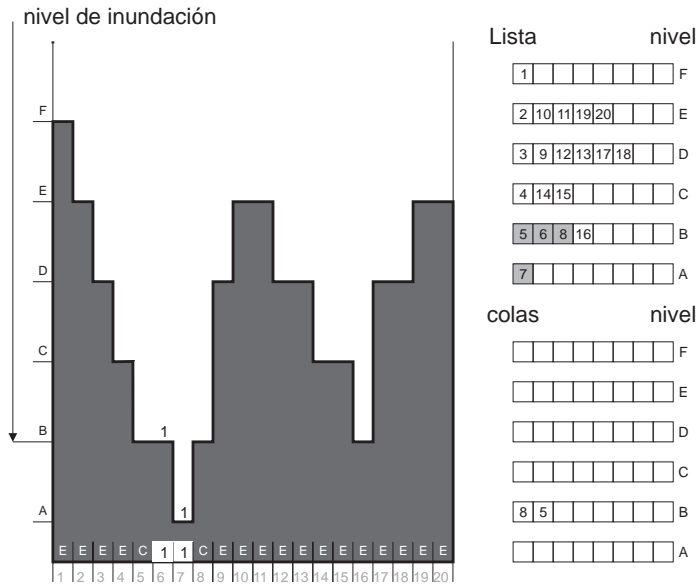

b)
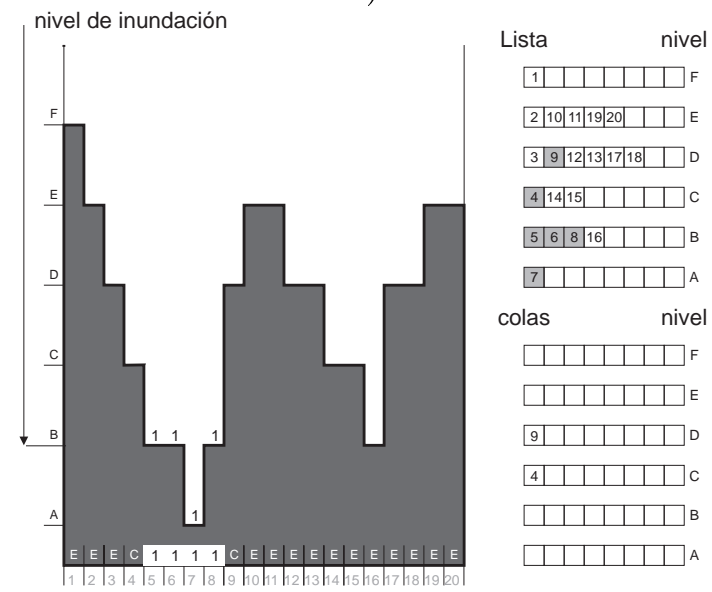

d)
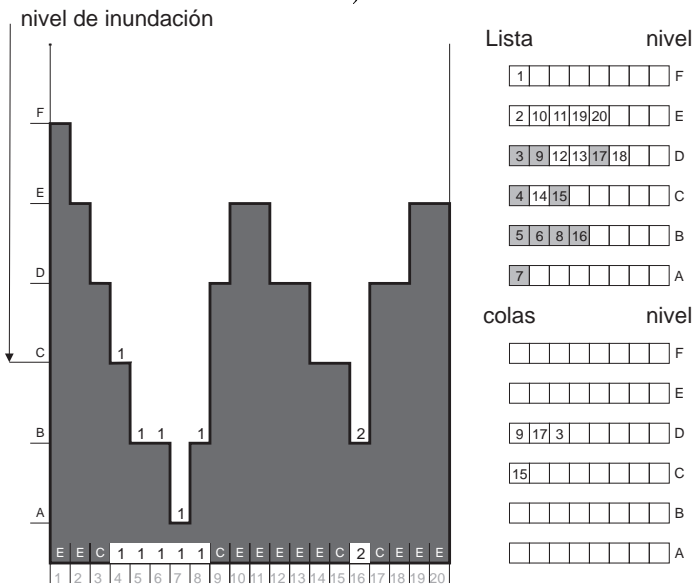

f)

Figura 4.25: Utilización de colas jerárquicas para etiquetar los pixels en el cálculo del cierre superficial. La etiqueta E significa en espera y la $\mathrm{C}$ en cola. 
en la cola D. El último paso ilustrado refleja que como ya se han procesado todos los pixels de nivel B se pasa a la cola de nivel C para etiquetar el pixel 4, tras lo cual se repite el proceso expuesto hasta llegar al último nivel de inundación.

Durante el proceso explicado, cuando un pixel ha sido puesto en la cola se ha asignado en el espacio dedicado a la etiqueta la etiqueta $C$, indicando que está en cola. A continuación se justifica este hecho.

Dado que un pixel es vecino de varios, un pixel puede ser puesto en alguna cola porque se haya llegado hasta él a través de su vecino de la derecha o de la izquierda (en el caso de funciones bidimensionales, por dos o más de entre sus ocho vecinos). Puede ocurrir lo siguiente: siguiendo con el proceso ilustrado en la figura 4.25 se llega a la situación ilustrada en la figura 4.26 a correspondiente al momento en que acaba de ser etiquetado el último pixel de nivel D. El siguiente paso consiste en extraer de la cola E el primer pixel, que resulta ser el 10, etiquetarlo y poner en la cola sus vecinos que todavía no tienen etiqueta (figura 4.26b). Si se hiciera esto volvería a ponerse en cola el pixel 11 que ya fue puesto cuando se procesó el pixel 12. Para evitar esto es necesario la utilización de la etiqueta en-cola que hemos denotado con la letra C.

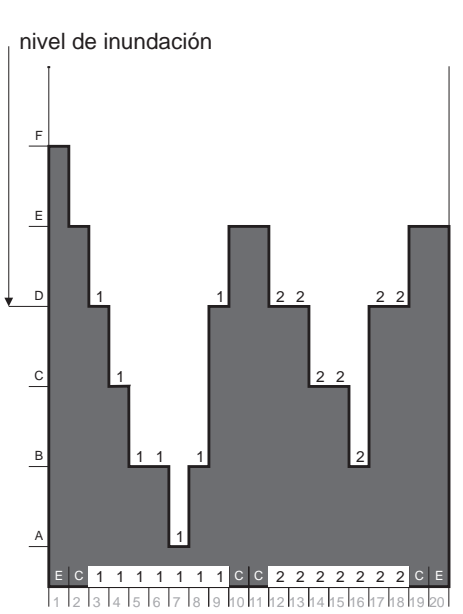

a)

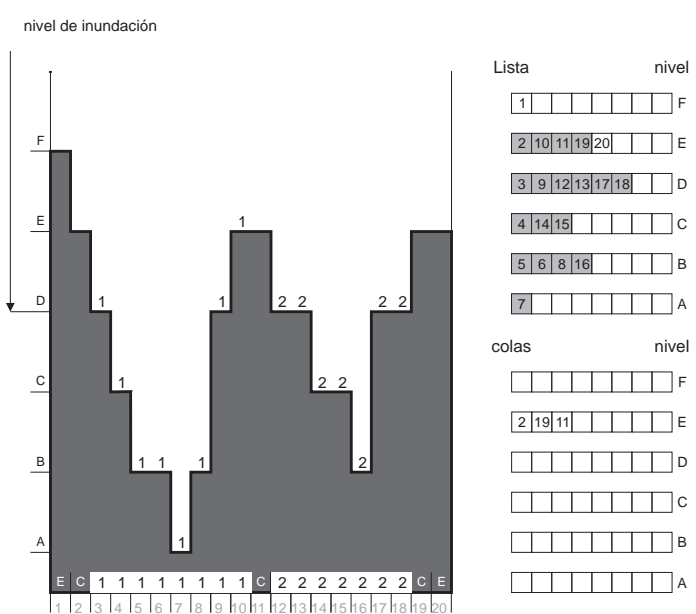

b)

Figura 4.26: Necesidad de la etiqueta en-cola. En este ejemplo si no se hubiera utilizado la etiqueta en-cola el pixel 11 hubiera sido puesto en la cola 2 veces.

Durante el proceso de etiquetado, dinámicamente, se van añadiendo y extrayendo pixels a y desde las colas. Añadiendo, porque son vecinos del actualmente etiquetado, y se extrae un nuevo pixel cada vez que termina el proceso asociado a etiquetar el pixel actual.

Los párrafos precedentes son aplicables en general a los algoritmos basados en inundación. En particular, en el cálculo del cierre superficial estamos interesados 
en conocer en qué nivel de inundación la superficie de cada cuenca alcanza un valor predeterminado $\lambda$. Cuando se etiqueta un nuevo pixel, la cuenca a la que pertenece incrementa su superficie en una unidad. Para saber cuando la superficie alcanza el valor $\lambda$ se debe tener un contador asociado a cada cuenca que se incrementará en una unidad cada vez que se etiquete un pixel con la etiqueta de una cuenca, comprobándose a continuación si se ha alcanzado el valor $\lambda$, en cuyo caso se registra para esta cuenca el nivel de inundación actual, por lo que se necesita una estructura de datos asociada a cada cuenca, entre cuyos elementos estarán dicho contador y el campo que alberga el nivel de inundación para el cual la superficie de la cuenca alcanza el valor $\lambda$.

Consideremos para el ejemplo de la figura 4.27 un valor de $\lambda$ igual a 6 . La cuenca asociada a cada mínimo termina en una determinada zona cuando sus aguas se unen con las de la cuenca vecina, es decir en la línea divisoria de aguas. Puede ocurrir que cuando se alcanza esta línea la cuenca no tenga todavía una superficie de valor $\lambda$, tal como ocurre por ejemplo con las cuencas 2 y 3 de la figura 4.27. En dicha figura se han sombreado aquellos pixels de las cuencas que están por debajo de la línea divisoria de aguas. Dada la definición del cierre superficial, el nivel de gris $g_{c_{\lambda}}$ en el que la cuenca $c$ alcanza la superficie $\lambda$, para ambas cuencas es un valor superior al valor del nivel previo al de la línea divisoria de aguas y por tanto será común para ambas cuencas porque por encima de la línea divisoria de aguas la superficie es la suma de la aportada por cada una de ellas. Gráficamente, si no se ha alcanzado la superficie $\lambda$ el agua que cubre las dos cuencas pasa a ser común para ambas. Llamémosle a este hecho fusión de dos cuencas, y llamemos nivel de fusión al nivel de inundación en el que se alcanza el punto de la línea divisoria de aguas que comunica ambas cuencas.

Una vez se ha introducido de forma aproximada los conceptos para el cálculo eficiente, a continuación se presenta de una forma más estructurada el núcleo de la tarea a realizar cuando se etiqueta un pixel. Básicamente se pueden presentar tres situaciones distintas:

1. que ningún pixel vecino tenga etiqueta de cuenca: es un nuevo mínimo y por tanto hay que asignar una nueva etiqueta (por ejemplo el pixel número 7 de la figura 4.27).

2. que todos los pixels vecinos con etiqueta de cuenca tengan la misma etiqueta: es un pixel más de la cuenca y se asigna la misma etiqueta de cuenca que ellos (por ejemplo el pixel número 8 de la figura 4.27).

3. que los pixels vecinos con etiqueta de cuenca tengan etiquetas distintas: este pixel pertenece a la línea divisoria de aguas y se produce por tanto una fusión de cuencas (por ejemplo el pixel número 14 de la figura 4.27). 


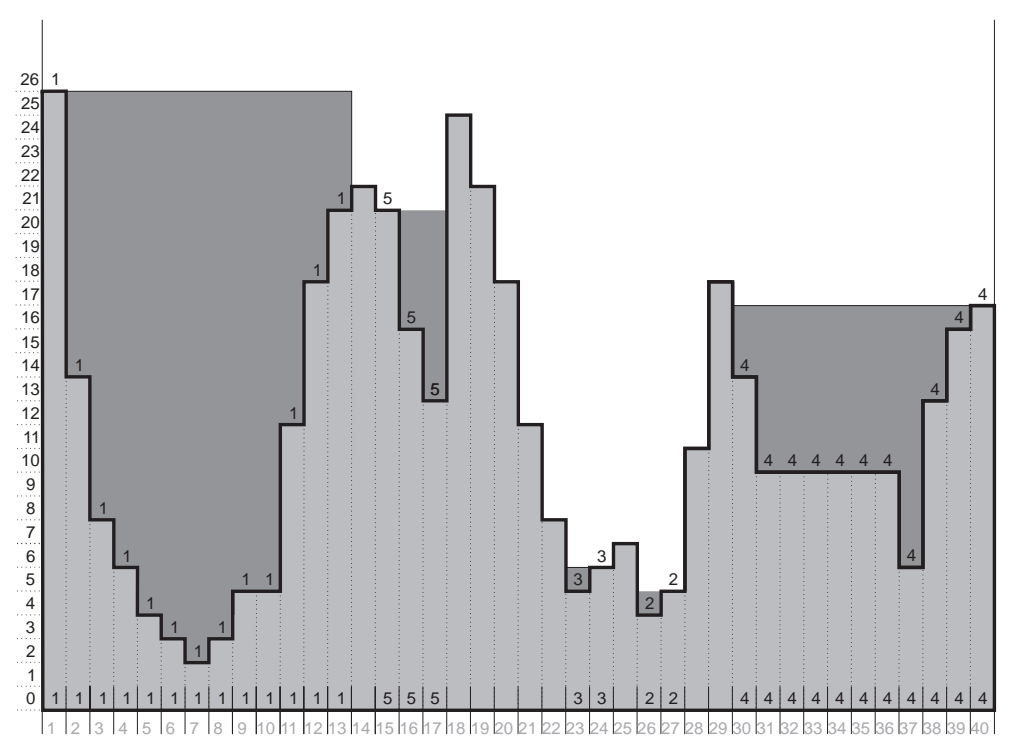

Figura 4.27: Cierre superficial. Pixels de las cuencas asociadas a los mínimos de la función antes de alcanzar la línea divisoria de aguas. Algunas cuencas pueden no haber alcanzado la superficie mínima $\lambda$ requerida en el cierre superficial. Por ejemplo para $\lambda=6$ las cuencas 5,3 y 2 tienen una superficie menor que $\lambda$.

La tarea a realizar, aparte de anotar la etiqueta correspondiente en el pixel de la imagen de etiquetas, en cada uno de los casos es la siguiente:

- en el primer caso inicializar una nueva estructura de datos que contenga la información relativa a la cuenca que se acaba de crear. Dicha información consiste en un campo contador, que llamaremos superficie, y que alberga la cantidad de pixels que van formando la cuenca, es decir la superficie, inicializándose a uno porque se acaba de encontrar el primer pixel de la cuenca. Otro campo de la estructura que llamaremos altura es el nivel de inundación en el que la superficie de la cuenca alcanza el valor $\lambda$; este campo se inicializa a un valor que no pertenezca a la escala de niveles de gris cuyo significado es que no se ha alcanzado todavía el nivel de inundación que permite tener una superficie de cuenca mayor o igual a $\lambda$. Cada vez que se modifica el campo superficie se comprueba si ha alcanzado el valor $\lambda$, en cuyo caso se anota en el campo altura el nivel de inundación actual.

- en el segundo caso la etiqueta que se asigna al pixel ya existe previamente con lo que la estructura de datos asociada a la cuenca también existe y simplemente hay que actualizarla porque se agrega un nuevo pixel a la cuenca, realizando las mismas comprobaciones mencionadas en el párrafo anterior. Cuando se alcanza una superficie de valor $\lambda$ se anota el nivel de inundación correspondiente en el campo altura. En posteriores agregaciones de pixels a la cuenca no se debe modificar su valor. Esto es así debido a 
la definición del cierre superficial en el que se busca el ínfimo del conjunto dado en la definición (ver definición de apertura superficial, página 102).

- el tercer caso requiere más atención debido a que se produce una fusión entre cuencas. Para registrar este hecho la estructura de datos asociada a cada cuenca debe disponer de dos campos más. Uno contendrá la información de qué cuencas se fusionan, y que llamaremos Equival. Este es un campo que contiene la etiqueta de la otra cuenca. Cuando la estructura de datos se crea por primera vez este campo se inicializa con la etiqueta de la propia cuenca. Cuando se produce una fusión entre dos cuencas se anota en el campo Equival de la segunda la etiqueta de la primera. Entendemos por segunda la que tenga un valor de etiqueta (no de superficie) mayor. Si un pixel produce una fusión de más de dos cuencas, la equivalencia múltiple queda registrada como la concatenación de equivalencias simples, por ejemplo, si se fusionan tres cuencas, en el campo Equival de la tercera se anota la etiqueta de la segunda y en el campo de la segunda se anota la etiqueta de la primera. En la primera permanece la etiqueta de ella misma indicando que aquí se termina la cadena de equivalencias, llamaremos a esta etiqueta irreducible. A partir de la fusión se deben entender todas ellas como una única cuenca y por tanto la estructura de datos de la cuenca con la etiqueta irreducible es la que contendrá la información relativa al conjunto de cuencas que se han fusionado. Así, en el campo superficie de la irreducible se debe sumar a la superficie que ya existía la superficie que aportan el resto de cuencas, y además incrementarla en una unidad por el pixel en curso, que es el que ha producido la fusión.

El otro campo de la estructura de cada cuenca albergará, si procede, el nivel de inundación en el que se ha producido la fusión, y que llamaremos Nfusión. El campo se inicializa a un valor que no pertenezca a la escala de niveles de gris (por ejemplo un valor negativo) indicando que todavía no se ha producido ninguna fusión. Si se produce una fusión entre varias cuencas, en todas menos en la que va a tener la etiqueta irreducible se anota el nivel de inundación actual. Más adelante se ilustra la función de registrar esta información.

A su vez en el tercer caso, concretando sobre los conceptos que se acaban de exponer podemos distinguir dos situaciones posibles según si las cuencas al fusionarse habían alcanzado o no una superficie $\lambda$. La primera situación consiste en que ninguna de ellas haya alcanzado, previamente a la fusión, una superficie $\lambda$. La segunda ocurre si al menos una de ellas ya había alcanzado una superficie $\lambda$.

Respecto a la primera, hay que realizar todo el proceso descrito anteriormente estableciendo la cadena de equivalencias de mayor a menor y asignar al nuevo 
pixel la etiqueta menor, que queda como la irreducible hasta que se produzca una nueva fusión. A partir de este momento, y mientras no se produzcan nuevas fusiones, cualquier pixel que se agregue a este grupo de cuencas que se han fusionado será etiquetado con la etiqueta menor. En la figura 4.28 se ilustra un ejemplo de este tipo y cómo quedarían etiquetados los pixels de las cuencas, así como el valor de la estructura de datos cuando se alcanza el nivel de inundación indicado en la figura. La ilustración corresponde a las cuencas 2 y 3 de la figura 4.27 .

En la segunda situación, lo que cambia respecto a la primera, es que cuando se establece la cadena de equivalencias, hay que respetar el requisito que se ha mencionado con anterioridad de que una vez una cuenca ha alcanzado una superficie $\lambda$ aunque se agreguen más pixels no hay que modificar nada en su estructura de datos. Por tanto hay que establecer las equivalencias de manera que quede como etiqueta irreducible una cualquiera de las que ya habían alcanzado una superficie de valor $\lambda$. Las demás que ya superaban $\lambda$ y que consecuentemente eran también irreducibles se mantienen al margen de la cadena de equivalencias. Para las que no superaban $\lambda$ se anota que son equivalentes a la irreducible elegida y en el campo Nfusión se anota el nivel de inundación actual. Dado que en una ilustración mediante una función unidimensional en un pixel sólo se puede producir la fusión de un máximo de dos cuencas, la figura 4.29 muestra un ejemplo de esta segunda situación, donde una cuenca que no ha alcanzado en el pixel que fusiona la superficie de valor $\lambda$ se fusiona con otra que sí lo ha hecho. La figura refleja también el etiquetado de los pixels hasta un nivel de inundación superior al pixel en el que se ha producido la fusión. Nótese que la etiqueta que se propaga en niveles superiores al de fusión es la de la cuenca que sí había alcanzado $\lambda$.

Cuando se alcanza el nivel de inundación correspondiente al valor máximo de la escala de niveles de gris y se etiquetan todos los pixels de ese nivel, se tiene completa la imagen de etiquetas y una lista de estructuras de datos cuyo número depende del número de cuencas que se han encontrado en la imagen. Si una cuenca antes de fusionarse con otra tiene una superficie mayor o igual a $\lambda$ tendrá en el campo altura un valor válido, en caso contrario en el campo altura no tendrá nada (representado por un valor fuera de la escala de niveles de gris, en nuestro caso -1) y tendrá en el campo Nfusion el valor correspondiente. La última fase del proceso es encontrar para cada pixel de la imagen de salida el nivel de gris que debe tener. Este nivel de gris es el máximo entre el nivel de gris de ese pixel en la imagen de entrada y otro nivel de gris que a su vez es el máximo de un grupo de niveles de gris extraídos a partir de la información contenida en la imagen de etiquetas y las estructuras de datos asociadas. Dicho grupo está formado por los valores válidos encontrados en los campos Nfusion y en el campo altura de las cuencas encontradas a lo largo de la cadena de equivalencias formada 


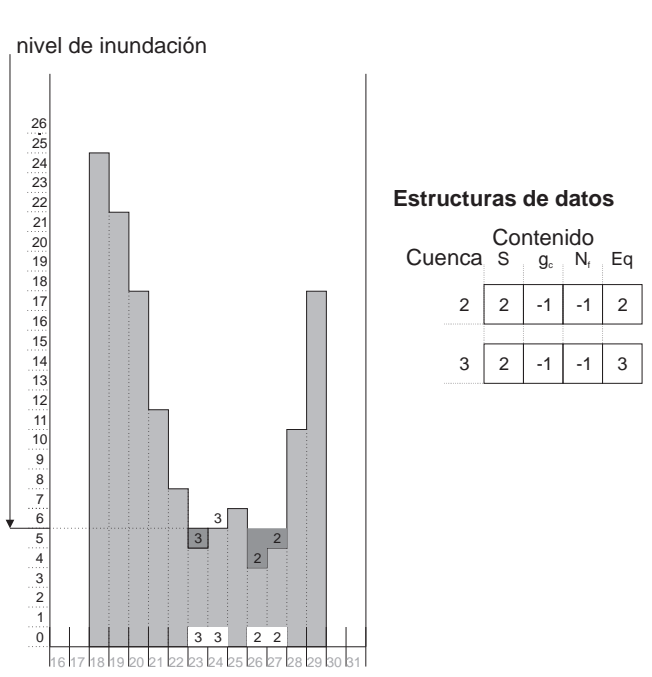

a)

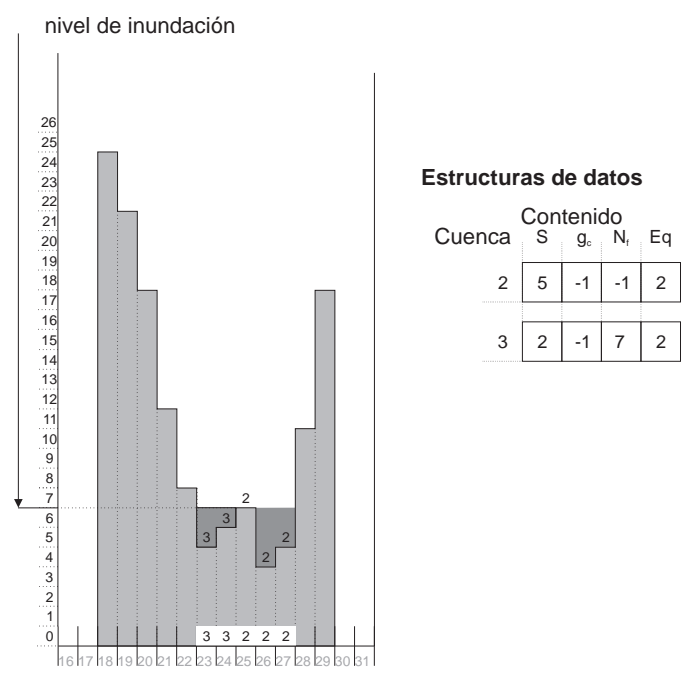

b)

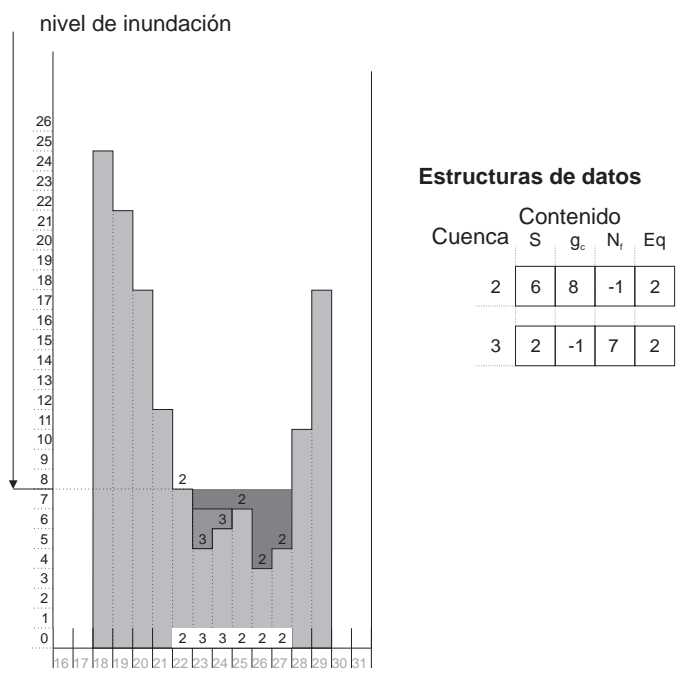

c)

Figura 4.28: Etiquetado en el cierre superficial. Se fusionan dos cuencas y ninguna de ellas había alcanzado la superficie de valor $\lambda$. a) Antes de alcanzar el nivel de fusión. b) Después de alcanzar el nivel de fusión. c) Alcanzan la superficie de valor $\lambda$.

Los nombres de los campos de datos son: $S$ superficie; $g_{c}$ altura (nivel de gris en el que se alcanza la superficie de valor $\lambda$ ); $N_{f}$ nivel de fusión; Eq etiqueta de la cuenca con la que se ha fusionado (si no se ha fusionado con ninguna contiene la etiqueta de la propia cuenca). 


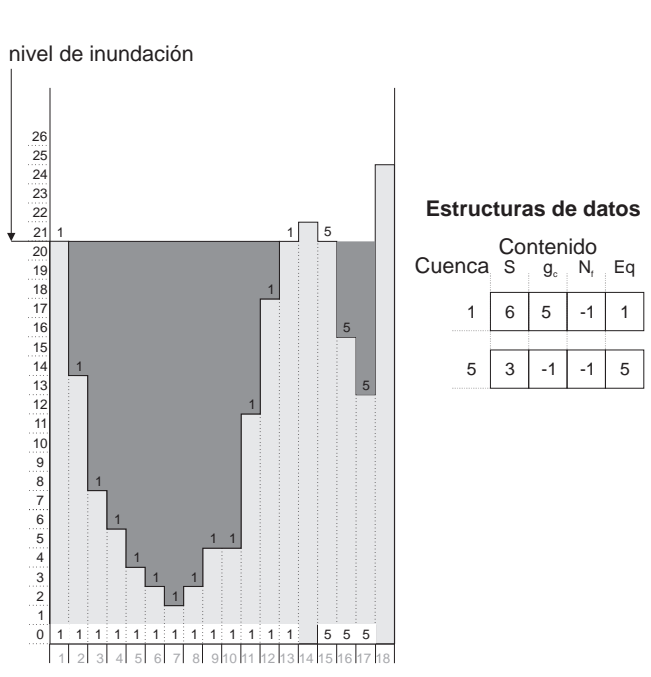

a)

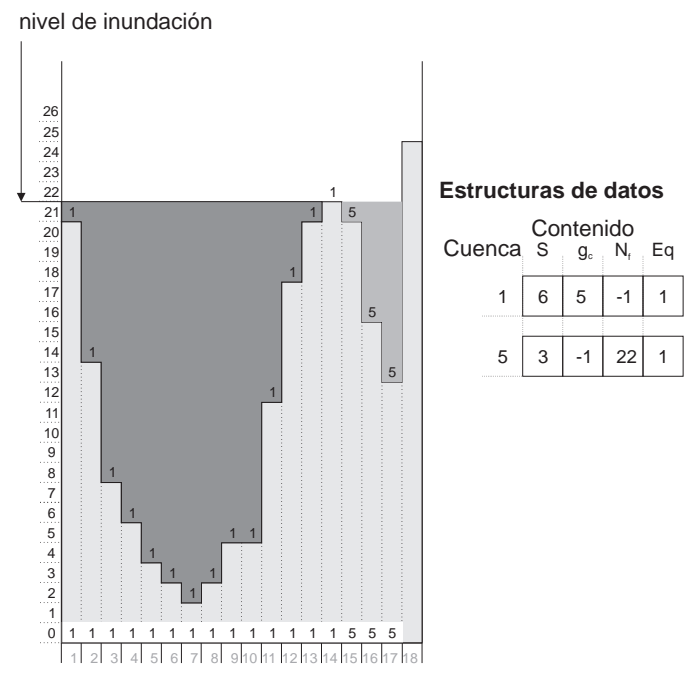

b)

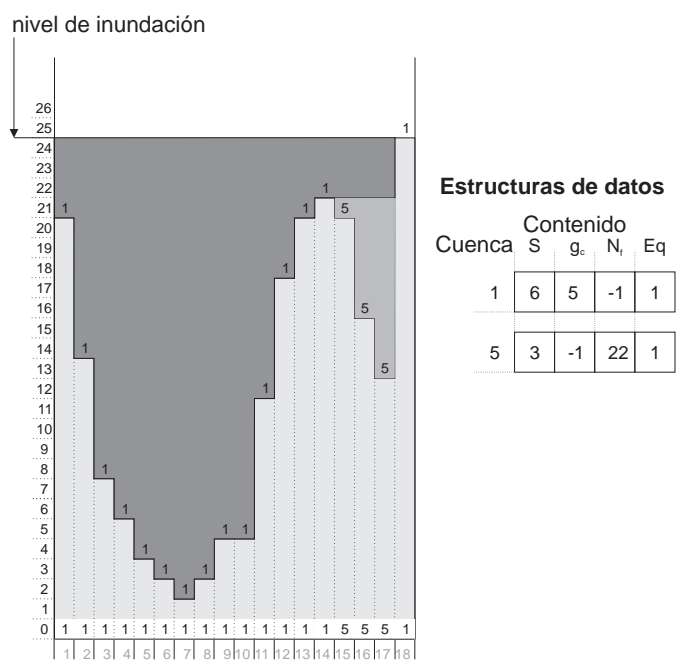

c)

Figura 4.29: Etiquetado en el cierre superficial. Se fusionan dos cuencas y alguna de ellas había alcanzado la superficie de valor $\lambda$. a) Antes de alcanzar el nivel de fusión. b) Después de alcanzar el nivel de fusión. c) Nivel de inundación superior al de fusión. 
comenzando en la cuenca a la que pertenece el pixel hasta llegar a la cuenca que contiene la etiqueta irreducible, que necesariamente cumple haber alcanzado una superficie de valor $\lambda$ salvo que dicho valor sea mayor que la superficie de la propia imagen, situación que se puede detectar antes de comenzar cualquier proceso y generar la correspondiente advertencia sin necesidad de comenzar el proceso de inundación. La figura 4.30 presenta un ejemplo de esta última parte del proceso; en $4.30 a$ aparece la función de entrada y el resultado del proceso de etiquetado y en $4.30 b$ la función de salida resultante. El conjunto de estructuras de datos asociadas a cada cuenca con los valores registrados al finalizar el proceso de etiquetado se presenta junto a las figuras. 

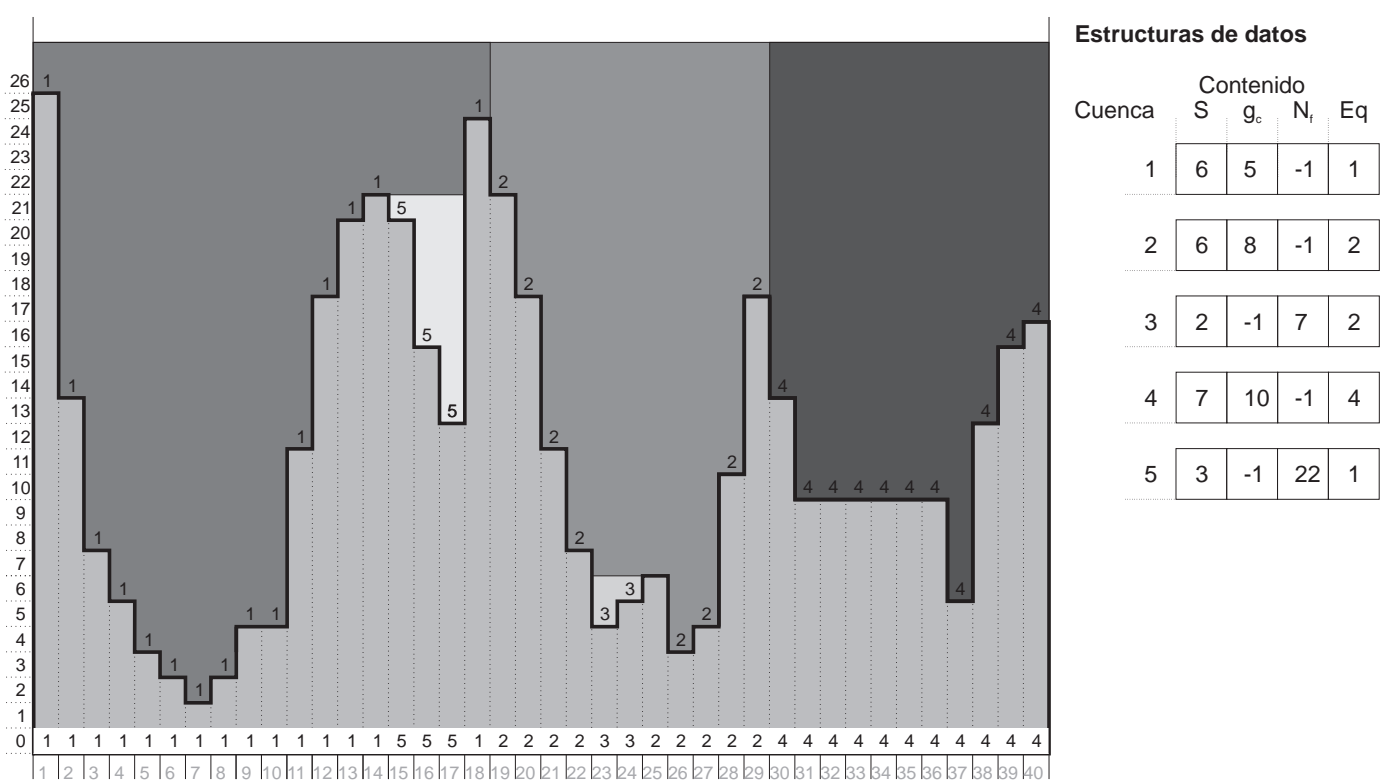

a)

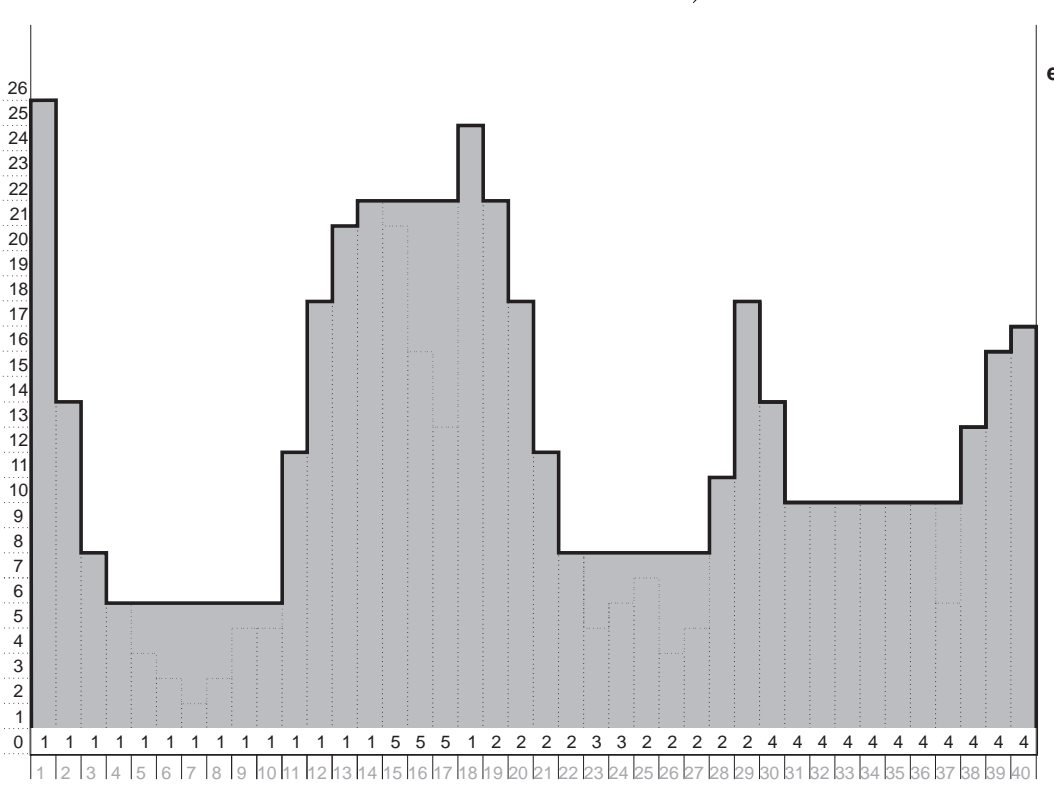

Conjunto de valores $\mathrm{g}_{\mathrm{c}}$ y $\mathrm{N}_{\mathrm{i}}$ a lo largo de la cadena de equivalencias de cada cuenca

Cuenca

Máximo

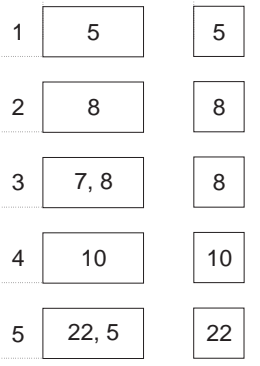

b)

Figura 4.30: Cierre superficial. Proceso final de obtener el nivel de gris en la imagen de salida tras finalizar el proceso de etiquetado. a) Etiquetado de la función y contenido de las estructuras de datos resultante al finalizar; b) Niveles de gris de la función resultante del cierre superficial junto con los valores $g_{c}$ y $N_{f}$ a lo largo de la cadena de equivalencias de cada cuenca. 


\section{Capítulo 5}

\section{Algoritmo}

\section{$5.1 \quad$ Introducción}

La propuesta que aquí se hace es realizar un uso conjunto de la morfología matemática y los campos aleatorios de Markov para la detección de las microcalcificaciones en mamografía. Tanto la morfología matemática como los campos aleatorios de Markov son herramientas y modelos aplicables a la segmentación genérica de imágenes, incluso la combinación de ambas ya ha sido utilizada para tal fin [77], pero dado que la mamografía es una imagen muy específica, es conveniente desarrollar algoritmos orientados a la aplicación.

Es importante hacer un examen de las imágenes a tratar y de las regiones que se desean detectar en dichas imágenes para desarrollar el algoritmo de segmentación adecuado.

La figura 5.1 presenta la imagen z01c, a escala reducida para que quepa en la página, de la base de imágenes mamográficas utilizada para la presente tesis, cuya presentación se realiza en el Anexo A. En dicha figura se encuentran indicadas con un recuadro las regiones que interesa detectar. Para una mayor claridad, se muestran tres ampliaciones y para cada una, una imagen binaria con fondo blanco y marcados en negro los pixels que en la imagen z01c corresponden a microcalcificación. Tal como se ha definido al plantear el problema de la segmentación en el capítulo 3, para delimitar las regiones de la imagen debemos definir las características de similitud de los pixels que pertenecen a una misma región y las características de diferenciación de pixels que pertenecen a regiones distintas. De la figura 5.1 se puede ver que las microcalcificaciones están formadas por pixels cuyo nivel de gris es más claro que el tejido circundante. También se puede apreciar que son regiones con un número de pixels mucho más pequeño que el número de pixels de la imagen, es decir las microcalcificaciones son objetos 


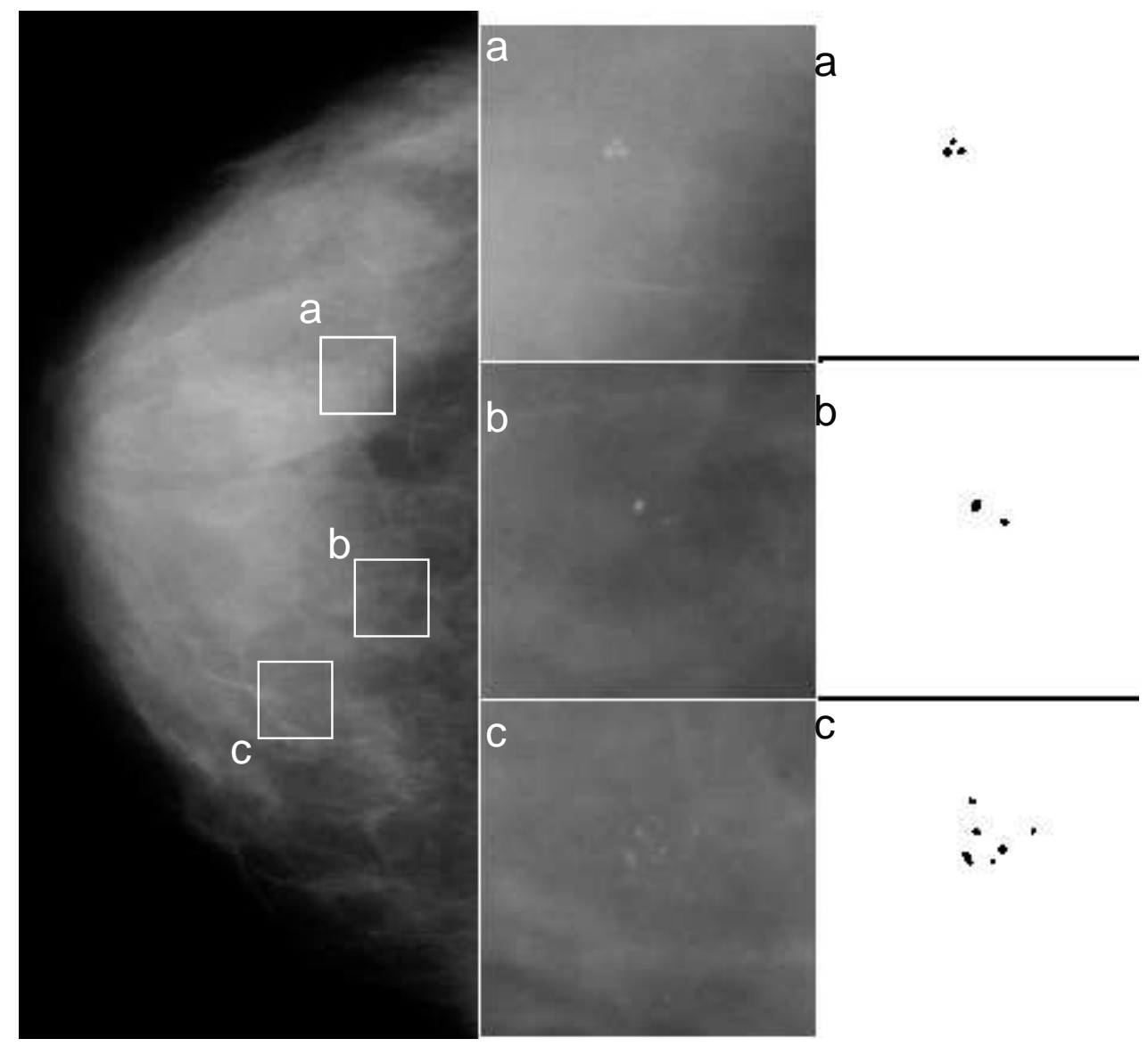

Figura 5.1: Imagen z01c con tres zonas ampliadas correspondientes a lo recuadros. La última columna corresponde a imágenes binarias que en negro indican los clusters de microcalcificaciones marcados por los radiólogos 
pequeños. No obstante en la mamografía existen muchas agrupaciones de pixels conexos caracterizados por tener un nivel de gris mayor que el de los pixels circundantes a la región y por tener un número de pixels pequeño y no son microcalcificaciones.

La detección de las microcalcificaciones en una mamografía se puede abordar directamente como un problema de segmentación binaria, donde la imagen resultado tendría dos etiquetas, por ejemplo, "microcalcificación" y "no microcalcificación". Esta segunda etiqueta para una mejor diferenciación lingüística podríamos llamarla "fondo". Dado que no hay ninguna microcalcificación que separe la imagen en dos partes, el fondo será una única región que abarcará la práctica totalidad de la imagen, mientras que la/s microcalcificación/es será/n una o varias regiones rodeadas totalmente por la región fondo, y en menor frecuencia, por el fondo y el borde de la imagen. Para realizar la segmentación se necesitará determinar un predicado común a todos los pixels del fondo y que no cumplan los pixels de las microcalcificaciones, hecho que considerando única y directamente los niveles de gris de la imagen no se puede encontrar.

Aunque el fin último de la tarea a realizar es llegar a una segmentación binaria partiendo de la imagen en niveles de gris de la mamografía, se puede plantear dicha segmentación binaria indirectamente como un primer paso de segmentación multietiqueta (más de dos etiquetas), seguido de un segundo paso de agrupar todas aquellas etiquetas distintas a microcalcificación en una única región, con lo que se llega a la segmentación binaria deseada. Esta forma indirecta facilita encontrar varios predicados que permitan implementar una segmentación.

La figura $5.2 a$ muestra la mamografía z01c reducida por dos donde se marcan dos regiones con sendos recuadros. La figura $5.2 b$ es una ampliación de la zona marcada por el recuadro inferior, donde se pueden apreciar tres regiones pequeñas con pixels cuyo nivel de gris es mayor que el tejido circundante. La figura $5.2 c$ es la ampliación de la zona marcada por el recuadro superior, donde también se pueden apreciar dos regiones pequeñas con pixels cuyo nivel de gris es mayor que el tejido circundante. La región de la figura $5.2 b$ ha sido marcada por los radiólogos como cluster de microcalcificaciones, mientras que las regiones de la figura $5.2 c$ no han sido consideradas por los radiólogos como microcalcificaciones. Las figuras $5.2 b$ y $c$ han sido impresas aumentado su contraste por cuatro para una mejor visualización.

Otro ejemplo del problema de la segmentación se ilustra en la figura 5.3. La parte $a$ muestra la mamografía z03c completa donde se marcan dos regiones con sendos recuadros. Las figuras $5.3 b$ y $c$ corresponden a las ampliaciones de las zonas marcadas por los recuadros superior e inferior respectivamente, y en ambas se pueden apreciar regiones con nivel de gris mayor que el tejido circundante. Mientras que las regiones claras de la figura $5.3 b$ deben ser etiquetadas como 

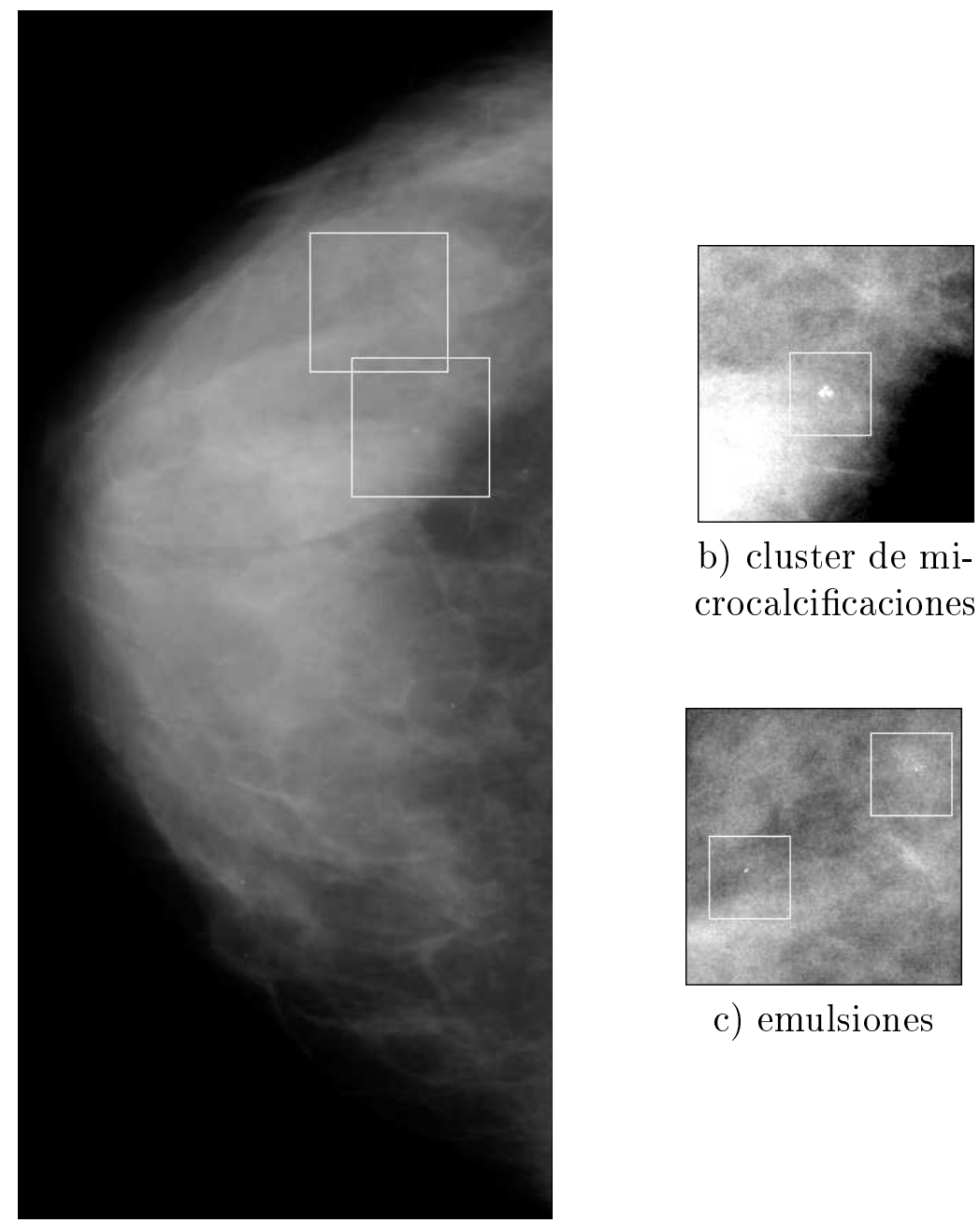

b) cluster de microcalcificaciones

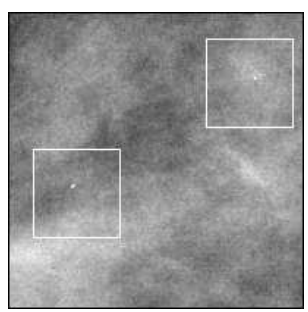

c) emulsiones

a)

Figura 5.2: a) Imagen z01c reducida en tamaño por dos, con dos zonas marcadas ampliadas en $b$ y $c$. b) corresponde al recuadro inferior, subimagen de 200x200 a partir del pixel $(480,500)$ ampliado en contraste por cuatro. Se aprecia un grupo de tres áreas pequeñas claras. Ha sido marcado por los radiólogos como cluster de microcalcificaciones. c) corresponde al recuadro superior, subimagen de 200x200 a partir del pixel $(420,320)$ ampliado en contraste por cuatro. Se aprecian dos áreas pequeñas claras. No ha sido marcado por los radiólogos como microcalcificaciones 
microcalcificación, las de la figura $5.3 \mathrm{c}$ no. Estas últimas corresponden a tejido fibroso de la mama, que en la mamografía aparece con niveles de gris mayores que su entorno. Las imagenes $b$ y $c$ han sido impresas con su contraste aumentado por cuatro para facilitar la visualización de los detalles de interés.

Independientemente de que la segmentación se aborde de forma binaria o multietiqueta, ésta no necesariamente se debe hacer tomando como única información de entrada el nivel de gris directamente de cada pixel, sino que la imagen de la mamografía se puede procesar para obtener otra imagen de niveles de gris que sean el resultado numérico de alguna transformación más útil para la segmentación como por ejemplo el contraste local, definido como la diferencia entre el nivel de gris del pixel y la media de los niveles de gris de un vecindario dado (es decir un filtrado paso alto). En este sentido son de utilidad aquellos procesos que dan un resultado numérico similar en todos los pixels que deban pertenecer a la misma región, y un resultado lo más diferente posible entre los pixels que deban tener etiquetas distintas.

El nivel de gris de las microcalcificaciones en las mamografías puede variar de una a otra, a su vez se puede apreciar en las figuras anteriores que en una misma mamografía el nivel de gris de un pixel de microcalcificación no es exclusivo de microcalcificación, sino que el mismo nivel de gris se puede encontrar en regiones que no son microcalcificación. Este hecho, junto con la característica de que las microcalcificaciones son regiones pequeñas hace que sean más apropiadas imágenes que resalten la diferencia entre el pixel y alguna característica de su vecindario, que el nivel de gris propiamente de cada pixel de la mamografía.

En una mamografía, basándonos en información local del vecindario de un pixel, se pueden encontrar varios tipos de regiones:

1. Regiones con pixels cuyo nivel de gris es similar en todos ellos, o cuya variación es muy pequeña de uno a otro, de tamaño generalmente mediano o grande (por encima de la centena de pixels)

2. Regiones debidas a fibras, con pixels cuyos niveles de gris son mayores que los de sus alrededores y que tienen formas alargadas. El tamaño de la región es variable.

3. Regiones debidas a microcalcificaciones y que quedan reflejadas en la mamografía con pixels cuyo nivel de gris es mayor que el de sus alrededores, con formas fundamentalmente redondeadas, aunque sus bordes no necesariamente son uniformes. El tamaño de la región es básicamente pequeño, con un margen desde menos de una decena de pixels a menos de una centena de pixels. Excepcionalmente se pueden alcanzar tamaños mayores. 

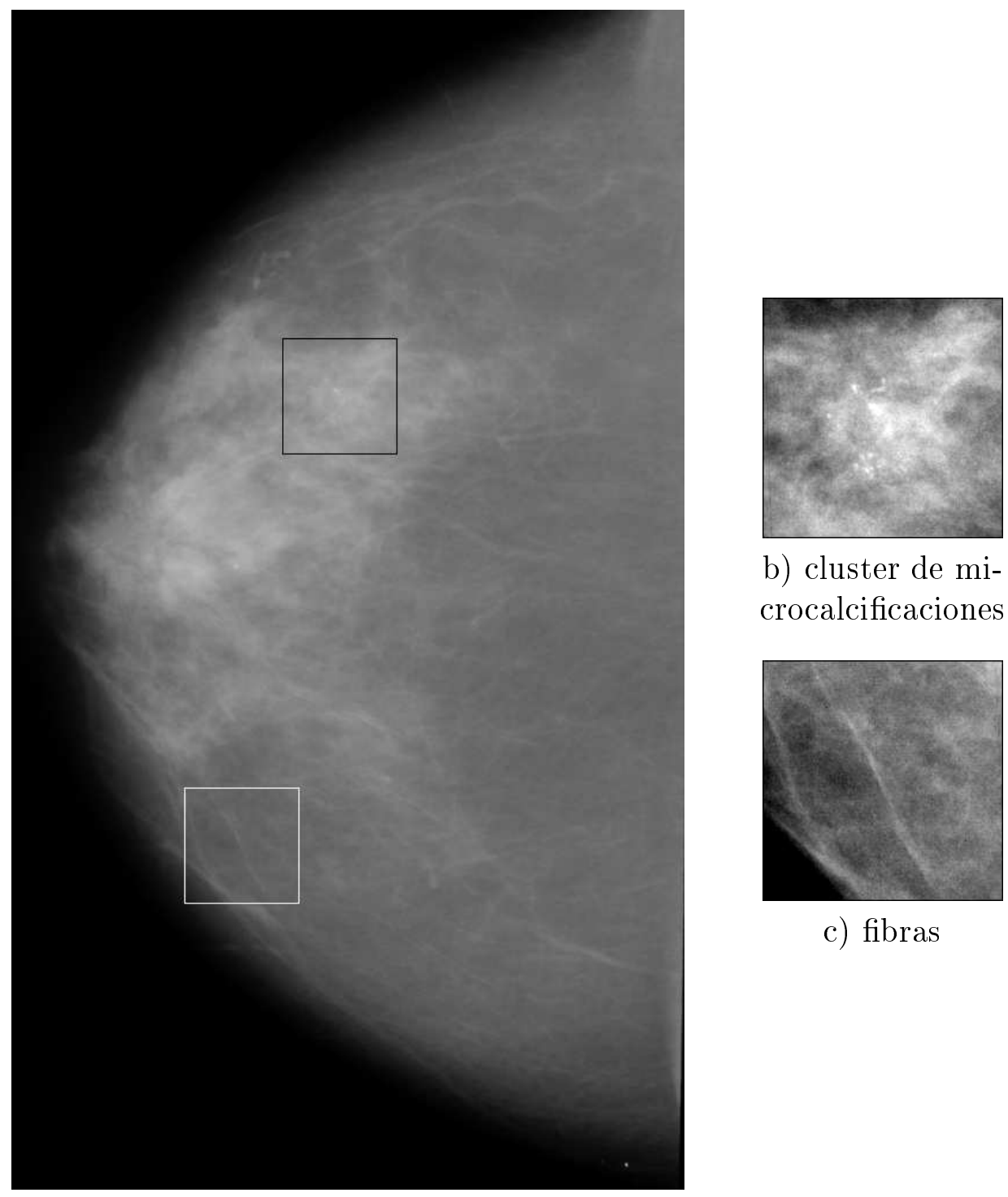

b) cluster de microcalcificaciones

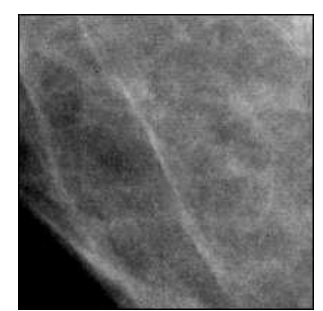

c) fibras

a)

Figura 5.3: a) Imagen z03c completa reducida en tamaño por dos; b) Ampliación de la zona marcada por el recuadro superior, aumentada por cuatro en contraste, en la que si se han detectado microcalcificaciones; c) Ampliación de la zona marcada por el recuadro inferior, aumentada por cuatro en contraste, en la que se puede apreciar la existencia de fibras estrechas. 
4. Regiones con una variación del nivel de gris de un pixel a otro grande, correspondiente a los situados en las fronteras de regiones del tipo 1.

5. y por último, regiones con pixels cuyo nivel de gris es mayor que el de sus alrededores, con formas diversas, con tamaño similar al de las microcalcificaciones pero que no lo son, y cuya diferencia de nivel de gris es mayor o similar que la originada por las microcalcificaciones. Estas regiones pueden aparecer por diversos motivos, entre otros debido a fallos de la emulsión fotográfica de la radiografía, a huellas dactilares del personal sanitario que manipula la radiografía durante su realización, a restos de materiales radiopacos que se hayan depositado previamente a la adquisición de la mamografía en alguna parte del equipo mamográfico o sobre la piel de la mama de la paciente [68] [72]. Salvo en los casos de huellas dactilares, este tipo de región suele aparecer individualmente sin formar grupos.

Los campos aleatorios de Markov compuestos son un modelo matemático adecuado para segmentar imágenes basándose en sus características locales y/o texturas. Para ello hay que asumir un tipo de campo para cada tipo de región en función de su textura [22] y otras características como geométricas y/o estadísticas; y otro campo aleatorio de Markov para la distribución de las regiones en la imagen (ver sección 3.4 ), pero el proceso para abordar la segmentación tomando como única entrada la imagen en niveles de gris y un modelo basado en campos aleatorios de Markov compuestos que tenga en cuenta la geometría de las regiones es extremadamente lento. Es mucho más eficiente dividir el proceso de segmentación en dos fases [58] [88] [24]

- una primera fase sin la participación de los campos aleatorios de Markov, donde a partir de la imagen en niveles de gris se obtiene con cualquier otra técnica adecuada, una segunda imagen (o varias) donde el nivel de gris sea el resultado numérico de una transformación sobre alguna/s característica/s local/es, ya sea de amplitud, forma o de cualquier otro tipo.

- una segunda, donde la base del proceso son los campos aleatorios de Markov, en la que a partir del resultado numérico de la fase anterior se obtiene el etiquetado de los pixels.

Nosotros proponemos como proceso para la primera fase operadores no lineales basados en morfología matemática, y los campos aleatorios de Markov como modelo que permite mejorar la segmentación que se alcanzaría utilizando sólo dichos operadores morfológicos.

Es importante destacar que radiológicamente lo significativo son los grupos 
(clusters) de microcalcificaciones más que las microcalcificaciones en sí. Para ello hay que definir un cluster. La definición atiende a dos conceptos:

- cantidad mínima de microcalcificaciones para que sean consideradas un cluster, y

- distancia entre ellas para que sean consideradas del mismo cluster.

En la literatura se pueden encontrar criterios que varían ligeramente de unos a otros. Respecto al número mínimo existen referencias que estipulan un número mínimo de dos [58] [135], en [30] se utiliza tres como criterio, y en [68] se propone cinco como índice de malignidad. Respecto a la distancia mínima las referencias citan desde $0.5 \mathrm{~cm}$ [58] [30] a $1 \mathrm{~cm}$ [135]. En la presente tesis se considera la siguiente definición:

Definición 28 Se define cluster de microcalcificaciones como el conjunto de dos o más microcalcificaciones en la que la distancia que separa cada una de la más próxima de las restantes es menor o igual que $0.5 \mathrm{~cm}$

\subsection{Elección del campo aleatorio de Markov}

Tal como se ha expuesto en la sección anterior, la imagen que se tomará como entrada al proceso de segmentación con campos aleatorios de Markov será el resultado de una transformación de la imagen mamográfica. Esta entrada al campo aleatorio de Markov, siguiendo la nomenclatura de Besag [10] la llamaremos observación. La observación en nuestro caso es un vector unidimensional en el sentido de que por cada pixel de la imagen (o celosía) a segmentar tenemos un valor de entrada; no obstante el modelo no está limitado al caso unidimensional. Es posible plantear un modelo con $n$ imágenes de entrada, de manera que para un pixel $(i, j)$, se construya un vector de n elementos, siendo cada elemento del vector el valor correspondiente a la misma posición del pixel $(i, j)$ en las imágenes de entrada [58]. Siguiendo la nomenclatura utilizada en la sección 3.5.2 la observación será Y . La segmentación de esta observación será X.

Las transformaciones morfológicas que más adelante se utilizan tienen como entrada la mamografía con 256 niveles de gris y el número de niveles de salida también es 256, por tanto el valor del parámetro $G$ de la sección 3.1 es $G=256$.

Respecto al número de etiquetas posibles $K$ para un pixel de la segmentación en el presente trabajo consideramos tres, que son fondo, (o background), 
microcalcificación y para los llamados artefactos en [72], es decir, aquellos objetos de la mamografía de orígenes diversos, con aspecto que podría confundirse con una microcalcificación o grupo de ellas, utilizaremos la etiqueta de emulsión; numéricamente en el algoritmo se identifican con $l=0,1,2$ respectivamente. En el texto se utilizará cuando sea posible los identificadores alfabéticos $b$ (background), $c$ (microcalcificación) y e (emulsión) que recuerdan mejor que los números a qué tipo de objeto se refiere cada etiqueta.

Respecto al modelo de campo aleatorio de Markov y valor de los potenciales de los cliques, utilizaremos el planteamiento que realiza Besag [10] (pag. 269), donde se plantea un modelo en el que los potenciales de cliques de dos pixels no dependen de las posiciones $(i, j)$ y $(m, n)$ concretas sino del par $k, l$ de etiquetas asignadas a los pixels $(i, j)$ y $(m, n)$, respectivamente. De igual manera, el conjunto de funciones $G_{i j}\left(x_{i j}\right)$ no dependen de las posiciones de los pixels $(i, j)$, y son un conjunto de constantes $\left\{\alpha_{1}, \ldots, \alpha_{K}\right\}$ que depende exclusivamente de la etiqueta del pixel $(i, j)$.

En general, debido a la markovianidad, los coeficientes $\beta_{i j, m n}$ son cero para todos aquellos pares que no son vecinos. El vecindario en un campo aleatorio de Markov se puede definir del orden que sea oportuno, y normalmente cuando se trata de imágenes es suficiente con orden 2 [47] [10] [77]. También se suele limitar el conjunto de cliques a aquellos de dos elementos. Respecto a la temperatura $T$ de la expresión 3.12 vamos a incluirla en el valor de los parámetros $\alpha$ y $\beta$ [58], dado que estos pueden tomar cualquier valor. El conjunto de parámetros del modelo con el vecindario de orden 2 es entonces

$$
\begin{array}{llll}
\alpha_{b} & \beta_{b b} & \beta_{b c} & \beta_{b e} \\
\alpha_{c} & \beta_{c b} & \beta_{c c} & \beta_{c e} \\
\alpha_{e} & \beta_{e b} & \beta_{e c} & \beta_{e e}
\end{array}
$$

Los valores de $\alpha_{p}, p=\{b, c, e\}$ permiten controlar la sensibilidad de detección de cada clase con independencia del vecindario, mientras que los parámetros $\beta_{p q}$, $p, q=\{b, c, e\}$ modelan la interacción entre pixels vecinos con sus respectivas etiquetas. Dado que en el modelo que utilizamos sólo deseamos tener en cuenta el par de etiquetas del clique y no qué pixel particularmente tiene cada una, los parámetros $\beta$ serán simétricos, cumpliendo

$$
\beta_{p q}=\beta_{q p} \quad \text { con } p, q=\{b, c, e\} o p, q=\{0,1,2\}
$$

quedando la expresión 3.31

$$
p\left(x_{i j}=l \mid \mathbf{X}_{S \backslash i j}\right) \propto \exp \left\{-\alpha(l)-\sum_{m=0}^{2} \beta_{l m} g(m)\right\}
$$

donde $\mathrm{g}(\mathrm{m})$ es el número de pixels con la etiqueta $m$ en el vecindario de orden 2. En el presente trabajo se pretende aprovechar el modelo de campo aleatorio 
de Markov para que si en las proximidades a un pixel que va a ser etiquetado existen otras microcalcificaciones, a éste le sea signada con mayor probabilidad la etiqueta de microcalcificación. Las microcalcificaciones próximas pueden estar a una distancia considerablemente mayor que dos pixels (vecindario de orden 2), por lo que si queremos incluir la influencia de las microcalcificaciones vecinas habría que ampliar el vecindario de orden 2 a un vecindario mucho mayor, con el consiguiente aumento considerable del coste computacional (se debe entender aquí como microcalcificaciones próximas las que forman parte del mismo cluster). En lugar de esto, y aprovechando que del vecindario más grande sólo nos interesan las microcalcificaciones, se añade al modelo un termino de "vecindario ampliado" [58], quedando:

$$
p\left(x_{i j}=l \mid \mathbf{X}_{S \backslash i j}\right) \propto \exp \left\{-\alpha(l)+\gamma(l)\left[h_{i j}(C)-h_{o}\right]-\sum_{m=0}^{2} \beta_{l m} g(m)\right\}
$$

donde $h_{i j}(C)$ es una función definida sobre el conjunto de pixels etiquetados como microcalcificación en el vecindario ampliado de pixel $(i, j)$, que sencillamente se define como la suma de pixels etiquetados como microcalcificación en dicho vecindario con un valor de saturación hmax; alternativamente se puede definir como el número de microcalcificaciones; ho permite controlar la influencia de las microcalcificaciones vecinas en el etiquetado como microcalcificación en el pixel actual y por tanto en la sensibilidad de detección de clusters en la segmentación final.

En la expresión 5.3 aparece la segmentación de la imagen $\mathbf{X}_{S \backslash i j}$, pero durante el proceso iterativo no se dispone de $\mathbf{X}$ sino de una estimación $\hat{\mathbf{X}}$ de ella, así que la expresión que realmente se debe utilizar es:

$$
p\left(x_{i j}=l \mid \hat{\mathbf{X}}_{S \backslash i j}\right) \propto \exp \left\{-\alpha(l)+\gamma(l)\left[h_{i j}(C)-h_{o}\right]-\sum_{m=0}^{2} \beta_{l m} g(m)\right\}
$$

y como además también se dispone de la observación, se puede poner:

$$
\begin{aligned}
& p\left(x_{i j}=l \mid \mathbf{Y}, \hat{\mathbf{X}}_{S \backslash i j}\right) \propto \\
& \quad p\left(y_{i j} \mid x_{i j}=l, \hat{\mathbf{X}}_{S \backslash i j}\right) \exp \left\{-\alpha(l)+\gamma(l)\left[h_{i j}(C)-h_{o}\right]-\sum_{m=0}^{2} \beta_{l m} g(m)\right\}
\end{aligned}
$$


Si la influencia del vecindario se limita al modelo del campo aleatorio de Markov, y se excluye de la observación, entonces:

$$
p\left(y_{i j} \mid x_{i j}=l, \hat{\mathbf{X}}_{S \backslash i j}\right)=p\left(y_{i j} \mid x_{i j}=l\right)
$$

que permite reducir la expresión 5.5 y llegar a la forma final de la expresión utilizada en el proceso iterativo de etiquetado, donde la etiqueta asignada es la que maximiza la probabilidad según:

$$
\begin{aligned}
p\left(x_{i j}=l \mid \mathbf{Y}, \hat{\mathbf{X}}_{S \backslash i j}\right) & = \\
\max _{l}\left[p \left(y_{i, j} \mid x_{i j}\right.\right. & \left.=l) \exp \left\{-\alpha(l)+\gamma(l)\left[h_{i j}(C)-h_{o}\right]-\sum_{m=0}^{2} \beta_{l m} g(m)\right\}\right]
\end{aligned}
$$

queda constancia en la expresión 5.7 que es necesaria una estimación de la segmentación buscada; al igual que [10] se tomará la estimación de máxima verosimilitud (Maximum Likelihood Estimate, MLE) que maximiza en cada pixel

$$
x_{i j}^{I}=\max _{l}\left[p\left(y_{i j} \mid x_{i j}=l\right)-\alpha(l)\right]
$$

La cantidad de operaciones a realizar para una imagen es elevada puesto que la carga computacional para un pixel es elevada y la cantidad de pixels en cada imagen es del orden del millón. Para evitar tiempo de cálculo innecesario, todos aquellos pixels que su valor del operador morfológico sea cero serán etiquetados inicialmente como fondo, y no volverán a ser procesados. El por qué se toma como criterio el valor cero es debido a que para todos los operadores morfológicos utilizados las regiones de la clase microcalcificación o emulsión tienen valores de los operadores mayores que cero, y a priori la etiqueta con diferencia más probable para un pixel que tiene valor cero en los operadores morfológicos es la etiqueta fondo. Esta afirmación queda justificada a la vista de las gráficas presentadas en la siguiente sección.

\subsection{Entrada al campo aleatorio de Markov}

Se presentan en esta sección el conjunto de operaciones morfológicas realizadas a la mamografía cuyo resultado se ha utilizado como entrada para la segmentación basada en campos aleatorios de Markov. Para los conceptos fundamentales sobre estas operaciones se puede consultar el capítulo 4 o bien la bibliografía referenciada en el mismo. En esta sección para cada una de dichas operaciones 
se presenta el elemento estructurante particular utilizado, así como el análisis estadístico necesario para el término $p\left(y_{i j} \mid x_{i j}=l\right)$ de la expresión 5.7. Para estimar esta estadística se ha de partir de una segmentación verdadera que identifique a cada pixel de la imagen. Como nuestro vector de observaciones para cada pixel es unidimensional, estimar el conjunto de funciones $p\left(y_{i j} \mid x_{i j}=l\right.$ ) para $l=\{b, c, e\}$ se puede hacer a través de los histogramas de cada clase independientemente. El histograma de una clase está constituido por los pixels de las imágenes resultado del operador morfológico que en la segmentación verdadera pertenecen a esa clase.

Una vez calculado el histograma buscamos un modelo de función densidad de probabilidad que se ajuste a los histogramas. No es nuestra intención afirmar que los histogramas siguen los modelos propuestos, sino buscar una función analítica que permita evitar los problemas que surgirían al utilizar directamente los histogramas como aproximación a la función de densidad de probabilidad, como son por ejemplo el rizado de los mismos, o que para varios niveles de gris el valor del histograma es cero y como para el algoritmo se necesita el logaritmo, éste no existe. En gran parte de la literatura, por ejemplo [10] [58] [77], el modelo elegido es el gaussiano. En el presente trabajo también se elige el modelo gaussiano cuando es posible, pero en algunos operadores para el caso de los histogramas del fondo, tal como se verá en las siguientes secciones, una proporción muy elevada de los pixels tienen valor cero. Este hecho, junto con que la parte significativa del histograma tiene forma asimétrica (puesto que el margen de niveles de gris es de 0 a 255) y amplitud especialmente grande para el nivel 0 , impide ser correctamente ajustado por una gaussiana. En su lugar elegimos una distribución exponencial [86]:

$$
f(t)=\alpha e^{-\alpha t} \quad 0 \leq t<\infty
$$

Aún así, el número de pixels del fondo es mucho mayor que el de la fdp para $t=0$, por lo que para mejorar el ajuste del histograma se ha considerado una función $f_{a}$ como suma de una función exponencial multiplicada por una constante $C_{1}$ más una delta de Dirac multiplicada por una constante $C_{2}$, calculadas a partir de $\int_{+\infty}^{-\infty} f_{a}(t) d t=1$, condición que debe cumplir toda función densidad de probabilidad.

$$
f_{a}(t)=C_{1} \alpha e^{-\alpha t}+C_{2} \delta(t)
$$

En el ajuste del histograma por parte de la función hay dos hechos importantes:

- El valor de $\alpha$. 
- Los primeros valores del histograma son más importantes que los últimos, por ser en los primeros donde se concentra la mayor parte de la energía del histograma.

En la distribución exponencial, $\alpha$ se puede calcular a partir del cociente entre dos valores de la función.

$$
\begin{gathered}
\frac{f\left(t_{1}\right)}{f\left(t_{2}\right)}=\frac{\alpha e^{-\alpha t_{1}}}{\alpha e^{-\alpha t_{2}}} \\
\alpha=\frac{\ln \left(f\left(t_{1}\right) / f\left(t_{2}\right)\right)}{t_{2}-t_{1}}
\end{gathered}
$$

En el caso de un histograma discreto $\mathrm{h}(\mathrm{g})$, tomando $g_{1}$ y $g_{2}$ cualquier par de elementos sucesivos del histograma, el valor de $\alpha$ es directamente:

$$
\alpha=\ln \left(h\left(g_{1}\right) / h\left(g_{2}\right)\right)
$$

Los valores de $\alpha$, calculados a partir de los histogramas de las imágenes resultado de los operadores morfológicos no son exactamente iguales para todos los pares de valores sucesivos, así que, para ajustar el valor de $\alpha$, hemos considerado la media de los calculados. En el cálculo de la media sólo incluimos los primeros valores del histograma por la razón expuesta anteriormente, exceptuando desde $g=0$ hasta $g=g_{0}$, donde la relación no es exponencial.

$$
\hat{\alpha}=\frac{1}{k+1} \sum_{g=g_{0}}^{g_{0}+k} \ln (h(g) / h(g+1))
$$

donde $h(g)$ es el valor del histograma para el nivel de gris $g$.

A continuación, se calcula la constante $C_{1}$ para que $f_{a}(1)=h(1)$, es decir:

$$
C_{1}=\frac{h(1)}{\hat{\alpha} e^{-\hat{\alpha}}}
$$

posteriormente, y a partir de la condición de que $\int_{-\infty}^{+\infty} f_{a}(t) d t=1$, se calcula $C_{2}$

$$
C_{2}=1-\int_{-\infty}^{+\infty} C_{1} \hat{\alpha} e^{-\hat{\alpha} t} d t
$$

Como nuestro caso es discreto, la integración debe ser sustituida por sumatorio y el margen de $\mathrm{t}$ de $-\infty \mathrm{a}+\infty$ por índice discreto $g=\{0,1, \ldots, 255\}$. 


$$
C_{2}=1-\sum_{g=0}^{255} C_{1} \hat{\alpha} e^{-\hat{\alpha} g}
$$

Referente al ajuste de los histogramas mediante una gaussiana hay que tener presente, de nuevo, que el margen de niveles de gris es de 0 a 255. Al calcular la media y desviación estándar del histograma como estimación de la media y desviación estándar de la gaussiana, este par de valores hace que una parte significativa del área de la gaussiana esté en el semiplano izquierdo hay que tener en cuenta el efecto de la truncación. En ese caso la media y desviación estándar del histograma corresponden a la esperanza y raíz cuadrada de la varianza de la gaussiana truncada hacia la izquierda en cero y para obtener la gaussiana que ajuste el histograma hay que disponer de la media y la desviación estándar de la gaussiana sin truncar. La relación entre la media de la distribución truncada $\mu_{t}$ y la media de la distribución sin truncar $\mu$, se obtiene a partir de:

Sea $f(x)$ la distribución gaussiana sin truncar

$$
f(x)=\frac{1}{\sqrt{2}} \exp \left[-\frac{1}{2}\left(\frac{x-\mu}{2}\right)^{2}\right], \quad-\infty<x<+\infty
$$

y sea $f_{t}(x)$ la distribución gaussiana truncada, hacia la izquierda en $x=$

$$
f(x)= \begin{cases}\frac{1}{1-\Phi\left(\frac{-\mu}{-}\right)} \frac{1}{\sqrt{2}} \exp \left[-\frac{1}{2}\left(\frac{x-\mu}{2}\right)^{2}\right] & x \geq \\ 0 & x<\end{cases}
$$

siendo $\Phi(\cdot)$ la función de distribución acumulativa de la gaussiana normalizada $N(0,1)$, el valor de $\mu_{t}$ es:

$$
\begin{aligned}
\mu_{t} & =\int^{+\infty} x f(x) d x \\
& =\frac{1}{1-\Phi\left(\frac{-\mu}{-}\right)} \int^{+\infty} \frac{x}{\sqrt{2}} \exp \left[-\frac{1}{2}\left(\frac{x-\mu}{2}\right)^{2}\right] d x \\
& =\mu+\frac{\log }{1-\Phi\left(\frac{-\mu}{-}\right) \sqrt{2}} \exp \left[-\frac{1}{2}\left(\frac{x-\mu}{}\right)^{2}\right]
\end{aligned}
$$

La resolución de $\mu$ no se puede realizar por procedimiento analítico y lo mismo sucede con la relación entre la desviación estándar de la función truncada y sin truncar. Con ambas relaciones se construye un sistema de ecuaciones que se puede resolver con cualquier método numérico apropiado. 


\subsection{Operaciones morfológicas}

En esta sección se estudian las particularizaciones de los operadores morfológicos utilizados. Todos ellos tienen como finalidad que en la imagen de salida las regiones pequeñas más claras que sus inmediaciones queden más resaltadas en la imagen de salida que en la imagen de entrada, procurando en la medida de lo posible que las regiones claras lineales y las variaciones que pueda haber en regiones de fondo queden atenuadas. En primer lugar se trata el Top-Hat clásico con fines meramente comparativos puesto que es fácilmente predecible que el ratio de falsos positivos será alto debido a que no discrimina las fibras respecto de las microcalcificaciones. En segundo lugar se estudia el residuo del operador llamado aquí fondofibra, que supone una mejora sustancial respecto al Top-Hat clásico y por último el operador fondofibra con reconstrucción. En el capítulo 6 se presentan además los resultados alcanzados con este operador añadiendo una transformación para eliminar estructuras de la imagen que pueden ser confundidas con microcalcificaciones.

\subsubsection{Top-Hat}

En el caso del Top-Hat clásico, para que extraiga las áreas pequeñas contrastadas de la mamografía el elemento estructurante debe ser circular, ya que a priori las microcalcificaciones se acercan más a esta forma que a otras, y cualquier otra forma puede ser incluida en un círculo de suficiente tamaño. Alternativamente el elemento estructurante podría ser cuadrado, primero porque el Top-Hat con elemento cuadrado sigue extrayendo las áreas que extrae con elemento circular, y segundo porque con un elemento cuadrado la implementación es más eficiente.

En cuanto al tamaño, éste depende del tamaño de las microcalcificaciones. Un tamaño grande daría lugar a gran cantidad de áreas extraídas y consecuentemente una mayor probabilidad de falsos positivos. Un tamaño demasiado pequeño provocaría que las microcalcificaciones grandes no fueran extraídas. Dentro de ciertos límites lo segundo es menos problemático por varias razones:

- la forma tridimensional de las microcalcificaciones no es en forma de meseta, sino que su nivel de gris aumenta gradualmente hacia el centro, por lo que en muchas ocasiones aunque la microcalcificación sea grande tiene una cumbre de menor tamaño que la base y, esta cumbre sí es extraída por el Top-Hat

- es menos probable que microcalcificaciones grandes pasen desapercibidas al radiólogo 
- las microcalcificaciones grandes aisladas generalmente son benignas

Las microcalcificaciones que se asocian con malignidad en general son menores que $0.5 \mathrm{~mm}$ de diámetro y prácticamente siempre menores que $1 \mathrm{~mm}$ [68], por lo que el diámetro del elemento estructurante debe estar, para la distancia de muestreo de la base de mamografías digitalizadas utilizada, entre 7 y 11 pixels.

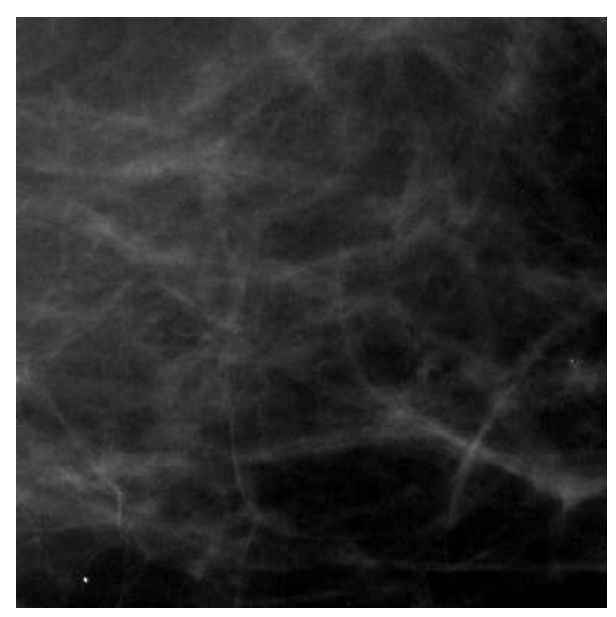

a) original

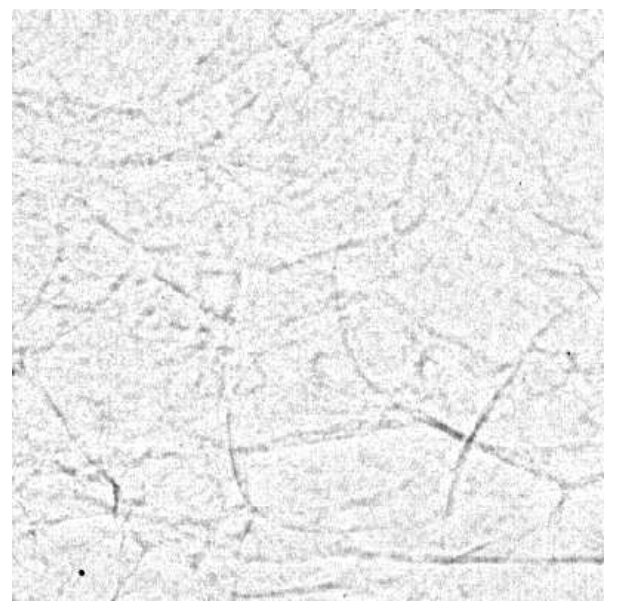

b) EE circular

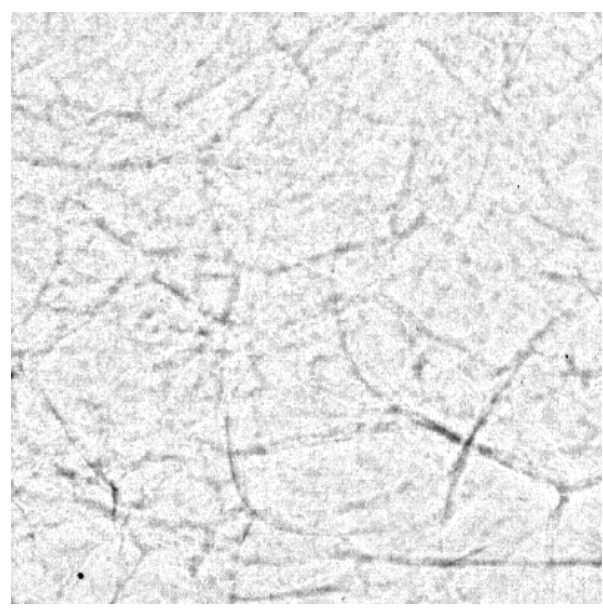

c) EE cuadrado

Figura 5.4: a) subimagen $(400 \times 400)$ de la mamografía z11o a partir del pixel (400,1080), ampliado en contraste por dos para una mejor visualización. b) y c) resultado del Top-Hat con un elemento estructurante circular de diámetro 9 y otro cuadrado de lado 9 respectivamente. Para una mejor visualización se han multiplicado por 10 y se han invertido las imágenes $b$ y $c$.

Para ilustrar el proceso que realiza el Top-Hat sobre una imagen mamográfica en la figura $5.4 a$ se presenta una subimagen de 400x400, origen $(400,1080)$ de la 
mamografía z11o. En la figura $5.4 b$ y $c$ se muestra respectivamente el resultado del Top-Hat con un elemento estructurante circular y otro cuadrado ambos de diámetro 9. Para una mejor visualización se han multiplicado por $10 \mathrm{y}$ se han invertido las imágenes $b$ y $c$. Se puede observar que extrae tanto objetos pequeños puntuales (esquina inferior izquierda) como las fibras que existen a lo largo de toda la subimagen. En el capítulo 6 se tratan con más detalle los aspectos relativos al tamaño del elemento estructurante.

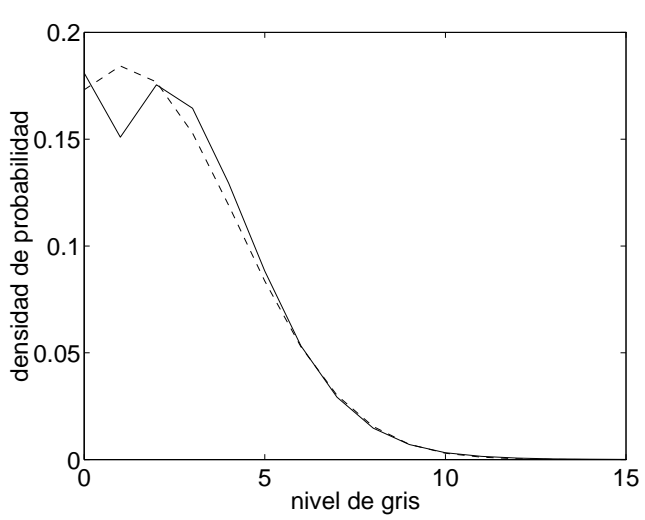

a) eje y lineal

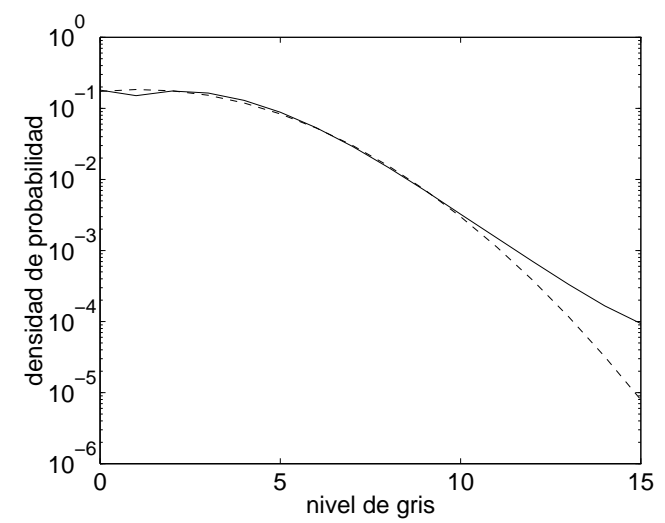

b) eje y logarítmico

Figura 5.5: Histograma de los pixels fondo (trazo continuo) y aproximación gaussiana (trazo discontinuo) del resultado del Top-Hat con elemento estructurante cuadrado de tamaño 9. a) representación con eje de ordenadas lineal y b) representación con eje de ordenadas logarítmico

En la figura 5.5 se presenta el histograma resultante de los pixels considerados fondo del grupo de mamografías de entrenamiento, para el resultado del Top-Hat con elemento estructurante cuadrado de tamaño 9. En trazo continuo aparece el histograma. Superpuesto a él y en trazo discontinuo está la gaussiana truncada que lo aproxima. En todas las figuras de esta sección, para poder apreciar mejor la diferencia entre ambas curvas, el eje de ordenadas en la figura $a$ está representado con escala lineal y la figura $b$ con escala logarítmica. Se puede observar que para niveles de gris por encima de 10 la diferencia se va haciendo apreciable. Se debe a que en la mamografía hay muchos pixels con gradiente relativamente elevado que corresponden a zonas de transición entre regiones de distinto nivel de gris pertenecientes todas ellas al fondo. Aunque en todas las curvas el margen de niveles de gris va de 0 a 255, en cada figura el eje de abcisas se ha limitado a un valor menor para poder mantener un nivel de detalle mejor en el margen más importante de cada una de ellas.

En la figura 5.6 se presenta el histograma resultante de los pixels considerados microcalcificación del grupo de mamografías de entrenamiento, para el resultado del Top-Hat con elemento estructurante cuadrado de tamaño 9. En trazo 


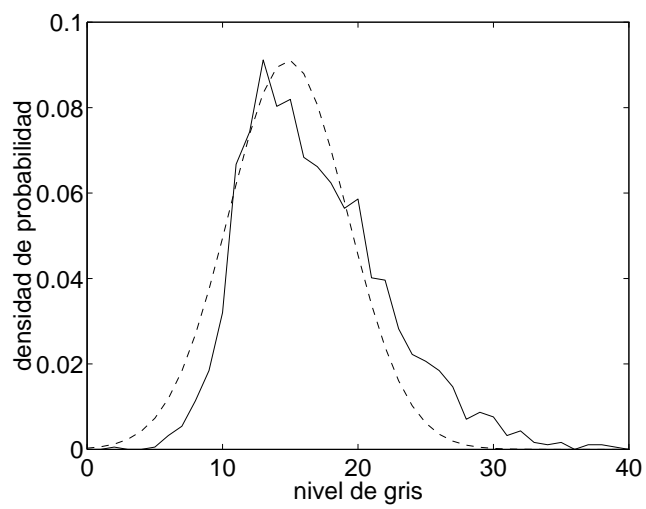

a) eje y lineal

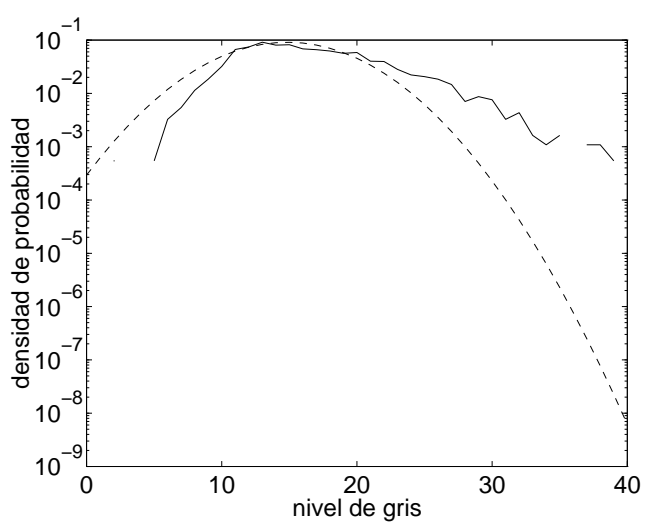

b) eje y logarítmico

Figura 5.6: Histograma de los pixels microcalcificación (trazo continuo) y aproximación gaussiana (trazo discontinuo) del resultado del Top-Hat con elemento estructurante cuadrado de tamaño 9. a) representación con eje de ordenadas lineal y b) representación con eje de ordenadas logarítmico

continuo aparece el histograma. Superpuesto a él y en trazo discontinuo está la gaussiana que lo aproxima.

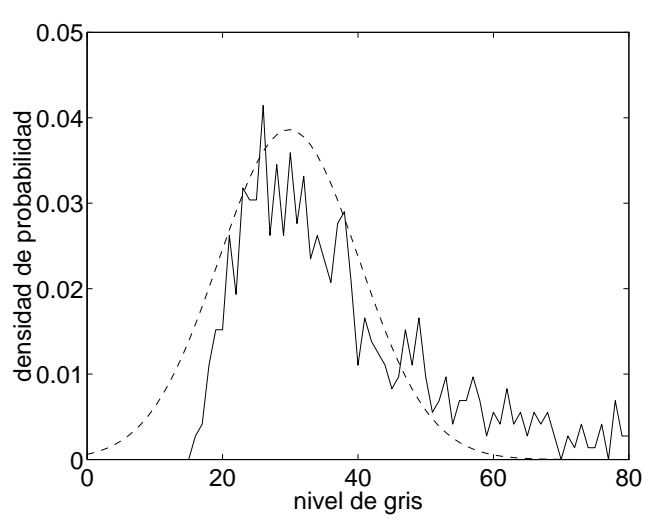

a) eje y lineal

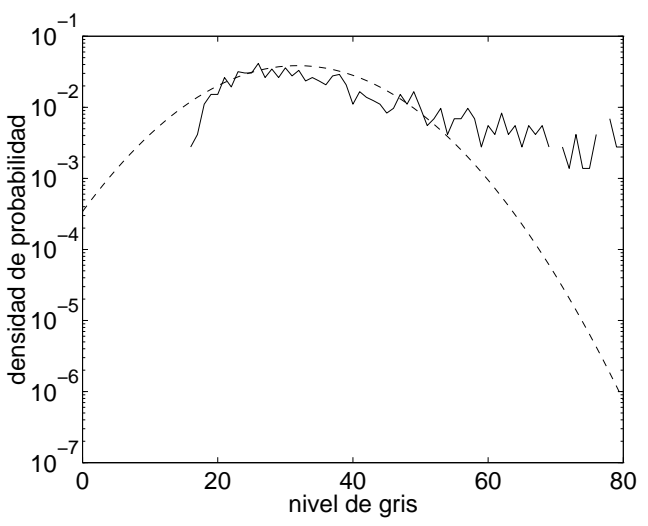

b) eje y logarítmico

Figura 5.7: Histograma de los pixels emulsión (trazo continuo) y aproximación gaussiana (trazo discontinuo) del resultado del Top-Hat con elemento estructurante cuadrado de tamaño 9 . a) representación con eje de ordenadas lineal y b) representación con eje de ordenadas logarítmico

En la figura 5.7 se presenta el histograma resultante de los pixels considerados emulsión del grupo de mamografías de entrenamiento, para el resultado del Top-Hat con elemento estructurante cuadrado de tamaño 9. En trazo continuo aparece el histograma. Superpuesto a él y en trazo discontinuo está la gaussiana que lo aproxima. La diferencia en los niveles bajos es elevada debido a la forma en que se han generado las imágenes máscara de entrenamiento para la clase 
emulsión en las que se han eliminado los pixels por debajo de un cierto nivel de gris. 


\subsubsection{Residuo del fondofibra}

Tal como se expuso en el capítulo 4 cuando se busca extraer objetos de la imagen que no responden a una única forma u orientación se pueden utilizar operadores morfológicos definidos a partir del supremo (u otro operador relacional). Dado que queremos evitar en el resultado del residuo la aparición de las zonas contrastadas lineales debidas a fibras, debemos aportar como entrada al calculo del mismo una imagen procesada por un operador que incluya a la vez fondo y fibra. Al efecto, particularizamos aquí la definición del Supremo de aperturas de la sección 4.2.3 para un conjunto de elementos lineales de un tamaño $t$. Para identificar a este operador con un nombre corto le llamamos fondofibra. Tiene la particularidad de que en su salida incluye cualquier región en la que quepa el elemento lineal y por tanto a la vez el fondo y fibra. Para que el operador fondofibra no incluya las microcalcificaciones y poder ser extraídas luego mediante el residuo, el tamaño $t$ del elemento lineal deberá ser mayor que éstas, utilizando el mismo criterio que en el Top-Hat de la sección anterior, es decir, tamaño 9.

La figura 5.8 muestra el residuo del fondofibra de la imagen original presentada en la figura 5.4. Se ha multiplicado por 10 para poder comparar con los resultados presentados en la figura 5.4 y se ha invertido para facilitar la impresión en papel. Se puede observar que el objeto pequeño circular de la parte inferior izquierda aparece igual de contrastado que en la figura $5.4 c$ sin embargo las fibras aparecen con mucha menor amplitud.

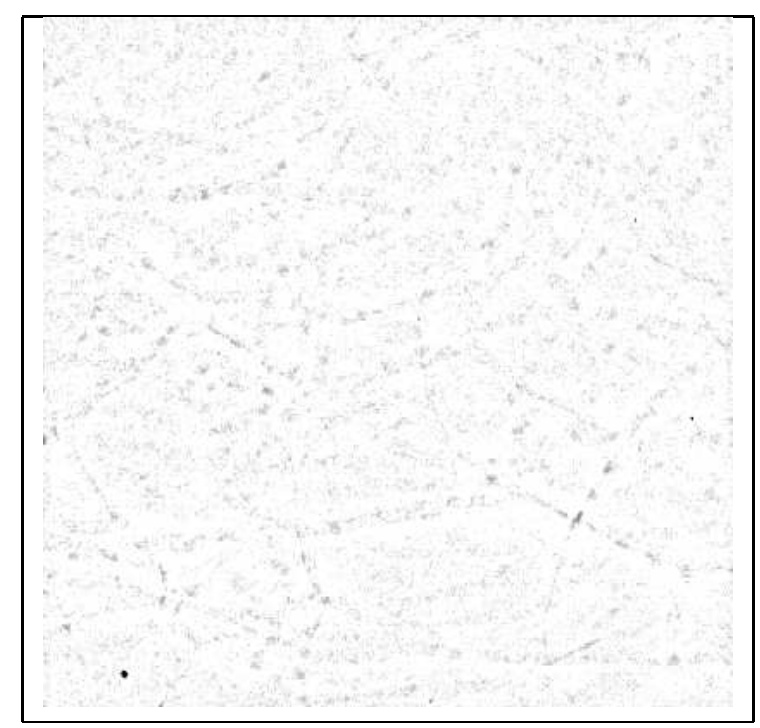

Figura 5.8: Residuo del fondofibra de la imagen de la figura 5.4a, multiplicado por 10 e invertido.

En la figura 5.9 se presenta el histograma resultante de los pixels considerados fondo del grupo de mamografías de entrenamiento, para el resultado del residuo 


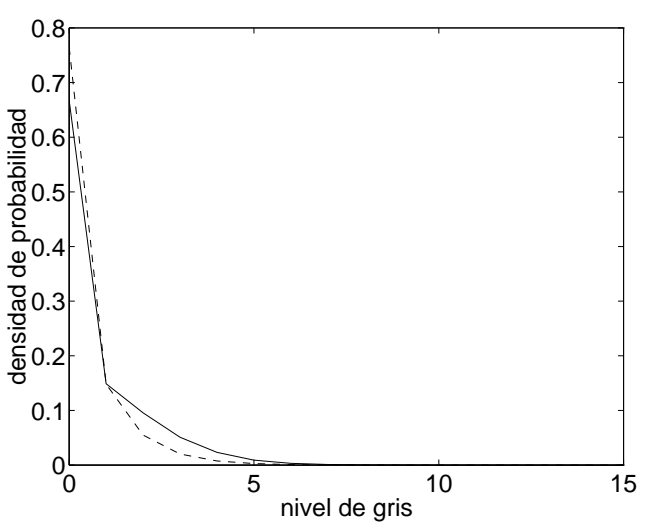

a) eje y lineal

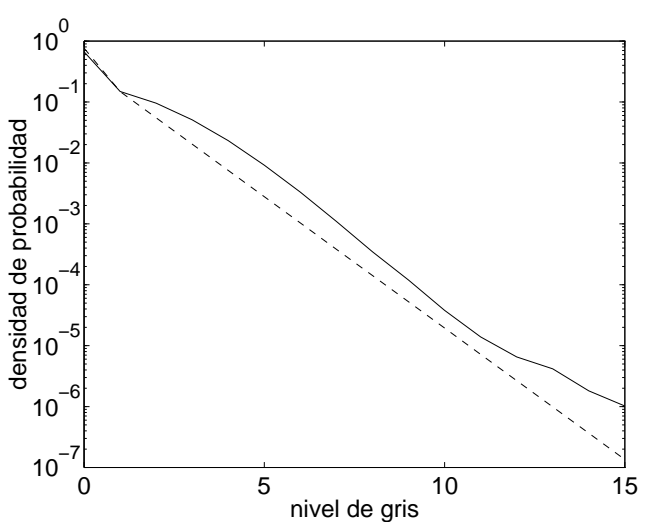

b) eje y logarítmico

Figura 5.9: Histograma de los pixels fondo (trazo continuo) y aproximación (trazo discontinuo) del resultado del residuo del fondofibra con elemento estructurante de tamaño 9. a) representación con eje de ordenadas lineal y b) representación con eje de ordenadas logarítmico

del fondofibra con elemento estructurante de tamaño 9. En trazo continuo aparece el histograma. Superpuesto a él y en trazo discontinuo está la función que lo aproxima. Dicha función es la exponencial más la delta que se ha presentado en la sección anterior. Se puede observar en la figura $5.9 b$ que una función exponencial, que en la representación logarítmica aparece como una recta, aproxima mejor el histograma durante un mayor número de niveles de gris que una gaussiana, que en la representación logarítmica aparecería como una parábola.

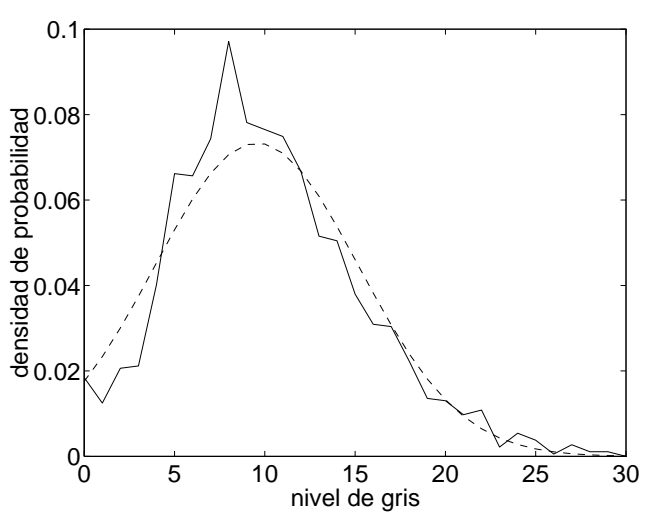

a) eje y lineal

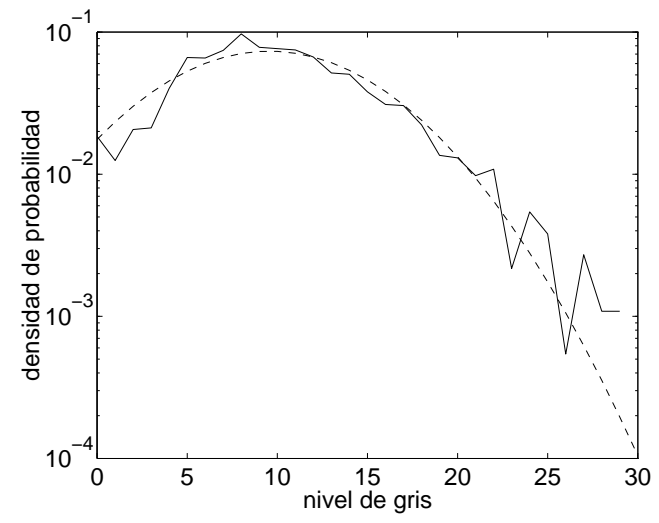

b) eje y logarítmico

Figura 5.10: Histograma de los pixels microcalcificación (trazo continuo) y aproximación gaussiana (trazo discontinuo) del resultado del residuo del fondofibra con elemento estructurante de tamaño 9. a) representación con eje de ordenadas lineal y b) representación con eje de ordenadas logarítmico

En la figura 5.10 se presenta el histograma resultante de los pixels consi- 
derados microcalcificación del grupo de mamografías de entrenamiento, para el resultado del residuo del fondofibra con elemento estructurante de tamaño 9. En trazo continuo aparece el histograma. Superpuesto a él y en trazo discontinuo está la gaussiana que lo aproxima. Para el cálculo de la media y desviación estándar de esta gaussiana que aproxima el histograma se ha tenido en cuenta el efecto de la truncación en cero. El histograma a partir de las proximidades del nivel de gris 30 tiene valor cero. Dado que para el algoritmo ICM se utiliza el logaritmo de la probabilidad esto supondría un problema que se evita con la utilización de una función que lo aproxima.

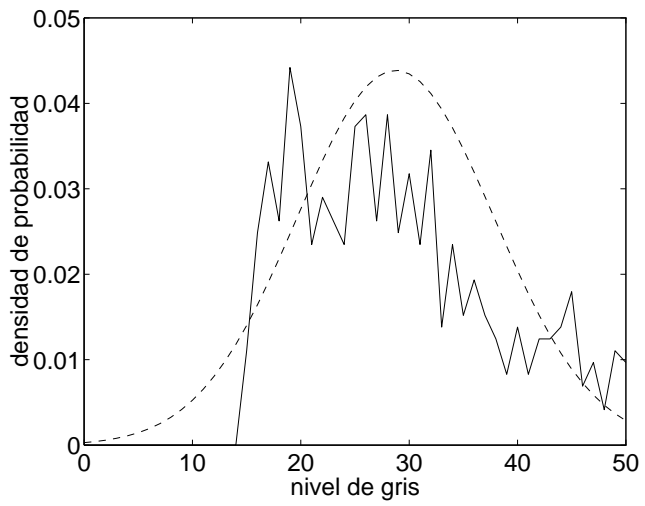

a) eje y lineal

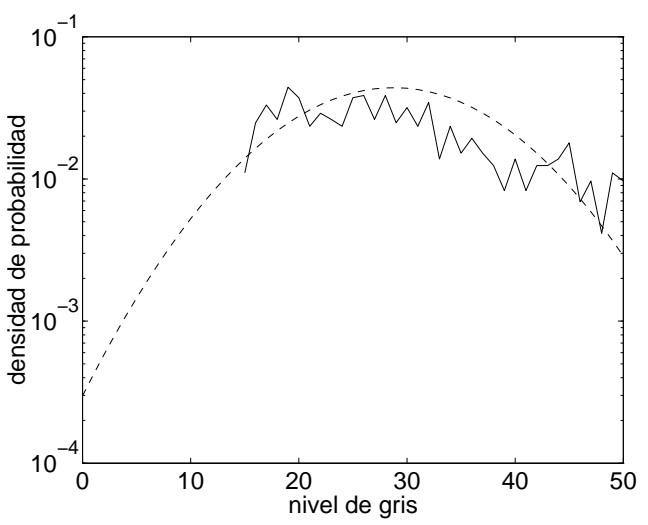

b) eje y logarítmico

Figura 5.11: Histograma de los pixels emulsión (trazo continuo) y aproximación gaussiana (trazo discontinuo) del resultado del residuo del fondofibra con elemento estructurante de tamaño 9. a) representación con eje de ordenadas lineal y b) representación con eje de ordenadas logarítmico

En la figura 5.11 se presenta el histograma resultante de los pixels considerados emulsión del grupo de mamografías de entrenamiento, para el resultado del residuo del fondofibra con elemento estructurante de tamaño 9. En trazo continuo aparece el histograma, y superpuesto a él y en trazo discontinuo está la gaussiana que lo aproxima. La diferencia en los niveles bajos es elevada debido a la forma en que se ha generado las imágenes máscara de entrenamiento para la clase emulsión (ver subsección anterior). Una correcta aproximación es complicada porque en la clase emulsión entran pixels de muy diversas procedencias los cuales tienen en común un elevado nivel de gris en los residuos. Mientras que esa diversa procedencia (ruido, estructuras densas de la mama, transiciones entre diversos tipos de tejidos), en el caso de la clase fondo no genera un rizado tan grande debido a que la cantidad de pixels que se computan en el histograma del fondo es muy elevado, en el caso de la clase emulsión el rizado es apreciable debido a que el número de pixels contabilizados es al menos tres órdenes de magnitud menor. 


\subsubsection{Residuo del fondofibra con reconstrucción}

Tal como se ve en el capítulo de resultados el residuo del fondofibra produce parte de sus falsos positivos en pixels situados en fibras. Esto es debido a que el operador fondofibra no genera en su resultado el mismo nivel de gris que la imagen original, es decir no extrae correctamente la fibra. Los motivos son dos:

- las fibras no tienen un nivel de gris uniforme

- las fibras no únicamente tienen formas rectilíneas

- el número limitado de orientaciones del elemento estructurante lineal

las curvas de las fibras durante el proceso de extracción de las mismas se aproximan por tramos rectilíneos del tamaño $t$ del elemento estructurante. En ocasiones si la curvatura en determinadas zonas de la fibra es muy pronunciada el elemento no cabe y por tanto en el residuo aparecen.

La reconstrucción [127] permite recuperar el nivel de gris de una parte de estos pixels no extraídos correctamente por el operador fondofibra, siempre que se cumplan estas condiciones en la región de pixels a recuperar:

- que pertenezcan a una región conexa con otra en la que ha cabido el elemento estructurante.

- que la región en la que ha cabido el elemento estructurante tenga un nivel de gris mayor.

- que no haya un mínimo entre ambas regiones.

La figura 5.12 muestra el residuo del fondofibra con reconstrucción de la imagen de la figura $5.4 a$, multiplicado por 10 e invertido. Se puede comparar con el residuo del fondofibra sin reconstruir (figura 5.8) para ver que el nivel de gris de muchos pixels de la imagen es menor. A efectos comparativos, indicar que el porcentaje de pixels que en la imagen original del residuo del fondofibra sin reconstruir tiene un nivel de gris mayor que 0 es de $31.5 \%$ mientras que con reconstrucción es de $14.6 \%$, si se toma el nivel de gris 2 los porcentajes son respectivamente $6.5 \%$ y $2.1 \%$, es decir el decremento es muy significativo; sin embargo el objeto pequeño circular de la parte inferior izquierda tiene prácticamente los mismos niveles de gris en ambas imágenes que son respectivamente 133 y 132 .

En la figura 5.13 se presenta el histograma resultante de los pixels considerados fondo del grupo de mamografías de entrenamiento, para el resultado del 


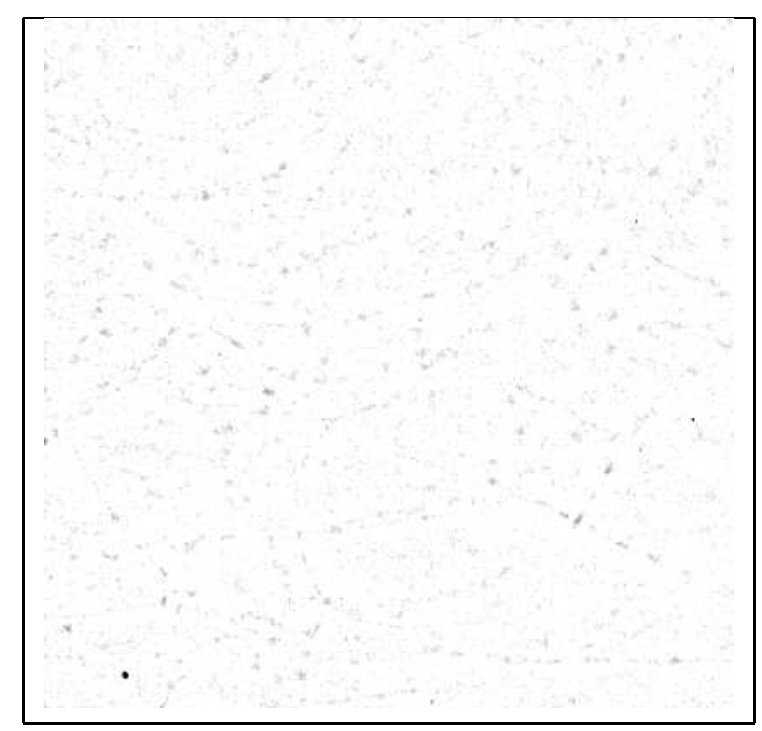

Figura 5.12: Residuo del fondofibra con reconstrucción de la imagen de la figura $5.4 a$, multiplicado por 10 e invertido.

residuo del fondofibra con reconstrucción con elemento estructurante de tamaño 9. En trazo continuo aparece el histograma. Superpuesto a él y en trazo discontinuo está la función que lo aproxima. Dicha función es la exponencial más la delta que se ha presentado en la sección anterior. Al igual que en el caso de residuo del fondofibra sin reconstrucción, se puede observar en la figura $5.13 b$ que una función exponencial aproxima mejor el histograma durante un mayor número de niveles de gris que una gaussiana. La exponencial aparece en la representación logarítmica como una recta mientras que la gaussiana tendría forma parabólica alejándose del histograma a medida que aumenta el nivel de gris.

En la figura 5.14 se presenta el histograma resultante de los pixels considerados microcalcificación del grupo de mamografías de entrenamiento, para el resultado del residuo del fondofibra con reconstrucción con elemento estructurante de tamaño 9. En trazo continuo aparece el histograma. Superpuesto a él y en trazo discontinuo está la gaussiana que lo aproxima. Al igual que en el residuo del fondofibra sin reconstrucción, para el cálculo de la media y desviación estándar de esta gaussiana que aproxima el histograma se ha tenido en cuenta el efecto de la truncación en cero. El histograma a partir de las proximidades del nivel de gris 30 tiene valor cero. Dado que para el algoritmo ICM se utiliza el logaritmo de la probabilidad esto supondría un problema que, de nuevo, se evita con la utilización de una función que lo aproxima.

En la figura 5.15 se presenta el histograma resultante de los pixels considerados emulsión del grupo de mamografías de entrenamiento, para el resultado del residuo del fondofibra con reconstrucción con elemento estructurante de tamaño 


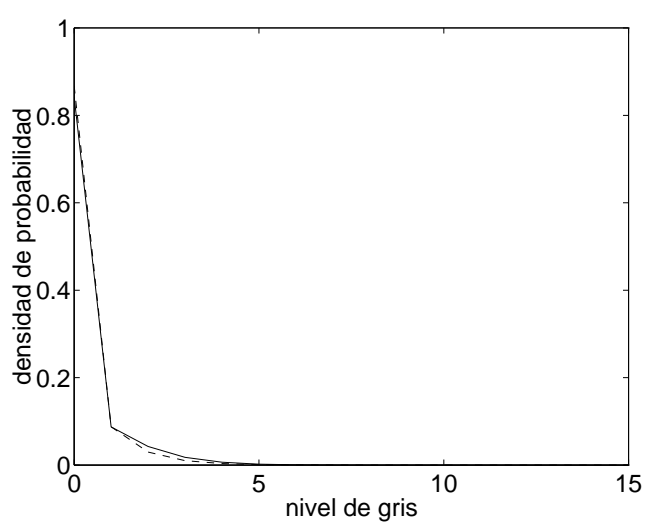

a) eje y lineal

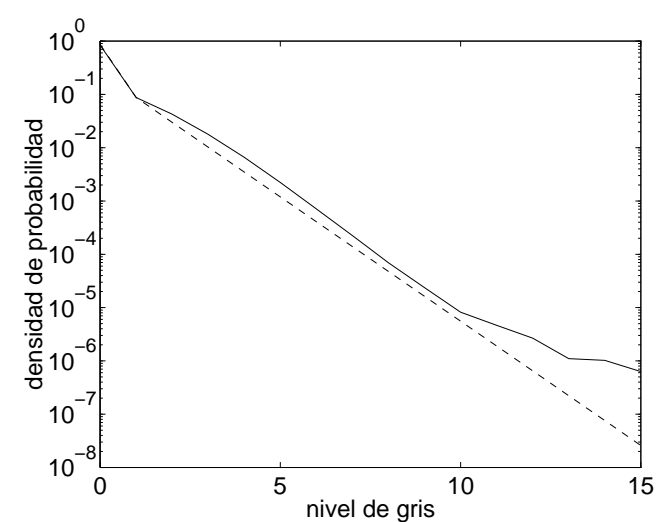

b) eje y logarítmico

Figura 5.13: Histograma de los pixels fondo (trazo continuo) y aproximación (trazo discontinuo) del resultado del residuo del fondofibra con reconstrucción con elemento estructurante de tamaño 9. a) representación con eje de ordenadas lineal y b) representación con eje de ordenadas logarítmico

9. En trazo continuo aparece el histograma, y superpuesto a él y en trazo discontinuo está la gaussiana que lo aproxima. Al igual que en el caso del residuo del fondofibra sin reconstrucción, la diferencia en los niveles bajos es elevada debido a la forma en que se ha generado las imágenes máscara de entrenamiento para la clase emulsión (ver subsección anterior). También en este caso una correcta aproximación es complicada porque en la clase emulsión entran pixels de muy diversas procedencias los cuales tienen en común un elevado nivel de gris en los residuos. De igual manera que en la sección anterior, en la estadística del fondo el rizado es menor porque el número de pixels computados es mucho mayor que en emulsión. 


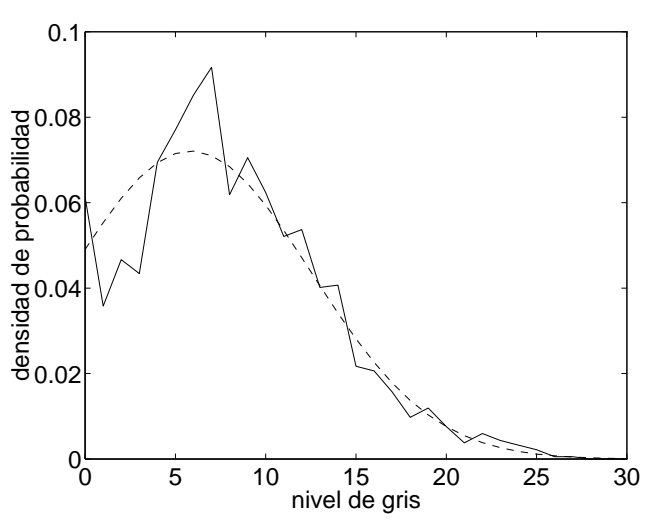

a) eje y lineal

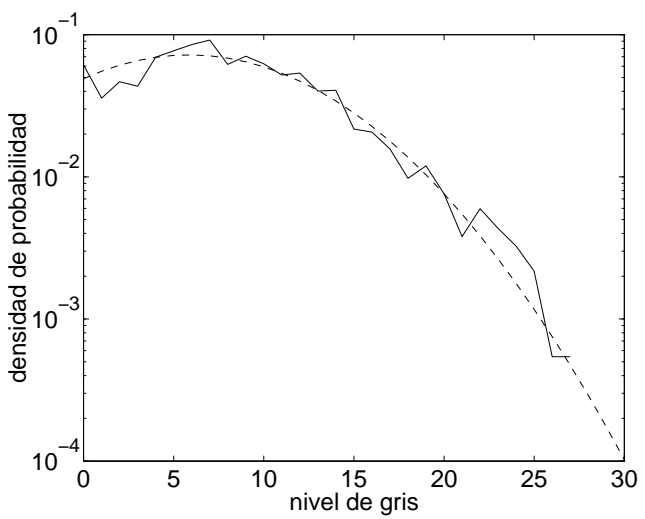

b) eje y logarítmico

Figura 5.14: Histograma de los pixels microcalcificación (trazo continuo) y aproximación (trazo discontinuo) del resultado del residuo del fondofibra con reconstrucción con elemento estructurante de tamaño 9. a) representación con eje de ordenadas lineal y b) representación con eje de ordenadas logarítmico

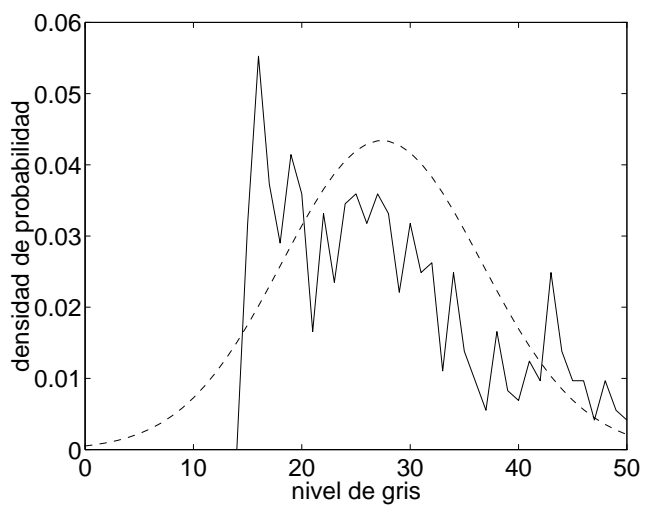

a) eje y lineal

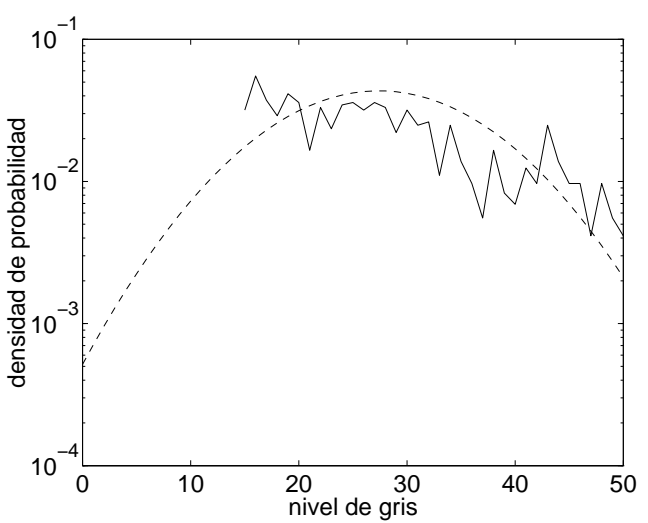

b) eje y logarítmico

Figura 5.15: Histograma de los pixels emulsión (trazo continuo) y aproximación gaussiana (trazo discontinuo) del resultado del residuo del fondofibra con elemento estructurante de tamaño 9. a) representación con eje de ordenadas lineal y b) representación con eje de ordenadas logarítmico 


\section{Capítulo 6}

\section{Resultados}

En este capítulo se van a mostrar los resultados de los diferentes operadores morfológicos junto con el modelo de campo aleatorio de Markov, para el subconjunto de test de la base de datos mamográfica utilizada. Para cada operador morfológico se realizan ejecuciones del algoritmo con diferentes valores de los parámetros del campo aleatorio de Markov con el objetivo de obtener las curvas de probabilidad de detección en función de la probabilidad de falsa alarma. Para cada ejecución se obtienen como resultado sobre el conjunto de las mamografías de test dos valores. El primero esta relacionado con los verdaderos positivos encontrados en el resultado para cada imagen. El segundo valor esta relacionado con los falsos positivos encontrados en el resultado para cada imagen. Se considera exclusivamente como objeto de interés los clusters de microcalcificaciones y no las microcalcificaciones individualmente. Se considera que se ha detectado un verdadero positivo si dos o más centros de los objetos etiquetados como microcalcificación de la imagen resultante están dentro de los círculos de diagnóstico marcados por los radiólogos expertos que acompañan a la base de datos. Se considera un falso negativo todo cluster de microcalcificaciones que no tiene al menos dos microcalcificaciones dentro de los círculos de diagnóstico. Este criterio es coherente con la definición de cluster realizada en el capítulo 5.

Como en todo proceso encaminado a detectar, el algoritmo tiene una probabilidad de detección que varía (o puede variar) en función de la probabilidad de falsa alarma. Para calcular la probabilidad de falsa alarma hay que dividir el número de falsas alarmas producidas por el número de falsas alarmas posibles. En el caso de detectar clusters de microcalcificaciones en mamografías, el número posible de falsos clusters de microcalcificaciones no tiene sentido práctico y en lugar de probabilidad de falsa alarma así definida, se redefine como el cociente entre el total de falsos positivos producidos por el número de imágenes procesadas. La probabilidad de detección sí tiene sentido como cociente entre 
verdaderos positivos producidos partido por verdaderos positivos posibles porque se toman como verdaderos positivos posibles los marcados por los radiólogos expertos. Para variar la probabilidad de detección (o sensibilidad) y ver la correspondiente variación de la probabilidad de falsa alarma se varía el parámetro $h_{0}$ de la ecuación 5.7 .

Para poder establecer comparaciones de forma resumida entre las diferentes ejecuciones de un mismo operador, y también entre operadores, se hará uso de los dos valores referidos anteriormente, y para poder analizar en detalle y extraer conclusiones se mostrarán ejemplos de un pequeño grupo de imágenes, ya que mostrar los resultados para todas las ejecuciones sobre toda la base de datos resulta demasiado voluminoso. Como punto de compromiso el grupo de imágenes estará formado para todos los operadores en parte por las mismas imágenes para todos los operadores, y el resto estará formado por las imágenes que particularmente sean de más interés en cada caso. La forma de presentar los resultados para imágenes concretas será de dos formas:

- una en la que se mostrará la imagen de la mama entera en forma binaria, con el fondo blanco y los pixels etiquetados como microcalcificación en negro, en la que se podrán ver globalmente las microcalcificaciones y los clusters detectados, tanto verdaderos positivos como falsos positivos. Estarán sobreimpresos el borde de la región de la mama dentro de las imágenes "z" (ver Anexo A) y los círculos de diagnóstico marcados por los radiólogos. Como las imágenes son grandes se imprimen diezmadas por un factor 3, pero el diezmado se realiza de manera que no desaparezca ningún pixel negro puesto que hay muchas microcalcificaciones tan pequeñas que si la imagen se diezma de forma normal, aunque sea sólo por dos, podrían desaparecer. En el diezmado, si desaparecen los pixels blancos, puede ocurrir que dos pixels negros que originalmente estén separados, en la imagen diezmada aparezcan juntos; en estos casos, sí es importante, se incluirá un comentario al respecto.

- otra en la que se mostrarán porciones de la mamografía con el suficiente tamaño como para apreciar en detalle la segmentación alcanzada en dicha porción y poder realizar comentarios individualizados para dicha porción de la imagen.

La determinación de los parámetros del campo aleatorio de Markov es experimental y es interesante mostrar la incidencia de estos valores en el resultado final. Para no extendernos demasiado en esta memoria, sólo se reportará el análisis en el caso del residuo del fondofibra con reconstrucción. 


\subsection{Tamaño del Elemento Estructurante}

En esta sección se discute el tamaño del elemento estructurante que se utiliza en los diferentes operadores morfológicos de las siguientes secciones para calcular la imagen observación utilizada como entrada al algoritmo ICM con el modelo de campo aleatorio presentado en el capítulo 5. Los operadores morfológicos que procesan la mamografía tienen como finalidad extraer las regiones contrastadas de la imagen transformando los niveles de gris del fondo al valor cero en la imagen de salida. Para extraer todas las zonas de interés el elemento estructurante debe ser mayor que la mayor de dichas zonas, pero cuanto mayor sea el tamaño del elemento estructurante mayor es la cantidad de pixels extraídos y la probabilidad de extraer zonas no deseadas que pueden dar lugar a falsas alarmas también aumenta. Otra razón para elegir un tamaño pequeño es el coste computacional de las operaciones morfológicas a realizar. Lógicamente cuanto más pequeño menos tiempo de cálculo.

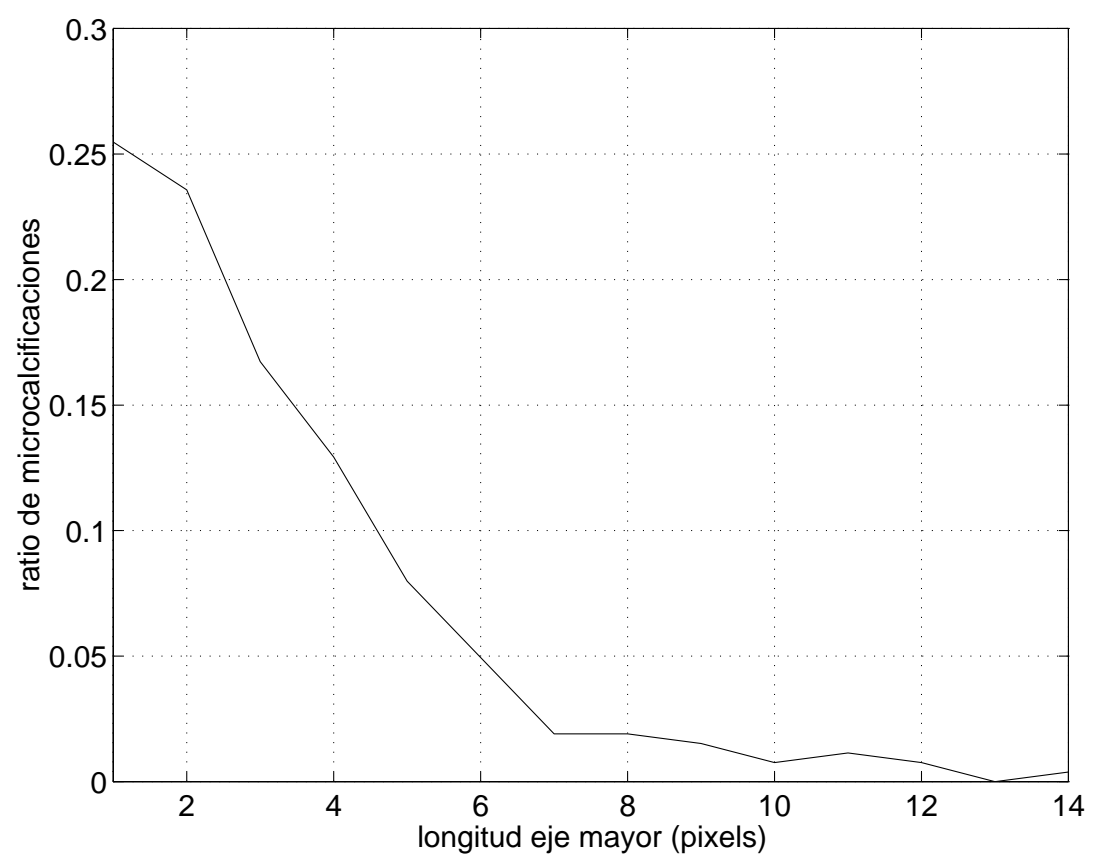

Figura 6.1: Histograma de tamaño del eje mayor de las microcalcificaciones de grupo de imágenes de entrenamiento.

A partir del grupo de imágenes de entrenamiento, habiendo determinado sobre ellas las regiones correspondientes a microcalcificaciones, se muestra en la figura 6.1 el histograma del tamaño del eje mayor de las microcalcificaciones. Dicho eje mayor se ha calculado proyectando para cada microcalcificación las coordenadas de los pixels activos de la imagen binaria que representa la región 
en la dirección principal [97], $\theta$, de cada una de ellas, calculada según:

$$
\theta=\frac{1}{2} \arctan \left(\frac{2 m c_{11}}{m c_{20}-m c_{02}}\right)
$$

donde $m c_{i j}$ son los momentos centrados de orden $i j$. Una vez proyectado el objeto sobre la dirección principal, el tamaño del eje mayor es la coordenada máxima menos la coordenada mínima, en dicha dirección.

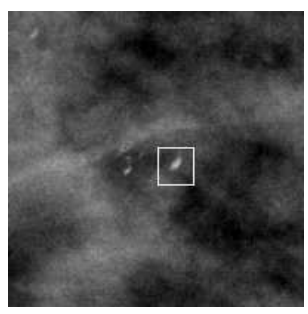

a) original

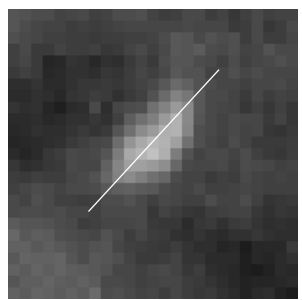

b) ampliación

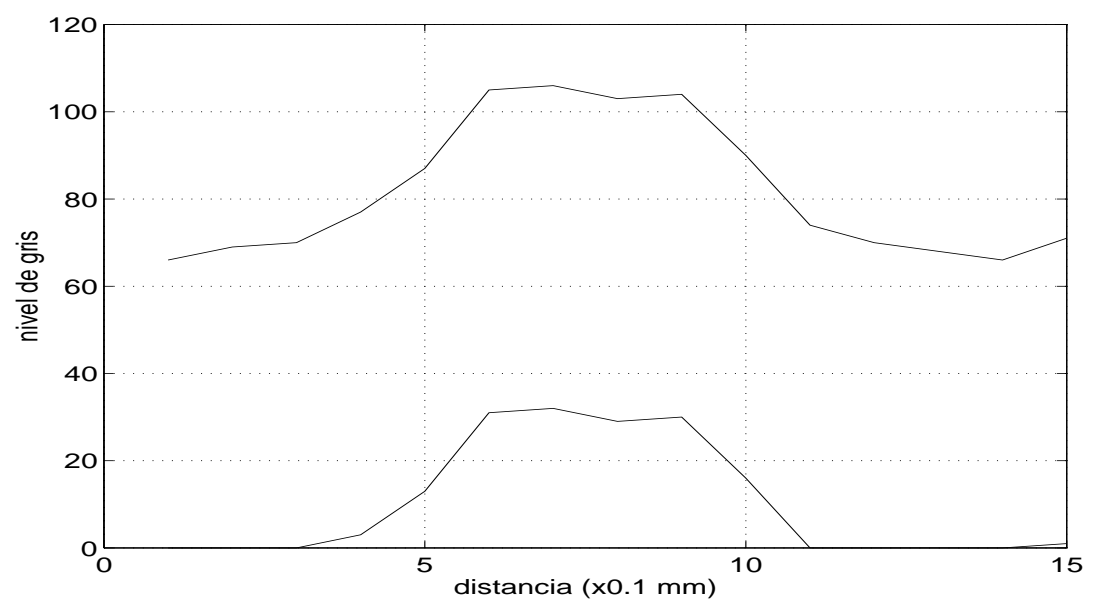

c) perfil de la microcalcificación

Figura 6.2: Perfil de las microcalcificaciones. Extracción de las microcalcificaciones grandes con un elemento estructurante menor que su tamaño. a) Porción de 200x200 pixels de la mamografía z08o. b) Ampliación por 8 respecto a la escala de la porción de la zona marcada en $a$ correspondiente a la microcalcificación más grande de la porción; c) perfil de los niveles en la dirección principal de la microcalcificación; la curva superior corresponde a los niveles de gris de la mamografía original y la curva inferior a los niveles del residuo del fondofibra con reconstrucción.

A la vista de la figura 6.1 el tamaño mayor es 14 pixels. Dado que usualmente el elemento estructurante tiene un tamaño impar para que sea simétrico respecto al pixel central, el tamaño final debe ser 15. Con el ánimo de reducir esa cifra, es importante observar que las microcalcificaciones en general y las grandes en particular tienen un perfil en su nivel de gris que no cambia bruscamente del 
fondo al valor máximo, por lo que un elemento estructurante más pequeño no extraería absolutamente toda el área de la microcalcificación pero sí una gran parte, aunque con menos contraste. Este hecho se muestra en la figura 6.2.

En ella (imagen a) se muestra una porción de la mamografía z08o en la que existe una microcalcificación de tamaño 12 pixels. En $b$ se amplia la zona de interés para observar nítidamente los niveles de gris y ver que dichos niveles no son iguales a lo largo de toda la microcalcificación, hecho que se muestra más claro todavía en $c$ donde aparece el perfil de los niveles a lo largo de la dirección principal de la microcalcificación. La curva superior corresponde a los niveles de gris de la mamografía original y en ella se observa que la transición desde los niveles inferiores a los superiores no es totalmente abrupta. En la curva inferior se muestra el perfil de los niveles obtenidos en la imagen resultante al calcular el residuo del fondofibra con reconstrucción utilizando un elemento estructurante de tamaño 9 pixels que es menor a los 12 pixels de la microcalcificación. El resultado es que en el residuo hay en esa dirección 7 pixels mayores que cero, por lo que esa microcalcificación queda suficientemente extraída. Por esta razón y junto a que el $95 \%$ de las microcalcificaciones tienen una longitud de su eje mayor menor que 9 se toma como tamaño del elemento estructurante la cifra de 9 pixels. Si en el futuro la comunidad médica considerase importantes las microcalcificaciones grandes no habría inconveniente en realizar varios procesados a diferentes escalas de tamaño.

\subsection{Parámetros del campo aleatorio de Markov}

En esta sección se presenta la variación de las prestaciones del algoritmo en función de los parámetros del modelo del campo aleatorio de Markov. En la literatura referente al tema se recomienda que estos sean fijados manualmente y permanezcan constantes durante el proceso de segmentación en vez de que el propio algoritmo los estime en función de la imagen que se está procesando porque es una tarea muy costosa en tiempo de computación y no siempre se puede realizar [77] [10] [74]. En [10] se ofrece también la alternativa de modificar los parámetros en cada iteración para inicialmente dar mayor peso en las decisiones a la información de la observación y evolucionar hacia dar mayor peso al modelo a priori, que el modelo de campo aleatorio de Markov. Así pues, en las siguientes subsecciones se estudia la influencia de los parámetros del modelo. Dado que son varios los parámetros del modelo, para estudiar la influencia de uno de ellos se mantienen constantes el resto. Los valores de estas constantes se han elegido en función de los estudios previos realizados y en las siguientes subsecciones se presentan los resultados con variaciones respecto a estos valores; se ha tomado como operador morfológico el residuo del fondofibra con reconstrucción. Son los 
siguientes:

\begin{tabular}{|c|c|c|}
\hline$\alpha_{b}$ & $\alpha_{c}$ & $\alpha_{e}$ \\
\hline 0 & 6.5 & 10.5 \\
\hline
\end{tabular}

\begin{tabular}{|c|c|c|}
\hline$\beta_{b c}$ & $\beta_{b e}$ & $\beta_{c e}$ \\
\hline 0.5 & 0.0 & 3.0 \\
\hline
\end{tabular}

\begin{tabular}{|c|c|c|c|}
\hline$\gamma_{c}$ & $h_{0}$ & $h_{\max }$ & $N_{\text {Iter }}$ \\
\hline 0.8 & 7 & 10 & 8 \\
\hline
\end{tabular}

Tabla 6.1: Valores utilizados para los parámetros del campo aleatorio de Markov.

Para comparar con el resto de figuras que aparecen en las siguientes subsecciones se presenta a continuación una muestra de tres mamografías procesadas con los valores de la tabla 6.1 para los parámetros de la ecuación 5.7. Las figuras $6.3 a, b, c$ muestran la inicialización, y las figuras $6.3 d, e, f$ muestran el resultado del algoritmo tras 8 iteraciones. El número de verdaderos y falsos positivos se muestra debajo de las figuras.

Dentro de lo posible, en las imágenes de gris de las figuras que se presentan se intenta que la calidad de la impresión permita ver los detalles que en cada caso se discuten. Para una mejor observación de los detalles en el Anexo B se incluyen impresas en papel a página completa las tres mamografías de la figura 6.3 y que se utilizan a lo largo de distintas secciones para comparar resultados.

\subsubsection{Influencia de los parámetros alfa}

Los parámetros alfa influyen en dos frentes.

- Por una parte en la inicialización que se calcula sobre la imagen de grises de entrada (resultado del operador morfológico correspondiente) según la expresión 5.8 y que es el punto de partida del algoritmo iterativo utilizado

- y por otra, en el cálculo de la energía en cada iteración del propio algoritmo iterativo.

Dada la estructura de la mamografía en la que el número de pixels del fondo es mucho mayor que el número de pixels de microcalcificación, inicializar según la expresión 6.2 de la probabilidad exclusivamente a priori

$$
x_{i j}^{I}=\max _{l}\left[p\left(y_{i j} \mid x_{i j}=l\right)\right]
$$




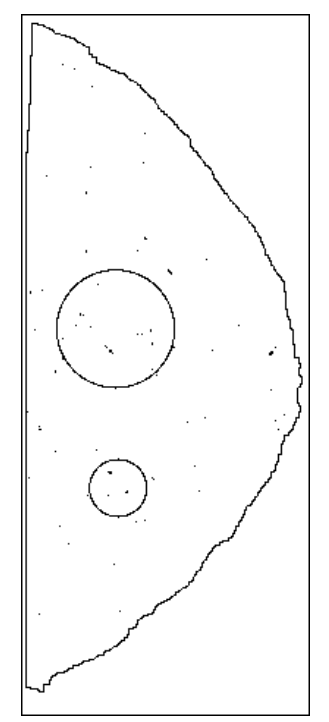

$v p=2, \quad f p=12$

a) z02c inicialización

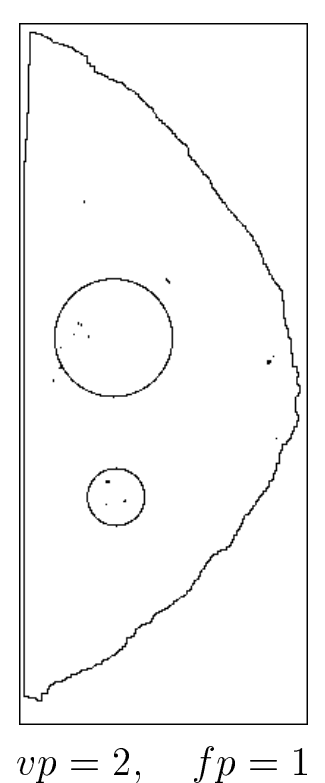

d) z02c resultado

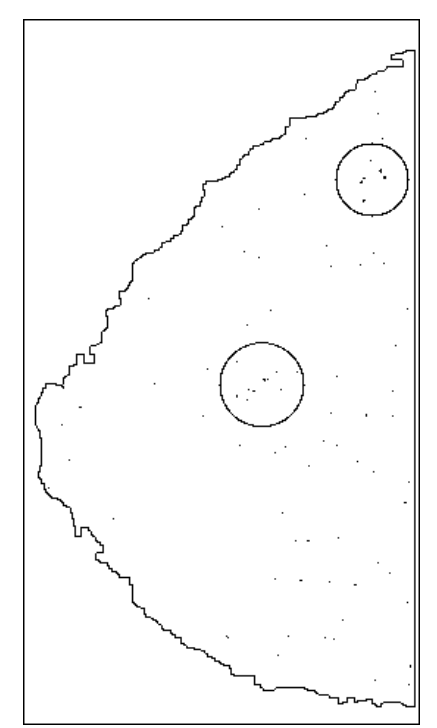

$v p=2, \quad f p=18$

b) z14c inicialización

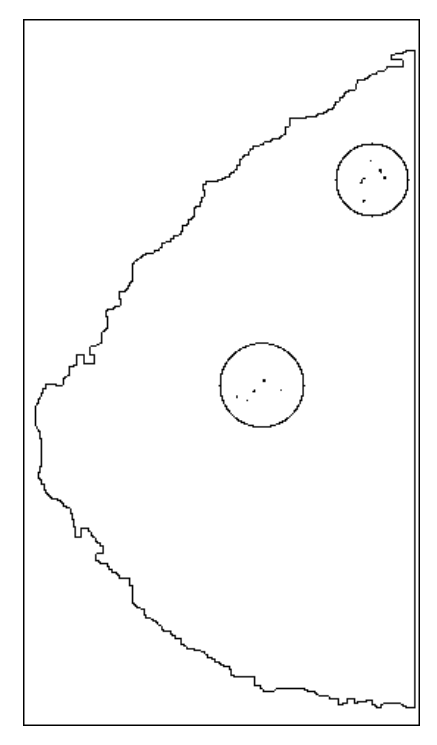

$v p=2, \quad f p=0$

e) z14c resultado

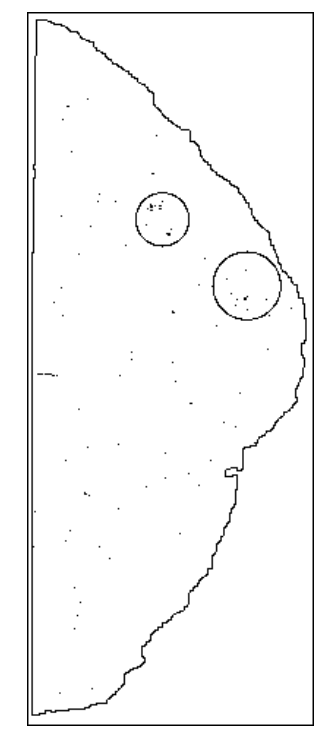

$v p=2, \quad f p=12$

c) z19c inicialización

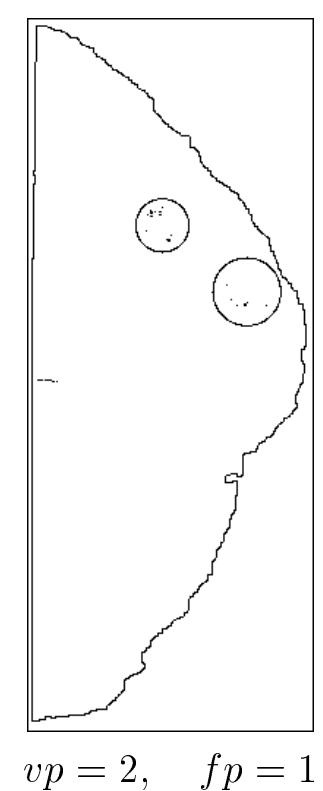

f) $\mathrm{z} 19 \mathrm{c}$ resultado

Figura 6.3: Las figuras $a, b, c$ muestran en negro los pixels que en la inicialización han sido etiquetados como microcalcificación con los parámetros de la tabla 6.1 Las figuras d,e,f muestran el resultado al finalizar el algoritmo. Se observa en el resultado una reducción importante de los falsos positivos, mientras que los verdaderos positivos permanecen. 
en vez de según la expresión 5.8, repetida a continuación para facilitar la referencia,

$$
x_{i j}^{I}=\max _{l}\left[p\left(y_{i j} \mid x_{i j}=l\right)-\alpha(l)\right]
$$

supondría una gran cantidad de pixels resultantes en falsas microcalcificaciones, por lo que al estar restando estos valores en la expresión se ha de elegir $\alpha$ (fondo) menor que $\alpha$ (microcalcificación) y a su vez menor que $\alpha$ (emulsión ).

Por otra parte, dada la expresión 5.7 para el caso de microcalcificación, si no hay varias microcalcificaciones en las proximidades, el término que depende de $h(C)$ contribuye restando en la energía de la etiqueta microcalcificación debido al valor $h_{o}$. Para pixels con niveles de gris intermedios en las imágenes observación, la energía total de la etiqueta microcalcificación tenderá a ser más pequeña que la del fondo por dos razones; la primera se debe a que el término $+\gamma(c)\left[h(C)-h_{o}\right]$ probablemente sea negativo para la etiqueta microcalcificación, mientras que siempre es cero para la etiqueta fondo, la segunda se debe a que el valor de $\alpha$ (microcalcificación) es mayor que el valor de $\alpha$ (fondo); dado esto, el algoritmo tiende a eliminar microcalcificaciones a partir de la inicialización por lo que es conveniente que la inicialización etiquete como microcalcificación todos aquellos pixels que potencialmente puedan ser realmente microcalcificaciones, siendo esta causa contraria a la del párrafo anterior y por tanto debe llegarse a un compromiso para los valores de los parámetros $\alpha$.

Como la asignación de etiqueta a cada pixel se hace con el máximo de un conjunto de valores según la expresión 6.3 lo importante es la diferencia entre valores de $\alpha$ y no los propios valores. Así pues elegimos arbitrariamente para $\alpha($ fondo $)$ el valor cero, quedando los otros dos como parámetros que se pueden variar.

Las figuras $6.4 a, b, c$ y $6.5 a, b, c$ muestran en negro los pixels que en la inicialización han sido etiquetados como microcalcificación con $\alpha_{c}=5.5$ y $\alpha_{c}=7.5$, respectivamente. Estos dos valores de $\alpha_{c}$ están por debajo y por encima del valor utilizado como parámetro final para ilustrar mejor la dependencia del resultado respecto a $\alpha_{c}$. Las figuras $6.4 d, e, f$ y $6.5 d, e, f$ muestran el resultado al finalizar el algoritmo con dichos valores de alfa, respectivamente. Se observa que al final del proceso el número de falsos positivos se reduce significativamente, mientras que en $6.4 d, e, f$ el número de verdaderos positivos permanece en el $100 \%$.

En las imágenes de la figura $6.5 d, e, f$ se observa que al final del proceso el número de falsos positivos se reduce significativamente, pero también se reducen los verdaderos positivos, habiéndose perdido el verdadero positivo inferior de la imagen z14c. Esto es así, porque las microcalcificaciones de este cluster son las más tenues de entre las tres imágenes presentadas y es el primero en desaparecer cuando se eleva el valor de $\alpha_{c}$. También se puede apreciar la reducción generalizada de microcalcificaciones en todos los clusters cuando se comparan 


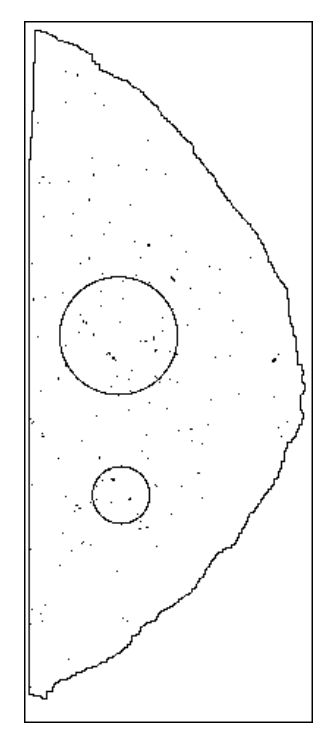

$v p=2, \quad f p=19$

a) z02c inicialización

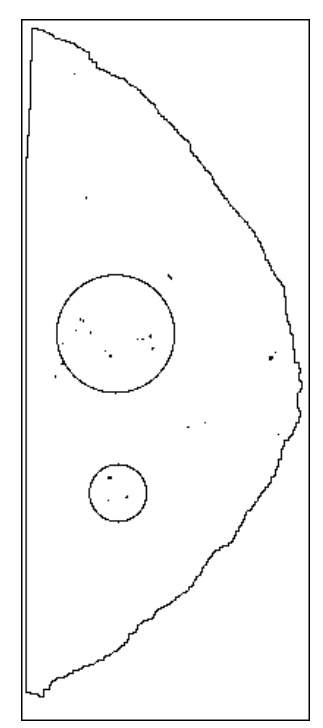

$v p=2, \quad f p=2$

d) z02c resultado

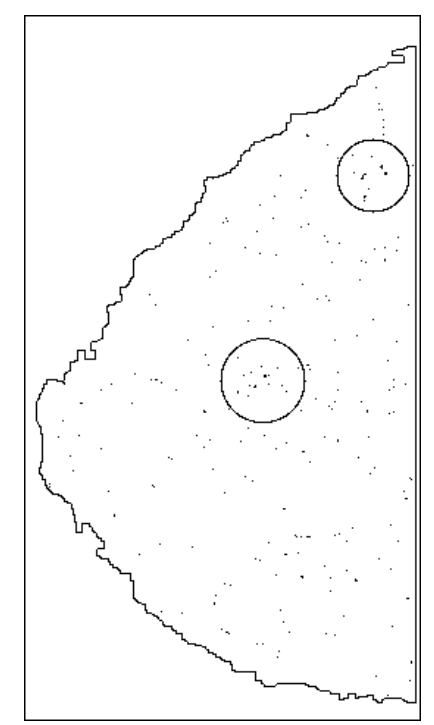

$v p=2, \quad f p=38$

b) z14c inicialización

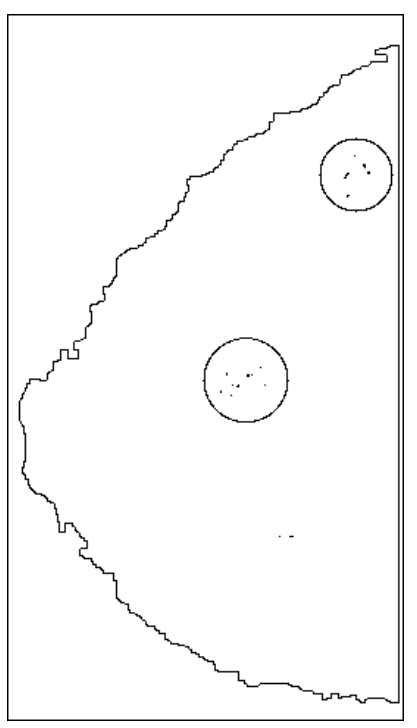

$v p=2, \quad f p=1$

e) z14c resultado

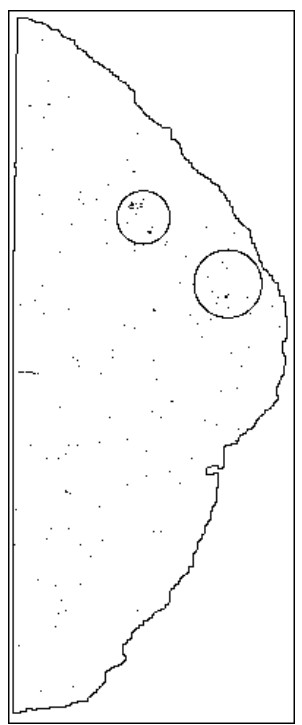

$v p=2, \quad f p=19$

c) z19c inicialización

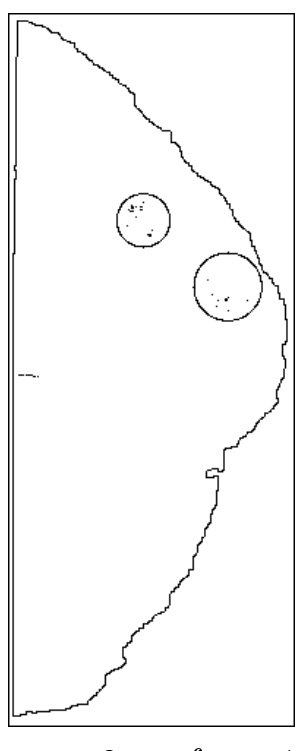

$v p=2, \quad f p=1$

f) $\mathrm{z} 19 \mathrm{c}$ resultado

Figura 6.4: Las figuras $a, b, c$ muestran en negro los pixels que en la inicialización han sido etiquetados como microcalcificación con $\alpha_{c}=5.5$. Las figuras $d, e, f$ muestran el resultado al finalizar el algoritmo. Se ve la reducción de pixels etiquetados como microcalcificación y de verdaderos y falsos positivos respecto a la inicialización, pero en estas imágenes $d$ y $e$ hay más falsos positivos que en $6.3 d$ y $e$. 
las figuras $6.4 d, e, f$ y $6.5 d, e, f$.

Los resultados para el grupo de test en función del valor de $\alpha_{c}$ se presentan en la figura 6.6. El eje de ordenadas de la gráfica superior indica el ratio de verdaderos positivos detectados y el de la gráfica inferior el número medio de falsos positivos por imagen. En ambas gráficas se utiliza la misma escala de valores de $\alpha_{c}$ para poder comparar. Obsérvese que cuanto más pequeño es el valor de $\alpha_{c}$ mayores son el número de verdaderos y falsos positivos, tal y como cabe esperar. Se observa que para el valor de $\alpha_{c}$ de la tabla 6.1 el ratio de verdaderos positivos está en $89 \%$. Como se verá más adelante este ratio se puede aumentar o disminuir si se disminuye o aumenta respectivamente el valor de $h_{o}$, que es el parámetro elegido para controlar la sensibilidad.

Respecto del valor de $\alpha_{e}$ cabe decir que para la misma variación, la influencia sobre el número de verdaderos y falsos positivos es menor que la de $\alpha_{c}$; las figuras 6.7 y 6.8 presentan los resultados para $\alpha_{e}=6$ y $\alpha_{e}=14$. Estos valores son una variación mayor que para $\alpha_{c}$ para poder ver la incidencia. El falso positivo que desaparece en la figura 6.7 corresponde a valores no muy altos del residuo que con $\alpha_{e}=6$ son etiquetados como emulsión y desaparece por tanto como microcalcificación. Recuérdese que en la figura sólo aparecen las microcalcificaciones.

Al igual que para $\alpha_{c}$, a continuación se presentan en la figura 6.9 los resultados para el grupo de test en función del valor de $\alpha_{e}$. El eje de ordenadas de la gráfica superior indica el ratio de verdaderos positivos detectados y el de la gráfica inferior el número medio de falsos positivos por imagen. En ambas gráficas se utiliza la misma escala de valores de $\alpha_{e}$ para poder comparar. Nótese que a partir del valor de $\alpha_{e}=7$ en adelante, el ratio de verdaderos positivos no aumenta; sin embargo el número de falsos positivos por imagen crece. Este crecimiento se debe a que si aumenta el valor de $\alpha_{e}$, la probabilidad de que se etiqueten como emulsión pixels que son verdaderamente del tipo emulsión disminuye, aumentándose consecuentemente la probabilidad de que esos pixels sean etiquetados como microcalcificación, y si hay dos regiones de este tipo que distan menos de $0.5 \mathrm{~cm}$ generan un falso positivo. Por contra para los valores bajos de la escala de la figura el número de positivos, tanto verdaderos como falsos, decrece debido a que se favorece que las regiones contrastadas sean etiquetadas como emulsión y por tanto no como microcalcificación.

\subsubsection{Influencia de los parámetros beta}

Recordemos que estos parámetros modelan la interacción de unos vecinos con otros (ver sección 5.2). Dada la simetría planteada en la ecuación 5.2 de los 


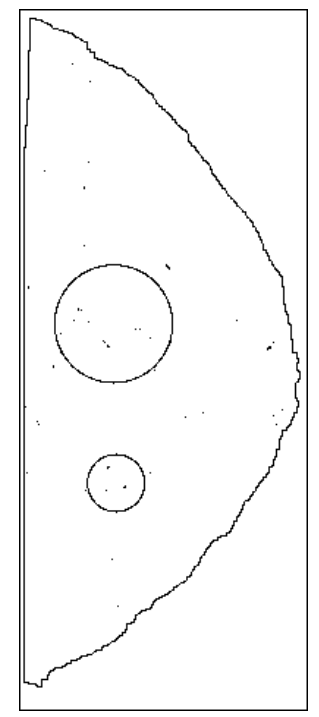

$v p=2, \quad f p=5$

a) z02c inicialización

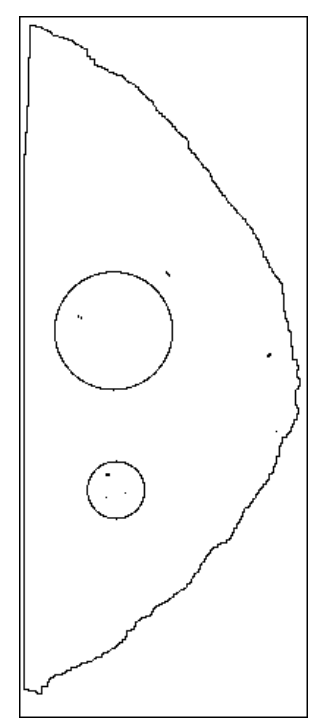

$v p=2, \quad f p=0$

d) z02c resultado

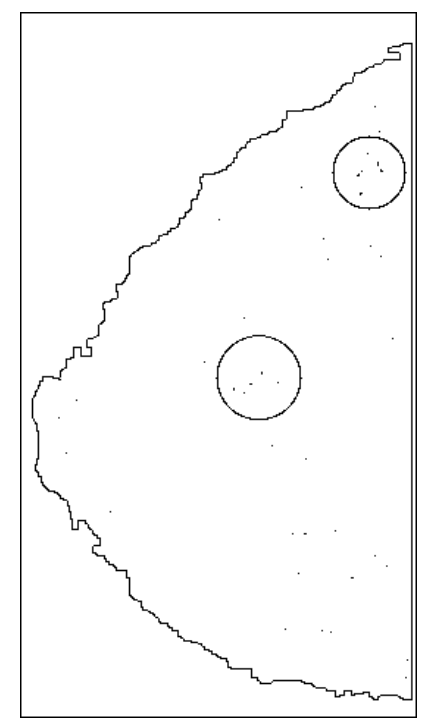

$v p=2, \quad f p=8$

b) z14c inicialización

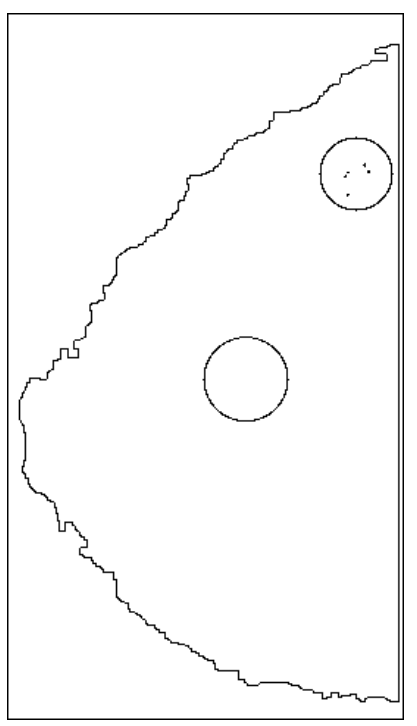

$v p=1, \quad f p=0$

e) z14c resultado

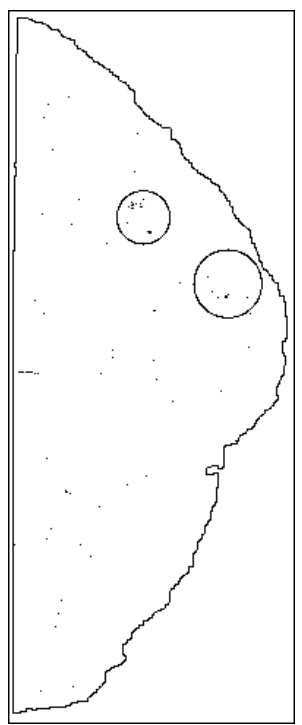

$v p=2, \quad f p=10$

c) z19c inicialización

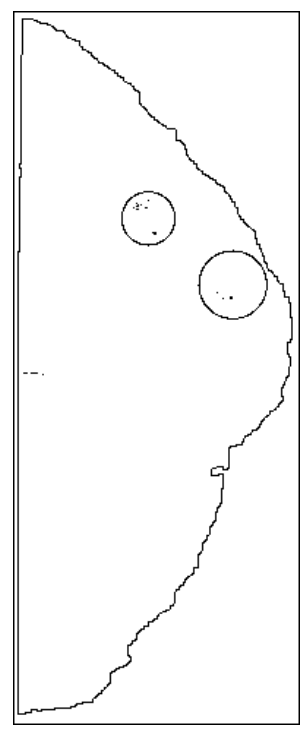

$v p=2, \quad f p=1$

f) $\mathrm{z} 19 \mathrm{c}$ resultado

Figura 6.5: Las figuras $a, b, c$ muestran en negro los pixels que en la inicialización han sido etiquetados como microcalcificación con $\alpha_{c}=7.5$. Las figuras $d, e, f$ muestran el resultado al finalizar el algoritmo. Se ve la reducción de pixels etiquetados como microcalcificación, y de verdaderos y falsos positivos. Se pierde el verdadero positivo inferior de la mamografía z14c. Al comparar esta figura con la anterior se observa que el resultado depende de la inicialización. 

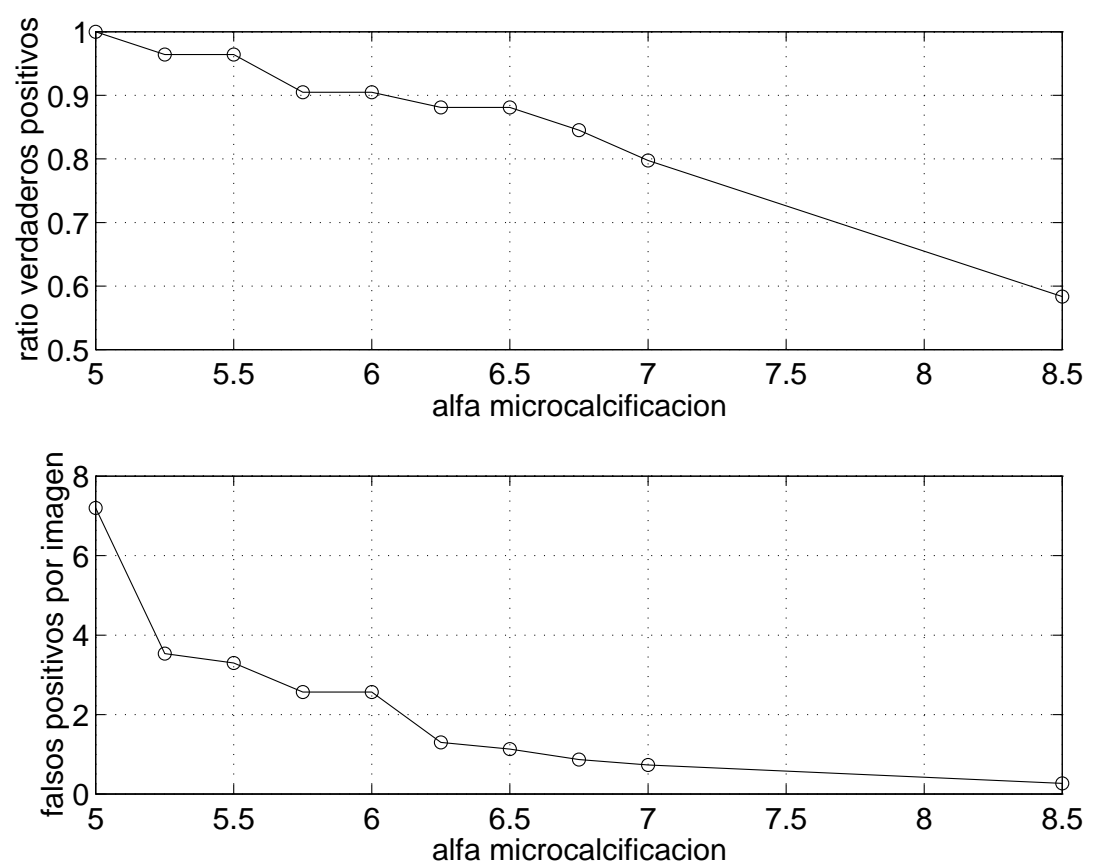

Figura 6.6: La gráfica superior indica el ratio de verdaderos positivos y la inferior el número de falsos positivos por imagen, tras 8 iteraciones, ambas en función del valor de $\alpha_{c}$.

nueve parámetros $\beta_{i j}$ sólo hay que determinar 6 de los 9 . Como el término donde están estos parámetros contribuye restando en la expresión de la energía y el modelo debe favorecer que los pixels vecinos tengan etiquetas similares, los términos $\beta_{i i}$ de la diagonal en la expresión 5.1 deben ser los menores y se toman cero. Queda entonces por determinar $\beta_{b c}, \beta_{b e} \mathrm{y} \beta_{c e}$. Como la etiqueta emulsión es debida a artefactos de diversas procedencias entre los que se incluyen regiones de un pixel, se debe dar una compatibilidad elevada a que los pixels de fondo y emulsión puedan ser vecinos por lo que al parámetro $\beta_{b e}$ también se le da valor cero. Sin embargo al parámetro $\beta_{b c}$ se le debe dar un valor mayor que cero para que no favorezca que los pixels fondo y microcalcificación sean vecinos, que junto con que los parámetros $\beta_{i i}$ son cero resulta en favorecer que los pixels microcalcificación y fondo queden agrupados por separado y formen regiones de varios pixels en vez de varias regiones de un pixel; lo cual corresponde a lo que ocurre en la mamografía y es que el fondo tiene altísima probabilidad de estar formado por regiones de más de un pixel, y por parte de las microcalcificaciones es poco frecuente que estén formadas por un único pixel.

En la figura 6.10 se presenta como ejemplo el resultado para las mamografías z02c, z14c y z19c con un valor de $\beta_{b c}=0.0$ y otro de $\beta_{b c}=1.0$, que están por debajo y por encima respectivamente del valor $\beta_{b c}=0.5$ utilizado en la figura 6.3. Se puede observar que en las figuras $6.10 a, b, c$ aparecen mayor cantidad 


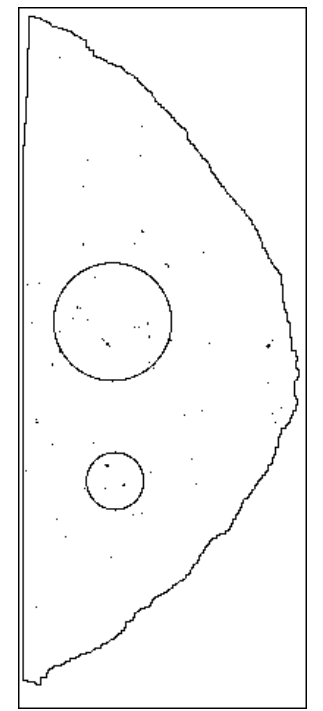

a) z02c inicialización

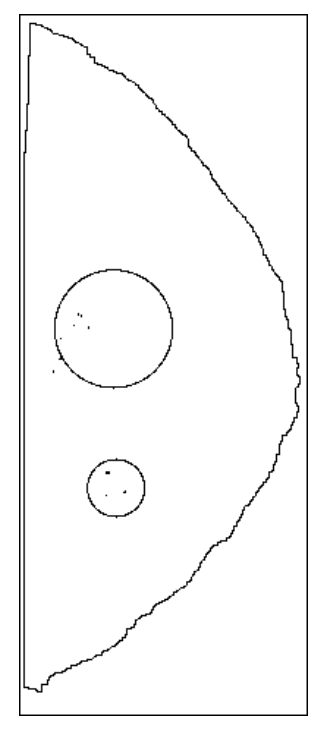

$v p=2, \quad f p=0$

d) z02c resultado

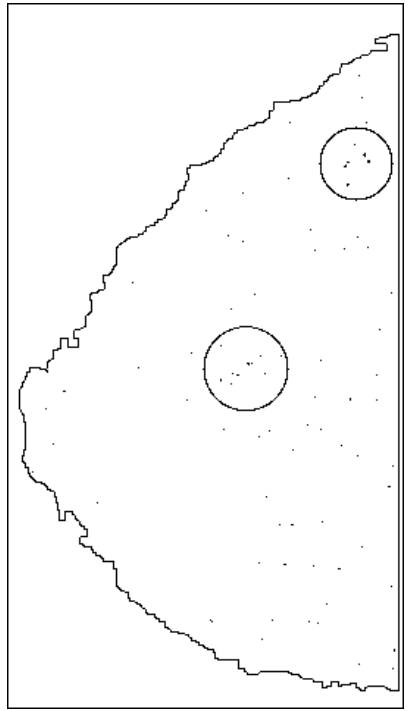

b) z14c inicialización

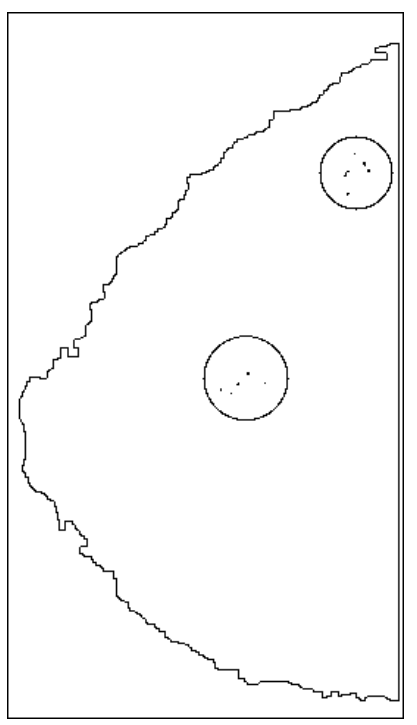

$v p=2, \quad f p=0$

e) z14c resultado

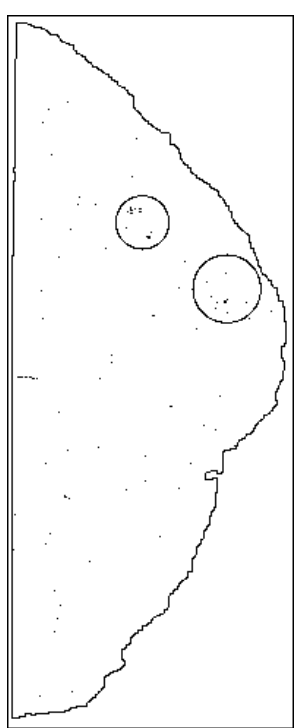

c) z19c inicialización

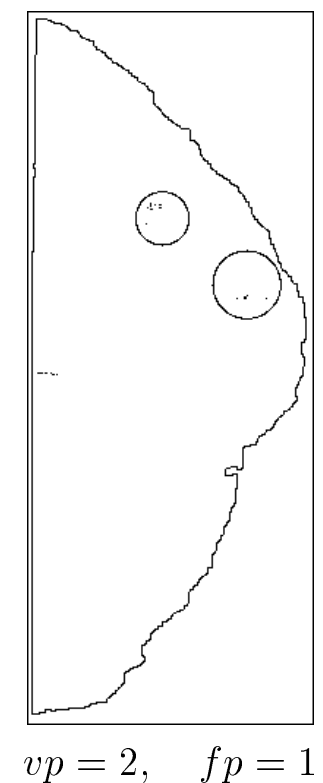

f) z19c resultado

Figura 6.7: Las figuras $a, b, c$ muestran en negro los pixels que en la inicialización han sido etiquetados como microcalcificación con $\alpha_{e}=6$ y las figuras $d, e, f$ muestran el resultado al finalizar el algoritmo. Obsérvese que en la imagen $d$ hay un falso positivo menos que en la figura $6.3 d$. 


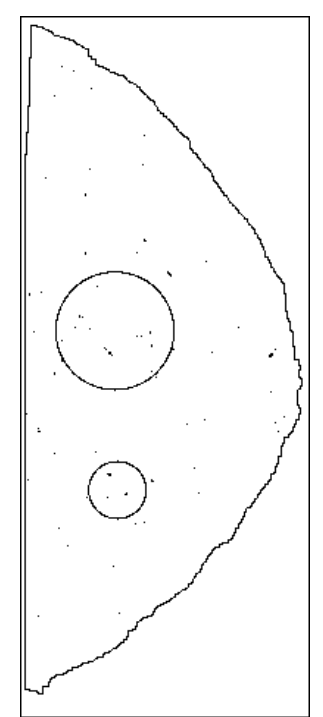

a) z02c inicialización

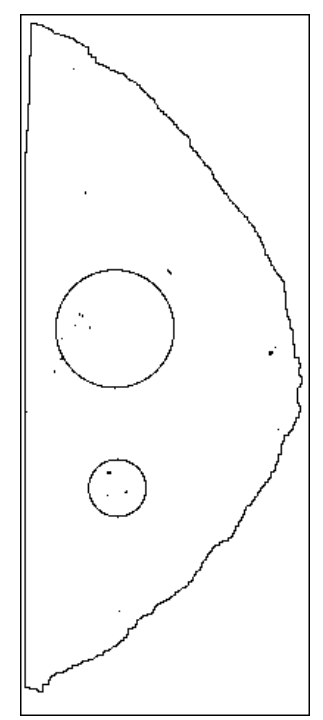

$v p=2, \quad f p=1$

d) z02c resultado

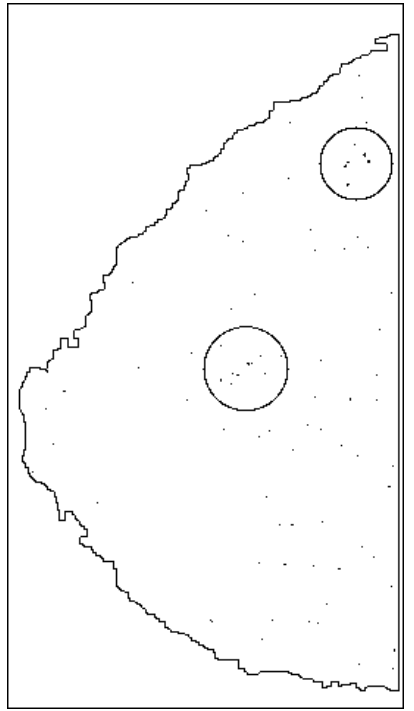

b) z14c inicialización

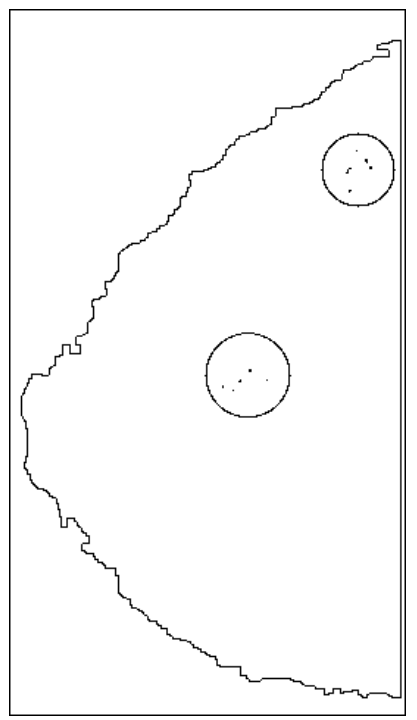

$v p=2, \quad f p=0$

e) $\mathrm{z} 14 \mathrm{c}$ resultado

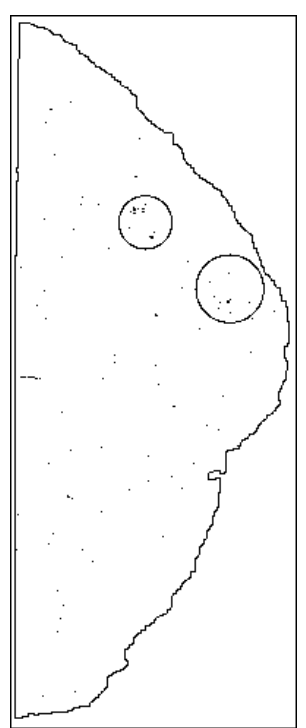

c) z19c inicialización

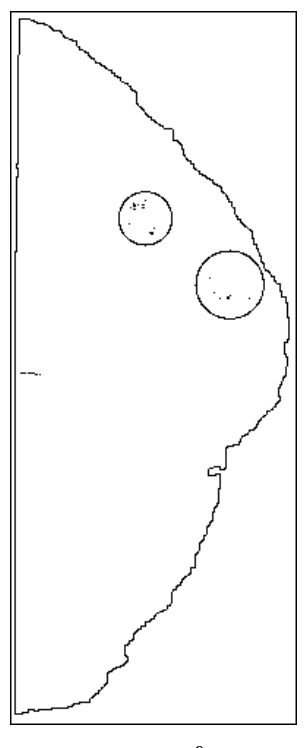

$v p=2, \quad f p=1$

f) $\mathrm{z} 19 \mathrm{c}$ resultado

Figura 6.8: Las figuras $a, b, c$ muestran en negro los pixels que en la inicialización han sido etiquetados como microcalcificación con $\alpha_{e}=14$. El resultado tras 8 iteraciones del algoritmo se presenta en las figuras $d, e, c$. Obsérvese que en $d$ aparece un falso positivo más que en $6.7 d$. 

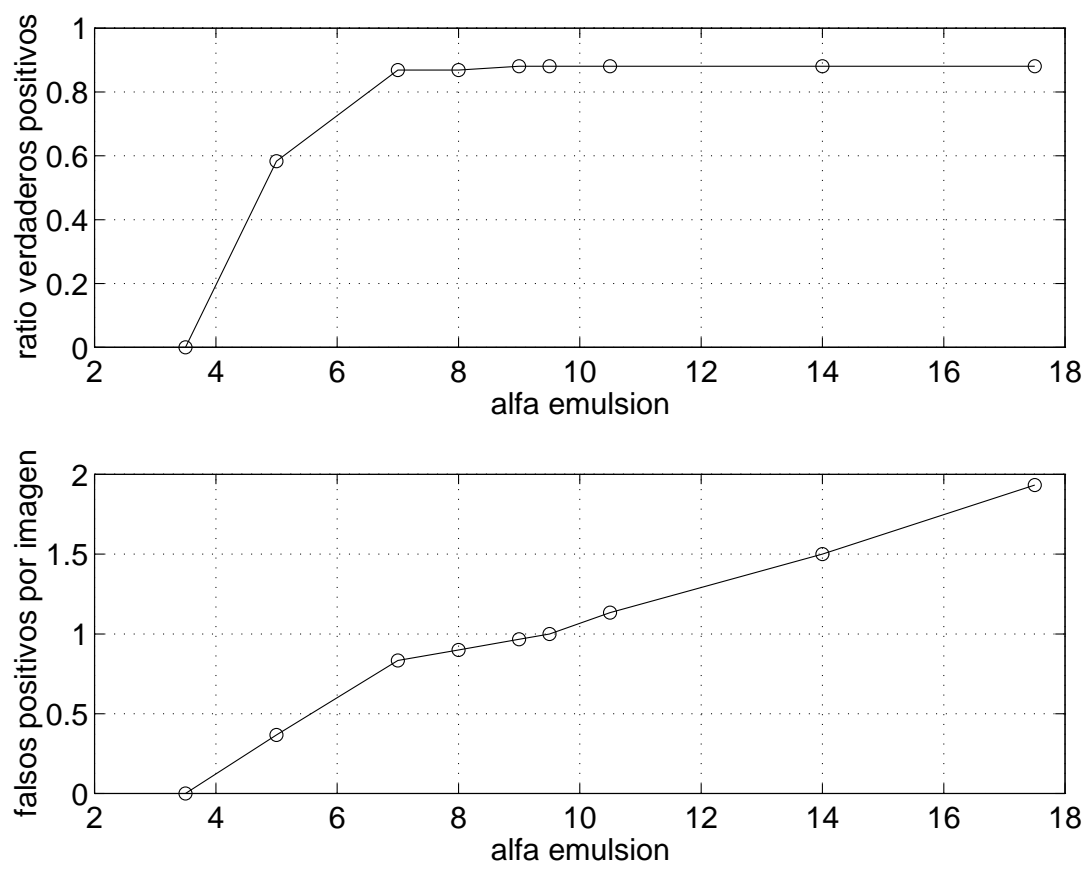

Figura 6.9: La gráfica superior indica el ratio de verdaderos positivos y la inferior el número de falsos positivos por imagen, ambas en función del valor de $\alpha_{e}$.

de calcificaciones de un pixel que en las figuras 6.10d,e,f, debido al valor bajo de $\beta_{b c}$. En las figuras $6.10 d, e, f$ al tener un valor mayor de $\beta_{b c}$ que favorece la creación de regiones grandes y la desaparición de las regiones pequeñas, desaparecen la mayor parte de las microcalcificaciones de un pixel y algunas de más de un pixel. En [10] [100] se da como valor de $\beta$ para el modelo allí utilizado $\beta=1.5$. Aunque los modelos no son exactamente los mismos, sí cabe pensar en que existe un cierto paralelismo que podría inducir a utilizar el mismo valor. En el trabajo de Besag, al igual que las figuras presentadas en el capítulo 3, las regiones que compiten son de tamaños del mismo orden de magnitud, o al menos la diferencia no es de varios órdenes de magnitud. En el caso de las microcalcificaciones en las mamografías esa condición no se cumple y hay que disminuir el valor, de ahí que se elija $\beta_{b c}=0.5$.

Respecto del valor de $\beta_{c e}$ debe ser más alto todavía que $\beta_{b c}$ porque es menos probable que suceda un artefacto en una microcalcificación que en el fondo. Además, considerando que los artefactos tienen un valor medio mayor que el valor medio de las microcalcificaciones, ocurre que los pixels que siendo microcalcificación tengan valores más altos pueden ser etiquetados como emulsión. En algunas microcalcificaciones el centro tiene un valor mayor que en el resto de la microcalcificación y consecuentemente en la inicialización, en la que todavía no ha entrado en juego el modelo de campo aleatorio de Markov son etiquetados como emulsión. Cuando comienzan las iteraciones, comienzan a tener efecto los 


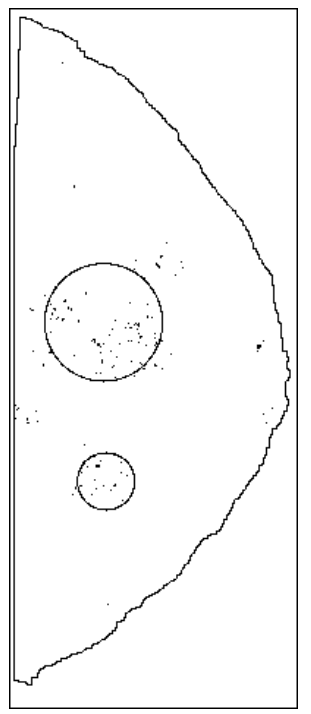

a) z02c, $\beta_{b c}=0.0$

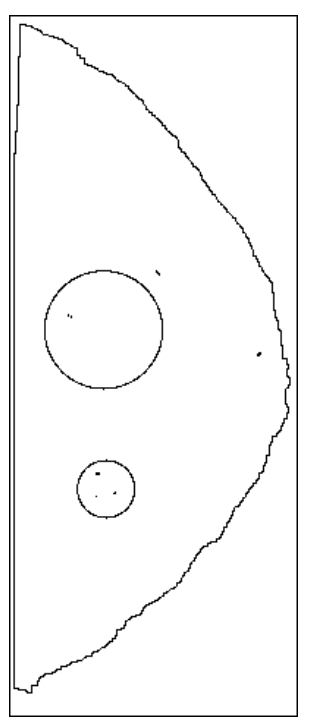

d) z02c, $\beta_{b c}=1.0$

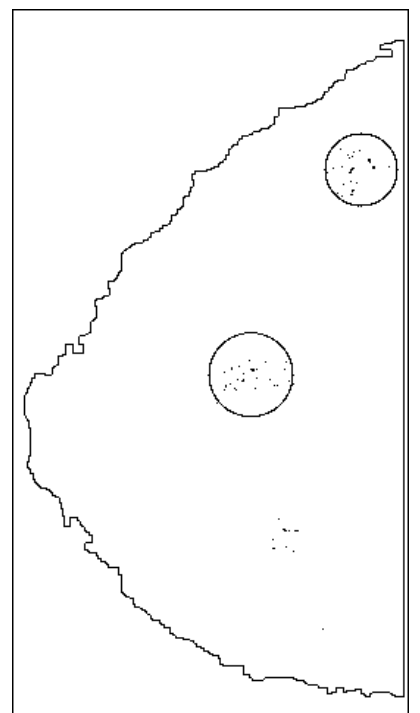

b) z14c, $\beta_{b c}=0.0$

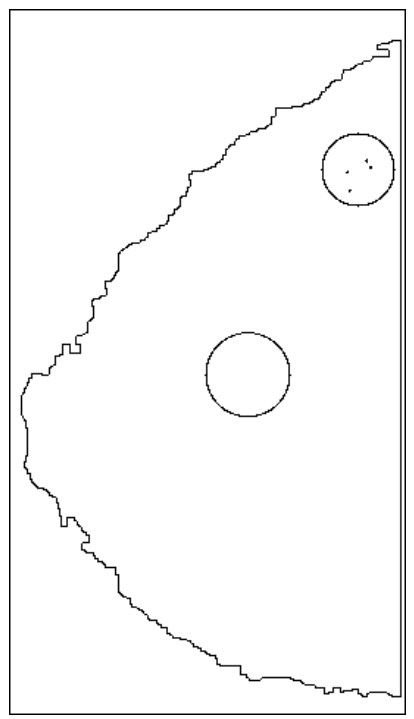

e) $\mathrm{z} 14 \mathrm{c}, \beta_{b c}=1.0$

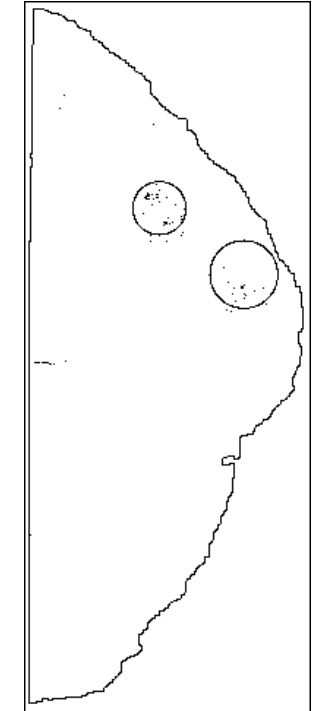

c) $\mathrm{z} 19 \mathrm{c}, \beta_{b c}=0.0$

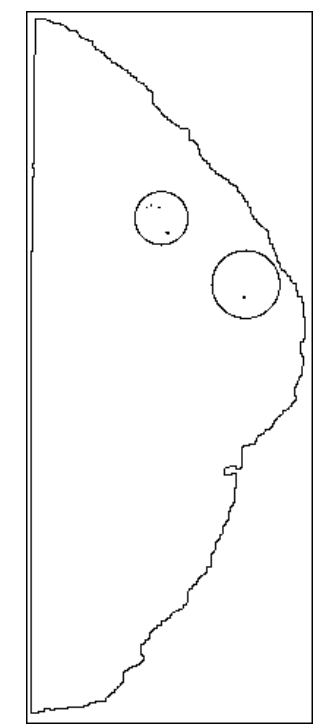

f) $\mathrm{z} 19 \mathrm{c}, \beta_{b c}=1.0$

Figura 6.10: Las figuras muestran en negro los pixels que han sido etiquetados como microcalcificación al finalizar el algoritmo (8 iteraciones) con los valores de $\beta_{b c}$ indicados. Se observa una mayor presencia de regiones de un pixel en las figuras $a, b, c$ debido al valor bajo de $\beta_{b c}$. 
parámetros $\beta_{i j}$ y por tanto $\beta_{c e}$. Un valor bajo de $\beta_{c e}$ permite la coexistencia de pixels vecinos etiquetados como microcalcificación y como emulsión, pudiendo dar como resultado al finalizar las iteraciones regiones de microcalcificación con huecos e irregularidades debido a que parte de sus pixels (los de mayor nivel) han quedado finalmente etiquetados como emulsión. Este hecho queda ilustrado en la figura 6.11. La figura 6.11 a corresponde a la inicialización de la mamografía z01o en la que se ha marcado un rectángulo de tamaño en pixels 48x106 con origen en $(288,796)$. La figura $6.11 b$ corresponde a la ampliación del resultado del algoritmo con $\beta_{c e}=0.0$ del recuadro marcado en 6.11a. Se puede observar que la microcalcificación grande tiene un forma irregular y con huecos. En $6.11 c$, se muestra el resultado habiendo utilizado en el algoritmo $\beta_{c e}=3.0$ y se puede observar que la microcalcificación queda segmentada como una región sólida.

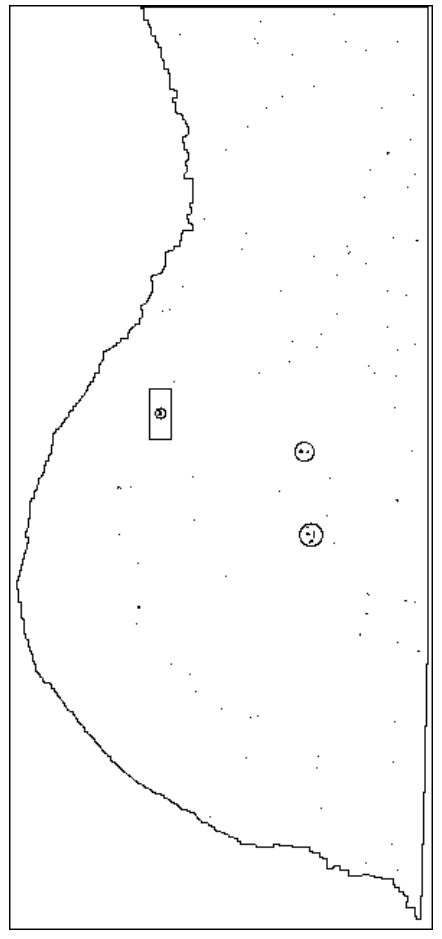

a) z01o, inicialización

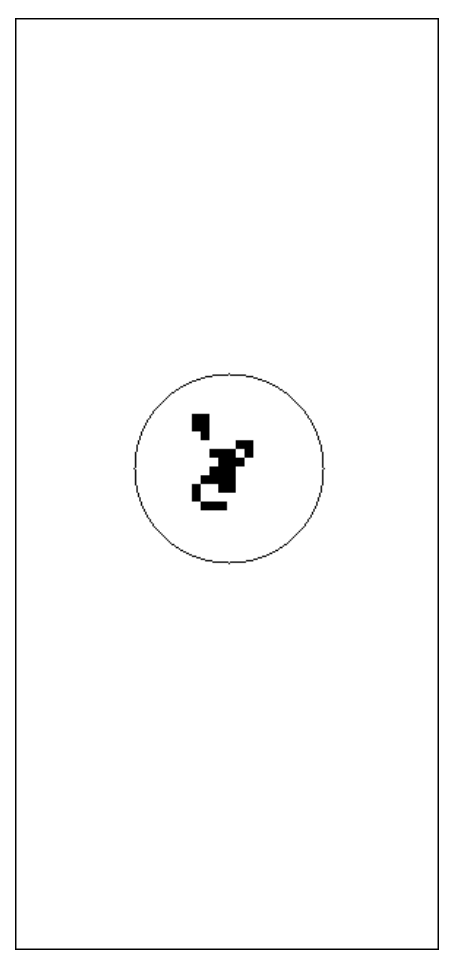

b) z01o, $\beta_{c e}=0.0$

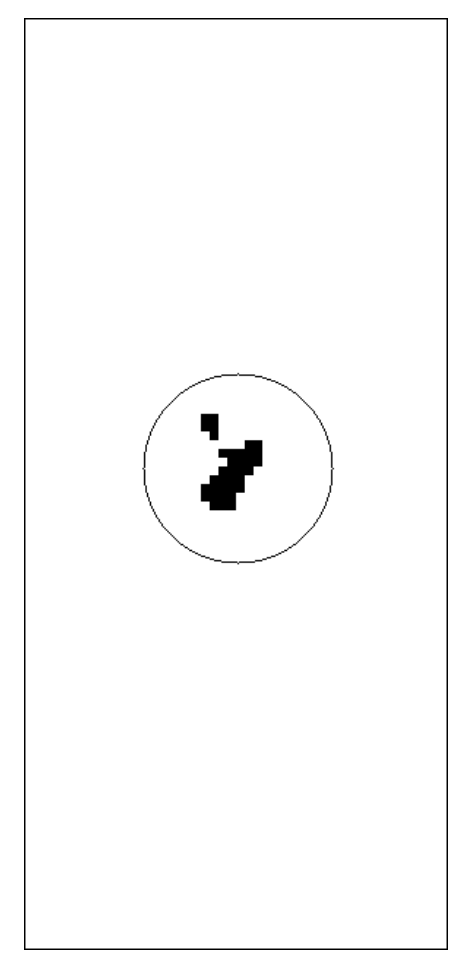

c) z01o, $\beta_{c e}=3.0$

Figura 6.11: La figura a muestra la inicialización para la mamografía z01o con $\alpha_{c}$ $=6.5$ y $\alpha_{e}=7$. Las figuras $b$ y $c$ muestran la ampliación del resultado del algoritmo tras 8 iteraciones del recuadro marcado en a para los valores de $\beta_{c e}=0.0$ y $\beta_{c e}=3.0$, respectivamente. Obsérvese que en la figura $b$ la microcalcificación queda segmentada irregularmente. El tamaño del recuadro corresponde en pixels a $48 \times 106$ con origen en el pixel $(288,796)$. 


\subsubsection{Influencia de los parámetros del vecindario amplia- do}

El conjunto de los parámetros $\gamma($ fondo $), \gamma($ microcalcificación $)$ y $\gamma($ emulsión $)$ controlan la influencia del vecindario ampliado (ver sección 5.2). Recordemos que en nuestro modelo de campo aleatorio de Markov se utiliza un vecindario de orden 2 que es insuficiente para modelar el hecho de que las microcalcificaciones es frecuente que ocurran en clusters, ya que estos clusters son de tamaño de decenas de pixels, incluso cientos y están formados por pequeñas regiones (las microcalcificaciones) aisladas separadas por el fondo; por contra el fondo está formado por una región grande pero que todos sus pixels son vecinos entre sí y por tanto el vecindario de orden 2 a través de que todos los pixels son vecinos tiene influencia sobre pixels alejados. Es por ello que para el fondo no se considera otro vecindario que el de orden 2 y consecuentemente se toma $\gamma($ fondo $)=0$. Asimismo como las emulsiones no tienen porqué producirse en clusters también $\gamma($ emulsión $)=0$.

Para que las zonas de la inicialización que tienen pocos pixels etiquetados como microcalcificación, y por tanto es poco probable que lo sean, tiendan a desaparecer, la forma del termino de vecindario ampliado es $+\gamma(l)\left[\left(h_{i j}(C)-h_{o}\right]\right.$. Para valores bajos de $h_{i j}(C)$ (con $h_{o}$ positivo) la contribución total es negativa y por tanto favorece que no sean etiquetadas como microcalcificación.

La figura 6.12 muestra en negro los pixels que han sido etiquetados como microcalcificación al finalizar el algoritmo (8 iteraciones) con los valores de $\gamma(c)$ indicados. La inicialización de cada imagen para ambos valores de $\gamma(c)$ se corresponde con las de las figuras $6.3 a, b, c$. Tanto para las figuras $6.12 a, b, c$ como para las $d, e, f$ el número de pixels etiquetados como microcalcificación se reduce debido al modelo de campo aleatorio de Markov con vecindario de orden 2. Sin embargo debe observarse que debido al término del vecindario ampliado, en las figuras $d, e, f$ hay más microcalcificaciones formando clusters y menos fuera de ellos, lo cual es coherente con la afirmación de los radiólogos y contribuye a un mejor resultado. En la figura $6.12 a, b, c$ el vecindario ampliado no tiene efecto debido a que $\gamma(c)=0$.

La figura 6.13 resume los resultados para el grupo de test en función del valor de $\gamma(c)$. El eje de ordenadas de la gráfica superior indica el ratio de verdaderos positivos detectados y el de la gráfica inferior el número medio de falsos positivos por imagen. En ambas gráficas se utiliza la misma escala de valores de $\gamma(c)$ para poder comparar. Puede observarse en la gráfica de los falsos positivos por imagen la reducción a casi la mitad cuando se pasa de $\gamma(c)=0$ a $\gamma(c)=0.2$, sin apenas modificación del ratio de verdaderos positivos. Luego a medida que aumenta $\gamma(c)$, aumentan ambos y finalmente por encima de $\gamma(c)=1.2$ el ratio de verdaderos 


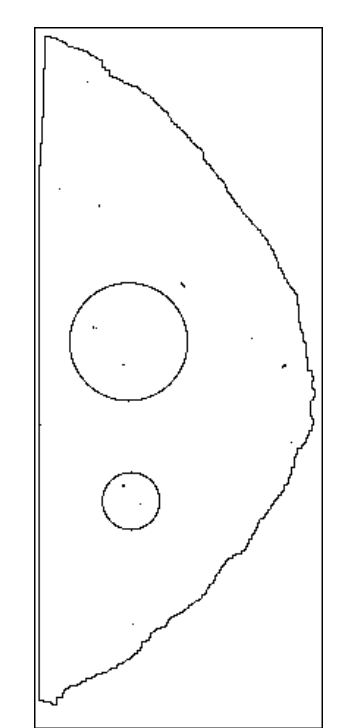

a) z02c, $\gamma(c)=0.0$

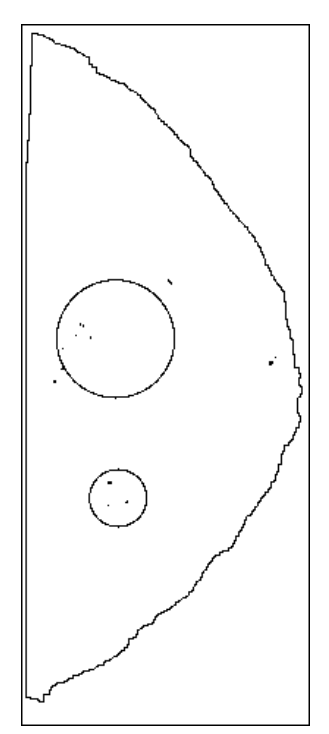

d) z02c, $\gamma(c)=1.2$

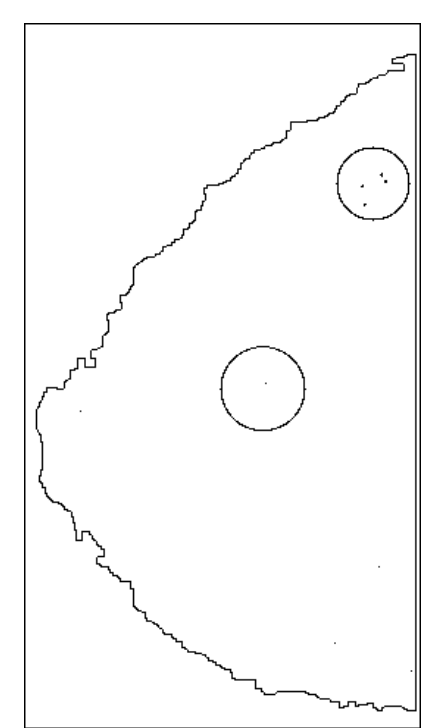

b) $\mathrm{z} 14 \mathrm{c}, \gamma(c)=0.0$

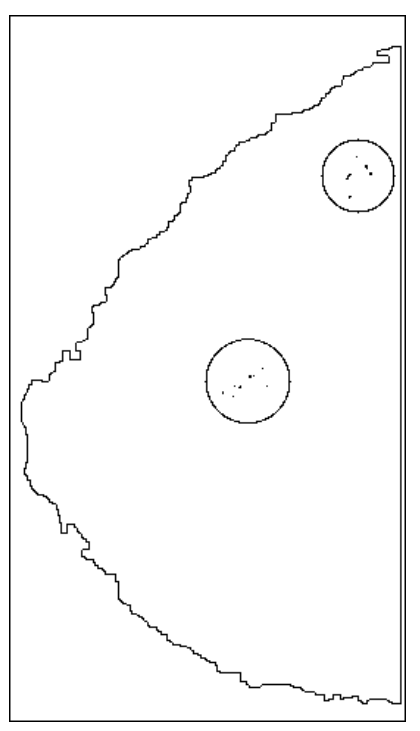

e) z14c, $\gamma(c)=1.2$

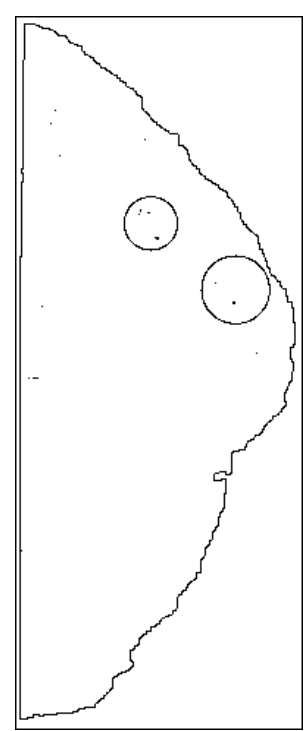

c) $\mathrm{z} 19 \mathrm{c}, \gamma(c)=0.0$

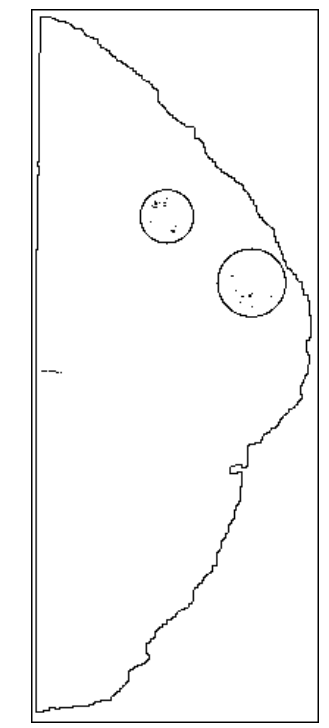

f) z19c, $\gamma(c)=1.2$

Figura 6.12: La figura muestra en negro los pixels que han sido etiquetados como microcalcificación al finalizar el algoritmo (8 iteraciones) con los valores de $\gamma(c)$ indicados. Se observa que para el valor mayor de $\gamma(c)$ la tendencia a formar clusters de microcalcificaciones es mayor, al mismo tiempo que se reducen los falsos positivos. 

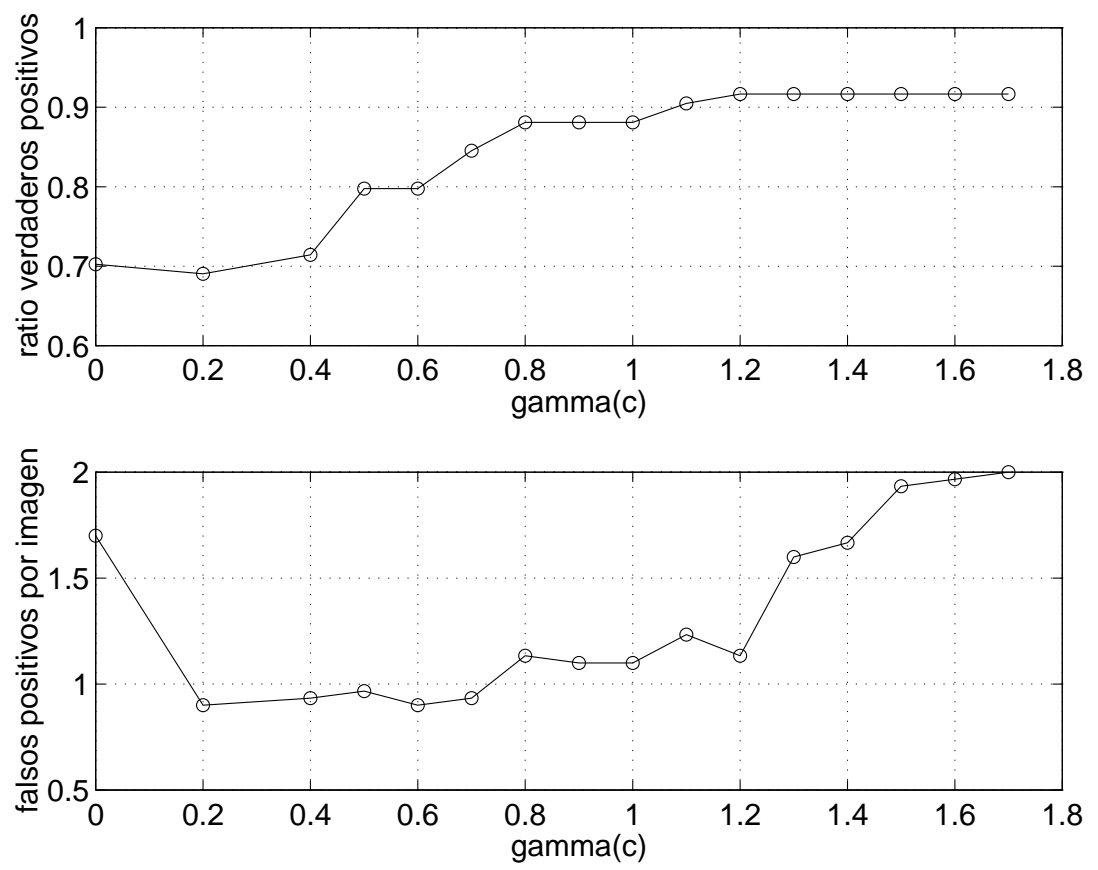

Figura 6.13: La gráfica superior indica el ratio de verdaderos positivos y la inferior el número de falsos positivos por imagen, ambas en función del valor de $\gamma(c)$.

positivos apenas varía, mientras que los falsos positivos siguen creciendo.

El parámetro $h_{o}$ incide directamente sobre la cantidad de microcalcificaciones que van desapareciendo a partir de la inicialización, ya que para valores positivos de $h_{o}$ y $h_{i j}(C)$, cuanto mayor sea $h_{o}$ menor es la energía de la etiqueta microcalcificación y por tanto más difícil es que sea etiquetada como tal. Por ello se elige este parámetro para controlar la sensibilidad. Como los resultados para cada operador morfológico se darán para diferentes sensibilidades, la influencia de $h_{o}$ se ilustrará en la sección dedicada al residuo del fondofibra con reconstrucción. Respecto al valor de saturación $h_{\max }$ en $h_{i j}(C)$ de la expresión 5.7, éste es necesario para evitar que clusters con gran cantidad de microcalcificaciones, o microcalcificaciones con gran cantidad de pixels, crezcan desmesuradamente. Esto también se podría evitar reduciendo el valor de $\gamma(c)$, pero entonces para clusters pequeños se perdería la eficacia de tener un valor elevado de $\gamma(c)$. Las figuras $6.14 a, b, c$ muestran el resultado tras 8 iteraciones con $h_{\max }=16$ en vez de $h_{\max }=10$ que se viene utilizando en las figuras precedentes. En las figuras se observa la gran incidencia que tiene este valor. En realidad la dependencia no es debida únicamente a $h_{\max }$ sino al término $+\gamma(c)\left[h_{i j}(C)-h_{o}\right]$ en el que directamente participa $h_{\max }$. En concreto y con los valores que se están utilizando $\left(h_{o}=7, \gamma(c)=0.8\right)$, en un cluster de más de 16 pixels etiquetados como microcalcificación el término $+\gamma(c)\left[h_{i j}(C)-h_{o}\right]$ con $h_{\max }=16$ vale 7.2 y con 
$h_{\max }=10$ vale 2.4. Para ver cuan importante es esta diferencia de 4.8 unidades de energía comparémosla con la diferencia de nivel necesaria $g_{1}-g_{2}$ en la imagen observación de entrada al algoritmo para compensar en energía estas cifras. Con los valores de $\alpha_{b}$ y $\alpha_{c}$ de la tabla 6.1, las estadísticas obtenidas a partir del grupo de entrenamiento y suponiendo igual etiquetado en el vecindario de orden 2 , un pixel es etiquetado como microcalcificación si su nivel en la observación es mayor o igual que 14. Si ese mismo pixel tiene una energía aportada por el término de vecindario ampliado de 4.8 unidades es etiquetado como microcalcificación si su nivel es mayor o igual que 9. Por ejemplo, en el residuo del fondofibra con reconstrucción de la mamografía z02c, el número de pixels con nivel mayor o igual que 14 es 5874, y el número de pixels con nivel mayor o igual que 9 es 10908 , lo que supone una diferencia de 5034 pixels más etiquetados como microcalcificación y que a su vez en la siguiente iteración contribuirían de nuevo a aumentar el número de pixels etiquetados como microcalcificación. De ahí la importancia del valor $h_{\max }$. Como se ha dicho al principio del párrafo la trascendencia de $h_{\max }$ es menor con un valor menor de $\gamma(c)$. La figura 6.14 muestra varias realizaciones con un valor más alto del utilizado normalmente para ver claramente su efecto.

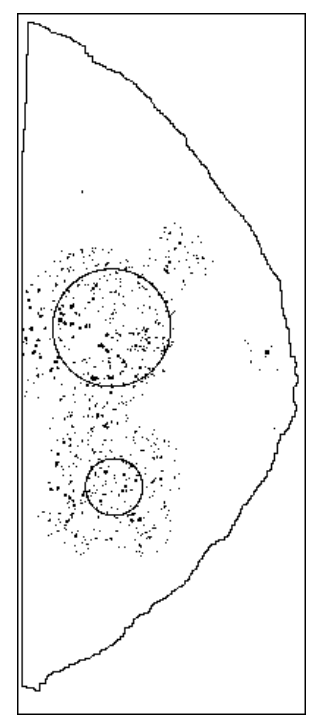

a) z02c resultado

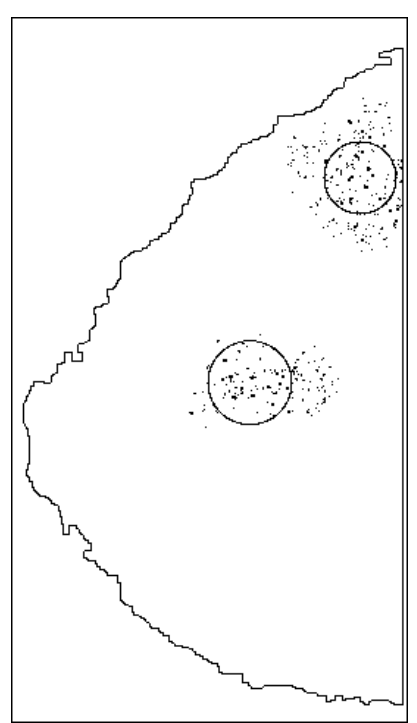

b) z14c resultado

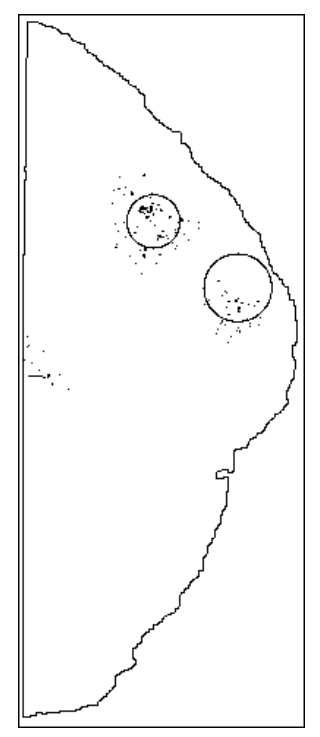

c) z19c resultado

Figura 6.14: Las figuras $a, b, c$ muestran el resultado tras 8 iteraciones con un valor de $h_{\max }=16$. Se observa claramente el efecto de sobrecrecimiento de los clusters de microcalcificación.

\subsubsection{Influencia del número de iteraciones}

En la literatura referente al algoritmo ICM [10] [77] [100] se dice que el número de iteraciones que en la mayoría de las aplicaciones es necesario para llegar a 
la convergencia o para que el número de cambios de etiquetas de una iteración a otra sea muy bajo, no sobrepasa las 8 . En nuestro trabajo también constatamos que con 8 iteraciones o incluso menos es suficiente. La mayor parte de las etiquetas quedan correctamente asignadas tras la primera iteración. En las tres mamografías que se vienen utilizando como ejemplo del grupo de test en las dos primeras iteraciones se llega al número final de verdaderos y falsos positivos. La figura 6.15 muestra este hecho. Las figuras $6.15 a, b, c$ corresponden a la inicialización. Son las mismas que $6.3 a, b, c$ reproducidas aquí para facilitar la comparación con el resultado tras la primera iteración presentado en las figuras $6.15 d, e, f$. Finalmente las figuras $6.15 g, h, i, j, k, l$ presentan el resultado tras la segunda y la octava (última) iteración.

\begin{tabular}{|c||c|c|c|}
\hline Niter & z02c & z14c & z19c \\
\hline \hline 0 & $(2,12)$ & $(2,18)$ & $(2,12)$ \\
\hline 1 & $(2,2)$ & $(2,0)$ & $(2,1)$ \\
\hline 2 & $(2,1)$ & $(2,0)$ & $(2,1)$ \\
\hline 8 & $(2,1)$ & $(2,0)$ & $(2,1)$ \\
\hline
\end{tabular}

Tabla 6.2: Número de verdaderos y falsos positivos de las imágenes de la figura 6.15 .

El número de verdaderos y falsos positivos (vp, fp) de las imágenes de la figura 6.15 se dan en la tabla 6.2. Respecto a los resultados sobre el total de las mamografías del grupo de test se da en la tabla 6.3 el ratio de verdaderos positivos y el número de falsos positivos por imagen alcanzados tras cada iteración, siendo la iteración cero la inicialización. Asimismo en la figura 6.16 se presentan estos mismos datos gráficamente.

\begin{tabular}{|c|c|c|}
\hline Niter & Ratio vp & fp/img \\
\hline \hline 0 & 1.0 & 22.27 \\
\hline 1 & 0.90 & 2.63 \\
\hline 2 & 0.90 & 1.60 \\
\hline 3 & 0.88 & 1.27 \\
\hline 4 & 0.88 & 1.27 \\
\hline 5 & 0.88 & 1.20 \\
\hline 6 & 0.88 & 1.13 \\
\hline 7 & 0.88 & 1.13 \\
\hline 8 & 0.88 & 1.13 \\
\hline
\end{tabular}

Tabla 6.3: Ratio de verdaderos positivos y número de falsos positivos por imagen del grupo de test tras cada iteración. 


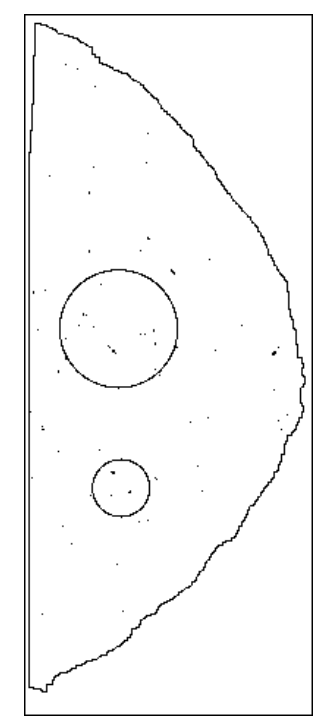

a) z02c inicialización

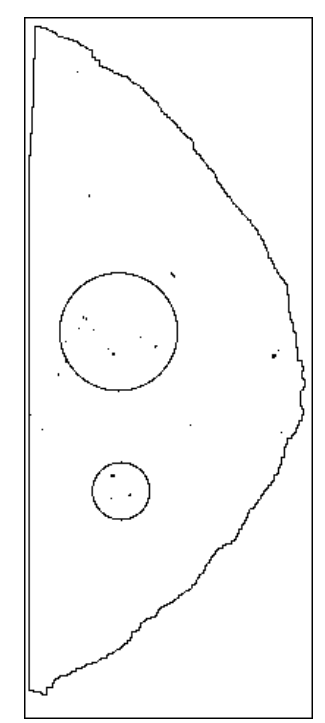

d) z02c 1 Iteración
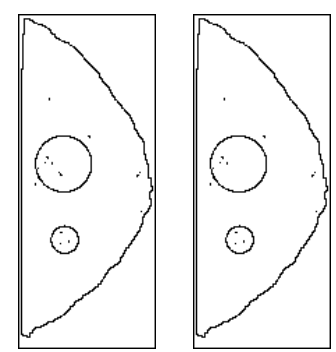

g, h) z02c 2 y 8 Iteraciones

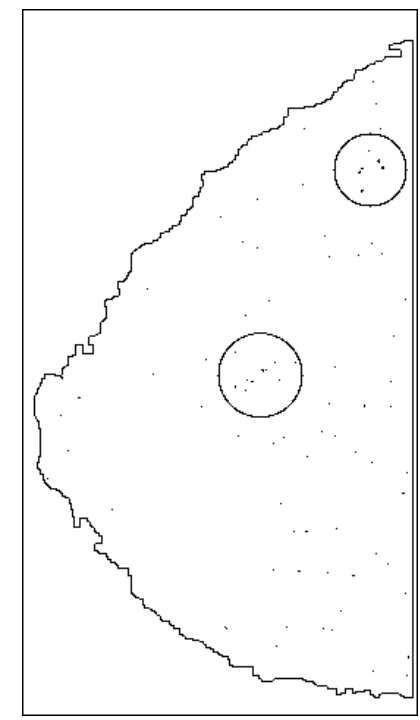

b) z14c inicialización

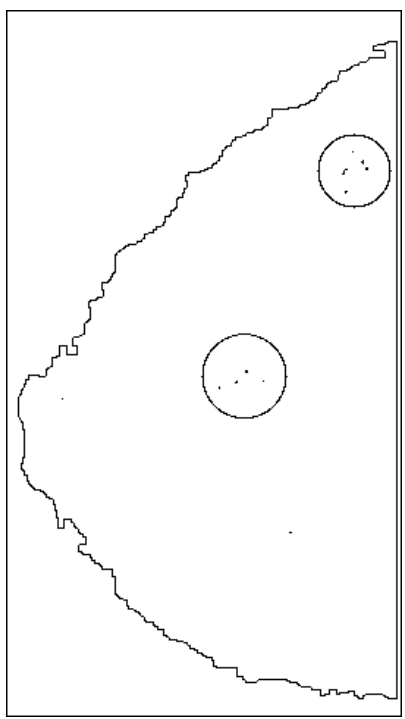

e) z14c 1 Iteración

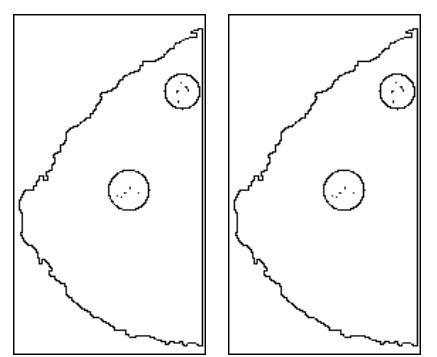

i,j) z14c 2 y 8 Iteraciones

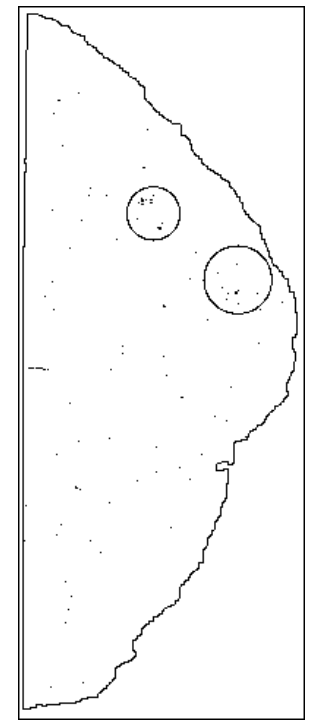

c) z19c inicialización

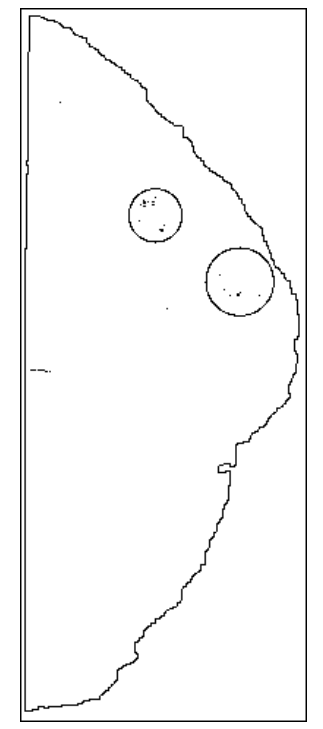

f) z19c 1 Iteración
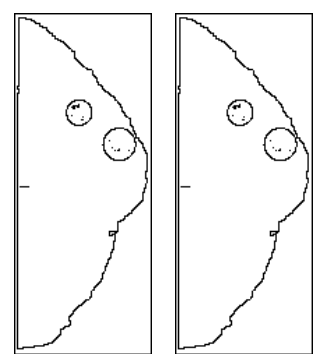

k,l) z19c 2 y 8 Iteraciones

Figura 6.15: Evolución con el número de iteraciones. 

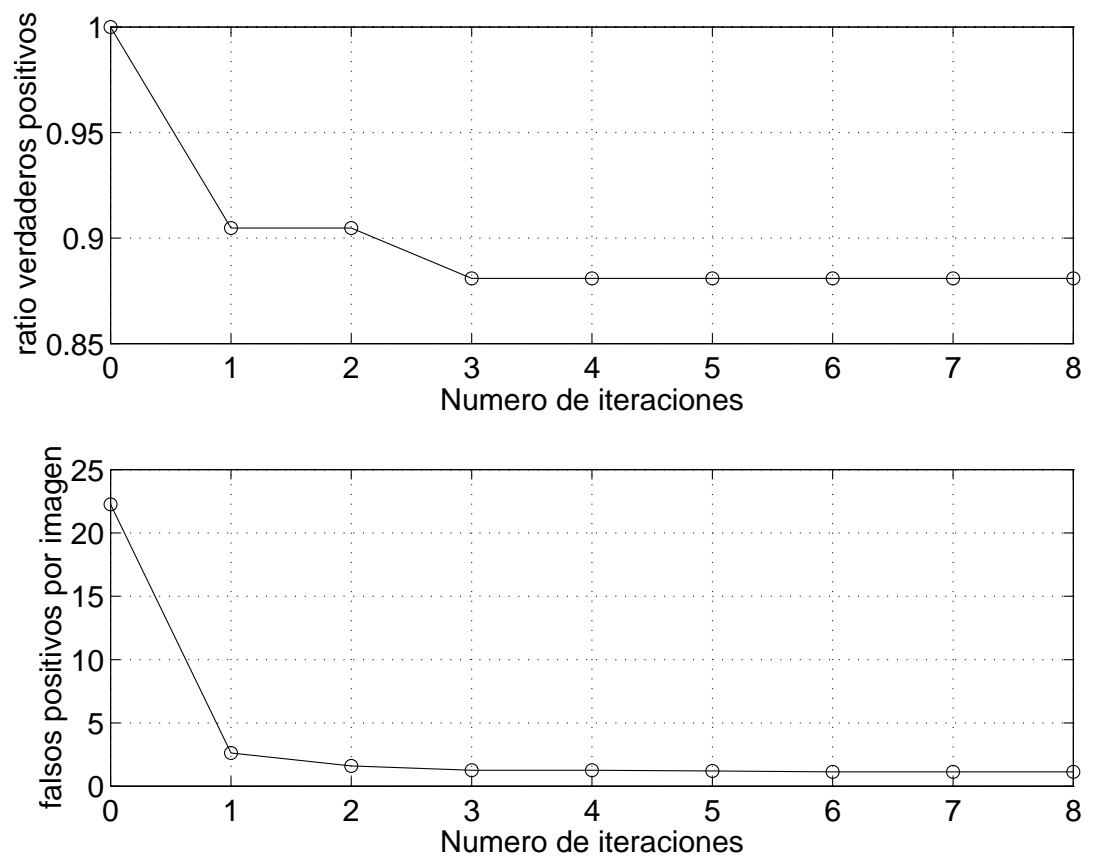

Figura 6.16: La gráfica superior indica el ratio de verdaderos positivos y la inferior el número de falsos positivos por imagen, ambas en función del número de iteraciones. 


\subsection{Top-Hat}

Tal como se ha dicho en el capítulo 5 el operador Top-Hat clásico se presenta aquí meramente como punto de referencia a efectos comparativos puesto que es fácilmente previsible que sus prestaciones serán bajas porque no distingue las fibras de los objetos circulares pequeños. A título de ejemplo, y para poder realizar comentarios sobre casos concretos se presenta en la figura 6.17 las imágenes que se vienen utilizando en las secciones precedentes. Los pixels en negro corresponden a los etiquetados como microcalcificación. Las imágenes $a, b, c$ corresponden a la inicialización, y las $d, e, f$ al resultado tras 8 iteraciones del algoritmo. Como se verá más adelante, el Top-Hat es el que menor número de verdaderos positivos da, para un mismo número de falsos positivos por imagen, entre los distintos operadores morfológicos utilizados.

Es ilustrativa para este caso la figura 6.17e, donde con sendos recuadros se han marcado los dos falsos positivos que aparecen en esa mamografía. Para poder ver con más detalle la procedencia de estos falsos positivos se ha incluido la figura 6.18. La figura a corresponde a la imagen en niveles de gris de la mamografía z14c, donde se ha marcado una porción de 300x300 pixels con origen en $(460,950) ; b$ corresponde a la ampliación del recuadro marcado en $a$ ampliado respecto a $a$ en tamaño por 3 y en contraste también por 3; se pueden apreciar zonas pequeñas más claras que su entorno con formas alargadas; en $c$ parte de esas zonas alargadas han resultado clasificadas como microcalcificación, debido a que el elemento estructurante utilizado en el Top-Hat no cabe en ellas. Ambos falsos positivos no aparecen cuando se utilizan los operadores morfológicos de las siguientes secciones.

Cabe comentar, como hecho excepcional, lo que ocurre en la imagen z02c, donde el número de falsos positivos es el mismo que en la figura 6.3d. En ambas hay un sólo falso positivo, aunque no es el mismo. A pesar de que con el Top-Hat el número de pixels etiquetados como microcalcificación es mayor en el recuadro superior de la figura $6.17 d$ que en esa misma zona de la figura $6.3 d$, en $6.17 d$ no es un falso positivo porque todos esos pixels son conexos y forman una única región, lo cual no es un cluster porque para ello se necesitan dos regiones.

La tabla 6.4 muestra los resultados de detección para el conjunto de las treinta imágenes de test para distintas combinaciones del ratio verdaderos positivos y los correspondientes falsos positivos por imagen detectados; para ello se ha variado la sensibilidad de detección a través del parámetro $h_{o}$ (ver sección 5.2, 5.2). Es frecuente presentar estos datos gráficamente a través de las curvas ROC [18] [14] [84]. Dicha curva, con los valores de la tabla 6.4 se ha representado en la figura 6.19. 


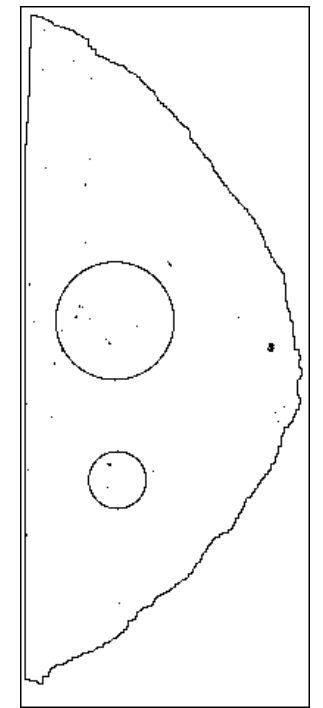

a) z02c inicialización

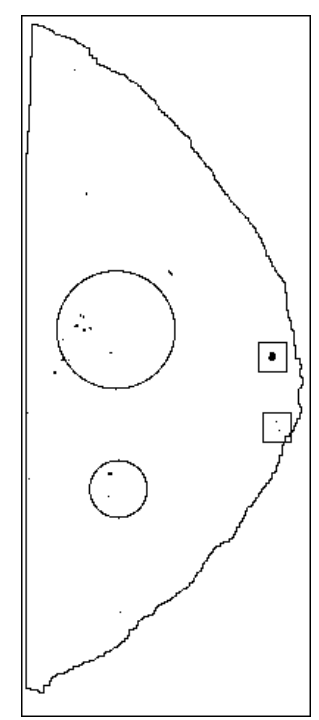

$v p=2, \quad f p=1$

d) z02c resultado

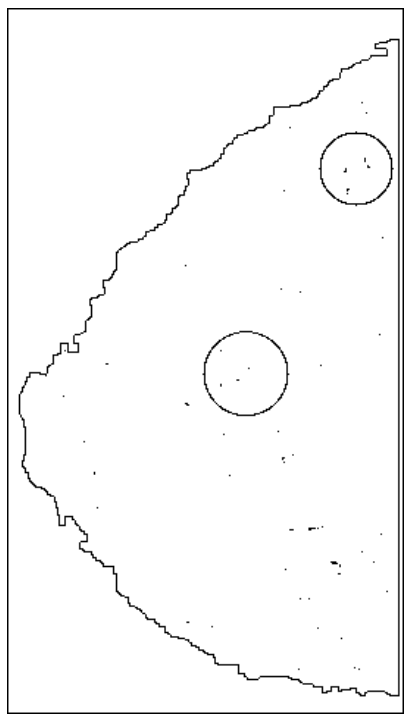

b) z14c inicialización

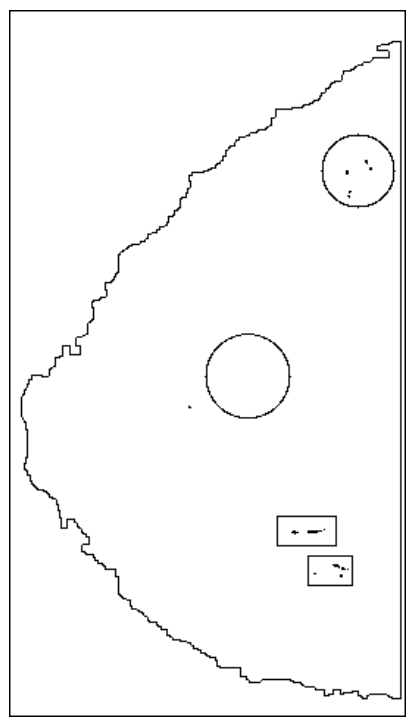

$v p=1, \quad f p=2$

e) z14c resultado

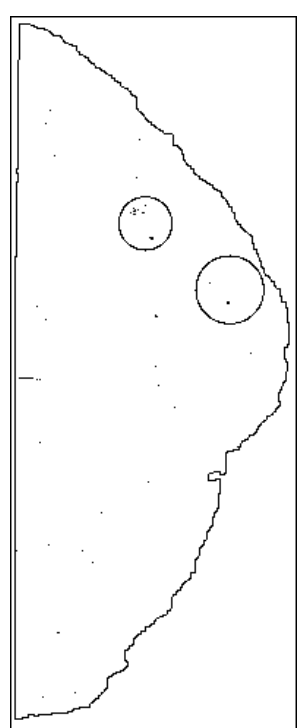

c) z19c inicialización

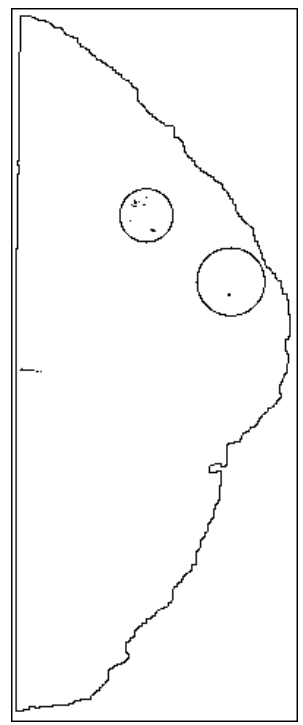

$v p=1, \quad f p=1$

f) z19c resultado

Figura 6.17: Los pixel en negro corresponden a los etiquetados como microcalcificación para el operador Top-Hat. Las figuras $a, b, c$ corresponden a la inicialización y las figuras $d, e, f$ al resultado. Con la sensibilidad utilizada se alcanzan unos resultados para el conjunto de las treinta imágenes de: ratio de verdaderos positivos $=0.8$, falsos positivos por imagen $=5.9$. 


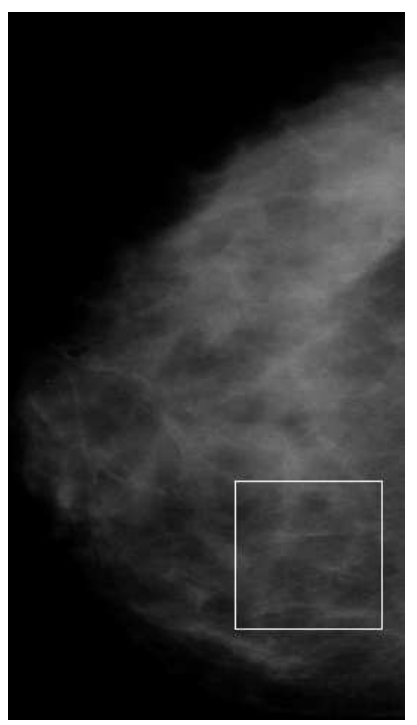

a) mamografía z14c

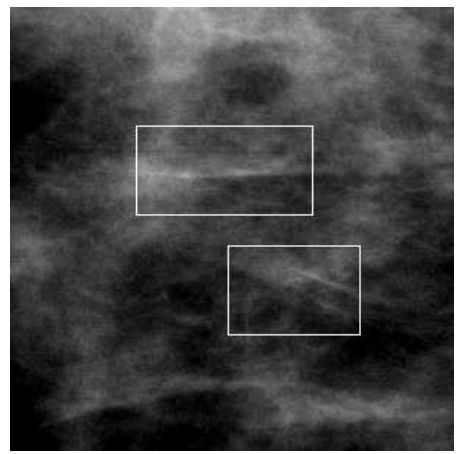

b) z14c detalle

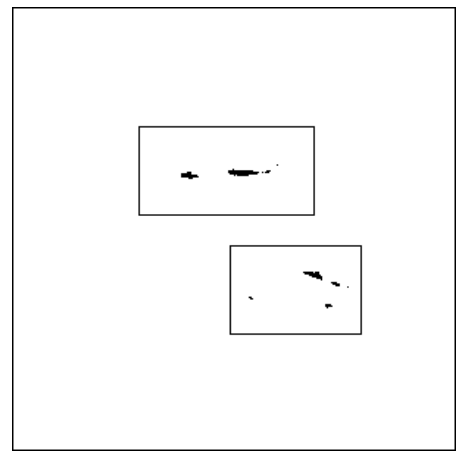

c) z14c resultado

Figura 6.18: Detalle del resultado sobre partes fibrosas de la mamografía; a) mamografía z14c donde se ha marcado una porción de 300x300 pixels con origen en $(460,950)$; b) detalle marcado en a, ampliado respecto a $a$ en tamaño por 3 y en contraste también por 3 ; c) detalle del resultado de la segmentación, donde se observan los dos falsos positivos.

Para establecer comparaciones con los resultados del resto de operadores morfológicos de las siguientes secciones se pueden tomar varios puntos como referencia. En la literatura referente al tema, tienen especial interés, por una parte aquellos donde el ratio de detección es alto, con su correspondiente cifra de falsos positivos, y por otra parte, aquellos donde el número de falsos positivos por imagen es relativamente bajo, que suele ser entorno a la unidad o menos. De la tabla 6.19 cabe resaltar entonces, para un ratio de detección próximo al 90\% (en la tabla $89 \%$ ) que el número de falsos positivos por imagen es 7.63 , y que para 1 falso positivo por imagen (en la tabla 1.06\%) el ratio de verdaderos positivos es el $40 \%$, cifra que resulta baja. 


\begin{tabular}{|c|c|c|c|}
\hline ratio vp & $\mathrm{fp} / \mathrm{img}$ & ratio vp & $\mathrm{fp} / \mathrm{img}$ \\
\hline \hline 0.93 & 8.90 & 0.55 & 2.60 \\
\hline 0.89 & 7.63 & 0.51 & 1.80 \\
\hline 0.80 & 5.90 \\
\hline 0.70 & 3.87 & 0.45 & 1.43 \\
\hline 0.67 & 3.06 & 0.40 & 1.06 \\
\hline 0.61 & 2.70 \\
\hline 0.37 & 0.53 \\
\hline 0.23 & 0.20 \\
\hline
\end{tabular}

Tabla 6.4: Valores del ratio de verdaderos positivos y número de falsos positivos con el operador Top-Hat y el modelo de campo aleatorio de Markov para el conjunto de imágenes de test.

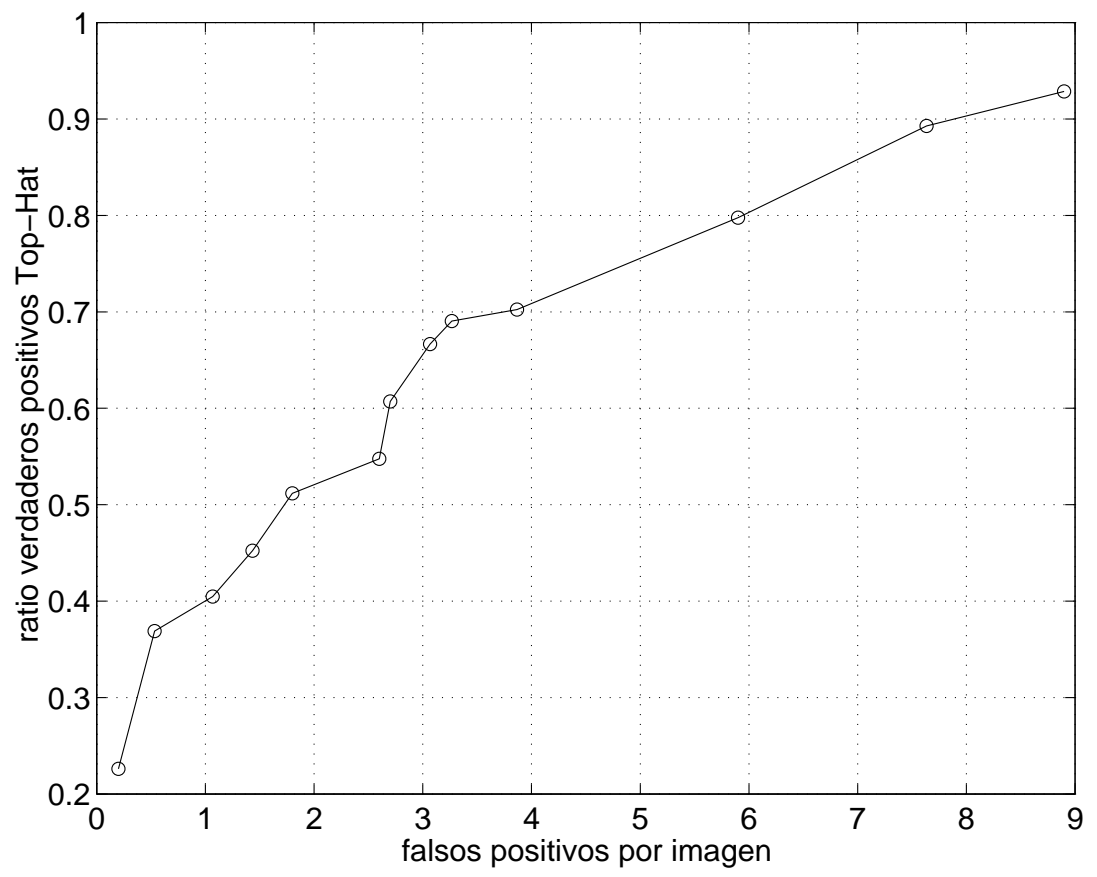

Figura 6.19: Curva "Response Operating Characteristics" de los resultados del operador Top-Hat y el modelo de campo aleatorio de Markov. 


\subsection{Residuo Fondofibra}

En esta sección se presentan los resultados del residuo del operador fondofibra expuesto en la sección 5.4.2. Siguiendo con la estructura de presentación, en la figura 6.20 aparecen las imágenes que se vienen utilizando en las secciones precedentes. Los pixels en negro corresponden a los etiquetados como microcalcificación utilizando como imagen de entrada al algoritmo el residuo del operador fondofibra. Las imágenes $a, b$ y $c$ corresponden a la inicialización, y las $d, e$ y $f$ al resultado tras 8 iteraciones. Sobre la figura $6.20 e$ se han indicado los mismos recuadros que en la figura correspondiente en la sección del Top-Hat, y que se había ampliado en la figura 6.18. Se observa que con el residuo del fondofibra esos falsos positivos no aparecen. Para ver en detalle por qué sucede así se presentan las figuras 6.21 y 6.22 . En $6.21 a$ se reproduce de nuevo la figura $6.18 b$ para facilidad de referencia. En $6.21 b$ se presenta la apertura de la figura $6.21 a$ con un cuadrado de tamaño 9, que es la función utilizada para calcular el Top-Hat de la sección anterior. Dicho Top-Hat aparece en la figura 6.21d. En 6.21c se presenta el resultado del operador fondofibra de tamaño 9, y en $6.21 e$ el residuo. Para poder apreciar los detalles adecuadamente en las imágenes impresas, las de la fila superior se han aumentado en contraste $\mathrm{x} 3 \mathrm{y}$ las dos de la fila inferior se han multiplicado por 10 y se han invertido. Se puede observar que los niveles de los pixels que en el Top-Hat dan lugar a falsos positivos, en el residuo del fondofibra son más pequeños, ya que en el operador fondofibra el elemento estructurante lineal con la orientación similar a la de las fibras que aparecen, da un nivel alto y en el residuo la diferencia con la original es baja.

Un ejemplo de mamografía con alto contenido fibroso se presenta en la figura 6.22. En $6.22 a$ se presenta la mamografía z18o entera para situar la zona de interés indicada por el recuadro. En $6.22 b$ se presenta la ampliación de dicha zona. Se pueden distinguir perfectamente las zona fibrosas existente. En 6.22c se presenta la apertura de la figura $6.22 b$ con un cuadrado de tamaño 9, que es la función utilizada para calcular el Top-Hat de la sección anterior. Dicho Top-Hat aparece en la figura $6.22 e$. En $6.22 b$ se presenta el resultado del operador fondofibra de tamaño 9 , y en $6.22 e$ el residuo. Para poder apreciar los detalles adecuadamente en las imágenes impresas, en $b, c$ y $d$ se ha aumentado en contraste $\mathrm{x} 3 \mathrm{y}$ en $e \mathrm{y} f$ se ha multiplicado por $10 \mathrm{y}$ se han invertido. Se puede observar que los niveles de los pixels que en el Top-Hat (imagen e) dan lugar a falsos positivos, en el residuo del fondofibra (imagen $f$ ) son más pequeños, consecuentemente la probabilidad de un falso positivo es menor en el residuo del fondofibra, y así sucede en la figura $h$.

La tabla 6.5 muestra los resultados de detección para el conjunto de las treinta imágenes de test para distintas combinaciones del ratio de verdaderos positivos y los correspondientes falsos positivos por imagen detectados; también aquí se 


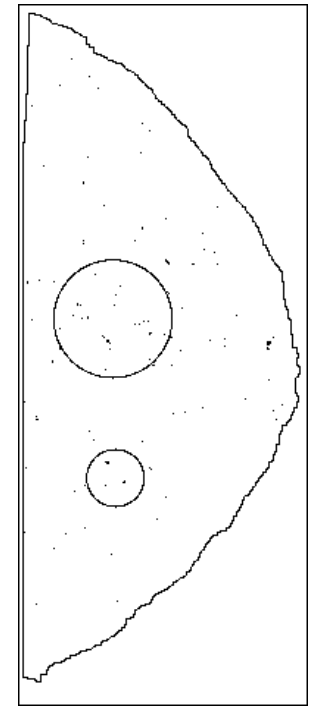

$v p=2, \quad f p=17$

a) z02c inicialización

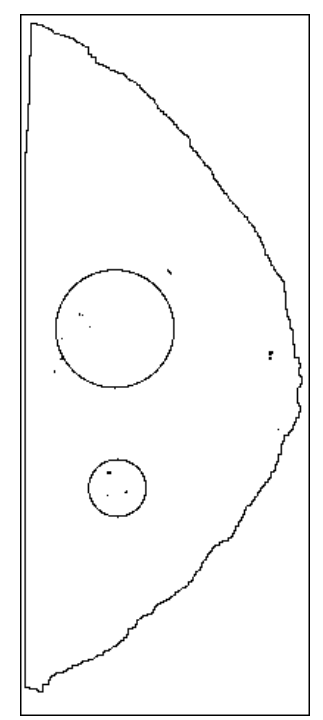

$v p=2, \quad f p=1$

d) z02c resultado

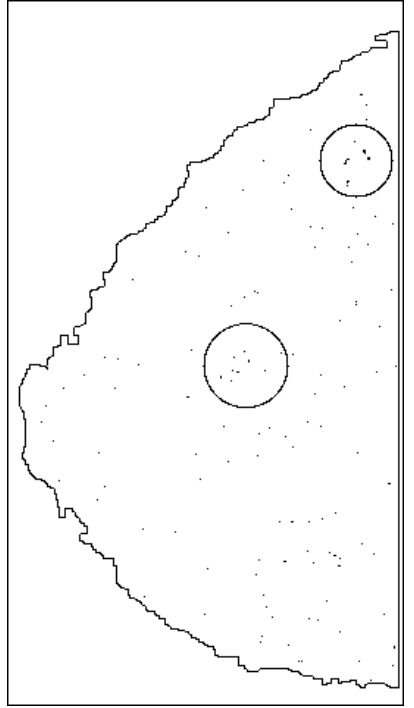

$v p=2, \quad f p=24$

b) z14c inicialización

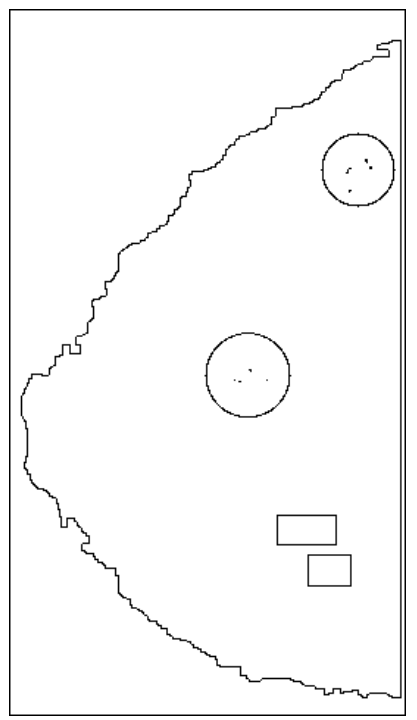

$v p=2, \quad f p=0$

e) z14c resultado

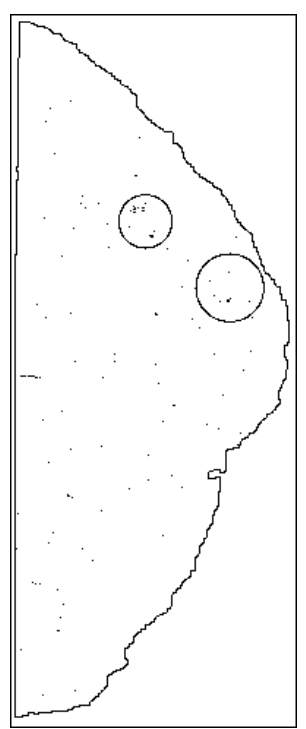

$v p=2, \quad f p=15$

c) z19c inicialización

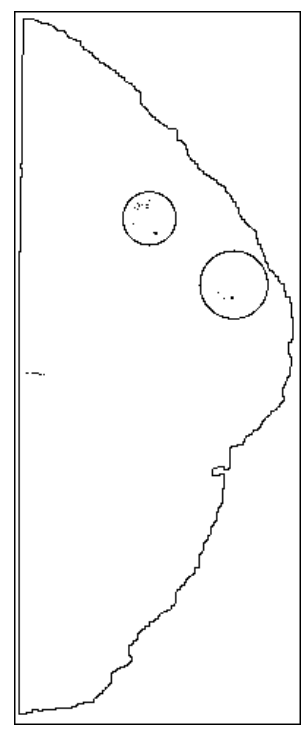

$v p=2, \quad f p=1$

f) z19c resultado

Figura 6.20: Los pixels en negro corresponden a los etiquetados como microcalcificación para el operador Residuo fondofibra. Las figuras $a, \mathrm{~b}, \mathrm{c}$ corresponden a la inicialización y las figuras $d, e, f$ al resultado. Con la sensibilidad utilizada se alcanzan unos resultados para el conjunto de las treinta imágenes de: ratio de verdaderos positivos $=0.84$, falsos positivos por imagen $=1.13$ 


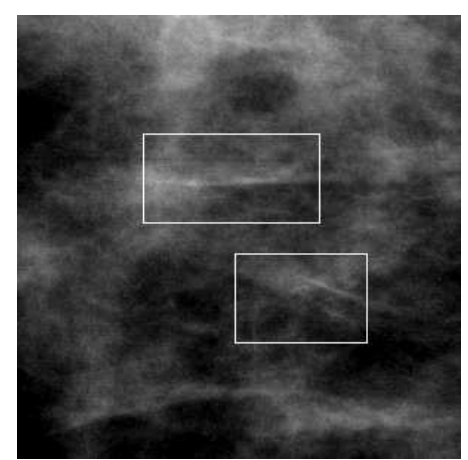

a) original

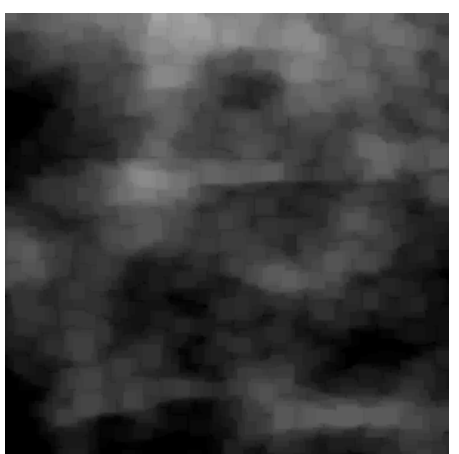

b) apertura cuadrado 9

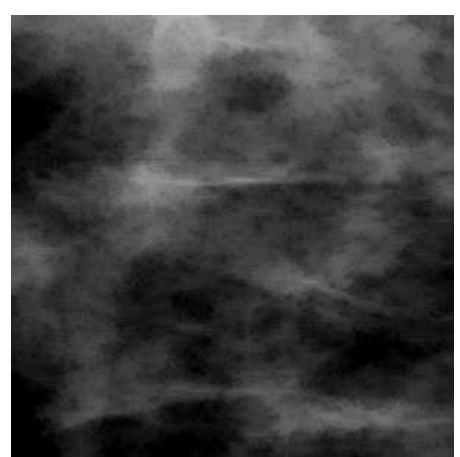

c) fondofibra 9

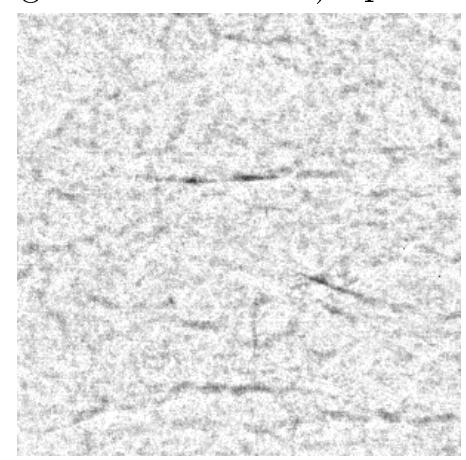

d) residuo apertura $(T o p-H a t) \quad$ e) residuo fondofibra

Figura 6.21: Detalle del fondofibra sobre z14c. En $a$ aparece la misma porción de z14c que en 6.21 ; b) corresponde a la apertura con cuadrado de tamaño 9 y c) al fondofibra. En d) y e) se presentan respectivamente los residuos de $b$ y $c$ 


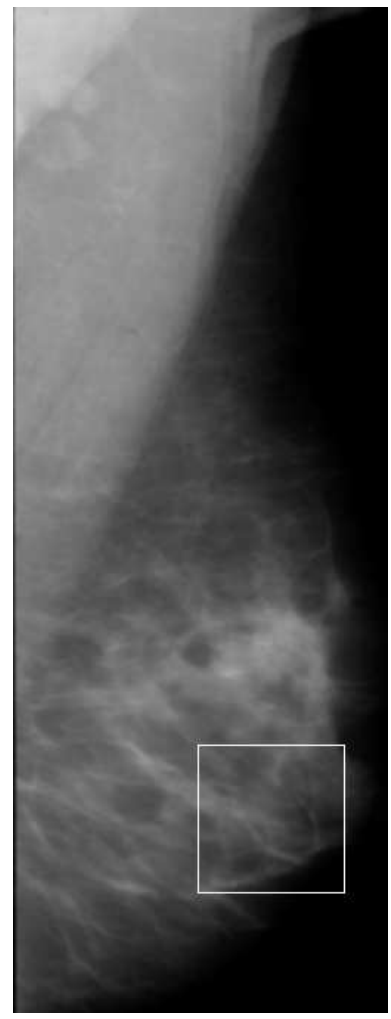

a) mamog. z180

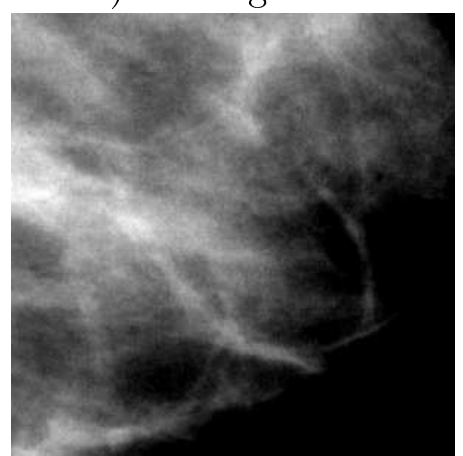

b) recuadro marcado en $a$

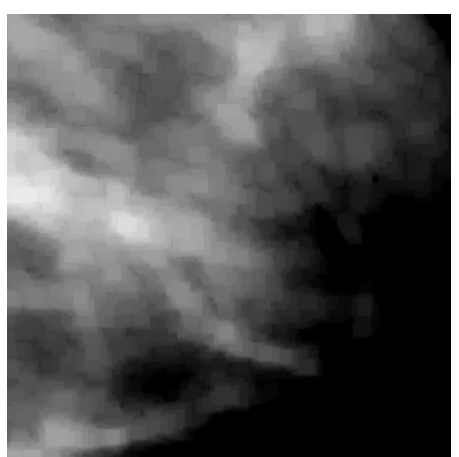

c) apertura cuadrado 9

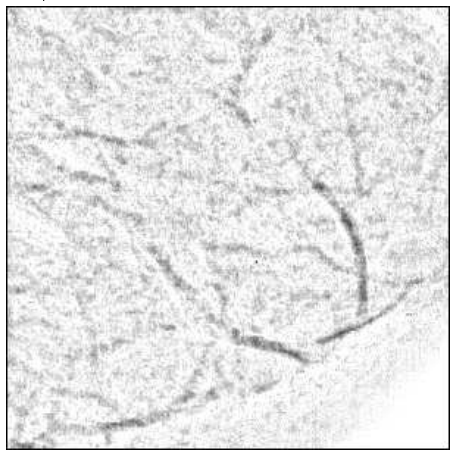

e) residuo apertura

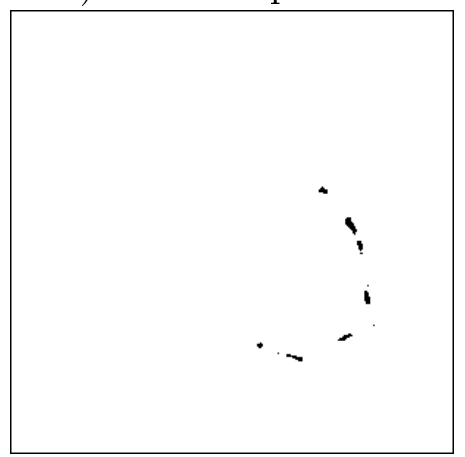

g) ICM con apertura

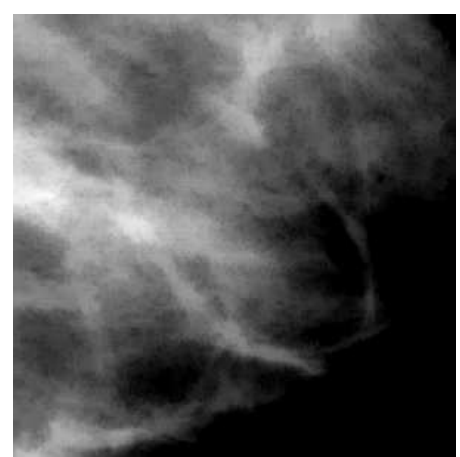

d) fondofibra 9

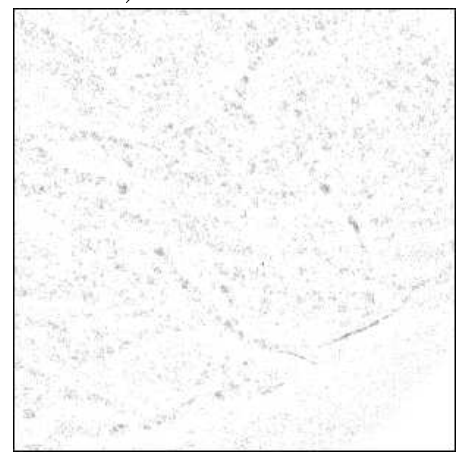

f) residuo fondofibra

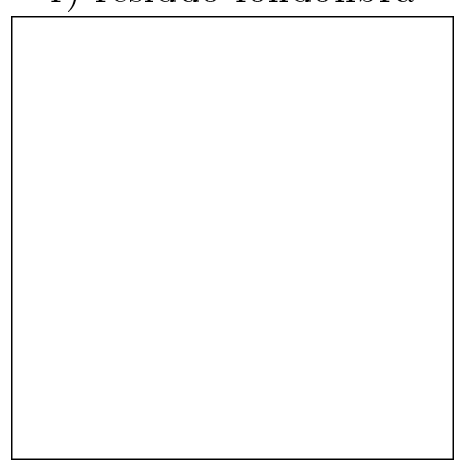

h) ICM con fondofibra

Figura 6.22: Detalle del fondofibra sobre z18o. En a mamografía completa con la zona de interés marcada por el recuadro; b) ampliación de la zona marcada en $a$; c) apertura con cuadrado de tamaño 9 ; d) fondofibra; e) y f) corresponden respectivamente a los residuos; g) y h) presentan el resultado final. Dado que en la zona marcada los radiólogos no han indicado presencia de microcalcificaciones, el resultado correcto es el del fondofibra. 
varia el parámetro $h_{o}$ para modificar la sensibilidad de detección. La curva ROC con los valores de la tabla 6.5 se presenta en la figura 6.23.

Si se compara la tabla 6.4 con la tabla 6.5 se observa una gran mejora de las prestaciones del algoritmo con el operador fondofibra respecto del operador Top-Hat. Tomando como referencia los valores mencionados al final de la sección del Top-Hat donde para un ratio de verdaderos positivos de $89 \%$, el número de falsos positivos por imagen es 7.63, con el presente operador para el mismo ratio de verdaderos positivos, el número de falsos positivos por imagen se reduce a 1.63. Para el otro valor de comparación situado en 1 falso positivo por imagen con el Top-Hat el ratio de verdaderos positivos es de $40 \%$ y pasa a ser con el fondofibra del $84 \%$.

Cabe observar a la vista de la tabla 6.4 y de la figura 6.23 que para valores bajos del ratio de verdaderos positivos, el incremento en dicho ratio partido por el incremento en falsos positivos por imagen es mayor que para valores altos. Lo cual significa que a medida que se alcanzan valores más altos de detección es más difícil mejorar las prestaciones. Pongamos por ejemplo que pasar del $62 \%$ de detección al $75 \%$ supone pasar de 0.47 a 0.73 falsos positivos por imagen $(0.26$ de incremento), mientras que pasar de $89.3 \%$ a $91.7 \%$ supone pasar de 1.63 a 2.26 falsos positivos por imagen (0.63 de incremento).

\begin{tabular}{|c|c|c|c|}
\hline ratio vp & $\mathrm{fp} / \mathrm{img}$ & ratio vp & $\mathrm{fp} / \mathrm{img}$ \\
\hline \hline 0.96 & 3.83 & 0.84 & 1.13 \\
\hline 0.93 & 2.93 & 0.75 & 0.73 \\
\hline 0.92 & 2.27 & 0.62 & 0.47 \\
\hline 0.89 & 1.63 & 0.51 & 0.26 \\
\hline
\end{tabular}

Tabla 6.5: Valores del ratio de verdaderos positivos y número de falsos positivos con el operador fondofibra y el modelo de campo aleatorio de Markov para el conjunto de imágenes de test.

En la figura 6.23 se incluyen dos curvas ROC. La marcada con aspas corresponde al caso para cuando se realiza el etiquetado de los pixels directamente sobre los niveles de gris a la salida del residuo del fondofibra sin utilizar el algoritmo basado en el campo aleatorio, es decir sin tener en cuenta la información del vecindario. Esta clasificación corresponde a la estimación MLE, Maximum Likelihood Estimate. La curva marcada con los círculos indica los resultados tras el algoritmo con el modelo de campo aleatorio de Markov. Se puede observar la mejora significativa de esta última.

En general la procedencia de los falsos positivos se debe a diversas causas, entre ellas el ruido, la diversidad de los niveles de gris de las microcalcificaciones que como algunas son muy tenues obliga a sensibilidades elevadas que traen 


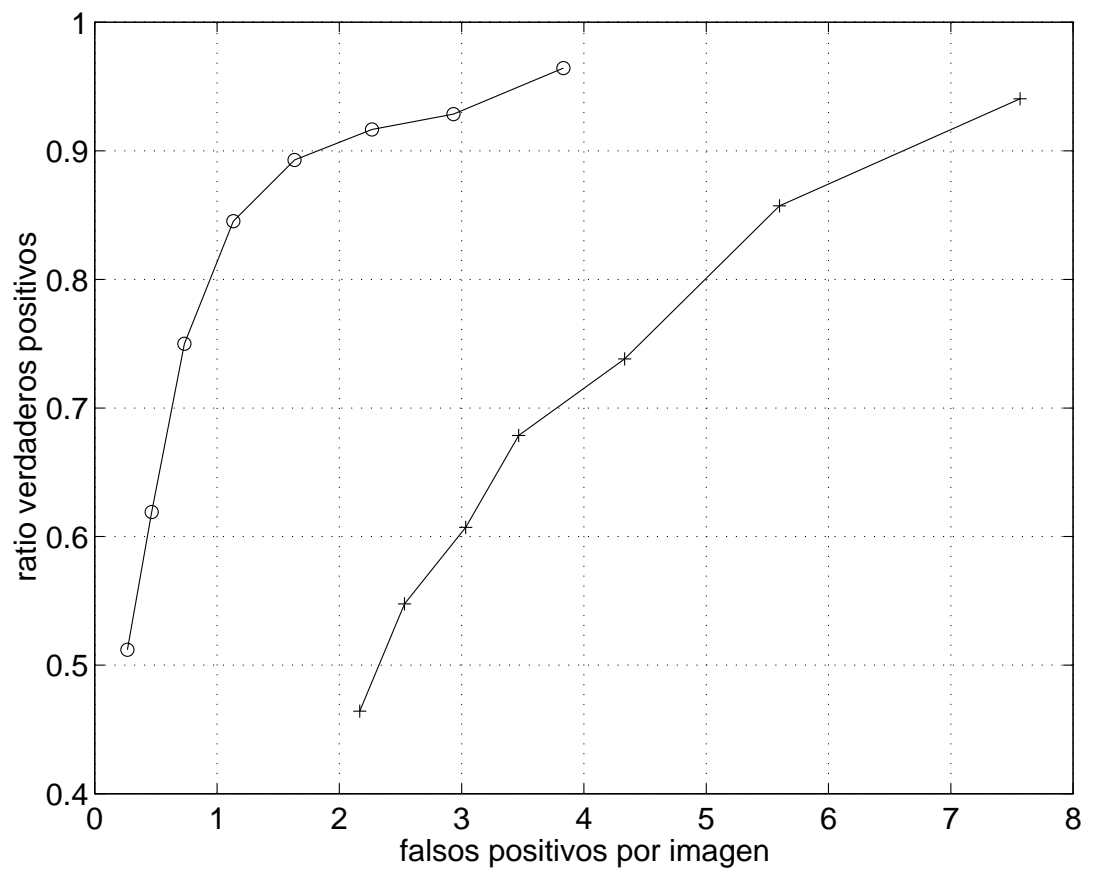

Figura 6.23: Curva "Response Operating Characteristics" de los resultados del operador fondofibra sin el modelo campo aleatorio de Markov (clasificación como microcalcificación según Maximum Likelihood Estimate) (+) y con el modelo de campo aleatorio de Markov (o) 


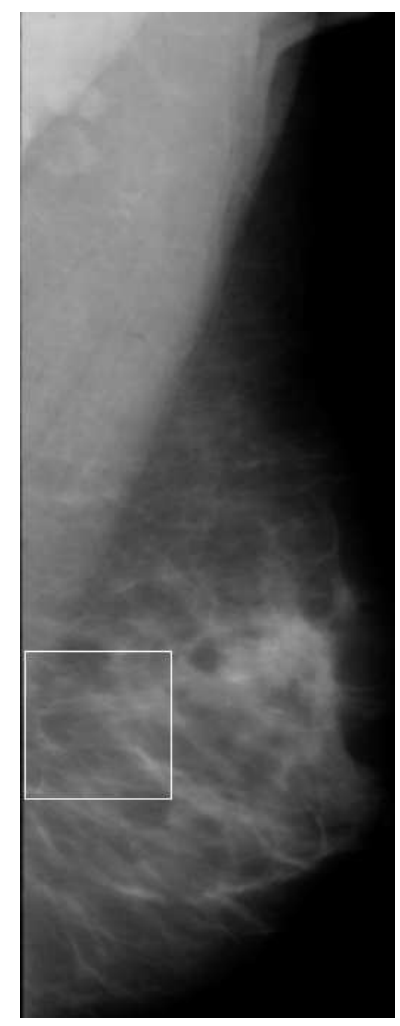

a) mamog. $z 180$

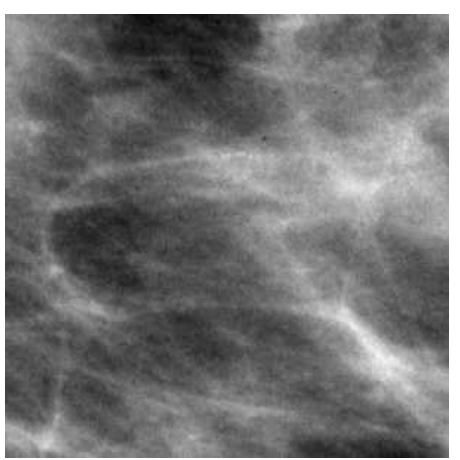

b) original

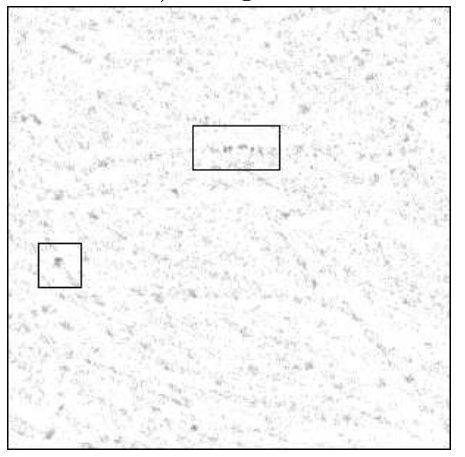

d) residuo

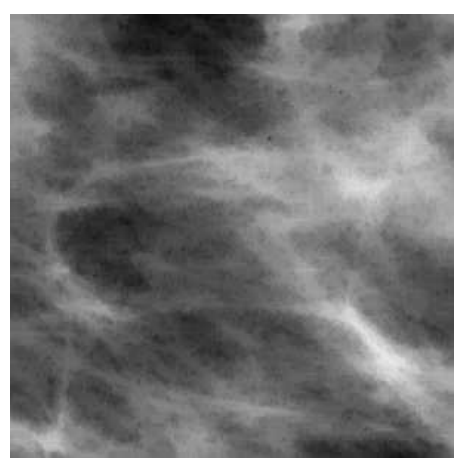

c) fondofibra 9

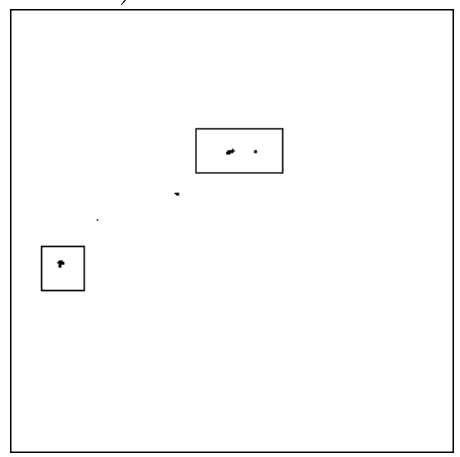

e) ICM

Figura 6.24: Detalle de un falso positivo con el fondofibra sobre z18o. En $a$ mamografía completa con la zona de interés marcada por el recuadro; b) ampliación de la zona marcada en $a$; c) fondofibra con EE de tamaño 9; d) corresponde al residuo y e) presentan el resultado final. Dado que en la zona marcada los radiólogos no han indicado presencia de microcalcificaciones, las microcalcificaciones marcadas son falsos positivos. 
consigo falsos positivos, y una causa importante son las fibras. Si estas estructuras fibrosas no son eliminadas por los operadores antes de aplicar el algoritmo con el modelo de campo aleatorio de Markov, cabe la posibilidad de que sean etiquetadas como microcalcificación; sobre todo si la cantidad de pixels de este tipo, vecinos entre sí, es de varias unidades en adelante. El operador fondofibra está obligado a utilizar un tamaño de elementos estructurantes lineales mayor que el diámetro de las microcalcificaciones para que éstas aparezcan en el residuo. Como las fibras no son estrictamente líneas rectas cuanto mayor sea el elemento estructurante peor se adapta a las fibras en sus zonas curvadas o en sus bordes que normalmente no son rectilíneos. Esto obliga a un compromiso en el tamaño del elemento estructurante, y que se ha fijado en 9. Para ilustrar que en el residuo del operador fondofibra todavía se originan falsos positivos en algunas zonas fibrosas se presenta el siguiente ejemplo. Sobre la misma mamografía z18o utilizada en la figura 6.22. En la figura 6.24a aparece marcada la nueva zona de interés $(300 x 300$ pixels a partir de la coordenada $(10,1300)$ ), y en $6.24 b$ ampliada en tamaño x3 y también aumentada en contraste x3. En la figura $6.24 c$ se presenta el resultado del operador fondofibra. Si las fibras fueran rectilíneas con bordes rectilíneos y de nivel de gris constante deberían aparecer completamente. Se puede observar, por ejemplo, en la fibra más larga que carece de todas estas características: es curvada, no es constante en niveles de gris, y además los bordes son irregulares. Por todo ello en $c$ los niveles de gris de algunos pixels pertenecientes a la fibra son inferiores a los de la imagen original, de ahí que en el residuo aparezcan con niveles relativamente altos. En la figura $6.24 d$ se muestra el residuo donde se puede apreciar la fibra referida con discontinuidades. Como más adelante se verá, los problemas debidos a los bordes irregulares y a las zonas curvadas se pueden evitar con la reconstrucción [127]. 


\subsection{Residuo Fondofibra con reconstrucción}

En esta sección se presentan los resultados del residuo del operador fondofibra con reconstrucción expuesto en la sección 5.4.3. Recordemos que llamamos aquí operador fondofibra con reconstrucción a la reconstrucción tomando como imagen de referencia la imagen original (mamografía) y como imagen marcador el resultado del operador fondofibra sobre la imagen original. Al igual que en las secciones anteriores, en la figura 6.25 aparecen las imágenes con los resultados sobre las mamografías z02c, z14c y z19c. Los pixels en negro corresponden a los etiquetados como microcalcificación, utilizando como imagen de entrada al algoritmo el residuo del operador fondofibra con reconstrucción. Las imágenes $a, b$ y $c$ corresponden a la inicialización, y las $d$, e y $f$ al resultado tras 8 iteraciones del algoritmo.

Las diferencias entre el operador residuo del fondofibra y residuo del fondofibra con reconstrucción no son tan importantes como las existentes entre el operador fondofibra y el Top-Hat. Concretamente se puede apreciar que en las figuras $6.25 d$, e y $f$ el número de verdaderos y falsos positivos es el mismo que las de la sección correspondiente al residuo del fondofibra. Para el conjunto de las imágenes de test los resultados mejoran al utilizar la reconstrucción. En la figura 6.25 se presentan los resultados para este operador en las tres imágenes que se vienen utilizando como ejemplo. Se puede observar que el número de falsos positivos en la inicialización es más bajo, aunque en estos tres casos, el resultado final es el mismo que el operador anterior. Más adelante se muestran ejemplos en los que sí hay diferencias.

A continuación se discuten los falsos positivos del resultado en las imágenes z02c y z19c. En z02c el falso positivo está formado por dos microcalcificaciones, una muy grande con una zona más brillante en su interior, tal como ilustra la figura $6.26 b$ (correspondiente a 50x50 pixels a partir de la coordenada $(485,665)$ ); los pixels de esta zona interior son los que quedan etiquetados como microcalcificación, tal como cabe esperar, ya que el resto de los pixels, aún estando contrastados con sus inmediaciones forman una región de tamaño mayor que el elemento estructurante y desaparecen en el residuo. La otra microcalcificación se debe a un único pixel bastante contrastado, que no pertenece a ninguna región. Para que la reconstrucción ayudase a eliminar esta falsa microcalcificación, el pixel debería pertenecer a una región parcialmente contenida en el marcador (en nuestro caso el fondofibra), y que dicho pixel estuviera en el resto que no está contenido en el marcador y que se quiere reconstruir. En este caso eso no sucede porque la región esta formada por un único pixel y nunca podría estar incluida en el marcador porque el tamaño del elemento estructurante va a ser mayor de un pixel. No obstante, si este pixel aislado no estuviera cercano a una microcalcificación de muchos pixels, el algoritmo lo etiquetaría como fondo; el falso 


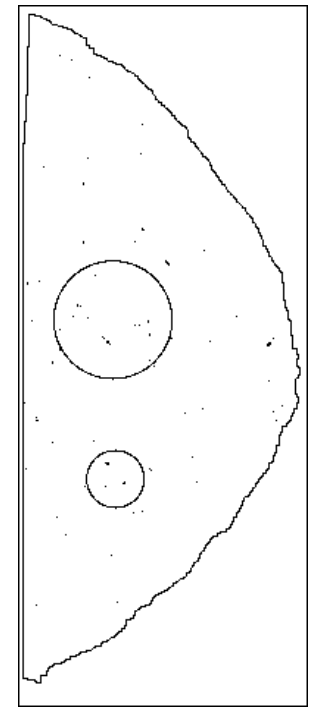

$v p=2, \quad f p=12$

a) z02c inicialización

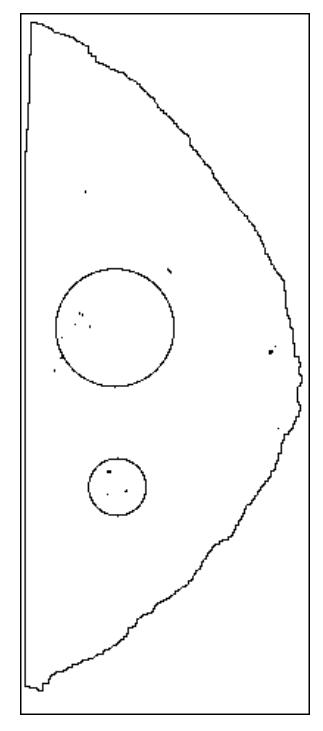

$v p=2, \quad f p=1$

d) z02c resultado

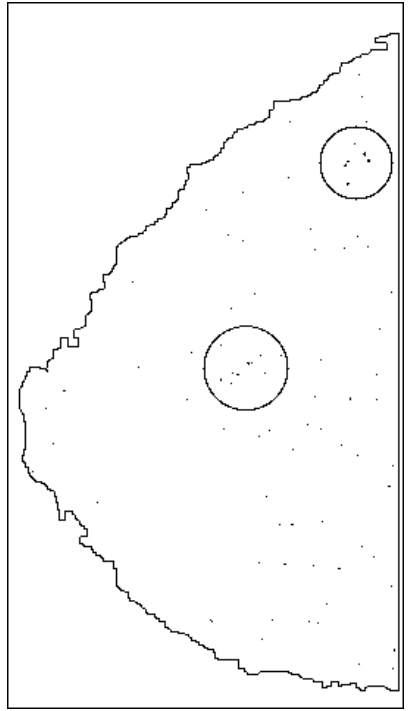

$v p=2, \quad f p=18$

b) z14c inicialización

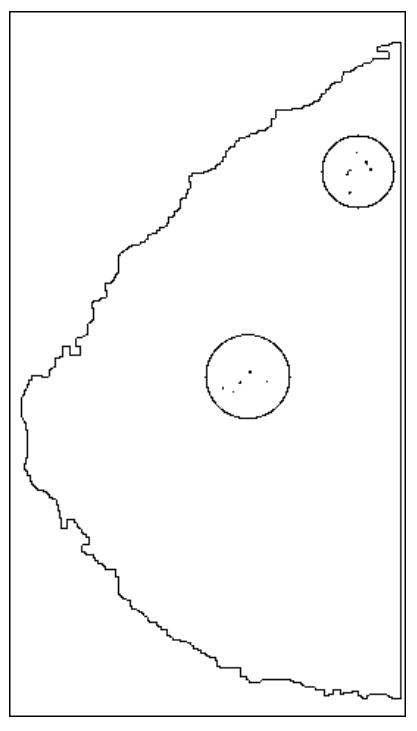

$v p=2, \quad f p=0$

e) z14c resultado

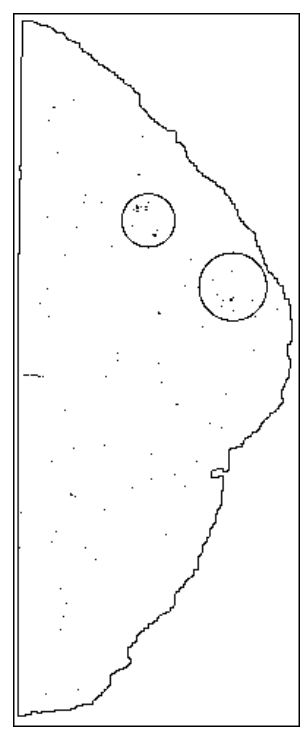

$v p=2, \quad f p=12$

c) z19c inicialización

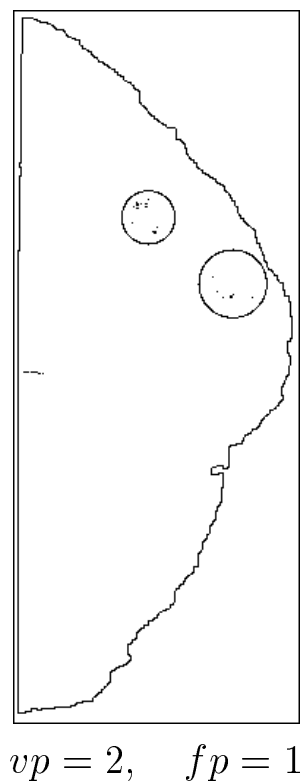

f) z19c resultado

Figura 6.25: Los pixels en negro corresponden a los etiquetados como microcalcificación para el operador Residuo fondofibra con reconstrucción. Las figuras a $, b, c$ corresponden a la inicialización y las figuras $d, e, f$ al resultado. Con la sensibilidad utilizada se alcanzan unos resultados para el conjunto de las treinta imágenes de: ratio de verdaderos positivos $=0.88$, falsos positivos por imagen $=$ 1.13 


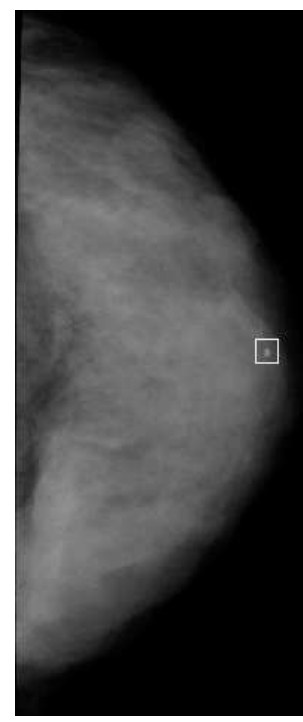

a) mamog. z02c

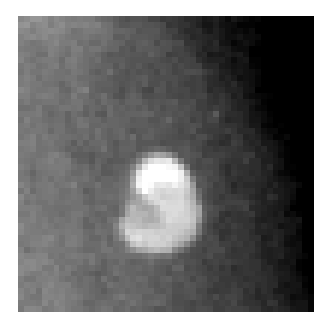

b) zona detalle

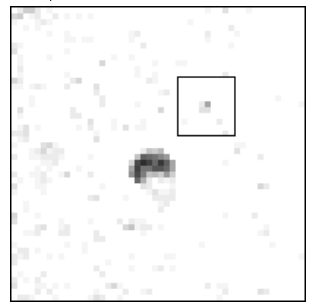

d) residuo

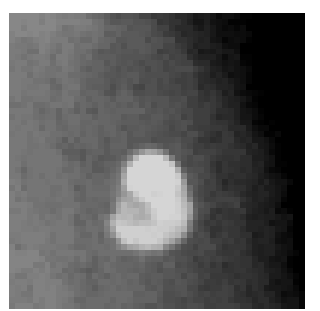

c) fondofibra con reconstrucción

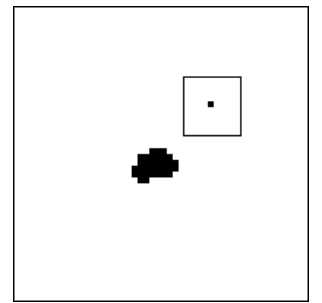

e) resultado ICM

Figura 6.26: Detalle del fondofibra con reconstrucción sobre z02c. a) mamografía completa con la zona de interés marcada por el recuadro; b) ampliación x12 de la zona marcada en $a$; c) fondofibra con reconstrucción; d) residuo; e) resultado del algoritmo ICM tras 8 iteraciones

positivo está entonces originado por la coincidencia de las dos causas: no poder ser recuperado en el fondofibra con reconstrucción y tener una microcalcificación grande en las proximidades.

El falso positivo de la mamografía z19c que aparece en la figura 6.25 b (subimagen de 50x50 pixels a partir de la coordenada $(15,720)$ ) es otro ejemplo de lo que la reconstrucción no puede recuperar tomando como marcador el operador fondofibra con el tamaño utilizado. En el residuo aparecen pixels con niveles de gris entre 8 y 16 sobre la región lineal que forma el falso positivo (figura $6.27 d$ ). $\mathrm{Al}$ ser una región con forma lineal cabe esperar que no aparezcan pixels en el residuo con estos niveles tan altos. Aparecen porque la región es lineal con niveles de gris no constantes, y son estas irregularidades las que dan lugar a un residuo distinto de cero, y como estos niveles de gris entran dentro del margen de las microcalcificaciones y son varios pixels vecinos entre sí el resultado es que son etiquetados como microcalcificación.

Para ilustrar lo que la reconstrucción puede hacer con el objetivo de que en el resultado final haya un menor número de falsos positivos, se dan a continuación dos ejemplos. El primero es sobre el mismo caso de la figura 6.24 presentado en la sección anterior dedicada al fondofibra. En la figura 6.28 se ilustran ahora los resultados con la reconstrucción. Se reproducen en la fila superior las figuras presentadas en la sección anterior para facilitar la comparación. Todas las imágenes 


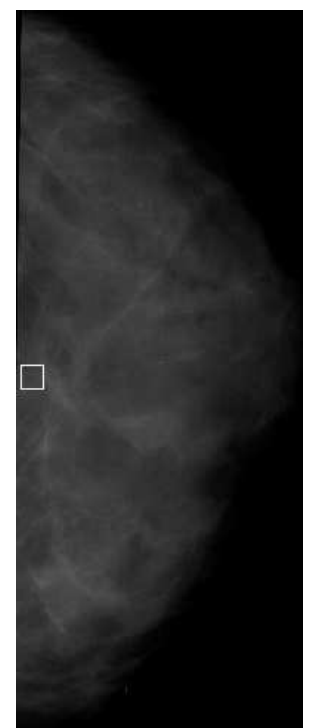

a) mamog. $z 19 \mathrm{c}$

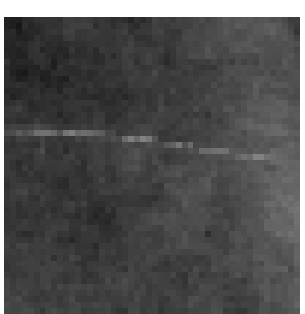

b) zona detalle

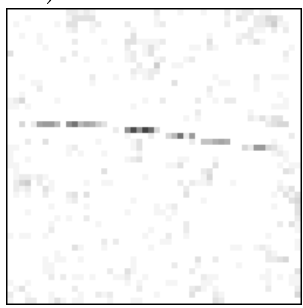

d) residuo

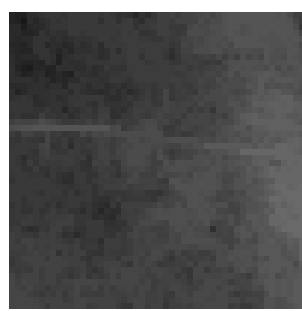

c) fondfib. con reconst.

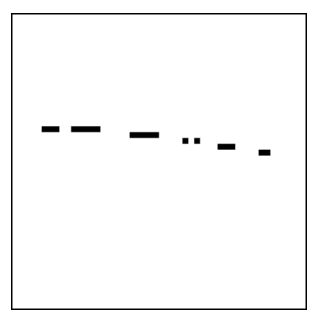

e) resultado $\mathrm{ICM}$

Figura 6.27: Detalle del fondofibra con reconstrucción sobre z19c. a) mamografía completa con la zona de interés marcada por el recuadro; b) ampliación x12 de la zona marcada en $a$; c) fondofibra con reconstrucción; d) residuo; e) resultado del algoritmo ICM tras 8 iteraciones

de grises están ampliadas en contraste x3. En $e$ se presenta el resultado del operador fondofibra con reconstrucción, y en $f$ el residuo del mismo. Comparando estas dos imágenes con las que tienen arriba se pueden apreciar ligeras diferencias que resultan importantes. Obsérvese en las imágenes $e$ y $b$ los pixels por ejemplo, correspondientes a los recuadrados por el recuadro de menor tamaño en $f$. En $e$ la región clara en la que la fibra se ensancha es de mayor nivel que en $b$, lo que da lugar a un residuo de menor nivel y consecuentemente menor probabilidad de que sea etiquetado como microcalcificación, como así ocurre finalmente y se puede observar en $d$.

El segundo ejemplo se ilustra en la figura 6.29, donde en $a$ se presenta la mamografía z11c completa con un recuadro marcando la zona de interés de 50x50 pixels con origen en la coordenada $(250,350) ; h$ presenta dicha zona ampliada en tamaño x12 y aumentado su contraste x4; aunque en las figuras precedentes se ha aumentado el contraste $\mathrm{x} 3$, aquí se hace una excepción para ver mejor los detalles ya que los niveles de gris en esta zona varían poco. Para ver las diferencias que la reconstrucción introduce las dos filas superiores presentan la secuencia de operaciones paralelemente sin reconstrucción y con reconstrucción. En las figuras $b$ en adelante, se ha acotado todavía más la zona de interés a 12x12 pixels con el recuadro que aparece. El resultado del operador fondofibra sobre la imagen original se presenta en $6.29 b$ mientras que la versión reconstruida aparece en $e$. Centrando la atención en los pixels del recuadro, la diferencia sobre las 


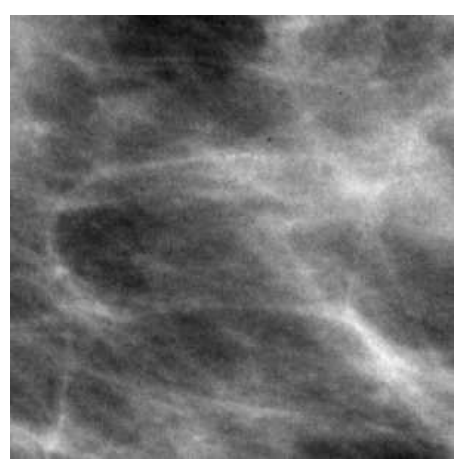

a) original

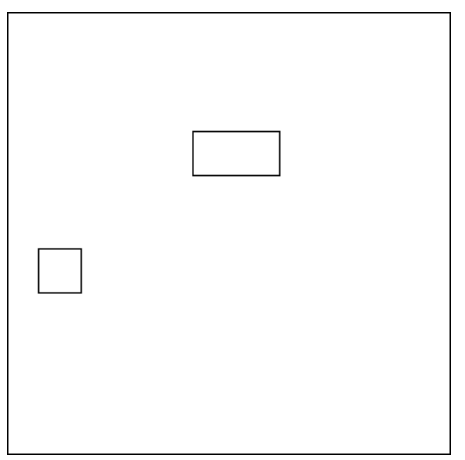

d) ICM sobre reconstrucción

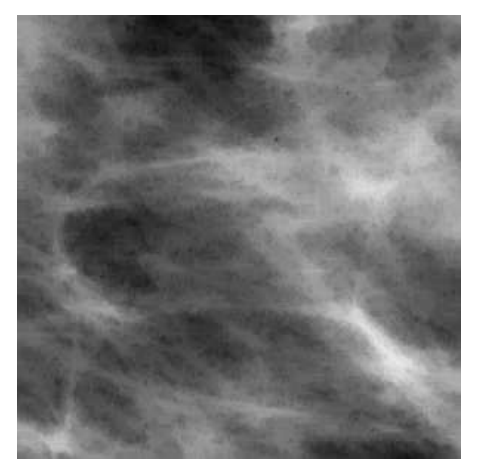

b) fondofibra

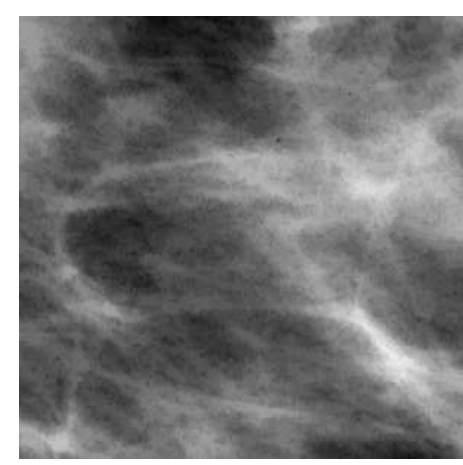

e) fondofibra con rec.

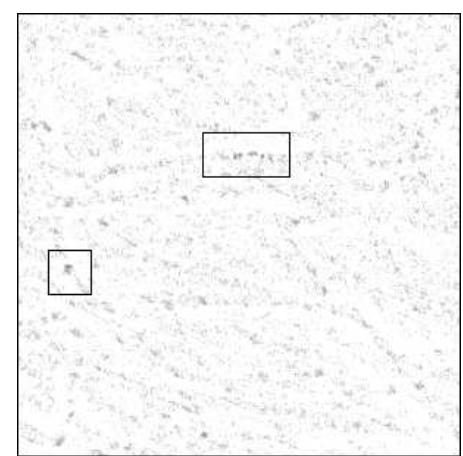

c) residuo fondofibra

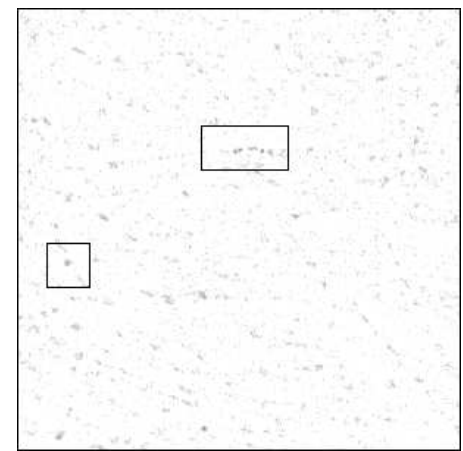

f) residuo fondofibra con rec.

Figura 6.28: Detalle del fondofibra con reconstrucción sobre z18o. En $a b$ y $c$ reproducción de las figuras $6.24 b, c$ y $d$ para facilitar la comparación. d) resultado del algoritmo ICM tras 8 iteraciones aplicado sobre el residuo con reconstrucción. e) fondofibra con reconstrucción; f) residuo del fondofibra con reconstrucción. 


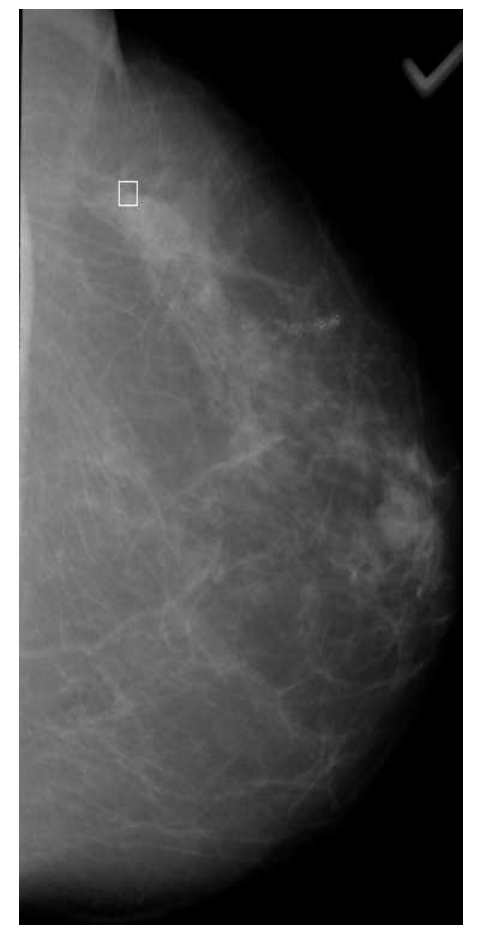

a) mamog. $z 11 \mathrm{c}$

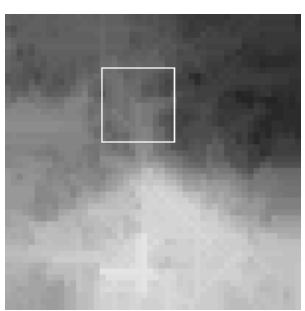

b) fondofibra (ff)

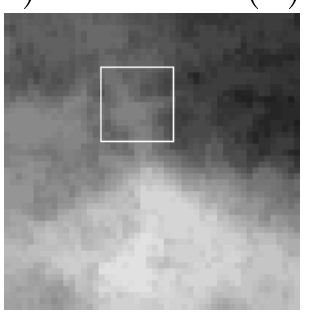

e) ff rec.

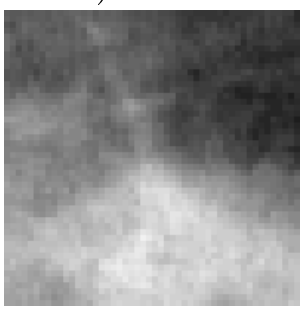

h) original

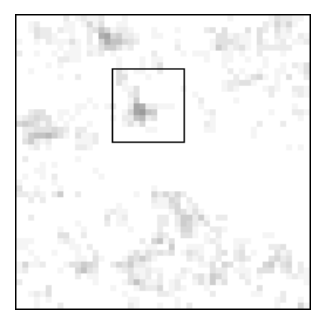

c) residuo fondfib.

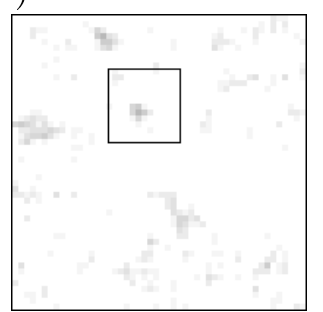

f) res. ff rec.

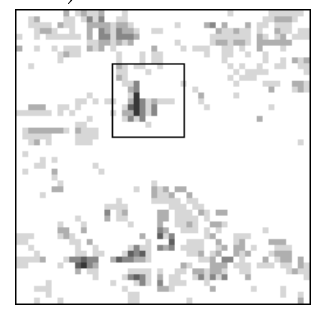

i) diferencia $c$ - $f$

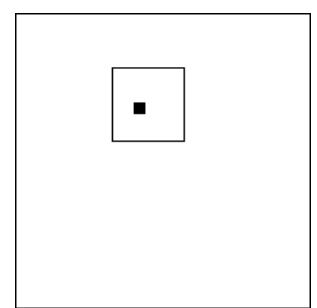

d) ICM sobre $c$

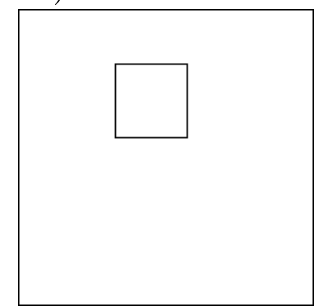

g) ICM sobre f)

Figura 6.29: Detalle del fondofibra con reconstrucción sobre z11c. a) mamografía completa con la zona de interés marcada por el recuadro; h) ampliación x12 en tamaño y en contraste $\mathrm{x} 4$ de la zona marcada en $a$; b) fondofibra de la zona marcada; c) residuo fondofibra; d) resultado del algoritmo ICM tras 8 iteraciones sobre el residuo del fondofibra; e) fondofibra con reconstrucción de la zona marcada; f) residuo del fondofibra con reconstrucción; g) resultado del algoritmo ICM tras 8 iteraciones sobre el residuo del fondofibra con reconstrucción; i) diferencia (multiplicada por 40) entre los residuos. 
imágenes impresas en papel es muy tenue, pero sí se puede apreciar claramente en los respectivos residuos (que se presentan con amplitud multiplicada por 10 seguida de una inversión) que la versión reconstruida tiene una menor amplitud. Se debe a que el operador fondofibra da un nivel alto en algunos puntos de la fibra marcados por el recuadro, pero el elemento estructurante lineal no cabe en algunas partes de la zona donde esa fibra se ensancha (interior de recuadro). Cuando se realiza la reconstrucción, los pixels donde sí ha cabido el elemento estructurante se propagan a lo largo de toda la zona de ensanchamiento reconstruyéndola, y al calcular el residuo esos niveles son más bajos. En la figura $6.29 d$ aparece un positivo, que junto con otro que aparece en las proximidades, pero fuera de la subimagen de 50x50 elegida forman un cluster falso positivo. Sin embargo el resultado del algoritmo ICM con el modelo de campo aleatorio de Markov utilizado no genera ese positivo cuando se aplica sobre el residuo con reconstrucción (figura 6.29g).

En esta misma figura 6.29 se puede ver otro ejemplo de la reconstrucción, aunque esta vez con reconstrucción o sin ella no se genera una microcalcificación falsa positiva. La zona a la que nos referimos aparece en la misma vertical del recuadro marcado, en la parte inferior. En $6.29 b$ se pueden apreciar dos zonas lineales formando un ángulo recto. Observando los pixels correspondientes a esa zona en la imagen original se puede observar una zona más clara que el resto pero de mayor número de pixels. Observando lo que aparece en 6.29 e se aprecia que la reconstrucción recupera mejor esa zona que solamente con el operador fondofibra. Las diferencias se pueden observar más nítidamente en $6.29 i$ donde la resta de los residuos se ha multiplicado por 40 e invertido y en esa zona aparecen varios puntos oscuros.

El conjunto de resultados sobre el grupo de las treinta imágenes de test para distintas combinaciones del ratio de verdaderos positivos y los correspondientes falsos positivos por imagen se presentan en la tabla 6.6; al igual que en las secciones anteriores se ha variado el parámetro $h_{o}$ para modificar la sensibilidad de detección. Los datos de la tabla 6.6 se representan gráficamente en la figura 6.30 (curva marcada con círculos), junto con resultados correspondientes a si el etiquetado se hace con el criterio de máxima verosimilitud $(M L E)$ en el que no se tiene en cuenta la información que el modelo de campo aleatorio de Markov puede aportar(curva marcada con cruces). También aquí se aprecia una mejora significativa cuando se aplica el modelo markoviano.

La diferencia introducida por la reconstrucción supone en promedio un aumento en 4 puntos porcentuales en el ratio de verdaderos positivos. Tomando un punto concreto, por ejemplo para un valor de 1.13 falsos positivos por imagen, sin reconstrucción se alcanza un ratio de 0.84 , mientras que con reconstrucción pasa a ser de 0.88. Gráficamente la comparación se puede hacer en la figura 6.30, donde la curva a trazos corresponde al caso sin reconstrucción. 


\begin{tabular}{|c|c|c|c|}
\hline ratio vp & $\mathrm{fp} / \mathrm{img}$ & ratio vp & fp/img \\
\hline 0.99 & 3.80 & 0.80 & 0.63 \\
\hline 0.94 & 2.20 & 0.65 & 0.43 \\
\hline 0.92 & 1.87 & 0.57 & 0.20 \\
\hline 0.88 & 1.13 & & \\
\hline
\end{tabular}

Tabla 6.6: Valores del ratio de verdaderos positivos y número de falsos positivos para el residuo del fondofibra con reconstrucción y el modelo de campo aleatorio de Markov sobre el conjunto de imágenes de test.

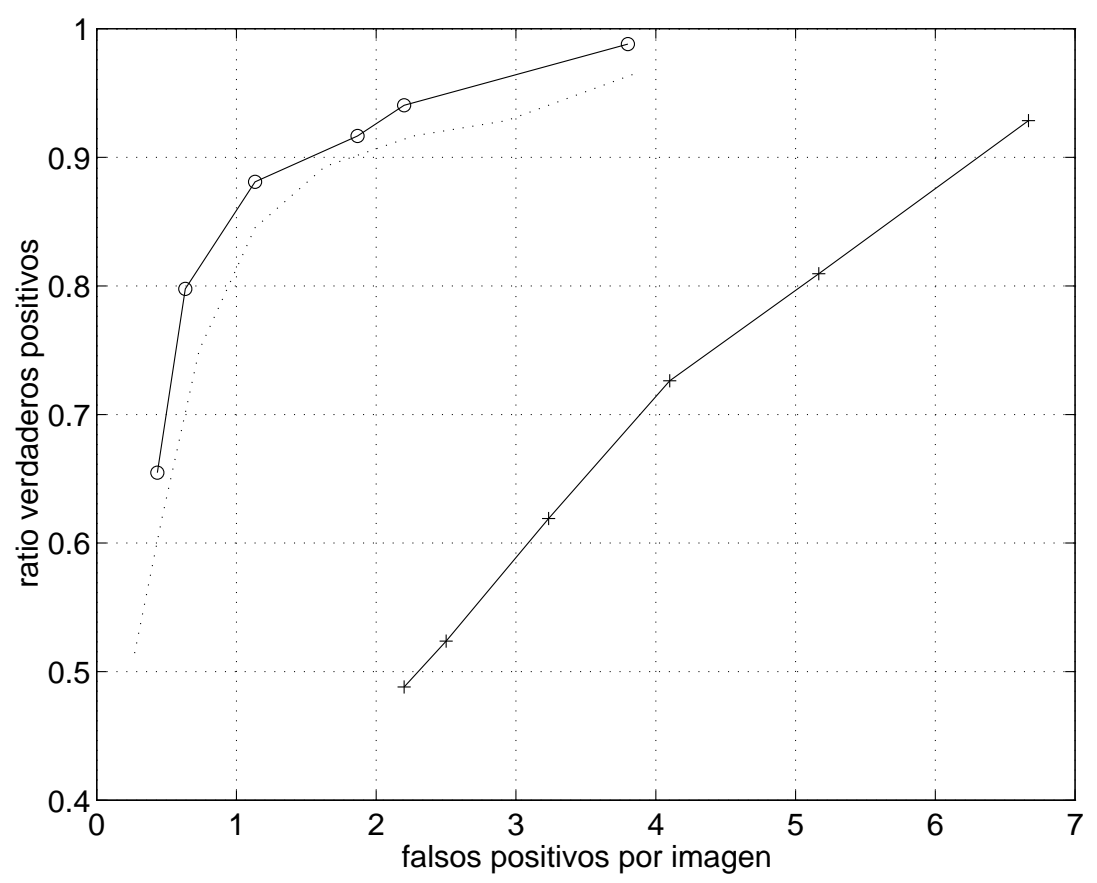

Figura 6.30: Curva ROC de los resultados del residuo del fondofibra con reconstrucción sin el modelo campo aleatorio de Markov (clasificación como microcalcificación según Maximum Likelihood Estimate) $(+)$ y con el modelo de campo aleatorio de Markov (o). Se observa el importante aumento del ratio de verdaderos positivos para los distintos valores de falsos positivos por imagen al utilizar el modelo de campo aleatorio. Para poder comparar se reproduce la curva (puntos) de la figura 6.23 correspondiente al caso sin reconstrucción. 
Se dan en la tabla 6.7 los resultados individualizados para cada mamografía cuando para el conjunto se tiene una sensibilidad que proporciona un ratio de verdaderos positivos de 0.88 con 1.13 falsos positivos por imagen; incluir más tablas detalladas para las diferentes sensibilidades y para los diferentes operadores morfológicos resulta excesivo.

\begin{tabular}{|c|c|c|c|c|c|c|c|}
\hline Imagen & $\mathrm{N}$ & vp & fp \\
\hline \hline Ima1o & 3 & 3 & 2 \\
\hline z02c & 2 & 2 & 1 \\
\hline z02o & 1 & 1 & 2 \\
\hline z03o & 1 & 1 & 0 \\
\hline z04c & 2 & 2 & 1 \\
\hline z04o & 2 & 2 & 1 \\
\hline z13c & 13 & 10 & 1 & 1 & 0 \\
\hline z13o & 1 & 1 & 2 \\
\hline z14c & 2 & 2 & 0 \\
\hline z05c & 1 & 1 & 0 \\
\hline z06o & 2 & 2 & 0 \\
\hline z15c & 1 & 1 & 2 \\
\hline z07c & 2 & 2 & 3 \\
\hline z08c & 1 & 1 & 0 \\
\hline z16o & 1 & 1 & 1 & 1 \\
\hline z17c & 9 & 1 & 0 \\
\hline z09c & 4 & 3 & 0 \\
\hline z09o & 2 & 1 & 2 & 3 \\
\hline z11c & 1 & 1 & 3 \\
\hline z12c & 15 & 11 & 1 \\
\hline z18c & 5 & 2 & 4 & 2 \\
\hline z19c & 1 & 2 & 2 & 0 \\
\hline z19o & 3 & 3 & 0 \\
\hline z21o & 1 & 1 & 1 \\
\hline Total & 84 & 74 & 34 \\
\hline
\end{tabular}

Tabla 6.7: Valores individuales del número de verdaderos positivos y de falsos positivos para el residuo del fondofibra con reconstrucción y el modelo de campo aleatorio de Markov sobre cada imagen del conjunto de imágenes de test, con la sensibilidad ajustada tal que el ratio de verdaderos positivos para el conjunto es 0.88 y resultan 1.13 falsos positivos por imagen.

$\mathrm{Al}$ analizar estos resultados es importante destacar que de los 10 clusters positivos no detectados, es decir los falsos negativos, 7 están en las imágenes z12c y z12o. La razón es que estas imágenes son atípicas respecto al resto de las imágenes de la base mamográfica en cuanto al aspecto de las microcalcificaciones y a que suponen por sí mismas el 27\% de los clusters. También en [119] se realiza esta misma observación y para que los resultados sean comparables con otros trabajos en los que no se incluyen las imágenes z12c y z12o en la figura 6.31 se puede comparar el impacto que tienen en los resultados sobre el conjunto de imágenes de test. En cifras, no incluir las imágenes 12 supone para $0.6 \mathrm{fp} /$ imagen un incremento de 13 puntos porcentuales en el ratio de verdaderos positivos y la diferencia disminuye hasta 3 puntos porcentuales para 1.8 fp/imagen; lógicamente la diferencia tiende a ser nula cuando se detectan todos los clusters. 


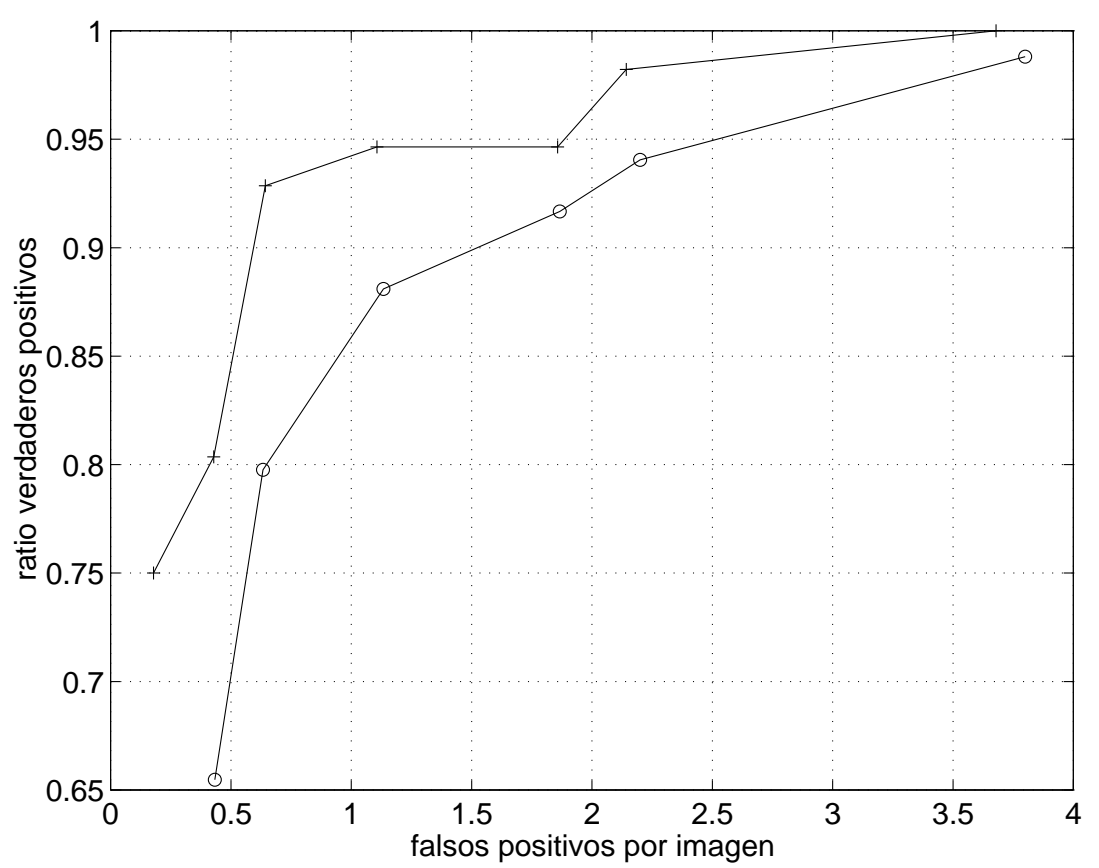

Figura 6.31: Influencia de las imágenes z12c y z12o. Curvas ROC del residuo fondofibra con reconstrucción y el modelo de campo aleatorio de Markov. (o) Conjunto de test; (+) Conjunto de test excluyendo z12c y z12o.

A continuación se presentan en la figura 6.32 varios ejemplos extraídos del conjunto de imágenes de test que ilustran la causa de algunos falsos positivos, así como de algunos falsos negativos. En las imágenes de la primera fila se presentan tres casos (subimágenes de 300x300 pixels, aumentadas en contraste por 3) donde el resultado que se obtiene con nuestro procedimiento marca un positivo incluso a sensibilidad baja, que resulta ser falso dado que los radiólogos no han marcado dicha zona como positiva. La imagen resultado para cada uno de los tres casos aparece debajo de cada original. A la vista de las imágenes en niveles de gris, en el interior de los recuadros marcados y en cada una de ellas se puede apreciar con bastante nitidez la presencia de pequeñas regiones contrastadas que tienen el mismo aspecto que las microcalcificaciones, tanto en forma como en nivel de contraste. No corresponde a regiones tipo emulsión porque su contraste no es lo suficientemente grande. El aspecto visual que tienen es perfectamente asumible como microcalcificación. Con los criterios que el algoritmo utiliza estas regiones son indistinguibles de las muchas microcalcificaciones que sí han sido marcadas como tales por los radiólogos, de manera que es lógico que el resultado en esas regiones sean positivos individualmente en cada una de esas pequeñas regiones. Como en las imágenes presentadas en la primera fila existen al menos dos microcalcificaciones distantes menos de $0.5 \mathrm{~cm}$ el algoritmo marca un cluster. El comentario que se puede hacer aquí es en primer lugar establecer que existe 


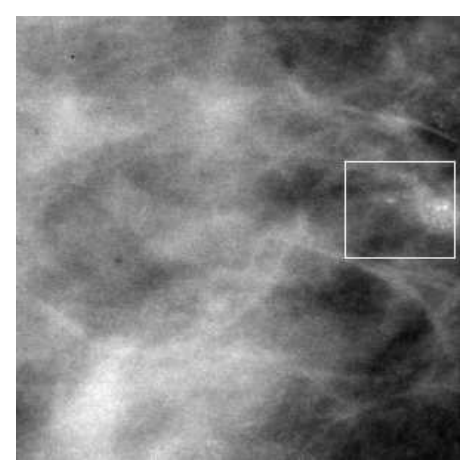

a) original z12o $(525,1150)$

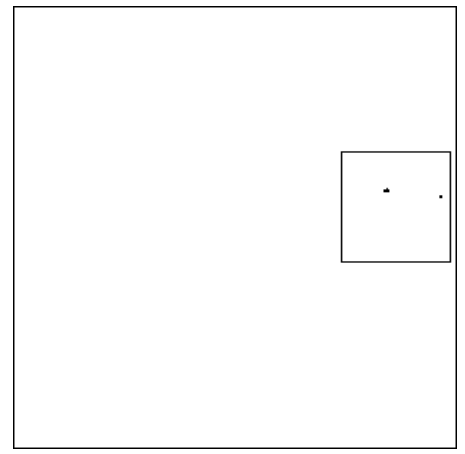

d) resultado $\mathrm{z} 12 \mathrm{O}$

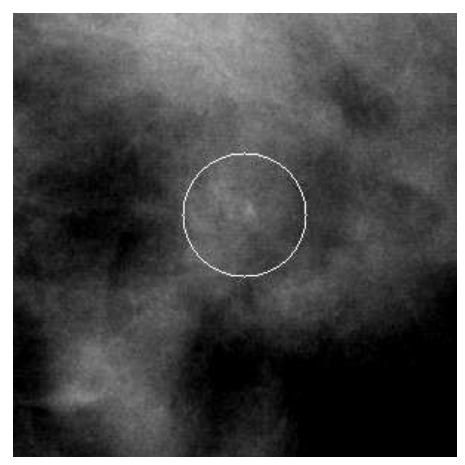

g) original z08c $(500,900)$

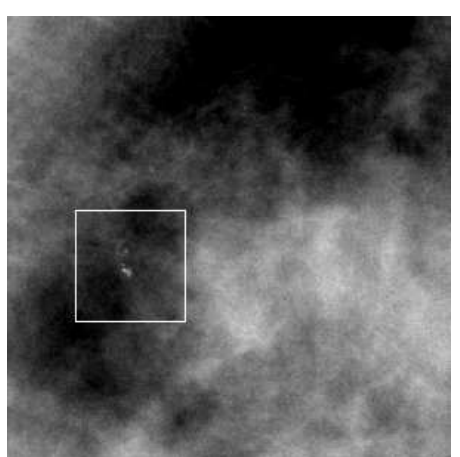

b) original z16o $(10,550)$

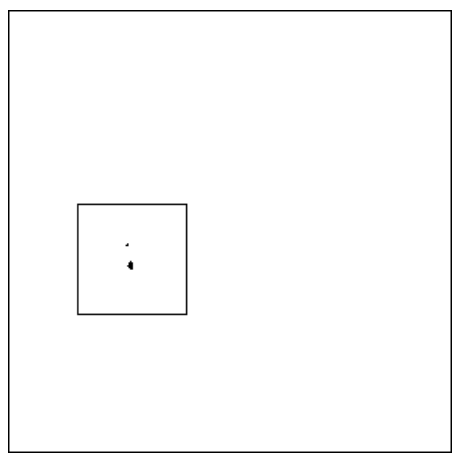

e) resultado z16o

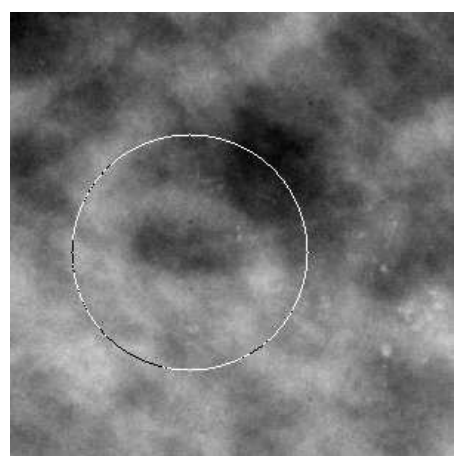

h) original z17c $(1110,250)$

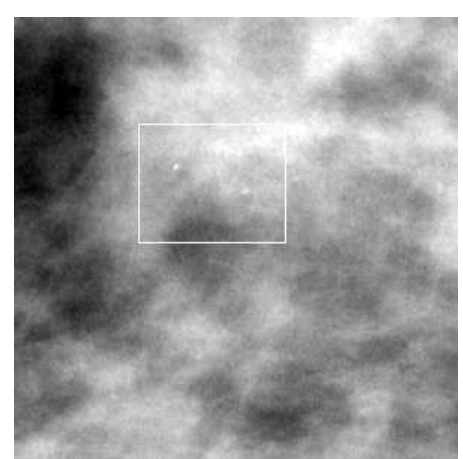

c) original z17o $(780,200)$

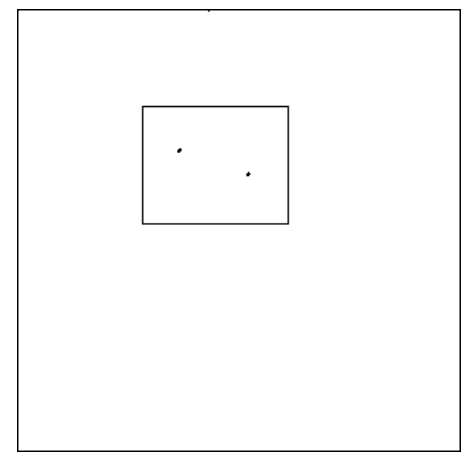

f) resultado $z 170$

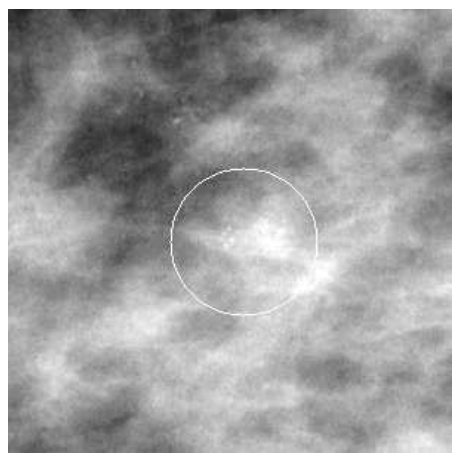

i) original z17o $(650,410)$

Figura 6.32: Detalle de falsos positivos y falsos negativos. La primera fila corresponde a imágenes en niveles de gris de porciones de mamografías donde incluso a niveles bajos de sensibilidad aparecen falsos positivos. La segunda fila ilustra los respectivos resultados. En la tercera fila se presentan porciones de mamografías donde incluso a sensibilidades altas no se detectan los clusters marcados. Se puede apreciar que en los casos de la primera fila, marcados por los radiólogos como negativos, se aprecian con mayor nitidez objetos tipo microcalcificación, que en los casos de la tercera fila, marcados por los radiólogos con una circunferencia como positivos. 
una duda razonable sobre la veracidad del diagnóstico negativo. Si realmente el diagnóstico es negativo, cabe preguntarse si se puede llegar e él únicamente a través de la imagen; máxime si se pretende llegar a diagnósticos positivos en los casos que se presentan en la fila inferior. En ella se presentan tres ejemplos de clusters marcados como positivos por los radiólogos a través de las respectivas circunferencias y que el algoritmo detecta sólo a muy altas sensibilidades. Las imágenes resultado para estos casos no se presentan porque en los tres casos son una imagen en blanco. El aspecto que presenta la figura $g$ es muy similar al que presenta la figura $b$. En $g$ los radiólogos han marcado un positivo indicado a través de la circunferencia, mientras que en $b$ han indicado lo contrario. Lógicamente a la vista de las imágenes difícilmente se puede llegar con un procedimiento automático a un diagnóstico correcto en ambos casos. Lo mismo se puede decir de $c$, las dos microcalcificaciones marcadas por el resultado de la figura $f$ tienen aspecto mucho más evidente de ser tales, que las existentes en $g$ o en $h$.

Un grupo importante de falsos positivos se debe a zonas del tipo de las presentadas en el párrafo anterior. Otro grupo importante se analiza a continuación. Consiste en un grupo de clusters formados por dos o tres microcalcificaciones en los que una de ellas es verdadera y tiene varios pixels o varias decenas de pixels y el resto no lo son y su tamaño es de uno o dos pixels. Retomando la definición de cluster hay un salto cualitativo importante en la decisión de si existe un cluster o no debido a que el criterio es si hay dos o más microcalcificaciones, independientemente de las características de las microcalcificaciones que lo forman. Es igual de positivo un cluster formado por dos microcalcificaciones de decenas de pixels que un cluster formado por dos microcalcificaciones de un pixel, con tal de que las distancias que las separen sea menor de $0.5 \mathrm{~cm}$. Sin embargo una región de un único pixel que ha sido etiquetado como microcalcificación, tiene cierta probabilidad de no corresponder realmente a una microcalcificación sino a ruido. Si es un sólo pixel con un cierto nivel en el residuo que no tiene próxima ninguna microcalcificación, muy probablemente el algoritmo acabe etiquetándolo como fondo o como emulsión, tal como es deseable, debido al término de vecindario ampliado; pero si tiene próxima una o varias microcalcificaciones grandes es probable que termine siendo etiquetado como microcalcificación. Si son varias microcalcificaciones las que forman el cluster, no tiene mayor trascendencia que un pixel forme una nueva microcalcificación puesto que el criterio de cluster ya se cumple independientemente de esta nueva microcalcificación de un pixel; pero si sólo es una microcalcificación con varios pixels, que aparezca o no una nueva microcalcificación próxima, tiene una trascendencia considerable porque significa la creación de un nuevo cluster. A la vista de los clusters marcados por los radiólogos, poquísimas microcalcificaciones son de un pixel; sin embargo sí hay regiones de un pixel contrastadas respecto a su entorno con un nivel similar al de las microcalcificaciones que no son microcalcificación, ni responden a una 
emulsión y que por tanto podemos asumir como ruido en la región del fondo. Estadísticamente el número de pixels de este tipo respecto al número de pixels que forman el fondo es muy pequeño, pero comparado con el número de clusters es significativo. Así pues podemos plantearnos filtrar la imagen de entrada al algoritmo basado en el campo aleatorio de Markov para eliminar aquellos valores que en el residuo tengan un nivel que pueda resultar etiquetado como microcalcificación si el tamaño de dicha región es de un pixel. En la sección siguiente se discute la creación de una transformación basada en morfología matemática para este fin. 


\subsection{Residuo Fondofibra con apertura superficial}

Esta sección trata de presentar un proceso ad-hoc para eliminar el ruido mencionado al final de la sección anterior, con herramientas generales de morfología matemática. Son varios los aspectos que hay que tener en cuenta y se expondrán a continuación. En primer lugar el aspecto más importante es el tamaño. Se pretende eliminar en imágenes de niveles de gris los picos positivos de un pixel, para ello se puede utilizar la apertura clásica con un elemento estructurante mayor de un pixel. En una imagen con retícula cuadrada un elemento estructurante mayor de un pixel y que además sea isótropo tiene que ser como mínimo una cruz de 5 pixels o un cuadrado que tiene 9 , cantidades excesivamente grandes porque hay calcificaciones de menos de 5 ó 9 pixels. Como lo que importa es el tamaño y no la forma, se puede hacer uso del operador apertura superficial expuesto en el capítulo 4. La apertura superficial elimina los máximos regionales por debajo de un cierto tamaño, como en este caso estamos interesados en que elimine los de tamaño un pixel, elimina lo que normalmente se entiende por un máximo, asignándole el valor del vecino mayor y convirtiendo lo que antes era un máximo en un máximo regional de al menos dos pixels, siendo la imagen resultado menor o igual a la de entrada (ver sección 4.4.3).

Al realizar la apertura superficial sobre el residuo del fondofibra con reconstrucción y utilizar el resultado como observación de entrada al algoritmo ICM con el modelo de campo aleatorio de Markov que se viene utilizando en este trabajo, el resultado no mejora. Con la introducción de la apertura superficial se pretende eliminar ruido que a la postre genera falsos positivos. La eliminación es suave en el sentido de que se eliminan picos de un sólo pixel pero aún así el recorte que se produce sobre las microcalcificaciones pequeñas es suficiente para que no se detecten. Este recorte se produce porque aunque la microcalcificación sea mayor de un pixel los niveles de gris de los pixels que la forman no son todos iguales y normalmente siempre hay alguno mayor que el resto, y ese pixel es el que sufre el recorte. Si la microcalcificación es tenue y pequeña con la apertura superficial puede perder sus pixels de mayor nivel y es probable que se deje de detectar. Esta pérdida de detección de verdaderos positivos es la causa de la no mejoría de los resultados cuando se realiza todo el proceso haciendo uso de la apertura superficial. La mayor incidencia de verdaderos positivos que se dejan de detectar ocurre sobre las imágenes z12c y z12o, que como se ha mencionado con anterioridad, contienen 28 clusters en los que el 35\% de las microcalcificaciones son de uno o dos pixels. Ciertamente también se consiguen eliminar los falsos positivos generados por falsas microcalcificaciones de un pixel, pero al reducirse los verdaderos positivos detectados, el resultado final no mejora respecto a utilizar como observación el residuo del fondofibra con reconstrucción. Hay que evitar el recorte de los máximos sobre las microcalcificaciones. 
Para corregir este problema realizamos la siguiente propuesta: restaurar los máximos regionales de un pixel que elimina la apertura superficial en aquellas regiones que tras la misma conserven un nivel por encima de un determinado valor. Con ello se pretende distinguir máximos estrechos sobre el fondo, de máximos estrechos sobre regiones que puedan ser microcalcificación. De acuerdo con este proceso definimos la siguiente transformación:

$$
\mathcal{T}(f)=\text { opensur } f(f)+\{f-\text { opensur } f(f)\} \cdot\{\text { opensur } f(f)>t\}
$$

donde opensurf es la apertura superficial de tamaño 1, la operación · es el producto, $t$ es un umbral y $f$ es la imagen obtenida con el residuo del fondofibra con reconstrucción. La suma del segundo término es equivalente a realizar una reconstrucción utilizando como marcador la imagen resultante de la operación umbral, sólo que implementada tal como está definida tiene un coste computacional menor. Para referirnos a esta transformación lo haremos con las siglas EPA (Elimina Picos Aislados).

Respecto al umbral, es un factor que tiene una gran influencia porque es quien determina sobre qué zonas se va a restaurar, y en aras a no perder verdaderos positivos es conveniente una decisión conservadora. Se ha situado en el $70 \%$ del valor por encima del cual se inicializa un pixel como microcalcificación en la estimación MLE de la sección anterior.

En la figura 6.33 se ilustra el efecto de esta transformación sobre una zona que crea un falso positivo y que tras la transformación el falso positivo desaparece. En $a$ se muestra la mamografía z04o completa con un recuadro indicando la zona de interés. En $b$ se muestra la ampliación x12 del recuadro marcado en $a$ correspondiente a una zona de $60 x 60$ pixels a partir del pixel $(480,1475)$. A su vez en $b$ se marca un nuevo recuadro para acotar la zona donde aparece el pico que se pretende eliminar. En $c$ se muestra cómo ese pico aparece en el residuo del fondofibra con reconstrucción y en $d$ el resultado final en el que la microcalcificación grande junto con el pixel que resulta ser etiquetado como microcalcificación forman un cluster que es falso positivo. En $d$ se muestra el resultado de aplicar la transformación EPA sobre el residuo del fondofibra con reconstrucción. Se puede observar fácilmente que la imagen $d$ es mucho más limpia que la $c$ debido a que todas las regiones formadas por un único pixel sobre el fondo (nivel de gris cero, que en la imagen aparece como blanco) han desaparecido. Si se mira con detenimiento la imagen $d$ se ve que a diferencia de $c$ no hay máximos regionales formados por un único pixel a excepción de los existentes en la microcalcificación grande. El pixel que origina la creación de un cluster no va a ser nunca etiquetado como microcalcificación en el algoritmo iterativo porque su nivel de gris ha sido reducido a cero y será etiquetado como fondo, tal y como se muestra en $f$.

Para ilustrar cómo esta transformación respeta los máximos sobre zonas que 


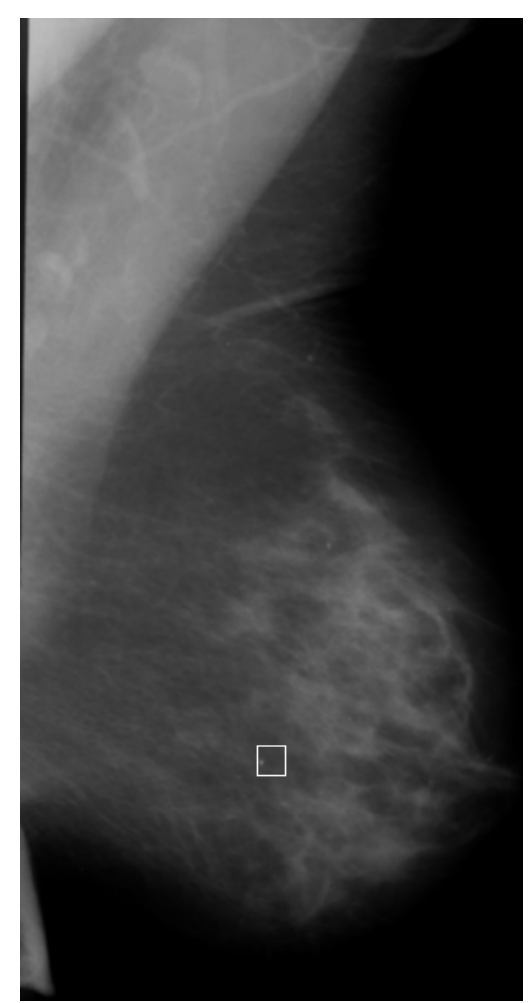

a) mamog. z04o

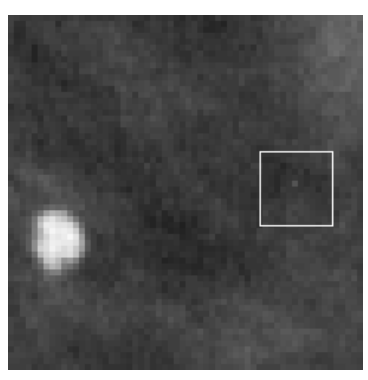

b) original

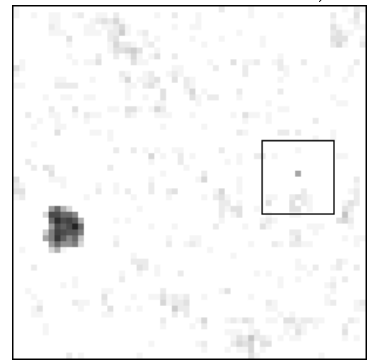

c) residuo

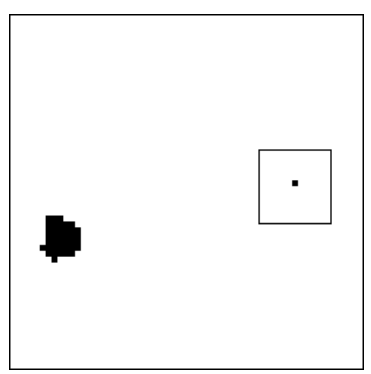

e) ICM residuo

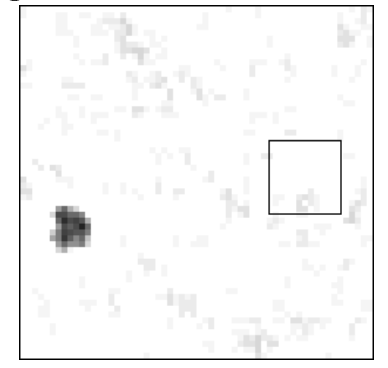

d) EPA

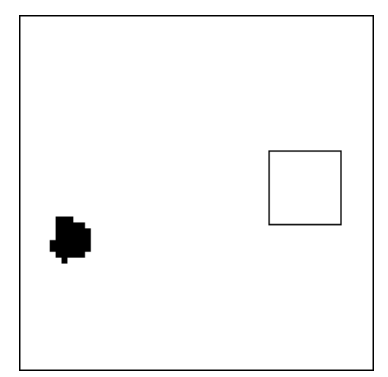

f) ICM EPA

Figura 6.33: Detalle de la eliminación de picos aislados utilizando la apertura superficial sobre z04o. a) mamografía completa con la zona de interés marcada por el recuadro; b) ampliación x12 de la zona marcada en $a$, donde a su vez se recuadra una pequeña zona; c) residuo del fondofibra con reconstrucción; d) eliminación de picos aislados de $c$; e) resultado del algoritmo tomando como entrada $c$; f) resultado del algoritmo tomando como entrada $d$. En $f$ se evita el cluster falso positivo porque no aparece la segunda microcalcificación. 


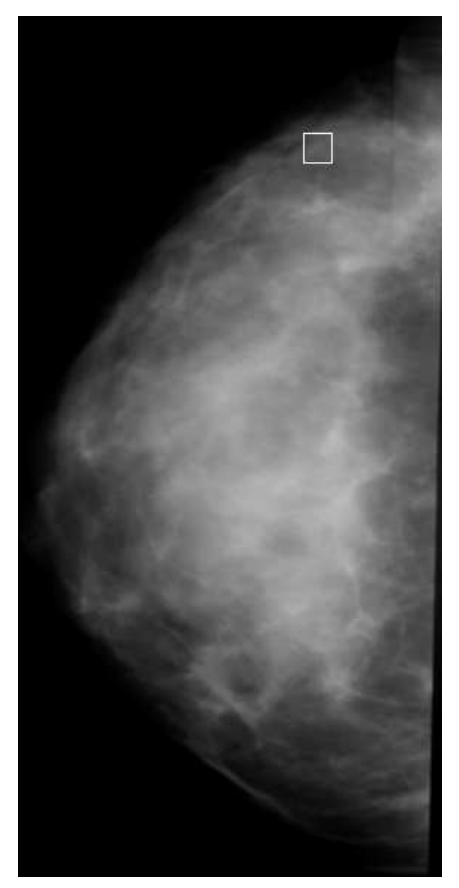

a) mamog. z12c

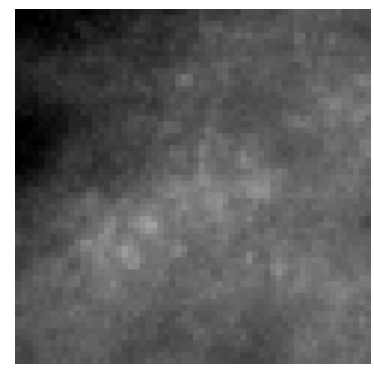

b) original

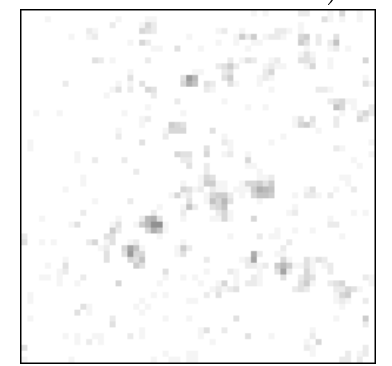

c) residuo

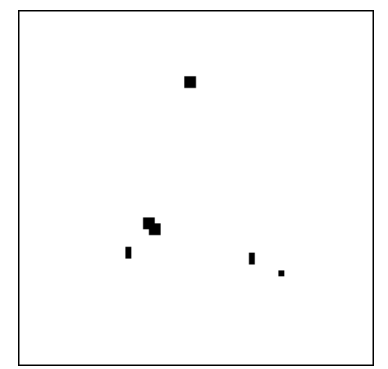

e) ICM residuo

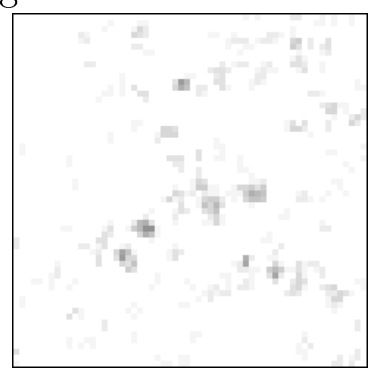

d) EPA

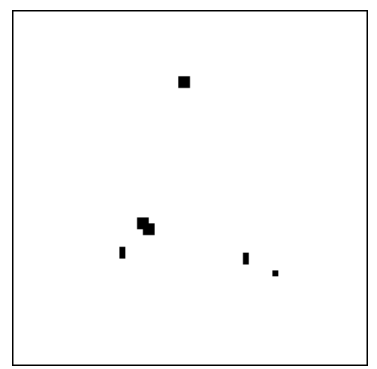

f) ICM EPA

Figura 6.34: Detalle de la conservación de picos superpuestos a regiones potencialmente microcalcificación sobre la mamografía z12c. a) mamografía completa con la zona de interés marcada por el recuadro; b) ampliación x12 de la zona marcada en $a$; c) residuo del fondofibra con reconstrucción; d) eliminación de picos aislados de $c$, se observa que muchos de los máximos regionales se conservan sobre pequeñas regiones de un cierto nivel; e) resultado del algoritmo tomando como entrada $c$; f) resultado del algoritmo tomando como entrada $d$. En $f$ se consigue seguir detectando el verdadero positivo gracias a que se han restaurado los máximos. 
no son fondo, y que por tanto podrían ser microcalcificaciones verdaderas se presenta la figura 6.34. Sigue la misma estructura que la figura 6.33 para facilitar la comparación. En a se presenta la mamografía z12c completa con la zona de interés recuadrada. En $b$ se presenta la ampliación x12 de dicha zona, en la que como se viene haciendo normalmente el contraste está aumentado x3 para una mejor visualización. La zona de interés es de 60x60 pixels a partir de la coordenada $(577,236)$. Siguiendo el proceso de la sección anterior se alcanza el etiquetado de la figura $e$, donde se observa que hay cinco microcalcificaciones pequeñas de las cuales una es de un pixel. En $d$ se presenta el resultado de la transformación EPA realizada sobre el residuo del fondofibra con reconstrucción. En la imagen han desaparecido gran parte de los máximos regionales de un pixel debido a la apertura superficial pero se puede observar que se conservan aquellos máximos que están sobre regiones de un cierto nivel y que a la postre son esos pixels los que determinan que el etiquetado final que les corresponde sea de microcalcificación.

Para finalizar se presenta el conjunto de resultados sobre el grupo de las treinta imágenes de test para distintas combinaciones del ratio de verdaderos positivos y los correspondientes falsos positivos por imagen se presentan en la tabla 6.8; En la figura 6.35 se presentan estos resultados (curva marcada con círculos) junto con los resultados previos del residuo del fondofibra con reconstrucción (curva a trazos) y sin reconstrucción (curva de puntos), para poder comparar. La diferencia introducida por la eliminación de los picos aislados se aprecia en la zona alrededor de un falso positivo por imagen, pero no es significativa en valores más bajos debido a que hay varios falsos positivos como los mostrados en la figura $6.32 a b$ y $c$ que son debidos a regiones de varios pixels y de niveles similares a los de las microcalcificaciones que no se ven afectados por la transformación introducida en esta sección y no se pueden eliminar. Para comparar las cifras de la tabla 6.8, decir que en [58] Karssemeijer detalla para cada imagen los resultados obtenidos en cada una de ellas, resultándole para las 30 utilizadas en nuestro trabajo como subconjunto de test un ratio de verdaderos positivos detectados del $86.9 \%$ con 1.2 falsos positivos por imagen.

\begin{tabular}{|c|c|c|c|}
\hline ratio vp & $\mathrm{fp} / \mathrm{img}$ & ratio vp & $\mathrm{fp} / \mathrm{img}$ \\
\hline \hline 0.99 & 3.80 \\
\hline 0.93 & 1.83 \\
\hline 0.92 & 1.53 \\
\hline 0.90 & 1.16 \\
\hline
\end{tabular} \begin{tabular}{|c|c|}
\hline \multicolumn{2}{|c}{} \\
\hline 0.67 & 0.80 \\
\hline
\end{tabular}

Tabla 6.8: Valores del ratio de verdaderos positivos y número de falsos positivos para el residuo del fondofibra con reconstrucción con eliminación de picos aislados y el modelo de campo aleatorio de Markov sobre el conjunto de imágenes de test. 


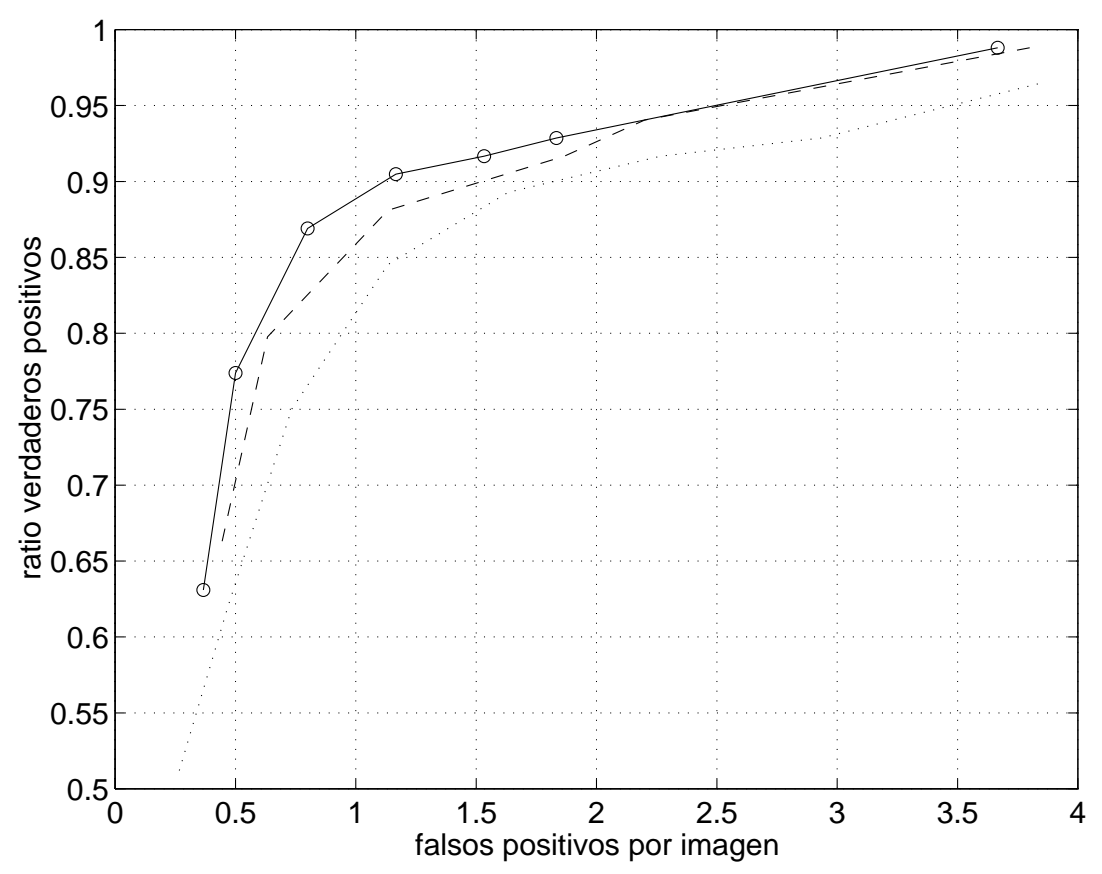

Figura 6.35: Curva ROC de los resultados del residuo del fondofibra con reconstrucción con eliminación de picos aislados y con el modelo campo aleatorio de Markov (o). Para poder comparar se reproduce la curva (trazos) de la figura 6.30 correspondiente al residuo del fondofibra con reconstrucción y la figura 6.23 correspondiente al residuo del fondofibra sin reconstrucción (puntos). 


\section{Capítulo 7}

\section{Conclusiones y futuras líneas}

\subsection{Conclusiones}

La presente tesis ha desarrollado un algoritmo para la detección de microcalcificaciones en mamografía. La propuesta ha consistido en acometer el problema desde el punto de vista de la segmentación de imágenes asignando a cada pixel una etiqueta de entre las disponibles en un conjunto. Qué etiquetas forman el conjunto ha sido la siguiente tarea a determinar. En la tesis se ha propuesto que sean tres: fondo, microcalcificación y emulsión. Dado que el tejido que forma la mama es diverso cabrían dos planteamientos, dividir el fondo en varios tipos de regiones aumentando entonces el número de etiquetas posibles, o, como se ha hecho en esta tesis, preprocesar la imagen para transformar los niveles de gris correspondientes a las variaciones en el fondo en otros niveles de gris más uniformes facilitando así la tarea siguiente de asignarles a todos ellos la misma etiqueta fondo en el proceso de segmentación. Se ha considerado necesaria la etiqueta emulsión para poder separar aquellas regiones con características más similares a las microcalcificaciones que al fondo pero que no son microcalcificaciones, tales como los defectos de la emulsión de la película radiográfica.

Aunque el proceso consiste en segmentar una imagen, también es un proceso de detección de manera que el resultado es una imagen binaria en la que algunos pixels han sido asignados a la clase que se pretende detectar (microcalcificación) y el resto no. Como lo que tiene importancia médica son las microcalcificaciones agrupadas (clusters) tras la segmentación se realiza la identificación de pixels asignados a la clase microcalcificación que son conexos en microcalcificaciones propiamente y a continuación se identifican los clusters existentes en la imagen resultante. Como es un problema de detección la conclusión de cada propuesta se da en forma de curva probabilidad de detección en función de probabilidad 
de falsa alarma, que en nuestro caso se traduce en ratio de clusters verdaderos positivos detectados en función de clusters falsos positivos por imagen. Durante el trabajo se ha considerado la posibilidad de, como han hecho otros autores, trabajar con ratio de falsos positivos en vez de falsos positivos por imagen, pero nuestra conclusión es que es más realista lo segundo porque para considerar ratio de falsos positivos hay que dividir número de falsos positivos detectados, es decir los falsos positivos producidos por el algoritmo, entre el número de falsos positivos posibles. Evaluar el número de falsos positivos posibles cuando se trabaja con porciones de la mamografía en vez de con la imagen entera y, el problema de clasificar consiste en determinar si la porción contiene cluster o no, es sencillo porque se conoce cuantas porciones contiene el conjunto de test y esa misma cantidad es el número de falsos positivos posibles. Pero determinar el número de falsos positivos posibles en un conjunto de imágenes no tiene demasiado sentido.

De entre los diversos modelos para la imagen, se ha elegido el modelo de campo aleatorio de Markov porque permite introducir como factor para la decisión de la etiqueta a asignar a un pixel la información que puedan aportar los pixels vecinos. Se han estudiado varios algoritmos de segmentación para imágenes modelas con campos aleatorios de Markov y se ha propuesto una modificación al algoritmo Highest Confidence First concluyendo finalmente con la elección del Iterated Conditional Modes por sus mejores prestaciones.

Para la fase previa a la segmentación se han estudiado y propuesto varias alternativas basadas en morfología matemática porque pensamos que esta técnica nos ha facilitado la confección de operadores para poder transformar la diversidad del fondo de la mamografía en una región más homogénea y con mejores resultados en el etiquetado. El principal problema ha sido que el fondo tiene intercalado tejido fibroso con contraste similar al que presentan las microcalcificaciones. La morfología matemática ha permitido, con la elección apropiada de los elementos estructurantes, reducir el número de falsos positivos debidos a la fibra en la detección de las microcalcificaciones. Al reducir este problema se puede percibir el siguiente. El fondo, una vez transformado con los operadores propuestos, tiene irregularidades de amplitud menor que en la mamografía original pero que puede alcanzar ocasionalmente en algunos pocos pixels niveles similares al de las microcalcificaciones. En la mayor parte de las microcalcificaciones la cantidad de pixels que las forman es mayor que las regiones contrastadas debidas a las irregularidades del fondo y eligiendo los niveles de sensibilidad no muy altos las irregularidades no aparecen en el resultado, pero otra parte de las microcalcificaciones son tan pequeñas que están formadas por dos o tres pixels y para detectarlas es necesario aumentar la sensibilidad, aumentando entonces la importancia de las irregularidades del fondo por la dificultad de distinguirlas de las microcalcificaciones más pequeñas. El último operador morfológico propuesto reduce la incidencia de este problema. 
Para la segmentación con el modelo de campo aleatorio de Markov es necesario disponer de las funciones densidad de probabilidad de cada clase, para ello se han tomado parte de las imágenes de la base de datos como grupo de entrenamiento para estimar dichas funciones. En nuestro caso debido a que los operadores morfológicos son no lineales y a que la apertura es anti-extensiva, el histograma para la clase fondo presenta una divergencia importante respecto a la distribución gaussiana que es la más utilizada en otros trabajos. Se ha propuesto una función ad-hoc para aproximar dicho histograma. Sin embargo para la clase microcalcificación y emulsión se ha seguido el modelo gaussiana con las modificaciones oportunas debidas al truncamiento impuesto porque el nivel mínimo de la imagen es cero. Aún así la conclusión es que es necesario mejorar las funciones para estas dos clases. Son varios los caminos que hay que seguir. Aumentar en lo posible el número de muestras, sobre todo en lo que respecta a la clase emulsión que es la más deficitaria. Asimismo, actualmente el diagnóstico médico asociado a la base de mamografías son los círculos que encierran los clusters pero no hay una indicación por parte de los radiólogos a nivel de qué pixels son o no microcalcificación y sería conveniente acometerla. Después de todo ello habrá que comprobar si el modelo gaussiano se ajusta suficientemente.

En cuanto a los resultados se han dado en forma de gráficas ROC pero para comparar seleccionamos de cada gráfica el valor de detección para 1 falso positivo por imagen aproximadamente, que es la situación mejor documentada para los otros trabajos realizados con la misma base de mamografías, específicamente [58] reporta detalladamente para cada mamografía el número de verdaderos positivos y negativos resultando un ratio de verdaderos positivos detectados (RVP) de $83.8 \%$ con $1.05 \mathrm{fp} / \mathrm{img}$. Los resultados con nuestras proposiciones han ido evolucionando desde un RVP de $84 \%$ con $1.13 \mathrm{fp} / \mathrm{img}$ para el operador fondofibra sin reconstrucción, con reconstrucción RVP 88\%,1.13 fp/img, y finalmente con el operador propuesto en la sección 6.6 se llega a RVP 90\%, 1.16 fp/img. La diferencia con [58] es pequeña pero a estos niveles de detección y con esta base de mamografías no hay trabajos que aporten detalladamente resultados con diferencias mayores por encima. Sí que los hay con resultados inferiores (RVP 55\%, 0.7 FP/img) [119]. No obstante pienso que todos los algoritmos presentados en los últimos años deben ser reevaluados con las bases de mamografías que van a ir apareciendo próximamente.

\subsection{Líneas futuras}

Una futura línea es estudiar si la introducción de más clases en el algoritmo de etiquetado mejora las prestaciones de la detección. El planteamiento que nosotros hemos seguido es construir operadores elaborados para que la diversidad 
de tejidos del fondo de la mamografía quede reducida en la imagen de salida y asignar la misma etiqueta a todo ello. Pero quizás el planteamiento contrario sea interesante, es decir, intentar estructurar esa diversidad no como un fondo único sino como distintos tipos de tejidos e intentar caracterizar cada uno de ellos e introducirlo como una clase propia en el problema de clasificación.

Por otra parte, el propósito de la tesis ha sido la detección de las microcalcificaciones como herramienta para advertir de la existencia de dicha anomalía en la mamografía y que un radiólogo proceda al análisis de la misma. En los resultados no se ha contemplado la valoración de la exactitud de la segmentación de las microcalcificaciones a nivel de pixel. Una línea futura una vez detectada la presencia de la mismas es desarrollar procedimientos con el objetivo de extraerlas con la mayor exactitud posible. Esto es importante porque el siguiente paso a la detección sería ayudar en el diagnóstico de benignidad malignidad y algunos trabajos realizados hasta el momento resaltan la necesidad de una correcta segmentación de las mismas. Estos trabajos basan su clasificación en características como la forma y si la segmentación no es adecuada como las microcalcificaciones son pequeñas un error en unos pocos pixels tiene una incidencia muy alta en las prestaciones.

Por supuesto que en mamografía quedan líneas abiertas en otros frentes distintos a la detección de microcalcificaciones, como son la detección de masas, sean bien definidas, mal definidas, espiculadas, como la detección de distorsiones en la arquitectura de la mama, asimetrías y otras, así como todo aquello que pueda ayudar al diagnóstico de benignidad o malignidad en base a la imagen mamográfica y poder evitar así tener que recurrir a la biopsia, que aunque no supone necesariamente tener la enfermedad sí es un trauma importante para la mujer.

Una futura línea de la que no hemos visto ningún trabajo en la literatura es la siguiente: en la práctica médica es frecuente cuando se tiene que diagnosticar si un caso es benigno o maligno y los indicios son dudosos recurrir a casos del pasado que hayan tenido indicios similares. El radiólogo emprende entonces una búsqueda por su archivo de mamografías para encontrar aquellas parecidas y estudiar el resultado de la biopsia practicada. Interesa que el archivo sea extenso para encontrar varios casos parecidos y poder analizar comparativamente con precisión los distintos factores entre las mamografías seleccionadas para establecer el nuevo diagnóstico. Si el archivo personal del radiólogo no es extenso sería interesante centralizar una base de imágenes con sus diagnósticos asociados. Es en este contexto donde se abre una nueva línea porque cuando la base es extensa buscar una a una las mamografías con microcalcificaciones parecidas es una tarea tediosa, máxime cuando esas imágenes no están físicamente en el mismo sitio que el radiólogo, por lo que sería interesante desarrollar un sistema automático de búsqueda de mamografías parecidas al caso que se quiere diagnosticar. 


\title{
Anexo A
}

\section{Base de datos de mamografías con microcalcificaciones}

El conjunto de mamografías utilizado para entrenar y evaluar los algoritmos de la presente tesis se ha obtenido de la base de datos pública accesible a través de ftp anonymous a la dirección figment.csee.usf.edu. Las imágenes han sido confeccionadas en el departamento de radiología del Nijmegen University Hospital, Netherlands, y presentado en [58] por Nico Karssemeijer. La base de datos consta de cuarenta mamografías digitalizadas cuyas especificaciones se describen a continuación.

\section{A.1 Especificaciones}

\author{
Mamografía Kodak MIN-R/SO177 \\ Cámara Eikonix 1412, CCD \\ Resolución 2048x2048 \\ Número de bits 12 bits $^{1}$ \\ Sampling aperture $0.05 \mathrm{~mm}$ de diámetro \\ Distancia de muestreo $0.1 \mathrm{~mm}$ \\ Iluminación Gordon plannar 1417 \\ Calibración de cámara Densidad 0.18 - máximo nivel
}

Las imágenes incluyen corrección por iluminación no homogénea de la fuente. El conjunto de mamografías corresponde a 21 pacientes con vistas craneocaudales y oblicuas, todas ellas con al menos un cluster de microcalcificaciones

\footnotetext{
${ }^{1} \operatorname{los} 12$ bits se convierten a 8 bits por el procedimiento expuesto más adelante en este mismo Anexo.
} 
marcado por radiólogos expertos. No se incluyen mamografías sin clusters de microcalcificaciones porque el tejido normal de una mamografía con microcalcificaciones es similar al tejido normal de una mamografía sin microcalcificaciones, y la cantidad de tejido normal en el conjunto de imágenes de la base de datos es suficientemente grande para que sirva como test de zonas sin microcalcificaciones.

En las 40 imágenes hay un total de 105 clusters, en los que se incluyen diversos tipos. Hay clusters formados por un número de microcalcificaciones pequeño (de 2 a 5), con un número grande, con microcalcificaciones muy contrastadas y poco contrastadas, con tamaño individual de microcalcificación desde 1 pixel a varias decenas de pixels. La base de datos pudiendo ser más extensa es bastante significativa.

\section{A.2 Área significativa de las mamografías}

Dado que las imágenes son de 2048x2048 y 12 bits, la cantidad de memoria necesaria para almacenarla utilizando 2 bytes por pixel es de 8 Mbytes. Como más adelante se expone, la base de datos va acompañada de una Look Up Table para transformar los 12 bits por pixel a 8 bits, lo que supone una cantidad de memoria por mamografía de 4 Mbytes. En promedio el área de la mamografía ocupada por tejido mamario es del 29\% [58], con una forma aproximada semicircular o semielíptica que permite determinar un área rectangular que incluye totalmente la mama, y de menor tamaño que el área total de la mamografía. A su vez este rectángulo menor, o subimagen, excluye las anotaciones que sobre la mamografía es habitual incluir durante el proceso de realización de la misma para dejar constancia de si la mama radiografiada es la derecha o izquierda, así como el tipo de vista (craneo-caudal, lateral, oblicua), y que durante el análisis automático pueden causar falsas interpretaciones. Por ambos motivos, previo al análisis automático, se preprocesa la mamografía de 2048x2048 con objeto de obtener una subimagen rectangular de menor tamaño. El proceso se basa en que la mayor parte de la mamografía es fondo y este tiene un nivel muy próximo al nivel de negro, por lo que se aplica un umbral bajo. En nuestro caso calculamos el histograma, detectamos el pico, sumamos una pequeña cantidad (5) y éste es el umbral. A continuación binarizamos poniendo a 0 lo que es menor o igual que el umbral y ponemos a 255 el resto.

Dentro de la mamografía la mama tiene un borde curvado, correspondiente al exterior del cuerpo, y otro rectilíneo correspondiente a la zona de unión de la mama y el tórax. Durante la digitalización, este último borde da lugar a un gradiente alto debido a que limita con el fondo negro de la mamografía. Además, si durante la digitalización el soporte plástico no está perfectamente unido al 
cristal del equipo de iluminación se producen difracciones que dan lugar a niveles de gris inapropiados. Es por ello que, en el borde rectilíneo la binarización con el umbral del párrafo anterior no funciona correctamente y para binarizar más adecuadamente realizamos el siguiente proceso:

1. Se calcula el valor absoluto del gradiente horizontal a lo largo de cada fila.

2. Se realiza la proyección en vertical del gradiente horizontal, obteniéndose una matriz fila.

3. Se busca el máximo de esta matriz fila. El índice del elemento que contiene el máximo es la coordenada horizontal donde está el borde vertical. Si esta coordenada horizontal es menor que la mitad del ancho de la imagen, el borde está a la izquierda, si es mayor el borde está a la derecha.

4. Si el borde está a la izquierda se pone a cero la franja vertical desde la coordenada cero hasta la coordenada del borde. Si está a la derecha, se pone a cero desde la coordenada del borde hasta el ancho de la imagen.

Una vez completadas las dos fases anteriores de eliminan todas aquellas componentes conexas de la imagen que son menores que la de mayor tamaño. El algoritmo de componentes conexas implementado es una variante con vecindad a 8 del expuesto en [5].

La subimagen rectangular delimitada por la esquina superior izquierda (exmin,eymin) y la esquina inferior derecha (exmax,eymax) es la mínima que contiene la componente conexa de mayor tamaño. Así pues, para el presente trabajo las imágenes utilizadas son las subimágenes de cada mamografía de la base de datos. La tabla A.1 muestra las coordenadas de la esquina superior izquierda (coordenada inicial) del pixel de la mamografía completa correspondiente a la coordenada $(0,0)$ de la subimagen y en la segunda columna, el tamaño en pixels de cada subimagen. Los nombres de las imágenes de 2048x2048 de la base de datos comienzan por la letra 'c', seguida de un número de dos cifras y a continuación la letra 'c', si la vista es craneo-caudal, la letra 'o' si la vista es oblicua, o la letra 'e' si la mamografía es de una exploración anterior. Los nombres de las subimágenes rectangulares que contienen la mama serán los mismos sustituyendo la 'c' inicial por la letra 'z'.

\section{A.3 Ecualización del ruido}

Las imágenes de la base de datos están acompañadas cada una de una Look Up Table para pasar de 12 bits/pixel a 8 bits/pixel. Esta transformación tiene como 


\begin{tabular}{|c|c|c|}
\hline Imagen & Coord. inic. & Tamaño \\
\hline \hline $\mathrm{c} 01 \mathrm{c}$ & $(869,168)$ & $771 \times 1742$ \\
\hline $\mathrm{c} 01 \mathrm{c}$ & $(846,0)$ & $876 \times 1920$ \\
\hline $\mathrm{c} 02 \mathrm{c}$ & $(180,323)$ & $586 \times 1432$ \\
\hline $\mathrm{c} 02 \mathrm{o}$ & $(191,0)$ & $668 \times 1861$ \\
\hline $\mathrm{c} 03 \mathrm{c}$ & $(566,0)$ & $1169 \times 2048$ \\
\hline $\mathrm{c} 03 \mathrm{o}$ & $(765,0)$ & $1031 \times 1938$ \\
\hline $\mathrm{c} 04 \mathrm{c}$ & $(200,288)$ & $956 \times 1604$ \\
\hline $\mathrm{c} 04 \mathrm{o}$ & $(182,0)$ & $1021 \times 1996$ \\
\hline $\mathrm{c} 05 \mathrm{c}$ & $(875,116)$ & $811 \times 1890$ \\
\hline $\mathrm{c} 05 \mathrm{o}$ & $(822,0)$ & $871 \times 2006$ \\
\hline $\mathrm{c} 06 \mathrm{c}$ & $(1175,0)$ & $569 \times 1667$ \\
\hline $\mathrm{c} 06 \mathrm{o}$ & $(1098,0)$ & $671 \times 1911$ \\
\hline $\mathrm{c} 07 \mathrm{c}$ & $(178,0)$ & $1306 \times 1968$ \\
\hline $\mathrm{c} 07 \mathrm{o}$ & $(178,0)$ & $1346 \times 2028$ \\
\hline $\mathrm{c} 08 \mathrm{c}$ & $(167,186)$ & $963 \times 1618$ \\
\hline $\mathrm{c} 08 \mathrm{o}$ & $(175,0)$ & $916 \times 1807$ \\
\hline $\mathrm{c} 09 \mathrm{c}$ & $(176,274)$ & $900 \times 1470$ \\
\hline $\mathrm{c} 09 \mathrm{o}$ & $(167,0)$ & $855 \times 1843$ \\
\hline $\mathrm{c} 10 \mathrm{c}$ & $(172,0)$ & $813 \times 1914$ \\
\hline $\mathrm{c} 11 \mathrm{c}$ & $(194,0)$ & $1112 \times 1856$ \\
\hline
\end{tabular}

\begin{tabular}{|c|c|c|}
\hline Imagen & Coord. inic. & Tamaño \\
\hline \hline $\mathrm{c} 11 \mathrm{c}$ & $(184,0)$ & $1189 \times 1745$ \\
\hline $\mathrm{c} 12 \mathrm{c}$ & $(811,0)$ & $863 \times 1751$ \\
\hline $\mathrm{c} 12 \mathrm{o}$ & $(833,0)$ & $825 \times 2031$ \\
\hline $\mathrm{c} 13 \mathrm{c}$ & $(1154,27)$ & $554 \times 1629$ \\
\hline $\mathrm{c} 13 \mathrm{o}$ & $(1068,0)$ & $678 \times 1752$ \\
\hline $\mathrm{c} 14 \mathrm{c}$ & $(842,173)$ & $805 \times 1437$ \\
\hline $\mathrm{c} 14 \mathrm{o}$ & $(818,0)$ & $870 \times 1664$ \\
\hline $\mathrm{c} 15 \mathrm{c}$ & $(193,0)$ & $1155 \times 1878$ \\
\hline $\mathrm{c} 15 \mathrm{o}$ & $(173,0)$ & $1149 \times 1904$ \\
\hline $\mathrm{c} 16 \mathrm{c}$ & $(187,166)$ & $732 \times 1581$ \\
\hline $\mathrm{c} 16 \mathrm{o}$ & $(179,0)$ & $820 \times 1759$ \\
\hline $\mathrm{c} 17 \mathrm{c}$ & $(277,0)$ & $1422 \times 2048$ \\
\hline $\mathrm{c} 17 \mathrm{o}$ & $(369,0)$ & $1325 \times 1964$ \\
\hline $\mathrm{c} 18 \mathrm{c}$ & $(171,136)$ & $619 \times 1672$ \\
\hline $\mathrm{c} 18 \mathrm{e}$ & $(188,0)$ & $903 \times 2048$ \\
\hline $\mathrm{c} 18 \mathrm{o}$ & $(238,0)$ & $762 \times 2048$ \\
\hline $\mathrm{c} 19 \mathrm{c}$ & $(183,119)$ & $582 \times 1459$ \\
\hline $\mathrm{c} 18 \mathrm{o}$ & $(194,0)$ & $574 \times 1801$ \\
\hline $\mathrm{c} 20 \mathrm{c}$ & $(574,0)$ & $1108 \times 1914$ \\
\hline $\mathrm{c} 21 \mathrm{o}$ & $(561,0)$ & $1163 \times 2048$ \\
\hline
\end{tabular}

Tabla A.1: Relación entre las imágenes de las mamografías completas y la imágenes que contienen solo la zona de la mama

objetivo realizar una ecualización del ruido adaptativa para cada mamografía en función del nivel de gris, a la vez que reducir el número de bits por pixel [59, 58].

El análisis automático de imágenes reales debe considerar un modelo de ruido. En el caso de las imágenes procedentes de la digitalización de radiografías, el ruido depende del nivel de gris mismo. Si esta dependencia no se tiene en cuenta, el ajuste de la sensibilidad de los algoritmos de detección será incorrecto porque un mismo valor de una característica extraída de la imagen tendrá una significación distinta si procede de zonas con distinto nivel de gris. Para resolver este problema hay dos alternativas:

1. establecer una sensibilidad en el espacio de las características en función de la media (u otro parámetro estadístico) del nivel de gris en el espacio de la imagen.

2. reescalar la imagen para que el nivel de ruido sea constante a lo largo de los niveles de gris del margen dinámico. Karssemeijer llama a esta transformación 'iso-precision scale' [59] 
Este reescalado sólo es útil si se va a utilizar una sola característica extraída de la imagen, o si hay más de una, todas ellas tienen una dependencia del ruido en función del nivel de gris similar. Como para detectar las microcalcificaciones los procesos se basan en las características locales, el ruido que importa es el ruido de alta frecuencia, por tanto el reescalado se basa en la desviación estándar del valor de los pixels en la imagen filtrada paso alto. La imagen filtrada paso alto se llama aquí contraste local.

\section{A.3.1 Estimación del ruido de la imagen}

Dado que se pretende determinar el ruido en función del nivel de gris, la forma directa de hacerlo es tomando un conjunto de muestras uniformes con diferentes niveles de exposición. El proceso seguido para la base de datos aquí utilizada, estima el ruido a partir de la propias mamografías basándose en dos hechos:

1. que en cada imagen hay pixels que cubren todo el margen de niveles de gris de interés, $y$

2. que su estructura es tal que el número de pixels en regiones homogéneas es mucho mayor que el número de pixels en los bordes de los diferentes tejido mamarios.

Sea $y(i, j)$ el valor del pixel en la posición $(i, j)$ de la imagen, se define el contraste local $c_{i, j}$ como:

$$
c(i, j)=y(i, j)-\frac{1}{N} \sum_{m, n \in \eta(i, j)} y(m, n)
$$

con $\eta(i, j)$ el vecindario del pixel $(i, j)$ y $N$ el número de pixels que pertenecen a dicho vecindario. Normalmente este vecindario es una ventana cuadrada de tamaño $\sqrt{N} \times \sqrt{N}$.

Para mejorar la estimación de la estadística del ruido, el margen de niveles de gris posibles se divide en $K$ bins con $k=1,2, \ldots, K$, donde el número de niveles de gris de cada bin crece exponencialmente y poder obtener así una distribución más uniforme de la cantidad de pixels incluidos en cada bin. Escaneando las imágenes se calculan los histogramas de $c$ para cada bin $k$, y normalizándolos se obtienen las funciones densidad de probabilidad $f(c / k)$, resultando tener forma gaussiana. Asumiendo esta gaussianidad la estimación $\hat{s}_{c}(k)$ de la desviación estándar $s_{c}(k)$ se calcula a través de:

$$
\hat{s}_{c}^{2}(k)=r(T) \int_{c \min }^{c \max } c^{2} \hat{f}(c / k) d c
$$


donde $c$ min y cmax son los valores de truncación de la densidad estimada $\hat{f}(c / k)$ en el primer valor de $c$ en el que la densidad es inferior a un umbral $T$, comenzando desde $c=0$. Este umbral permite excluir los pixels de los bordes que son los que tienen contraste alto y no deben ser incluidos porque el elevado contraste se debe a su ubicación en un borde y no al ruido de alta frecuencia.

El factor $r(T)$ corrige que, debido a la truncación, la integral de la función densidad de probabilidad no sea igual a la unidad.

Una vez obtenido $\hat{s}_{c}(k)$ para un conjunto de bins $k$ se obtiene por interpolación la función continua $s_{c}(y)$.

\section{A.3.2 Cálculo de la Transformación}

El proceso que se pretende realizar es similar al proceso de cálculo de la transformación en una ecualización de histograma de una imagen.

Para que la desviación estándar en cada nivel de gris de la imagen transformada sea constante, hay que multiplicar por el inverso de la desviación estándar en cada nivel de gris de la imagen de entrada. Como el factor de multiplicación en la transformación $L(y)$ es la derivada, dicha transformación se obtiene resolviendo numéricamente

$$
\frac{d L(y)}{d y}=S_{r} \cdot s_{c}^{-1}(y)
$$

donde $S_{r}$ representa el nivel de ruido de la imagen transformada, y su valor permite ajustar el valor máximo de la nueva escala. Se ha elegido 255 para que las imágenes sean de ocho bits por pixel.

La figura A.1 muestra la transformación media de las calculadas para el conjunto de las cuarenta mamografías. Se han calculado tomando para el contraste local una ventana cuadrada de tamaño 9 pixels de lado y valor de umbral $T=0.05$ para la truncación en la estimación de $\hat{s}_{c}(k)$.

\section{A.4 Diagnóstico médico de cada mamografía}

La base de datos de imágenes está acompañada por un fichero ascii para cada mamografía en el que se plasma el diagnóstico médico en el que se indican la zona o zonas en las que los radiólogos expertos han dictaminado que existen clusters 


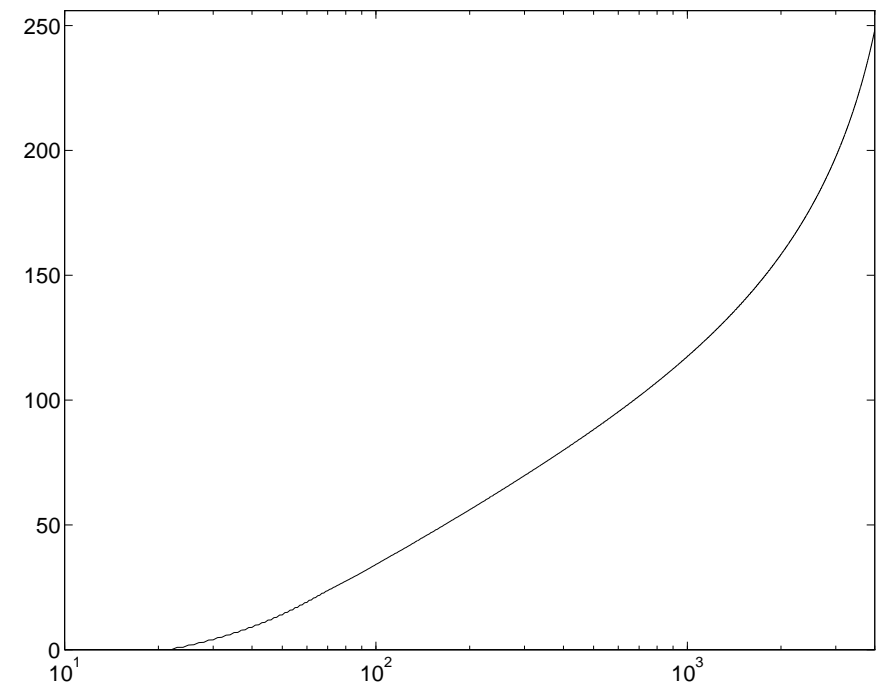

Figura A.1: Media de la transformación $L(y)$ calculada para cada una de las cuarenta mamografías

de microcalcificaciones consistente en circunferencias que encierran cada uno de ellos. El formato del fichero ascii consiste en un encabezamiento con un número $n$ indicando la cantidad de clusters que contiene la mamografía seguido de $n$ líneas cada una con tres números, los dos primeros son las coordenadas $x, y$ del centro de la circunferencia y el tercero el radio. Todas las cifras son en pixels. Durante la presentación de los resultados, en las imágenes que ilustran los clusters detectados por los procesos propuestos se superponen las circunferencias correspondientes al diagnóstico médico, tal como ilustra la figura siguiente (fig. A.2). 


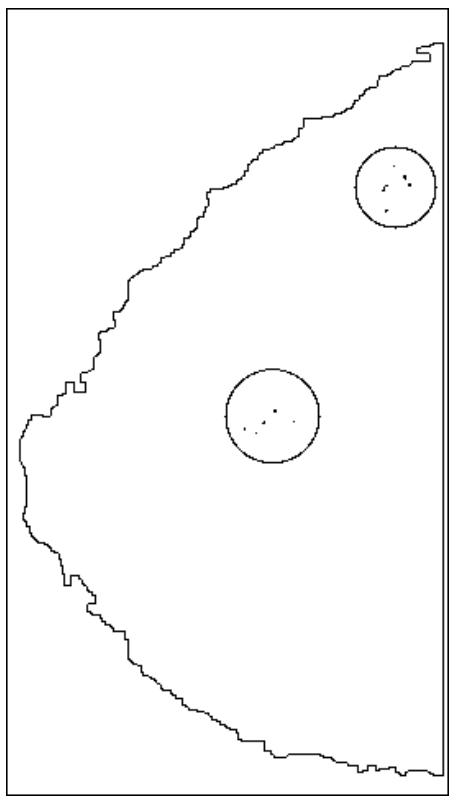

Figura A.2: Ejemplo de cómo se ilustra sobre las imágenes el diagnóstico médico. 


\section{Anexo B}

\section{Ejemplos de Mamografías}

Las siguientes páginas de este Anexo muestran las imágenes z02c, z14c y z19c, utilizadas como ejemplos ilustrativos en la mayor parte de las secciones del capítulo de resultados, a página completa y en papel fotográfico para poder apreciar mejor los detalles. En las fotografías se muestra sólo el área de la mama y no la mamografía completa para aprovechar mejor el espacio y ofrecer más detalle. Para ilustrar la situación de cada imagen dentro la mamografía completa se muestra a continuación la figura B.1, impresa en papel normal, con la tres mamografías completas reducidas en tamaño y con un recuadro en cada una indicando la zona de interés.

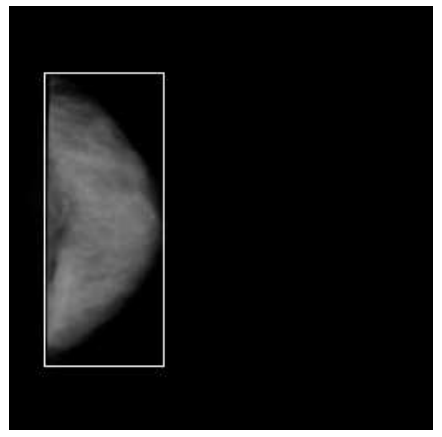

a) $\mathrm{c} 02 \mathrm{c}$

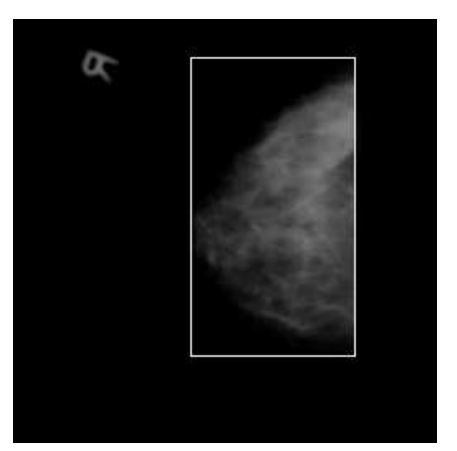

b) $\mathrm{c} 14 \mathrm{c}$

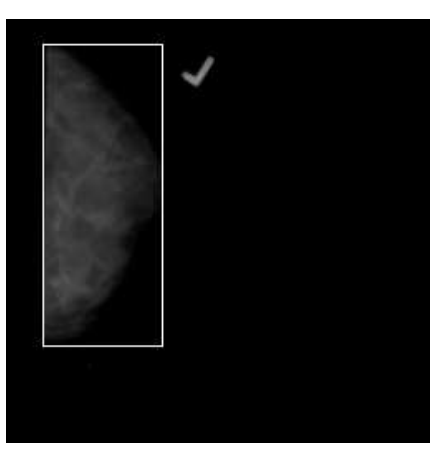

c) $\mathrm{c} 19 \mathrm{c}$

Figura B.1: Figura que muestra las mamografías completas con un recuadro en su interior indicando el área de interés seleccionada correspondiente a la mama. 


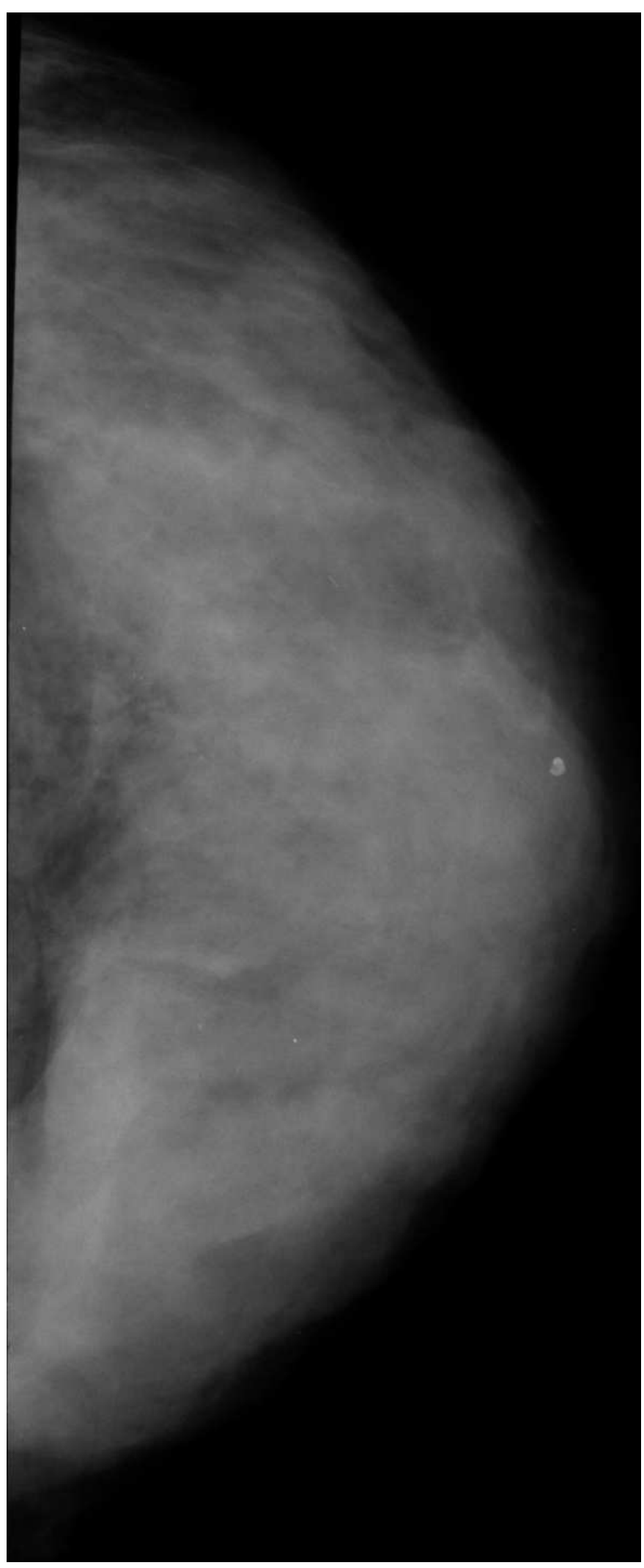

Figura B.2: Mamografía c02c. 


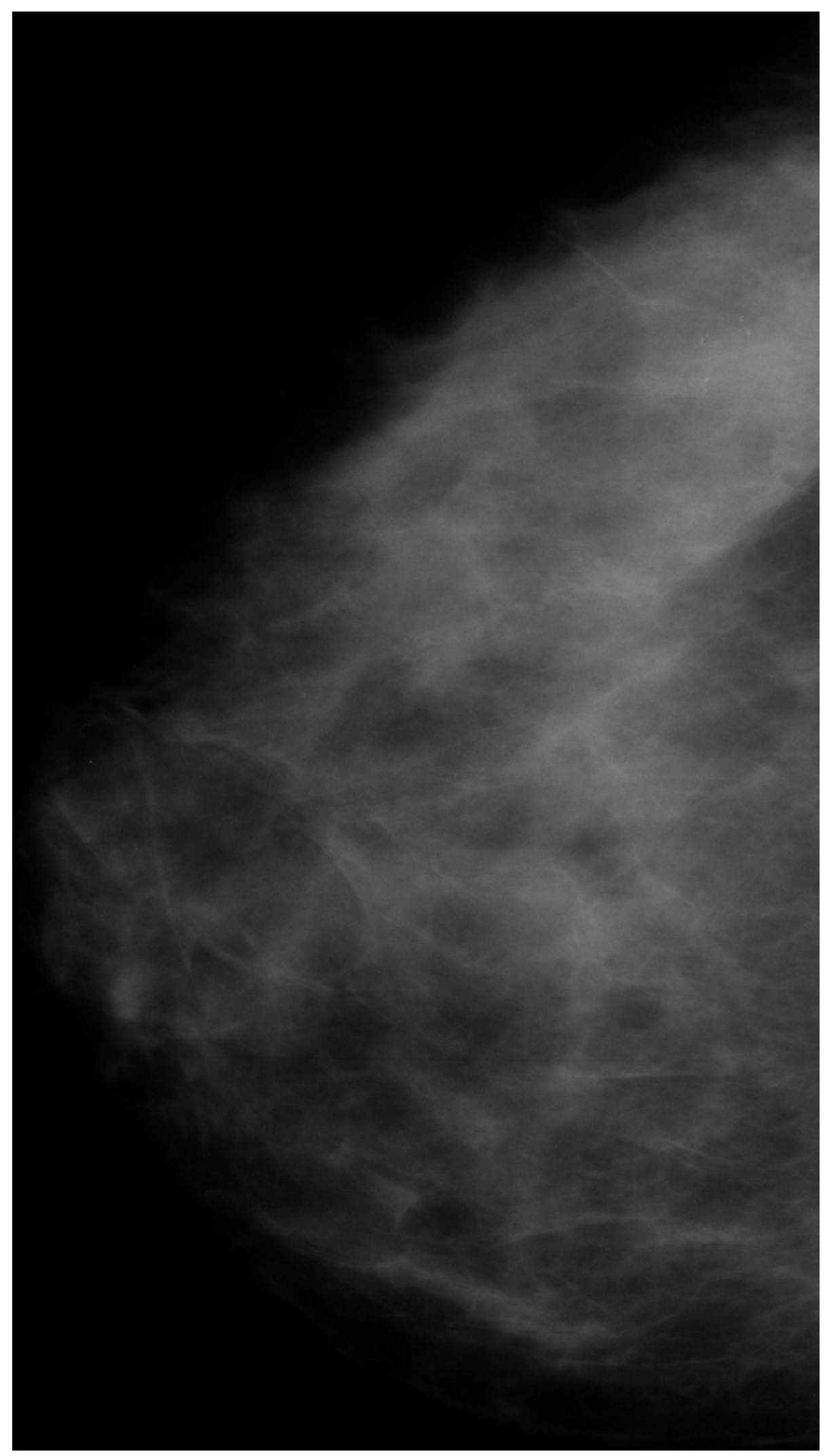

Figura B.3: Mamografía c14c. 


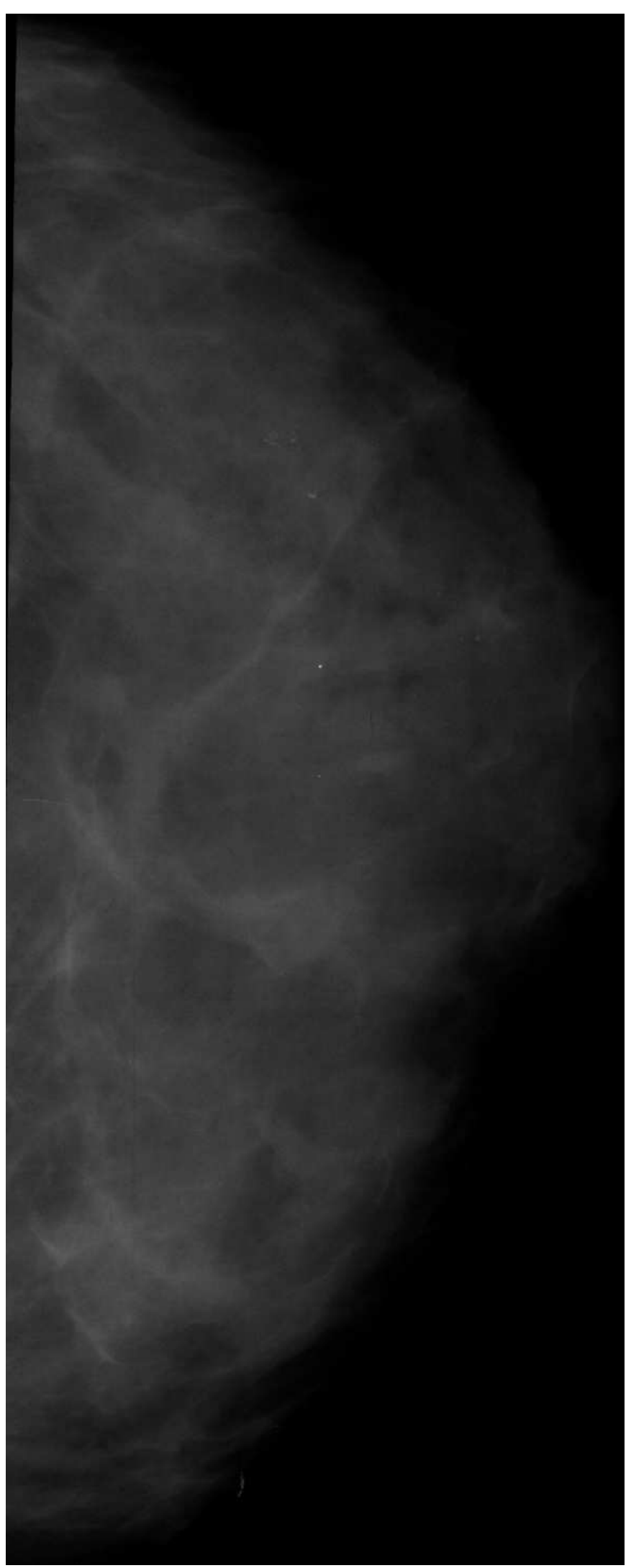

Figura B.4: Mamografía c19c. 


\section{Índice de Figuras}

1.1 Representación esquemática de la anatomía básica de la mama. Se aprecia el patrón ramificado de las glándulas a partir del pezón. Entremezclado con él están el resto de tejidos. Adaptado de [68] . 7

1.2 Microcalcificaciones secretorias ductales. Su aspecto es cilíndrico macizo. Benignas. Adaptado de [68] . . . . . . . . . . . . . . 9

1.3 Microcalcificaciones lobulares malignas. Son irregulares en forma y tamaño. Adaptado de [68] . . . . . . . . . . . . . . . . . 10

1.4 Microcalcificaciones lobulares benignas. Su aspecto es redondeado y su ubicación dispersa, en ocasiones aparecen varios grupos próximos entre sí. Adaptado de [68] . . . . . . . . . . . . . . . 10

1.5 Microcalcificaciones ductales malignas. Su aspecto es lineal con bordes irregulares y algunas presentan ramificaciones. Adaptado de $[68] \ldots \ldots \ldots \ldots \ldots \ldots \ldots$

1.6 Realización de una mamografía. Proyección craneo-caudal. Adap-

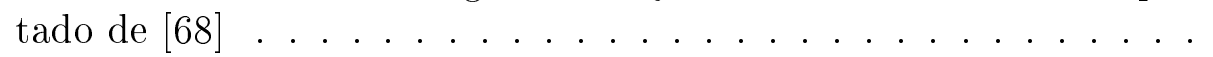

1.7 Diagrama de digitalización de la imagen mamográfica. a) dispositivo basado en láser. La resolución está determinada por el tamaño del haz láser; b) dispositivo basado en CCD lineal. La resolución está determinada por el tamaño de los sensores individuales dentro del array lineal. . . . . . . . . . . . . . . . . .

2.1 Diagrama del detector [61]. Sigue un planteamiento frecuente en la literatura referente a la detección de las microcalcificaciones al dividir el proceso en dos partes. En particular, en [61] la primera parte genera tres imágenes y a partir de ellas la etapa de segmentación genera el resultado. . . . . . . . . . . . . 17

2.2 Área bajo ROC. . . . . . . . . . . . . . . . . . 27 
3.1 Vecindarios de un pixel según el orden. . . . . . . . . . . . . . 43

3.2 Cliques posibles en los vecindarios de orden 1 y orden $2 . \quad$. . . . 44

3.3 Ejemplo de campo aleatorio compuesto . . . . . . . . . . . . . . . 49

3.4 a) Imagen cuacir con valores de objeto y fondo 0.4 y 0.6 respectivamente; b) imagen formas. . . . . . . . . . . . . . . 62

3.5 Imagen cuacir con diferentes niveles para el fondo y el objeto; la primera columna de $a$ y $b$ corresponde a las imágenes sin ruido, las segundas columnas a las imágenes con ruido y las terceras al etiquetado según la estimación de máxima verosimilitud (MLE). .

3.6 Representación de las funciones gaussianas utilizadas para la imagen cuacir. Debajo de cada gráfica figuran los valores para las dos medias utilizadas en cada caso. Se puede observar el solapamiento creciente entre ambas funciones. . . . . . . . . . . . . . 66

3.7 Imagen formas con diferentes niveles para cada uno de los seis tipos de regiones; la primera columna de $a$ y $b$ corresponde a las imágenes sin ruido, las segundas columnas a las imágenes con ruido y las terceras al etiquetado según la estimación de máxima verosimilitud (MLE). . . . . . . . . . . . . . .

3.8 Resultados de los cuatro primeros casos de la imagen cuacir; a) la primera columna de $a$ corresponde a las imágenes sin ruido, la segunda columna a las imágenes con ruido y la tercera al etiquetado según la estimación de máxima verosimilitud (MLE); b) primera columna resultado del etiquetado alcanzado con ICM, segunda columna con $\mathrm{HCF}$ y tercera columna con BHCF. . . . . . . . . .

3.9 Resultados de los cuatro segundos casos de la imagen cuacir; a) la primera columna de $a$ corresponde a las imágenes sin ruido, la segunda columna a las imágenes con ruido y la tercera al etiquetado según la estimación de máxima verosimilitud (MLE); b) primera columna resultado del etiquetado alcanzado con ICM, segunda columna con HCF y tercera columna con BHCF. . . . . . . . . .

3.10 Gráfica con los ratios de pixels etiquetados incorrectamente de los casos presentados en la tabla 3.4. La curva de trazo continuo corresponde al MLE, en trazo discontinuo y con 'o' el ICM, en trazo de puntos y con ' + ' el HCF; y en trazo de puntos y rayas y con '*' el BHCF 
3.11 Resultados de los cuatro primeros casos de la imagen formas; a) la primera columna de $a$ corresponde a las imágenes sin ruido, la segunda columna a las imágenes con ruido y la tercera al etiquetado según la estimación de máxima verosimilitud (MLE); b) primera columna resultado del etiquetado alcanzado con ICM, segunda columna con HCF y tercera columna con BHCF. . . . . . . . .

3.12 Resultados de los cuatro segundos casos de la imagen formas; a) la primera columna de $a$ corresponde a las imágenes sin ruido, la segunda columna a las imágenes con ruido y la tercera al etiquetado según la estimación de máxima verosimilitud (MLE); b) primera columna resultado del etiquetado alcanzado con ICM, segunda columna con HCF y tercera columna con BHCF. . . . . . . . . .

3.13 Gráfica con los ratios de pixels etiquetados incorrectamente de los casos presentados en la tabla 3.5. La curva de trazo continuo corresponde al MLE, en trazo discontinuo y con 'o' el ICM, en trazo de puntos y con ' + ' el HCF; y en trazo de puntos y rayas y con ${ }^{\prime *}$, el BHCF.

4.1 Relieve tridimensional y cortes con planos horizontales para formar imágenes binarias en cada nivel de gris. . . . . . . . . . . . 77

4.2 Subgrafo de un función. . . . . . . . . . . . . . . . 78

4.3 Ejemplos de celosía rectangular. a) Conectividad a 4 . b) Conectividad a $8 \ldots \ldots \ldots \ldots \ldots \ldots$

4.4 Celosía hexagonal. . . . . . . . . . . . . . . .

4.5 Componentes conexas. a) Celosía rectangular con conectividad a 4. Los pixels objeto forman tres componentes conexas distintas y también el fondo queda dividido en tres componentes conexas. b) Considerando conectividad a 8 para el fondo, éste forma una única componente conexa. c) Con conectividad a 8 hay una única componente para el objeto y otra para el fondo superponiéndose en algunas zonas. d) No hay superposición si se considera conectividad a 4 para el fondo, quedando dividido en tres componentes conexas. e) Celosía hexagonal. En este caso existe coherencia para objeto y fondo manteniendo para ambos la misma conectividad a $6 \ldots \ldots \ldots \ldots \ldots \ldots$

4.6 Dilatación y erosión de una imagen binaria. El elemento estructurante utilizado está recuadrado en la imagen original. . . . . . . 
4.7 Dilatación y erosión de una función por un elemento estructurante plano. . . . . . . . . . . . . . . . . 85

4.8 Apertura y cierre de una imagen binaria. El elemento estructurante utilizado está recuadrado en la imagen original. . . . . . . . 87

4.9 Apertura y cierre de una función. En a) está en gris claro la parte de la función que elimina la apertura y en b) está en gris oscuro la parte que aparece debida al cierre. . . . . . . . . . . . . . 88

4.10 Filtros morfológicos por combinación de transformaciones en paralelo. . . . . . . . . . . . . . . . . . . .

4.11 Ejemplo de aplicación de filtros morfológicos por combinación de transformaciones en paralelo. La transformación en su conjunto extrae de la imagen de entrada sólo las componentes con orientaciones horizontales y verticales, utilizando aperturas con elementos estructurantes en dichas orientaciones y combinando los resultados mediante el supremo. . . . . . . . . . . . . . . . . .

4.12 Familia de transformaciones basada en la diferencia entre transformaciones. . . . . . . . . . . . . . . . . . . 90

4.13 Reconstrucción geodésica binaria. La dilatación geodésica hasta la idempotencia permite recuperar exactamente las componentes de la máscara geodésica marcadas por la imagen marcador. . . . .

4.14 Reconstrucción geodésica de una función. a) Dilatación geodésica de tamaño 1 de $f$ con referencia $f_{M}$. b) Reconstrucción geodésica de $f_{M}$ con $f$ como marcador. . . . . . . . . . . . . . . . . . . . . 94

4.15 Transformaciones con reconstrucción. a) Original; b) apertura con el elemento estructurante recuadrado en el original; c) Apertura con reconstrucción tomando como imagen máscara la original y marcador la apertura. Nótese como en la apertura con reconstrucción la componente que permanece a la salida no ha perdido la forma a pesar de que hay zonas en las que no cabe el elemento estructurante y como consecuencia de ello en una apertura como la de la figura $b$ la forma queda modificada. Si hay componentes conexas en las que no cabe el elemento estructurante éstas desaparecen completamente tanto en una apertura como en una apertura con reconstrucción, tal como sucede con el círculo pequeño. . . . . 
4.16 Extremos de una imagen de niveles de gris. Se pueden distinguir planicies que forman mesetas, valles o ninguna de las dos cosas. Las mesetas y los picos forman los máximos regionales. Los valles formados por un único pixel o por varios forman los mínimos regionales. Los máximos regionales y los mínimos regionales forman los extremos de la imagen. . . . . . . . . . . . . . . . . 97

4.17 Extracción de los máximos regionales de una imagen $f$ por reconstrucción de $f$ a partir de $(f-1) \ldots \ldots . \ldots . \ldots 98$

4.18 Diferencia simétrica entre dos imágenes binarias . . . . . . . . . 100

4.19 Operador conexo binario . . . . . . . . . . . . . . . . . 100

4.20 Operador conexo de niveles de gris. a) Operador conexo, todas las planicies se mantienen como tales a la salida. La transformación ha fusionado las dos planicies no extremas de la entrada; b) Operador no conexo. La planicie mayor de la entrada ha generado dos planicies a la salida . . . . . . . . . . . . . . . . . 102

4.21 Proceso de inundación de un relieve topográfico. a) El agua penetra por los mínimos y alcanza el mismo nivel en todos los valles. b) Si se introduce por cada mínimo agua coloreada de forma diferente, en cada mínimo se pueden mantener identificados los pixels que pertenecen a la cuenca asociada a cada mínimo. . . . . . . . 103

4.22 Proceso de inundación y determinación de la línea divisoria de aguas105

4.23 Proceso de inundación y relación con el cálculo del cierre superficial. El nivel de gris mínimo de los pixels de una cuenca en la función de salida corresponde con el nivel de inundación en el que la cuenca alcanza una determinada superficie. Figuras a) a e): distintos instantes en el proceso de inundación; f) función de salida.107

4.24 Proceso de inundación y propagación de las etiquetas desde los mínimos hacia sus vecinos. Figuras a) a f) corresponden con niveles de inundación crecientes. La etiqueta que recibe cada pixel aparece sobre la parte inferior del gráfico y también a la altura de su nivel de gris. . . . . . . . . . . . . . . . . . . . . 108

4.25 Utilización de colas jerárquicas para etiquetar los pixels en el cálculo del cierre superficial. La etiqueta E significa en espera y la C en cola. . . . . . . . . . . . . . . . . . . . . . . . . 111 
4.26 Necesidad de la etiqueta en-cola. En este ejemplo si no se hubiera utilizado la etiqueta en-cola el pixel 11 hubiera sido puesto en la cola 2 veces. . . . . . . . . . . . . . . . . . . . . . . 112

4.27 Cierre superficial. Pixels de las cuencas asociadas a los mínimos de la función antes de alcanzar la línea divisoria de aguas. Algunas cuencas pueden no haber alcanzado la superficie mínima $\lambda$ requerida en el cierre superficial. Por ejemplo para $\lambda=6$ las cuencas 5,3 y 2 tienen una superficie menor que $\lambda$. . . . . . . . 114

4.28 Etiquetado en el cierre superficial. Se fusionan dos cuencas y ninguna de ellas había alcanzado la superficie de valor $\lambda$. a) Antes de alcanzar el nivel de fusión. b) Después de alcanzar el nivel de fusión. c) Alcanzan la superficie de valor $\lambda$.

Los nombres de los campos de datos son: $S$ superficie; $g_{c}$ altura (nivel de gris en el que se alcanza la superficie de valor $\lambda$ ); $N_{f}$ nivel de fusión; Eq etiqueta de la cuenca con la que se ha fusionado (si no se ha fusionado con ninguna contiene la etiqueta de la propia cuenca). ...................... . . . . . . . . . . . .

4.29 Etiquetado en el cierre superficial. Se fusionan dos cuencas y alguna de ellas había alcanzado la superficie de valor $\lambda$. a) Antes de alcanzar el nivel de fusión. b) Después de alcanzar el nivel de fusión. c) Nivel de inundación superior al de fusión. . . . . . . . . 118

4.30 Cierre superficial. Proceso final de obtener el nivel de gris en la imagen de salida tras finalizar el proceso de etiquetado. a) Etiquetado de la función y contenido de las estructuras de datos resultante al finalizar; b) Niveles de gris de la función resultante del cierre superficial junto con los valores $g_{c}$ y $N_{f}$ a lo largo de la cadena de equivalencias de cada cuenca. . . . . . . . . . . . . . 120

5.1 Imagen z01c con tres zonas ampliadas correspondientes a lo recuadros. La última columna corresponde a imágenes binarias que en negro indican los clusters de microcalcificaciones marcados por los radiólogos . . . . . . . . . . . . . . . . . . 122 
5.2 a) Imagen z01c reducida en tamaño por dos, con dos zonas marcadas ampliadas en $b$ y $c$. b) corresponde al recuadro inferior, subimagen de 200x200 a partir del pixel $(480,500)$ ampliado en contraste por cuatro. Se aprecia un grupo de tres áreas pequeñas claras. Ha sido marcado por los radiólogos como cluster de microcalcificaciones. c) corresponde al recuadro superior, subimagen de 200x200 a partir del pixel $(420,320)$ ampliado en contraste por cuatro. Se aprecian dos áreas pequeñas claras. No ha sido marcado por los radiólogos como microcalcificaciones . . . . . . . 124

5.3 a) Imagen z03c completa reducida en tamaño por dos; b) Ampliación de la zona marcada por el recuadro superior, aumentada por cuatro en contraste, en la que si se han detectado microcalcificaciones; c) Ampliación de la zona marcada por el recuadro inferior, aumentada por cuatro en contraste, en la que se puede apreciar la existencia de fibras estrechas.

5.4 a) subimagen $(400 \times 400)$ de la mamografía z11o a partir del pixel (400,1080), ampliado en contraste por dos para una mejor visualización. b) y c) resultado del Top-Hat con un elemento estructurante circular de diámetro 9 y otro cuadrado de lado 9 respectivamente. Para una mejor visualización se han multiplicado por 10 y se han invertido las imágenes $b$ y $c \ldots \ldots . \ldots \ldots$

5.5 Histograma de los pixels fondo (trazo continuo) y aproximación gaussiana (trazo discontinuo) del resultado del Top-Hat con elemento estructurante cuadrado de tamaño 9. a) representación con eje de ordenadas lineal y b) representación con eje de ordenadas logarítmico . . . . . . . . . . . . . . . . 13

5.6 Histograma de los pixels microcalcificación (trazo continuo) y aproximación gaussiana (trazo discontinuo) del resultado del Top-Hat con elemento estructurante cuadrado de tamaño 9. a) representación con eje de ordenadas lineal y b) representación con eje de ordenadas logarítmico . . . . . . . . . . . . . . 138

5.7 Histograma de los pixels emulsión (trazo continuo) y aproximación gaussiana (trazo discontinuo) del resultado del Top-Hat con elemento estructurante cuadrado de tamaño 9. a) representación con eje de ordenadas lineal y b) representación con eje de ordenadas

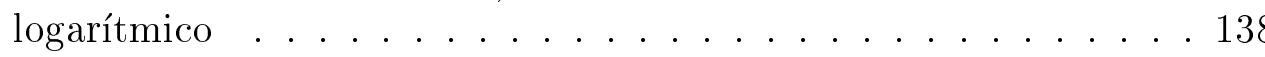

5.8 Residuo del fondofibra de la imagen de la figura 5.4a, multiplicado por 10 e invertido. 
5.9 Histograma de los pixels fondo (trazo continuo) y aproximación (trazo discontinuo) del resultado del residuo del fondofibra con elemento estructurante de tamaño 9. a) representación con eje de ordenadas lineal y b) representación con eje de ordenadas logarítmico141

5.10 Histograma de los pixels microcalcificación (trazo continuo) y aproximación gaussiana (trazo discontinuo) del resultado del residuo del fondofibra con elemento estructurante de tamaño 9. a) representación con eje de ordenadas lineal y b) representación con eje de ordenadas logarítmico . . . . . . . . . . . . . . 141

5.11 Histograma de los pixels emulsión (trazo continuo) y aproximación gaussiana (trazo discontinuo) del resultado del residuo del fondofibra con elemento estructurante de tamaño 9. a) representación con eje de ordenadas lineal y b) representación con eje de ordenadas logarítmico . . . . . . . . . . . . . . . . 142

5.12 Residuo del fondofibra con reconstrucción de la imagen de la figura $5.4 a$, multiplicado por 10 e invertido. . . . . . . . . . . . . 144

5.13 Histograma de los pixels fondo (trazo continuo) y aproximación (trazo discontinuo) del resultado del residuo del fondofibra con reconstrucción con elemento estructurante de tamaño 9. a) representación con eje de ordenadas lineal y b) representación con eje de ordenadas logarítmico . . . . . . . . . . . . . . . 145

5.14 Histograma de los pixels microcalcificación (trazo continuo) y aproximación (trazo discontinuo) del resultado del residuo del fondofibra con reconstrucción con elemento estructurante de tamaño 9. a) representación con eje de ordenadas lineal y b) representación con eje de ordenadas logarítmico . . . . . . . . . . . . . . . . 146

5.15 Histograma de los pixels emulsión (trazo continuo) y aproximación gaussiana (trazo discontinuo) del resultado del residuo del fondofibra con elemento estructurante de tamaño 9. a) representación con eje de ordenadas lineal y b) representación con eje de ordenadas logarítmico . . . . . . . . . . . . . . . . . 146

6.1 Histograma de tamaño del eje mayor de las microcalcificaciones de grupo de imágenes de entrenamiento. . . . . . . . . . . . . . 149 
6.2 Perfil de las microcalcificaciones. Extracción de las microcalcificaciones grandes con un elemento estructurante menor que su tamaño. a) Porción de 200x200 pixels de la mamografía z08o. b) Ampliación por 8 respecto a la escala de la porción de la zona marcada en a correspondiente a la microcalcificación más grande de la porción; c) perfil de los niveles en la dirección principal de la microcalcificación; la curva superior corresponde a los niveles de gris de la mamografía original y la curva inferior a los niveles del residuo del fondofibra con reconstrucción. . . . . . . . . . . . . . 150

6.3 Las figuras $a, b, c$ muestran en negro los pixels que en la inicialización han sido etiquetados como microcalcificación con los parámetros de la tabla 6.1 Las figuras $d, e, f$ muestran el resultado al finalizar el algoritmo. Se observa en el resultado una reducción importante de los falsos positivos, mientras que los verdaderos positivos permanecen. . . . . . . . . . . . . . . . . 15

6.4 Las figuras $a, b, c$ muestran en negro los pixels que en la inicialización han sido etiquetados como microcalcificación con $\alpha_{c}=5.5$. Las figuras $d, e, f$ muestran el resultado al finalizar el algoritmo. Se ve la reducción de pixels etiquetados como microcalcificación y de verdaderos y falsos positivos respecto a la inicialización, pero en estas imágenes $d$ y $e$ hay más falsos positivos que en $6.3 d$ y $e . \quad .155$

6.5 Las figuras $a, b, c$ muestran en negro los pixels que en la inicialización han sido etiquetados como microcalcificación con $\alpha_{c}=7.5$. Las figuras $d, e, f$ muestran el resultado al finalizar el algoritmo. Se ve la reducción de pixels etiquetados como microcalcificación, y de verdaderos y falsos positivos. Se pierde el verdadero positivo inferior de la mamografía z14c. Al comparar esta figura con la anterior se observa que el resultado depende de la inicialización.

6.6 La gráfica superior indica el ratio de verdaderos positivos y la inferior el número de falsos positivos por imagen, tras 8 iteraciones, ambas en función del valor de $\alpha_{c}$. . . . . . . . . . . . . . . . 158

6.7 Las figuras $a, b, c$ muestran en negro los pixels que en la inicialización han sido etiquetados como microcalcificación con $\alpha_{e}=6$ y las figuras $d, e, f$ muestran el resultado al finalizar el algoritmo. Obsérvese que en la imagen $d$ hay un falso positivo menos que en

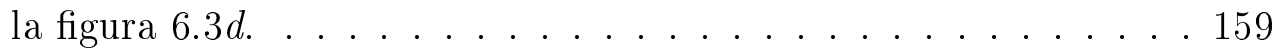


6.8 Las figuras $a, b, c$ muestran en negro los pixels que en la inicialización han sido etiquetados como microcalcificación con $\alpha_{e}=14$. El resultado tras 8 iteraciones del algoritmo se presenta en las figuras $d, e, c$. Obsérvese que en $d$ aparece un falso positivo más que en $6.7 d \ldots \ldots \ldots$. . . . . . . . . . . . . . . 160

6.9 La gráfica superior indica el ratio de verdaderos positivos y la inferior el número de falsos positivos por imagen, ambas en función del valor de $\alpha_{e} \ldots \ldots \ldots$. . . . . . . . . . . . . . . . . . . . . 161

6.10 Las figuras muestran en negro los pixels que han sido etiquetados como microcalcificación al finalizar el algoritmo (8 iteraciones) con los valores de $\beta_{b c}$ indicados. Se observa una mayor presencia de regiones de un pixel en las figuras $a, b, c$ debido al valor bajo de $\beta_{b c} .162$

6.11 La figura a muestra la inicialización para la mamografía z01o con $\alpha_{c}=6.5$ y $\alpha_{e}=7$. Las figuras $b$ y $c$ muestran la ampliación del resultado del algoritmo tras 8 iteraciones del recuadro marcado en a para los valores de $\beta_{c e}=0.0 \mathrm{y} \beta_{c e}=3.0$, respectivamente. Obsérvese que en la figura $b$ la microcalcificación queda segmentada irregularmente. El tamaño del recuadro corresponde en pixels a 48x106 con origen en el pixel $(288,796) \ldots$. . . . . . . . . . 163

6.12 La figura muestra en negro los pixels que han sido etiquetados como microcalcificación al finalizar el algoritmo (8 iteraciones) con los valores de $\gamma(c)$ indicados. Se observa que para el valor mayor de $\gamma(c)$ la tendencia a formar clusters de microcalcificaciones es mayor, al mismo tiempo que se reducen los falsos positivos. . . . . 165

6.13 La gráfica superior indica el ratio de verdaderos positivos y la inferior el número de falsos positivos por imagen, ambas en función

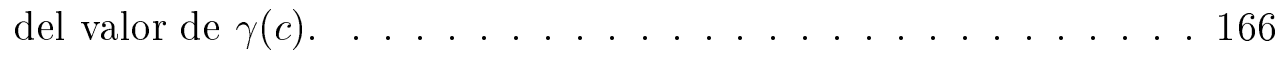

6.14 Las figuras $a, b, c$ muestran el resultado tras 8 iteraciones con un valor de $h_{\max }=16$. Se observa claramente el efecto de sobrecrecimiento de los clusters de microcalcificación. . . . . . . . . . 167

6.15 Evolución con el número de iteraciones. . . . . . . . . . . . . . . 169

6.16 La gráfica superior indica el ratio de verdaderos positivos y la inferior el número de falsos positivos por imagen, ambas en función del número de iteraciones. . . . . . . . . . . . . . . . 170 
6.17 Los pixel en negro corresponden a los etiquetados como microcalcificación para el operador Top-Hat. Las figuras $a, b, c$ corresponden a la inicialización y las figuras $d, e, f$ al resultado. Con la sensibilidad utilizada se alcanzan unos resultados para el conjunto de las treinta imágenes de: ratio de verdaderos positivos $=0.8$, falsos positivos por imagen $=5.9 \ldots \ldots \ldots \ldots \ldots$

6.18 Detalle del resultado sobre partes fibrosas de la mamografía; a) mamografía z14c donde se ha marcado una porción de 300x300 pixels con origen en $(460,950)$; b) detalle marcado en a, ampliado respecto a $a$ en tamaño por 3 y en contraste también por 3 ; c) detalle del resultado de la segmentación, donde se observan los dos falsos positivos. . . . . . . . . . . . . . . . 173

6.19 Curva "Response Operating Characteristics" de los resultados del operador Top-Hat y el modelo de campo aleatorio de Markov.

6.20 Los pixels en negro corresponden a los etiquetados como microcalcificación para el operador Residuo fondofibra. Las figuras $a, \mathrm{~b}$, c corresponden a la inicialización y las figuras $d, e, f$ al resultado. Con la sensibilidad utilizada se alcanzan unos resultados para el conjunto de las treinta imágenes de: ratio de verdaderos positivos $=0.84$, falsos positivos por imagen $=1.13 \ldots \ldots \ldots$

6.21 Detalle del fondofibra sobre z14c. En a aparece la misma porción de z14c que en 6.21 ; b) corresponde a la apertura con cuadrado de tamaño 9 y c) al fondofibra. En d) y e) se presentan respectivamente los residuos de $b$ y $c \ldots \ldots \ldots \ldots$

6.22 Detalle del fondofibra sobre z18o. En a mamografía completa con la zona de interés marcada por el recuadro; b) ampliación de la zona marcada en $a$; c) apertura con cuadrado de tamaño 9; d) fondofibra; e) y f) corresponden respectivamente a los residuos; g) y h) presentan el resultado final. Dado que en la zona marcada los radiólogos no han indicado presencia de microcalcificaciones, el resultado correcto es el del fondofibra. . . . . . . . . . . . . . 178

6.23 Curva "Response Operating Characteristics" de los resultados del operador fondofibra sin el modelo campo aleatorio de Markov (clasificación como microcalcificación según Maximum Likelihood Estimate) (+) y con el modelo de campo aleatorio de Markov (o) . . 180 
6.24 Detalle de un falso positivo con el fondofibra sobre z18o. En $a$ mamografía completa con la zona de interés marcada por el recuadro; b) ampliación de la zona marcada en $a$; c) fondofibra con EE de tamaño 9; d) corresponde al residuo y e) presentan el resultado final. Dado que en la zona marcada los radiólogos no han indicado presencia de microcalcificaciones, las microcalcificaciones marcadas son falsos positivos. . . . . . . . . . . . . 181

6.25 Los pixels en negro corresponden a los etiquetados como microcalcificación para el operador Residuo fondofibra con reconstrucción. Las figuras $a, b, c$ corresponden a la inicialización y las figuras $d$, $e, f$ al resultado. Con la sensibilidad utilizada se alcanzan unos resultados para el conjunto de las treinta imágenes de: ratio de verdaderos positivos $=0.88$, falsos positivos por imagen $=1.13 \ldots 184$

6.26 Detalle del fondofibra con reconstrucción sobre z02c. a) mamografía completa con la zona de interés marcada por el recuadro; b) ampliación x12 de la zona marcada en $a$; c) fondofibra con reconstrucción; d) residuo; e) resultado del algoritmo ICM tras 8 iteraciones . . . . . . . . . . . . . . . . . 185

6.27 Detalle del fondofibra con reconstrucción sobre z19c. a) mamografía completa con la zona de interés marcada por el recuadro; b) ampliación x12 de la zona marcada en $a$; c) fondofibra con reconstrucción; d) residuo; e) resultado del algoritmo ICM tras 8 iteraciones . . . . . . . . . . . . . . . 186

6.28 Detalle del fondofibra con reconstrucción sobre z18o. En $a b$ y $c$ reproducción de las figuras $6.24 b, c$ y $d$ para facilitar la comparación. d) resultado del algoritmo ICM tras 8 iteraciones aplicado sobre el residuo con reconstrucción. e) fondofibra con reconstrucción; f) residuo del fondofibra con reconstrucción. . . . . . . . . . . . . . 187

6.29 Detalle del fondofibra con reconstrucción sobre z11c. a) mamografía completa con la zona de interés marcada por el recuadro; h) ampliación x12 en tamaño y en contraste x4 de la zona marcada en $a$; b) fondofibra de la zona marcada; c) residuo fondofibra; d) resultado del algoritmo ICM tras 8 iteraciones sobre el residuo del fondofibra; e) fondofibra con reconstrucción de la zona marcada; f) residuo del fondofibra con reconstrucción; g) resultado del algoritmo ICM tras 8 iteraciones sobre el residuo del fondofibra con reconstrucción; i) diferencia (multiplicada por 40) entre los residuos.188 
6.30 Curva ROC de los resultados del residuo del fondofibra con reconstrucción sin el modelo campo aleatorio de Markov (clasificación como microcalcificación según Maximum Likelihood Estimate) (+) y con el modelo de campo aleatorio de Markov (o). Se observa el importante aumento del ratio de verdaderos positivos para los distintos valores de falsos positivos por imagen al utilizar el modelo de campo aleatorio. Para poder comparar se reproduce la curva (puntos) de la figura 6.23 correspondiente al caso sin reconstrucción.190

6.31 Influencia de las imágenes z12c y z12o. Curvas ROC del residuo fondofibra con reconstrucción y el modelo de campo aleatorio de Markov. (o) Conjunto de test; (+) Conjunto de test excluyendo z12c y z12o. . . . . . . . . . . . . . . . . . . . . 192

6.32 Detalle de falsos positivos y falsos negativos. La primera fila corresponde a imágenes en niveles de gris de porciones de mamografías donde incluso a niveles bajos de sensibilidad aparecen falsos positivos. La segunda fila ilustra los respectivos resultados. En la tercera fila se presentan porciones de mamografías donde incluso a sensibilidades altas no se detectan los clusters marcados. Se puede apreciar que en los casos de la primera fila, marcados por los radiólogos como negativos, se aprecian con mayor nitidez objetos tipo microcalcificación, que en los casos de la tercera fila, marcados por los radiólogos con una circunferencia como positivos. 193

6.33 Detalle de la eliminación de picos aislados utilizando la apertura superficial sobre z04o. a) mamografía completa con la zona de interés marcada por el recuadro; b) ampliación x12 de la zona marcada en $a$, donde a su vez se recuadra una pequeña zona; c) residuo del fondofibra con reconstrucción; d) eliminación de picos aislados de $c$; e) resultado del algoritmo tomando como entrada $c$; f) resultado del algoritmo tomando como entrada $d$. En $f$ se evita el cluster falso positivo porque no aparece la segunda microcalcificación. . . . . . . . . . . . . . . . . . . . . . 198 
6.34 Detalle de la conservación de picos superpuestos a regiones potencialmente microcalcificación sobre la mamografía z12c. a) mamografía completa con la zona de interés marcada por el recuadro; b) ampliación x12 de la zona marcada en $a$; c) residuo del fondofibra con reconstrucción; d) eliminación de picos aislados de $c$, se observa que muchos de los máximos regionales se conservan sobre pequeñas regiones de un cierto nivel; e) resultado del algoritmo tomando como entrada $c$; f) resultado del algoritmo tomando como entrada $d$. En $f$ se consigue seguir detectando el verdadero positivo gracias a que se han restaurado los máximos. . . . . . . . 199

6.35 Curva ROC de los resultados del residuo del fondofibra con reconstrucción con eliminación de picos aislados y con el modelo campo aleatorio de Markov (o). Para poder comparar se reproduce la curva (trazos) de la figura 6.30 correspondiente al residuo del fondofibra con reconstrucción y la figura 6.23 correspondiente al residuo del fondofibra sin reconstrucción (puntos). . . . . . . . 201

A.1 Media de la transformación $L(y)$ calculada para cada una de las cuarenta mamografías . . . . . . . . . . . . . . 213

A.2 Ejemplo de cómo se ilustra sobre las imágenes el diagnóstico médico.214

B.1 Figura que muestra las mamografías completas con un recuadro en su interior indicando el área de interés seleccionada correspondiente a la mama. . . . . . . . . . . . . . . . . . 215

B.2 Mamografía c02c. . . . . . . . . . . . . 216

B.3 Mamografía c14c. . . . . . . . . . . . . . . . 217

B.4 Mamografía c19c. . . . . . . . . . . . . . . . . . 218 


\section{Índice de Tablas}

3.1 Porcentaje de pixels etiquetados incorrectamente (ei) con el procedimiento de máxima verosimilitud sobre la imagen cuacir. . .

3.2 Niveles de gris de cada región de la imagen formas para cada uno de los ocho casos. . . . . . . . . . . . . . . 65

3.3 Porcentaje de pixels etiquetados incorrectamente (ei) con la estimación de máxima verosimilitud sobre la imagen formas. . . . . . 66

3.4 Porcentaje de pixels etiquetados incorrectamente (ei) con los diferentes algoritmos sobre la imagen cuacir. . . . . . . . . 67

3.5 Porcentaje de pixels etiquetados incorrectamente (ei) con los diferentes algoritmos sobre la imagen formas. . . . . . . . . . 70

6.1 Valores utilizados para los parámetros del campo aleatorio de Markov. . . . . . . . . . . . . . . . . . . . 152

6.2 Número de verdaderos y falsos positivos de las imágenes de la figura 6.15. . . . . . . . . . . . . . . . . . 168

6.3 Ratio de verdaderos positivos y número de falsos positivos por imagen del grupo de test tras cada iteración. . . . . . . . . . . . 168

6.4 Valores del ratio de verdaderos positivos y número de falsos positivos con el operador Top-Hat y el modelo de campo aleatorio de Markov para el conjunto de imágenes de test. . . . . . . . . . . . 174

6.5 Valores del ratio de verdaderos positivos y número de falsos positivos con el operador fondofibra y el modelo de campo aleatorio de Markov para el conjunto de imágenes de test. . . . . . . . . . . 179 
6.6 Valores del ratio de verdaderos positivos y número de falsos positivos para el residuo del fondofibra con reconstrucción y el modelo de campo aleatorio de Markov sobre el conjunto de imágenes de test. . . . . . . . . . . . . . . . . . . . 190

6.7 Valores individuales del número de verdaderos positivos y de falsos positivos para el residuo del fondofibra con reconstrucción y el modelo de campo aleatorio de Markov sobre cada imagen del conjunto de imágenes de test, con la sensibilidad ajustada tal que el ratio de verdaderos positivos para el conjunto es 0.88 y resultan 1.13 falsos positivos por imagen. . . . . . . . . . . . . . . 191

6.8 Valores del ratio de verdaderos positivos y número de falsos positivos para el residuo del fondofibra con reconstrucción con eliminación de picos aislados y el modelo de campo aleatorio de Markov sobre el conjunto de imágenes de test. . . . . . . . . . . . . . . . 200

A.1 Relación entre las imágenes de las mamografías completas y la imágenes que contienen solo la zona de la mama . . . . . . . . . . 210 


\section{Bibliografía}

[1] E. Aarts and J. Korst. Simulated annealing and Boltzmann machines. John Wiley and Sons Ltd., Chichester, 1989.

[2] L. V. Ackerman and E. E. Gose. Breast lesion classification by computer and xeroradiograph. Cancer, 30:1025-1035, Octuber 1972.

[3] Farzin Aghdasi. Application of neural network adaptive wavelets for signal representation and classification in digital mammography. In R.M.Nishikawa K. Doi, M.L Giger and R.A. Schmidt, editors, Digital Mammography '96, pages 307-310, Chicago, IL, 9-12 June 1996. Elsevier Science B.V.

[4] S. Astley, I. Hutt, S. Adamson, P. Miller, P. Rose, C.Boggis, C.J. Taylor, T. Valentine, J. Davies, and J. Armstrong. Automation in mammography: computer vision and human perception. In SPIE Symposium on Electronic Imaging Science and Technology, volume 1905, pages 716-730, San Jose, CA, Jan. 31 - Feb. 41993.

[5] D. H. Ballard and C. M. Brown. Computer vision. Prentice-Hall, New Jersey, 1982.

[6] I. N. Bankman, W. A. Christens-Barry, D. W. Kim, Weinberg, O. B. Gatewood, and W. R. Brody. Automated recognition of microcalcification clusters in mammograms. In SPIE Symposium on Electronic Imaging Science and Technology, volume 1905, pages 731-738, San Jose, CA, Jan. 31 - Feb. 41993.

[7] I. N. Bankman, W. A. Christens-Barry, I. N. Weinberg, D. W. Kim, R. D. Semmel, and W. R. Brody. An algorithm for early breast cancer detection in mammograms. In Fifth Annual IEEE Symposium on Computer-based Medical Systems, pages 362-369, 1992.

[8] H. Barman and G. H. Granlund. Hierarchical feature extraction for computer-aided analysis of mammograms. In SPIE Symposium on Electronic Imaging Science and Technology, volume 1905, pages 492-503, San Jose, CA, Jan. 31 - Feb. 41993. 
[9] Julian Besag. Spatial interaction and the statistical analysis of lattice systems. J. Royal Statistics Society Series B, 36:192-236, 1974.

[10] Julian E. Besag. On the statistical analysis of dirty pictures. Journal of Applied Statistics Society, Ser. B, pages 259-302, 1986.

[11] G. Birkhoff. Lattice theory, volume 25. A.M.S. Colloq., 3rd edition, 1983.

[12] D. Brzakovic, B. Brzakovic, and M. Neskovic. Approach to automated screening of mammograms. In SPIE Symposium on Electronic Imaging Science and Technology, volume 1905, pages 690-701, San Jose, CA, Jan. 31 - Feb. 41993.

[13] D. Brzakovic, X.M. Luo, and P. Brzakovic. An approach to automated detection of tumors in mammograms. IEEE Transactions on Medical Imaging, 9:233-241, September 1990.

[14] P. C. Bunch, J. F. Hamilton, G. K. Sanderson, and Simmons. A free response approach to the measurement and characterization of radiographicobserver performance. Journal Appl. Photogr. Eng., 4:166-171, 1978.

[15] C. J. Burdett, H. G. Longbothamm, M. Desai, W. B. Richardson, and J. F. Stoll. Nonlinear indicator of malignancy. In SPIE Symposium on Electronic Imaging Science and Technology, volume 1905, pages 853-860, San Jose, CA, Jan. 31 - Feb. 41993.

[16] C. B. Caldwell, S. J. Stapleton, D. W. Holdsworth, R. Jong, W. Weiser, G. Cooke, and M. J. Yaffe. Characterization of mammographic parenchymal patterns by fractal dimension. In SPIE Medical Imaging III: Image Processing, pages 10-16, 1989.

[17] Charles S. Carman and Gail Eliot. Detecting calcifications and calcifications clusters in digitized mammograms. In R.M. Nishikawa K. Doi, M.L Giger and R.A. Schmidt, editors, Digital Mammography '96, pages 253-255, Chicago, IL, 9-12 June 1996. Elsevier Science B.V.

[18] D. P. Chakraborty and H. L. Winter. Free response methodology: Alternate analysis and new observer-performance experiment. Radiology, 174:873881, 1990.

[19] H. P. Chan, K. Doi, S. Galhotra, C. J. Vyborny, H. MacMahon, and P. M. Jokich. Image feature analysis and computer-aided diagnosis in digital radiography 1 . automated detection of microcalcifications in mammography. Medical Physics, 14:538-548, July August 1987. 
[20] H. P. Chan, K. Doi, C. J. Vyborny, K. L. Lam, and R. A. Schmidt. Computer aided detection of microcalcifications in mammograms, methodology and preliminary clinical study. Investigative Radiology, 23:664-671, September 1988.

[21] Ramachandran Chandrasekhar and Yianni Attikiouzel. A simple method for automatically locating the nipple on mammograms. IEEE Transactions on Medical Imaging, 16(5):483-494, October 1997.

[22] Chau-Chir Chen and Chung-Ling Huang. Markov random fields for texture classification. Pattern Recognition Letters, 14:907-914, November 1993. North-Holland.

[23] Yateen Chitre and Atam P. Dhawan. Adaptive wavelet analysis and classification of mammographic microcalcification. In R.M. Nishikawa K. Doi, M.L Giger and R.A. Schmidt, editors, Digital Mammography '96, pages 323-326, Chicago, IL, 9-12 June 1996. Elsevier Science B.V.

[24] Paul B. Chou and Christopher M. Brown. The theory and practice of bayesian image labeling. International Journal of Computer Vision, 4:185210, 1990 .

[25] F. S. Cohen and D. B. Cooper. Simple parallel hierarchical and relaxation algorithms for segmenting noncausal markovian random fields. IEEE Trans. Pattern Analysis and Machine Intelligence, 9:195-219, 1987.

[26] D. R. Cox. Analysis of binary data. Methuen, London, 1970.

[27] G. R. Cross and A. K. Jain. Markov random field texture models. IEEE Trans. Pattern Analysis and Machine Intelligence, 5:pp. 25-39, 1983.

[28] Meersman D., Scheunders P., and Van Dyck D. Detection of microcalcifications using neural networks. In R.M. Nishikawa K. Doi, M.L Giger and R.A. Schmidt, editors, Digital Mammography '96, pages 287-290, Chicago, IL, 9-12 June 1996. Elsevier Science B.V.

[29] D. H. Davies and D. R. Dance. Automatic computer detection of clustered calcifications in digital mammograms. Physics in Medicine and Biology, 35(8):1111-1118, 1990.

[30] D.H. Davies, D.R. Dance, and C.H. Jones. Automatic detection of clusters of calcifications in digital mammograms. In Proc. of SPIE Medical Imaging IV: Image Processing, pages 185-191, 1990.

[31] Ulisses de Mendoca Braga Neto, Winston Araújo de siqueira Neto, and Ascendino Flávio Dias e Silva. Mammographic calcification detection by 
mathematical morphology methods. In R.M. Nishikawa K. Doi, M.L Giger and R.A. Schmidt, editors, Digital Mammography '96, pages 263-266, Chicago, IL, 9-12 June 1996. Elsevier Science B.V.

[32] J. Dengler, S. Behrens, and J.F. Desaga. Segmentation of microcalcifications in mammograms. IEEE Transactions on Medical Imaging, 12:634642, December 1993.

[33] H. Derin and H. Elliot. Modeling and segmentation of noisy and textured images using gibbs random fields. IEEE Trans. Pattern Analysis and Machine Intelligence, 9:39-55, 1987.

[34] H. Derin, H. Elliot, R. Cristi, and D. Geman. Bayes smoothing algorithms for segmentation of images modeled by markov random fields. In Proc. of the Int. conf. on Acoustic, Speech and signal Processing 84, pages 32.6.132.6.4, San Diego, 1984.

[35] H. Derin and P. Kelly. Discrete-index markov-type random processes. Proceedings IEEE, 77:1485-1510, 1989.

[36] P. A. Devijver. Pattern Recognition theory and Applications, chapter Advances in non parametric techniques of statistical pattern classification, pages 3-18. 1982.

[37] A. P. Dhawan, G. Buelloni, and R. Gordon. Enhancement of mammographic features by optimal adaptive neighbourhood image processing. IEEE Transactions on Medical Imaging, 5:8-15, March 1988.

[38] A. P. Dhawan, Y. S. Chitre, and M. Moskowitz. Artificial neural network-based classification of mammographic microcalcifications using image structure features. In SPIE Symposium on Electronic Imaging Science and Technology, volume 1905, pages 820-831, San Jose, CA, Jan. 31 Feb. 41993.

[39] A. P. Dhawan and E. LeRoyer. Mammographic feature enhancement by computerized image processing. Computer methods and programs in biomedicine, 27:23-35, 1988.

[40] Atam P. Dhawan, Yateen Chitre, Christine Kaiser-Bonasso, and Myron Moskowitz. Analysis of mammographic microcalcifications using graylevel image structure features. IEEE Transactions on Medical Imaging, 15(3):246-259, June 1996.

[41] R. C. Dubes and A. K. Jain. Random fields models in image analysis. Journal of Applied Statistics, 16(2):131-164, 1989. 
[42] H. Elliot, H. Derin, R. Cristi, and D. Geman. Application of the gibbs distribution to image segmentation. In Proc. of the Int. conf. on Acoustic, Speech and signal Processing 84, 32.5.1-32.5.4, 1984.

[43] B. W. Fam, S. L. Olson, P.F. Winter, and F. J. Scholz. Algorithm for the detection of fine clustered calcifications on film mammograms. Radiology, 169:333-337, November 1988.

[44] M. Fleck. Some defects in finite-difference edge finders. IEEE Transactions on Pattern Analysis and Machine Intelligence, 14(3):337-345, March 1992.

[45] S. H. Fox, U. M. Pujare, W. G. Wee, M. Moskowitz, and R. V. P. Hunter. A computer analysis of mammographic microcalcifications: Global approach. In Proceedings of IEEE Pattern Recognition Conference, pages 624-631, 1980.

[46] A. A. Gamal, L. A. Hemachandra, I. Shperling, and V. K. Wei. Using simulated annealing to design good codes. IEEE Transactions on Information Theory, 33:116-123, January 1987.

[47] Stuart Geman and Donald Geman. Stochastic relaxation, gibbs distributions, and the bayesian restoration of images. IEEE Trans. on Pattern Analysis and Machine Intelligence, 6(6):721-741, November 1984.

[48] R. Gordon and R. M. Rangayyan. Feature enhancement of film mammograms using fixed and adaptive neighbourhoods. Applied Optics, 23:560564, February 1984.

[49] Michel Grimaud. La geodesie numerique en morphologie mathematique. Application a la detectionautomatique de microcalcifications en mammographie numerique. PhD thesis, Ecole Nationale Supériore des Mines, Paris, Décembre 1991.

[50] M.Nafi Gurcan, Yasemin Yardimci, A. Enis Cetin, and Rashid Ansari. Detection of microcalcifications in mammograms using higher order statistics. IEEE Signal Processing letters, 4(8):213-216, August 1997.

[51] S. Hajnal, P.Taylor, M. H. Dilhuyduy, B. Barreau, and J. Fox. Classifying mammograms by density: Rationale and preliminary results. In SPIE Symposium on Electronic Imaging Science and Technology, volume 1905, pages 478-489, San Jose, CA, Jan. 31 - Feb. 41993.

[52] Takeshi Hara, Kenichi Hirako, Hiroshi Fujita, Tokiko Endo, Katsuhei Horita, Mitsuru Ikeda, Choichiro Kido, and Takeo Ishigaki. Automated detection algorithm for clustered microcalcifications based on density gradient and triple-ring filter analysis. In R.M. Nishikawa K. Doi, M.L Giger and 
R.A. Schmidt, editors, Digital Mammography '96, pages 257-262, Chicago, IL, 9-12 June 1996. Elsevier Science B.V.

[53] John J. Heine, Stanley R. Deans, D. Kent Cullers, Richard Stauduhar, and Laurence P. Clarke. Multiresolution statistical analysis of high-resolution digital mammograms. IEEE Transaction on Medical Imaging, 16(5):503515, October 1997.

[54] S. A. Hojjatoleslami and J. Kittler. Detection of clusters of microcalcifications using k-nearest neighbour rule with locally optimum distance metric. In R.M. Nishikawa K. Doi, M.L Giger and R.A. Schmidt, editors, Digital Mammography '96, pages 267-272, Chicago, IL, 9-12 June 1996. Elsevier Science B.V.

[55] A. K. Jain. Advances in mathematical models for image processing. Proc. of the IEEE, 69:502-528, 1981.

[56] F. C. Jeng and J. W. Woods. Compound gauss-markov random fields for image estimation. IEEE Trans. on Signal Processing, 39:683-697, 1991.

[57] M. Kallergi, L.P. Clarke, , W. Qianand M. Gavrielides, P. Venugopal, C. Berman, S. D. Holman-Ferris, M. Miller, and R. A. Clark. Interpretation of calcifications in screen/film, digitized, and wavelet-enhanced monitor displayed mammograms: An roc study. Acad. Radiol., 3:285-293, 1996.

[58] Nico Karssemeijer. Adaptive noise equalization and recognition of microcalcification clusters in mammograms. International Journal of Pattern Recognition and Artificial Intelligence, 7(6):1357-1376, 1993.

[59] N. Karssemijer and L. J. Th O. van Erning. Iso-precision scaling of digitized mammograms to facilitate image analysis. In SPIE Medical Imaging $V$ : Image Processing 1445, pages 166-177. SPIE, 1991.

[60] Nico Karssemijer. A sthocastic model for automated detection of microcalcifications in digital mammograms. In Information Processing in Medical Imaging, 12th International Conference, pages 227-238, 1991.

[61] Nico Karssemijer. Recognition of clustered microcalcifications using a random field model. In SPIE Symposium on Electronic Imaging Science and Technology, volume 1905, pages 776-786, San Jose, CA, Jan. 31 - Feb. 4 1993.

[62] W. P. Kegelmeyer. Computer detection of stellate lesions in mammograms. In SPIE Conference on Biomedical Image Processing, 1992. 
[63] Il Y. Kim and Hyun S. Yang. A systematic way for region-based image segmentation based on markov random field model. Pattern Recognition Letters, 15:969-976, October 1994.

[64] Jong Kook Kim and Hyun Wook Park. Surrounding region dependence method for detection of clustered microcalcifications on mammograms. In Proceedings of the International conference image processing, volume 3, pages 535-538, Santa Barbara, CA, USA, 26-29 October 1997.

[65] Jong Kook Kim, Jeong Mi Park, Koun Sik Song, and Hyun Wook Park. Adaptive mammographic image enhancement using first derivative and local statistics. IEEE Transactions on Medical Imaging, 16(5):495-502, October 1997.

[66] R. Kindermann and J. L. Snell. Contemporary Mathematics, volume 1, chapter Markov Random Fields and their Applications. American Mathematical Society, Providence,Rhode Island, 1980.

[67] J. C. Klein. Conception et réalisation d'une unité logique pour l'analyse quantitative d'images. PhD thesis, Université de Nancy, 1976.

[68] Daniel B. Kopans. La mama en imagen. Marbán, Madrid, 1994.

[69] S. Lai, X. Li, and W. Bischof. On techniques for detecting circumscribed masses in mammograms. IEEE Transactions on Medical Imaging, 8:377386, December 1989.

[70] C. Lantuejoul and H. Digabel. Interactive algorithms. In Proceedings of 2nd European Symposium of quant. analysis of microstructures in material sciences, biology and medicine, pages 39-49, October 1977.

[71] C. Lantuejoul and F. Maisonneuve. Geodesic methods in quantitative image analysis. Pattern Recognition, 17:117-187, 1984.

[72] Marton Lanyi. Diagnosis and differential diagnosis of breast calcifications. Springer-Verlag, Berlin, 1986.

[73] T. K. Lau and W. F. Bischof. Automated detection of breast tumors using the asymmetry approach. Computers and biomedical research, 24:273-295, 1991.

[74] H.D. Li, M. Kallergi, L. P. Clarke, V.K. Jain, and R.A. Clark. Markov random field for tumor detection in digital mammography. IEEE Trans. on Medical Imaging, 14(3):565-576, September 1995.

[75] I. E. Magnin, F. Cluzeau, C. L. Odet, and A. Bremond. Mammographic texture analysis: An evaluation of risk for developing breast cancer. Optical Engineering, 25:780-784, June 1986. 
[76] F. Maisonneuve. Extrema régionaux: algorithmes parallèles. Rapport Interne 781, Ecole des Mines de Paris, 1982.

[77] Ferrán Marqués. Multiresolution image segmentation based on compound random fields: Application to image coding. PhD thesis, DTSC Universitat Politécnica de Catalunya, Barcelona, Decembre 1992. Director: Antoni Gasull.

[78] D. Marr. Vision. W. H. Freeman, New York, 1982.

[79] L. N. Mascio, J. M. Hernandez, and C. M. Logan. Automated analysis for microcalcifications in high-resolution digital mammograms. In Medical Imaging 1993: Image Processing, pages 472-479, 1993.

[80] G. Matheron. Eléments pour une théorie des milieux poreux. Masson, Paris, 1967.

[81] G. Matheron. Random sets and integral geometry. John Wiley and Sons, New York, 1975.

[82] A. K. Mazur, E. J. Mazur, and R. Gordon. Digital differential radiography (ddr): a new diagnosis procedure for locating neoplasms, such as breast cancers in soft deformable tissues. In SPIE Symposium on Electronic Imaging Science and Technology, volume 1905, pages 443-455, San Jose, CA, Jan. 31 - Feb. 41993.

[83] G. McLeod, GJS Parkin, and AR Cowen. Automatic detection of clustered microcalcifications using wavelets. In R.M. Nishikawa K. Doi, M.L Giger and R.A. Schmidt, editors, Digital Mammography '96, pages 311-316, Chicago, IL, 9-12 June 1996. Elsevier Science B.V.

[84] C. E. Metz. Roc methodology in radiographic imaging. Investig. Radiology, 21:720-733, 1986.

[85] F. Meyer. Un algorithme optimal de lignes de partage des eaux. In 8ieme congrès RFIA, pages 847-857, 1991.

[86] Paul L. Meyer. Probabilidad y aplicaciones estadísticas. Addison-Wesley Iberoamericana, Wilmington, USA, 1992.

[87] P. Miller and S. Astley. Detection of breast asymmetry using anatomical features. In SPIE Symposium on Electronic Imaging Science and Technology, volume 1905, pages 433-442, San Jose, CA, Jan. 31 - Feb. 41993.

[88] James W. Modestino and Jun Zhang. A markov random field model-based approach to image interpretation. IEEE Trans. on Pattern Analysis and Machine Intelligence, 14(6):606-615, June 1992. 
[89] William M. Morrow, Raman B. Paranjape, Rangaraj Rangayyan, and Joseph E. L. Desautels. Region-based contrast enhancement of mammograms. IEEE Transactions on Medical Imaging, 11(3):392-406, September 1992.

[90] Jose M. Mossi and Antonio Albiol. Digital mammography: Mathematical morphology applied to detection of clusters of microcalcifications. In N.M. Namazi and C. M. Fan, editors, Proceedings of the IASTED International Conference on Signal and Image Processing, pages 150-153, New Orleans, Louisiana, USA, 4-6 December 1997.

[91] Jose M. Mossi and Antonio Albiol. Automatic detection of clustered microcalcifications using morphological reconstruction. In Nico Karssemeijer, editor, 4th International Workshop on Digital Mammography, To be published, 7-10 June 1998. Kluwer Academic Publishers.

[92] Thomas Netsch. A scale-space approach for the detection of clustered microcalcifications in digital mammograms. In R.M. Nishikawa K. Doi, M.L Giger and R.A. Schmidt, editors, Digital Mammography '96, pages 301-306, Chicago, IL, 9-12 June 1996. Elsevier Science B.V.

[93] R.M. Nishikawa, M. L. Giger, K. Doi, C.J. Vyborny, R. A. Schmidt, C. E. Metz, Y. Wu, F. Yin, Y. Jiang, Z. Huo, P.Lu, W. Zhang, and T. Ema. Computer aided detection and diagnosis of masses and clustered microcalcifications from digital mammograms. In SPIE Symposium on Electronic Imaging Science and Technology, volume 1905, pages 422-432, San Jose, CA, Jan. 31 - Feb. 41993.

[94] S. L. Olson, B. W. Fam, P. F. Winter, F. J. Scholz, A. K. Lee, and S. E. Gordon. Breast calcifications: Analysis of imaging properties. Radiology, 169:329-332, November 1988.

[95] A. Papoulis. Probability, random variables, and stochastic processes. McGraw-Hill, New York, 1965.

[96] J. Parker, D. R. Dance, and D. H. Davies. Classification of ductal carcinoma in-situ by image analysis of calcifications from mammograms. In SPIE Symposium on Electronic Imaging Science and Technology, volume 1905, pages 832-840, San Jose, CA, Jan. 31 - Feb. 41993.

[97] Ioannis Pitas. Digital Image Processing Algorithms. Prentice Hall International (UK) Ltd, 1993.

[98] W. Qian, L. P. Clarke, M. Kallergi, H. D. Li, R. P. Velthuizen, R. A. Clak, and M. L. Silberger. Tree-structured nonlinear filter and wavelet transform for microcalcification segmentation in mammography. In SPIE Symposium on Electronic Imaging Science and Technology, volume 1905, pages 509-520, San Jose, CA, Jan. 31 - Feb. 41993. 
[99] W. B. Richardson. Wavelet packets applied to mammograms. In SPIE Symposium on Electronic Imaging Science and Technology, volume 1905, pages 504-508, San Jose, CA, Jan. 31 - Feb. 41993.

[100] Brian D. Ripley. Statistics, images and pattern recognition. The Canadian Journal of Statistics, 14(2):83-111, 1986.

[101] Brian D. Ripley. Statistical Inference for Spatial Process. Cambridge University Press, 1988.

[102] Daniel Rosen, Benjamin Martin, Mark Monheit, Greg Wolff, and Martin Stanton. A bayesian neural network to detect microcalcifications in digitized mammograms. In R.M. Nishikawa K. Doi, M.L Giger and R.A. Schmidt, editors, Digital Mammography '96, pages 277-282, Chicago, IL, 9-12 June 1996. Elsevier Science B.V.

[103] A. Rosenfeld and A. C. Kak. Digital picture processing, volume I, II. Academic Press, San Diego, California, second edition, 1982.

[104] D. E. Rumelhart, R. Durbin, R. Golden, and Y. Chauvin. Backpropagation: Theory, architectures and applications, chapter Backpropagation: the basic theory. Lawrence Earlbaum Associates, Hillsdale, N.J., 1995.

[105] A. F. Saftlas and M. Szklo. Mammographic parenchymal patterns and breast cancer risk. Epidemiologic reviews, 9:146-174, 1987.

[106] Paul Sajda, Clay D. Spence, John C. Pearson, and Robert M. Nishikawa. Integrating multiresolution and contextual information for improved microcalcification detection in cad. In R.M. Nishikawa K. Doi, M.L Giger and R.A. Schmidt, editors, Digital Mammography '96, pages 291-296, Chicago, IL, 9-12 June 1996. Elsevier Science B.V.

[107] A. Sarwal, Y. Chitre, and A. P. Dhawan. Segmentation of mammographic microcalcifications. In Proceedings of 15th International conference IEEE Engineering in Medicine and Biology Society, volume 1, pages 112-113, 1993.

[108] J. L. Semmlow, A. Shadagopappan, L. V. Ackerman, W. Hand, and F. S. Alcorn. A fully automated system for screening xeromammograms. Computers and biomedical research, 13:350-362, 1980.

[109] Jean Serra. Image analysis and mathematical morphology. Academic Press, London, 1982.

[110] Jean Serra. Image analysis and mathematical morphology, vol. II: Theoretical advances. Academic Press, London, 1988. 
[111] Jean Serra and Phillipe Salembier. Connected operators and pyramids. In Proceedings of SPIE. Image Algebra and Mathematical Morphology 93, San Diego, July 1993.

[112] A. Shadagopan, J. L. semmlow, and L. V. Ackerman. Computerized quantification of breast duct patterns. Radiology, 143:675-678, June 1982.

[113] G. Sharma and R. Chellappa. Two dimensional spectral estimation using noncausal autoregressive models. IEEE Trans. on Information Theory, 32:268-275, March 1986.

[114] L. Shen, R. M. Rangayan, and J. E. L. Desautels. Automatic detection and classification system for calcifications in mammograms. In SPIE Symposium on Electronic Imaging Science and Technology, volume 1905, pages 799-805, San Jose, CA, Jan. 31 - Feb. 41993.

[115] R. D. Short and K. Fukunaga. A new nearest neighbour distance measure. In Proc. 5th International conference on pattern recognition, pages 81-86, Miami Beach, FL, 1980.

[116] W. Spiesberger. Mammogram inspection by computer. IEEE Transactions on Biomedical Engineering, 26:213-219, April 1979.

[117] A. Strauss, C. Monrocq, TP. Baum, and M. Le Gal. Selection of cluster candidates before clustered microcalcifications detection: a modular and hierarchical approach based on neural networks. In R.M. Nishikawa K. Doi, M.L Giger and R.A. Schmidt, editors, Digital Mammography '96, pages 297-300, Chicago, IL, 9-12 June 1996. Elsevier Science B.V.

[118] D. J. Strauss. Clustering on coloured lattices. J. Appl. Prob., 14:135-143, 1977.

[119] RobinN. Strickland and Hee Il Hahn. Wavelet transforms for detecting microcalcifications in mammograms. IEEE Trans. on Medical Imaging, 15(2):218-229, April 1996.

[120] J. A. Swets. Roc analysis applied to the evaluation of medical imaging techniques. Investigative Radiology, 14:109-121, 1979.

[121] P. G: Tahoces, J. Correa, M. Souto, C. Gonzalez, L. Gomez, and J. J. Vidal. Enhancement of chest and breast radiographs by automated spatial filtering. IEEE Transactions on medical imaging, 10:330-335, 1991.

[122] Baum TP. Foyers de microcalcifications: détecion automatique par réseau de neurones. Mémoire de DEA d'Informatique Médicale. Université de Paris VI, 1994. 
[123] Corinne Vachier. Extraction de caracteristiques, segmentation d'image et morphologie mathematique. PhD thesis, Ecole Nationale Supériore des Mines, Paris, Décembre 1995.

[124] L. Vincent and P. Soille. Watersheds in digital space and efficient algorithm based on immersion simulations. IEEE Transactions on Pattern Analysis and Machine Intelligence., 13(6):583-598, 1991.

[125] Luc Vincent. Algorithmes morphologiques a base de files d'attente et de lacets. Extension aux graphes. PhD thesis, Ecole Nationale Supériore des Mines, Paris, 1990.

[126] Luc Vincent. Morphological area openings and closings for grayscale images. In Shape in picture, NATO Workshop, Driebergen, September 1992.

[127] Luc Vincent. Morphological grayscale reconstruction in image analysis: Applications and efficient algorithms. IEEE Trans. on Image Processing, 2(2), April 1993.

[128] Isidro Vizcaino, Dolores Salas, Jose S. Vilar, Francisco Ruiz-Perales, Constantino Herranz, and Josefa Ibanez. Breast cancer screening: first round in the population-based program in valencia, spain. Radiology, 206(1):253260, January 1998.

[129] W. G. Wee, M. Moskowitz, N. C. Chang, Y. C. Ting, and S. Pemmeraju. Evaluation of mammographic calcifications using computer programs. Radiology, 116:717-720, September 1975.

[130] Datong Wei, Robert M. Nishikawa, and Kunio Doi. On the application of a shift invariant artificial neural network for the detection of clustered microcalcifications. In R.M. Nishikawa K. Doi, M.L Giger and R.A. Schmidt, editors, Digital Mammography '96, pages 283-286, Chicago, IL, 9-12 June 1996. Elsevier Science B.V.

[131] J. N. Wolfe, S. Albert, S. Belle, and M. Salane. Breast parenchymal patterns and their relationship to risk of having or developing carcinoma. Radiologic clinics of North America, 21:127-136, March 1983.

[132] J. W. Woods. Two-dimensional discrete markovian fields. IEEE Trans. Inform. Theory, 18:232-240, 1972.

[133] K. Woods, L. P. clarke, and R. Velthuizen. Enhancement of digitized mammograms using a local thresholding technique. In IEEE engineering in Medicine and Biology Society, volume 13, 1991. 
[134] K. S. Woods, J. L. Solka, C. E. Priebe, C. C. Doss, K. W. Bowyer, and L. P. Clarke. Comparative evaluation of pattern recognition techniques for detection of microcalcifications. In SPIE Symposium on Electronic Imaging Science and Technology, volume 1905, pages 841-852, San Jose, CA, Jan. 31 - Feb. 41993.

[135] Kevin Woods. Automated image analysis techniques for digital mammography. PhD thesis, Department of computer science and engineering, University of South Florida, December 1994.

[136] Kevin Woods and Kevin W. Bowyer. Generating roc curves for artificial networks. IEEE Transactions on Medical Imaging, 16(3):329-337, June 1997.

[137] F. F. Yin, M. L. Giger, K. Doi, C. E. Metz, C.J. Vyborny, and R. A. Schmidt. Computerized detection of masses in digital mammograms: analysis of bilateral subtraction images. Medical Physics, 18:955-963, 1991.

[138] Hiroyuki Yoshida, Robert M. Nishikawa, Maryellen L. Giger, and Kunio Doi. Optimally weighted wavelet packets for detection of clustered microcalcifications in digital mammograms. In R.M. Nishikawa K. Doi, M.L Giger and R.A. Schmidt, editors, Digital Mammography '96, pages 317-322, Chicago, IL, 9-12 June 1996. Elsevier Science B.V.

[139] D. Zhao. Rule-based morphological feature extraction of microcalcifications in mammograms. In SPIE Symposium on Electronic Imaging Science and Technology, volume 1905, pages 702-715, San Jose, CA, Jan. 31 - Feb. 4 1993.

[140] Baoyu Zheng, Wei Qian, and Laurence P. Clarke. Digital mammography: mixed feature neural network with spectral entropy decision for detection of microcalcifications. IEEE Transactions on Medial Imaging, 15(5):589-597, October 1996. 